CELSO MANOEL DA SILVA

\title{
FILTRO DE INTERFERÊNCIA VARIÁVEL E DESCRIÇÃO DE UMA APLICAÇÃO: DISPOSITIVO MULTICANAL ESPECTRAL PARA ANÁLISE AMBIENTAL
}

\author{
Dissertação apresentada à Escola Politécnica da \\ Universidade de São Paulo para obtenção do \\ título de Mestre em Engenharia Elétrica.
}

São Paulo

2010 


\title{
FILTRO DE INTERFERÊNCIA VARIÁVEL E DESCRIÇÃO DE UMA APLICAÇÃO: UM DISPOSITIVO MULTICANAL ESPECTRAL PARA ANÁLISE AMBIENTAL
}

\author{
Dissertação apresentada Escola Politécnica da \\ Universidade de São Paulo para a obtenção do \\ Título de Mestre em Engenharia Elétrica. \\ Área de Concentração: \\ Microeletrônica. \\ Orientador: \\ Professor Doutor Roberto Koji Onmori
}

São Paulo

2010 
Este exemplar foi revisado e alterado em relação à versão original, sob responsabilidade única do autor e com a anuência de seu orientador.

São Paulo, de fevereiro de 2010.

Assinatura do autor

Assinatura do orientador

FICHA CATALOGRÁFICA

Silva, Celso Manoel da

Filtro interferência variável e descrição de uma aplicação:

dispositivo multicanal espectral para análise ambiental / C.M. da Silva. -- ed.rev. --São Paulo, 2010.

$152 \mathrm{p}$.

Dissertação (Mestrado) - Escola Politécnica da Universidade de São Paulo. Departamento de Engenharia de Sistemas Eletrônicos.

1. Filtros ópticos 2. Filmes finos 3. Fotônica 4. Espectrometria 5. Avaliação ambiental I. Universidade de São Paulo. Escola Politécnica. Departamento de Engenharia de Sistemas Eletrônicos II. t. 


\section{Resumo}

O presente trabalho apresenta o desenvolvimento de um método de obtenção e a caracterização de filtros ópticos de interferência de banda passante variável que, constituídos por refletores dielétricos multicamadas de filmes finos intercalados por cavidades de FabryPerot não planares com espessuras linearmente variáveis, apresentam a propriedade do deslocamento linear da transmitância máxima espectral em função da posição, isto é, um Filtro de Interferência Variável (FIV). Este método apresenta novas e abrangentes possibilidades de confecção de filtros ópticos de interferência variável: lineares ou em outras formas desejadas, de comprimento de onda de corte variável (passa baixa ou alta) e filtros de densidade neutra variável, através da deposição de metais.

A primeira etapa do trabalho foi o projeto e a construção de um filtro óptico convencional, de um comprimento de onda central, com camadas homogêneas. A etapa seguinte foi, com base na teoria espectrométrica, promover a variação das espessuras das camadas em um perfil inclinado e linear. Para tanto, de acordo com os requisitos de projeto, foram feitas adaptações em uma evaporadora por e-Beam (elétron-Beam), acrescentando um obliturador mecânico especialmente projetado, ajustando parâmetros de técnicas de deposição e caracterizando o perfil inclinado de um filme depositado para ajustar o obliturador. E, ao final destas etapas, foi projetado e construído o FIV especificado.

Também é descrita uma possível aplicação do FIV: um dispositivo multicanal espectral para análise ambiental, e, dentre muitas, outras podem ser mencionadas: sistemas Lab-on-Chip, biosensores, detectores chip-sized, espectrometria de fluorescência on-chip, detectores de deslocamento de comprimento de onda, sistemas de interrogação e etc.

Palavras Chaves: Filtros ópticos, Filtros ópticos de interferência Variável, Filmes Finos, Técnica de Deposição, Fotônica, Espectrometria, Avaliação Ambiental. 


\begin{abstract}
This work presents the development of a method to obtain and characterize a variable interference optical bandpass filter, made up of a number of thin films forming dielectrical reflectors intercalated by non flat Fabry-Perot cavities whose thickness variates linearly. These filters present the propriety of a linear variation in the maximum spectral transmittance as a function of the position in the filter, for this reason this is called Variable Interference Filter (VIF). This method allows of manufacturing linear interference filters or any other function disered, with variable cut wavelength (low or high pass) and variable neutral density filters by means of metallic depositions.

The first step in this work was to design and built a conventional filter, with homogeneous layers and a fixed central wavelength. The following step was, using spectrometric theory basis, introduce the variation in the thickness of the layers in a linear inclined outline. Accordingly with the design requirements, it was made some adaptations in an e-beam evaporator (electron-beam), adding a mechanical obliterator adjusted with series of depositions and characterizations of a single layers in order to find a linearly inclined outline. In the end of this step it was designed and built the specified VIF.

It is also described a possible application of this VIF: a multichannel spectral device for environmental analysis. Between many applications, others can be cited, such as: Lab-onChip systems, biosensors chip-sized detectors, on-chip fluorescence spectrometry, shift wavelength detectors, interrogation systems, etc.
\end{abstract}

Key Words: Optical filters, Variable interference optical filters, Thin Films, Deposition techniques, Photonics, Spectrophotometry, Environmental Analysis. 
Dedico este trabalho aos amores da minha vida, minha companheira, amiga e esposa, Maria Luiza Fiorini da Silva, aos companheiros, amigos e queridos filhos, Tiago Fiorini da Silva, Daniela Fiorini da Silva e Natália Fiorini da Silva. Estas pessoas são a razão da minha existência e a parte essencial em tudo o que faço. Dedico, igualmente, à minha genitora Constantina M. da Silva e ao bem feitor Dr. Fabio Fanucci (em memória). 


\section{Agradecimentos}

Minha gratidão e reconhecimento ao meu orientador professor Dr. Roberto Koji Onmori pela confiança, paciência e orientação e pela contribuição a minha formação acadêmica e humana.

Agradeço as pessoas que compartilharam, em alguma etapa deste trabalho, a sua inteligência, o seu esforço e o seu tempo, assim como também, o seu interesse em ver o mesmo realizado.

Agradeço ao pessoal do Centro de Lasers e Aplicações - CLA, Laboratório de Filmes Finos, do IPEN, especialmente a Solange Eiko Mitani pela ajuda indispensável na condução dos trabalhos de confecção dos filtros, pelas aulas práticas e toda a inumerável ajuda, ao Dr. Leandro Hostalácio Freire de Andrade, pela disponibilidade dos equipamentos e pelo apoio, a Dra. Sônia Lícia Baldochi, por manter a disponibilidade, o apoio e por confiar em nossa capacidade e a Dra. Vera Lúcia Ribeiro Salvador do Laboratório de Fluorescência de raios X, do CQMA, pelo uso do equipamento e ajuda na discussão dos resultados.

Agradeço ao pessoal do IF-USP: especialmente ao Dr. Tiago Fiorini da Silva, do LAL, que sempre solícito, contribuiu de forma importante e constante, ao Dr. Alexandre Malafronte, pela colaboração e apoio, ao Sr. Alex Silva pela ajuda nos ajustes mecânicos; ao pessoal do LAMFI, especialmente ao Dr. Marcel Dupret pela condução dos trabalhos de medidas de RBS e ajuda nos ajustes dos dados e simulações; ao Dr. Manfredo Tabacknics, pela disponibilidade do equipamento acelerador de íons; ao Sr. Gilderlon Fernandes de Oliveira pela condução dos trabalhos de medidas de AFM e ajuda no tratamento dos dados; e ao Dr. Antonio Domingues dos Santos pela disponibilidade do Microscópio de Força Atômica, em desenvolvimento no Laboratório de Materiais Magnéticos.

Agradeço ao pessoal do Laboratório de Óptica da Divisão de Mecânica e Eletricidade do Instituto de Pesquisas Tecnológicas do Estado de São Paulo - IPT: especialmente ao M. Sc. Antônio Francisco Gentil Ferreira Júnior e ao Sr. Raul Leone Filho, pela condução dos trabalhos de medidas de resposta espectral; ao Dr. Mário Leite Pereira, pela disponibilidade dos equipamentos e pelo apoio. 
Agradeço ao professor Dr. Alexandre Alarcon do Passo Suaide pelo acesso ao material e dispositivos do Laboratório Didático do IF-USP.

Agradeço a Dra. Márcia Akemi Yamazoe, do IAG, pelas importantes discussões sobre instrumentação e também ao amigo de sempre André Cozza Sayão, pela ajuda e incentivo.

Agradeço ao pessoal da EPUSP-Engenharia Elétrica, especialmente ao Dr. Henrique Estanislau Maldonado Peres, pela ajuda com a captura dos dados do perfilômetro, e, as senhoras e aos senhores, Antônio Marco de Souza, Cristina Gomes da Silva, Gerson da Silva Rodrigues, Jair Pereira de Souza, Tereza Fumiyo Mori, Ana Rita Pereira dos Santos e João Carlos de Lima, pela disponibilidade de instrumentos e equipamento dos laboratórios e oficinas e pela ajuda no uso dos mesmos.

Agradeço ao professor Dr. Álvaro Vanucci do IF-USP e ao professor Dr. Fernando Josepetti Fonseca da EPUSP pelas fundamentais contribuições na etapa de qualificação deste trabalho.

Finalmente, agradeço a SOLIDUR Ltda., pela disponibilidade de amostras de plásticos de engenharia; agradeço a ARTIMAR Ltda., representante da TAOSINC, na pessoa do Sr. Martin Rabner pela disponibilidade do PDA TLS1410R e, muito especialmente, agradeço a INDUTRON Engenharia e Aplicações Ltda., pelo uso dos seus laboratórios, instrumentos, recursos e principalmente pela condução técnica e patrocínio da recuperação do equipamento BALZER PLS-500 do CLA-IPEN. 


\section{Índice}

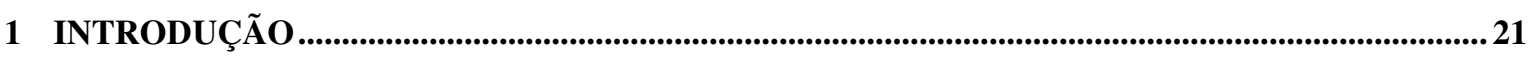

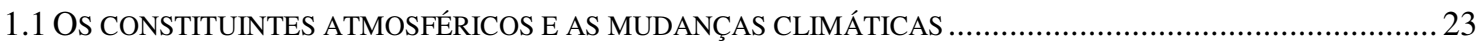

1.1.1 A interação do aerossol atmosférico com a radiação solar............................................2 27

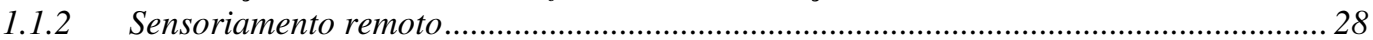

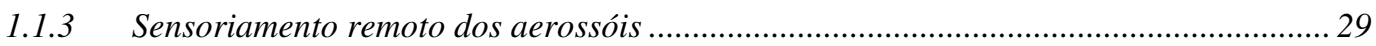

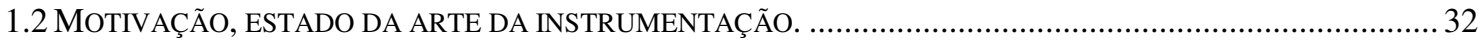

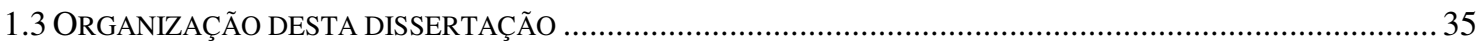

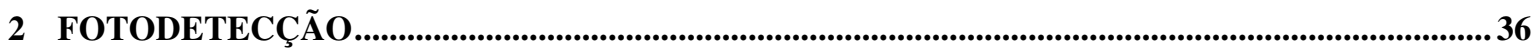

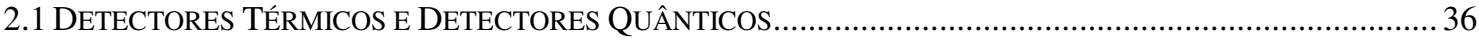

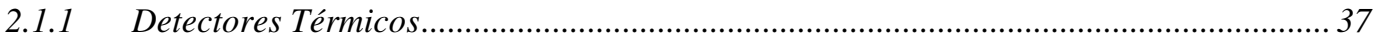

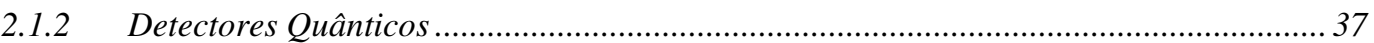

3 ANÁLISE ESPECTRAL DA LUZ VISÍVEL .................................................................................. 46

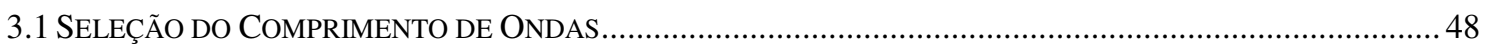

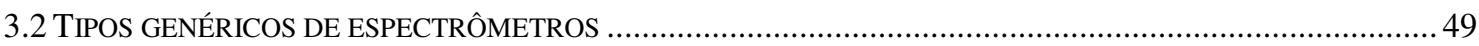

3.2.1 Espectrômetros miniaturizados ............................................................................... 49

3.2.2 Deposição de Filmes Finos ...................................................................................... 51

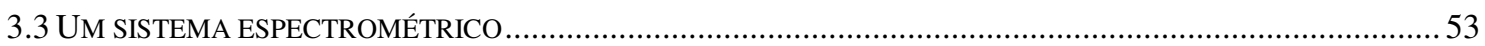

4 TEORIA ÓPTICA ESPECTROMÉTRICA..................................................................................55

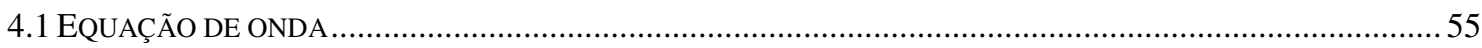

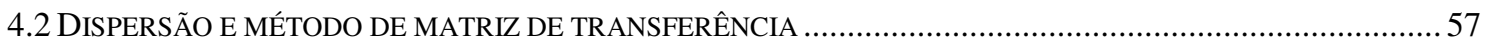

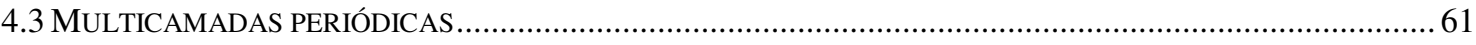

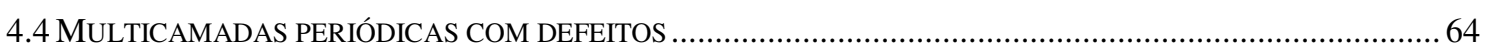

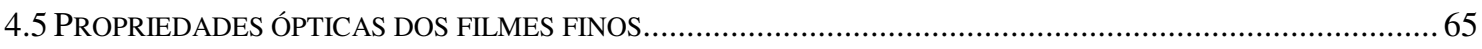

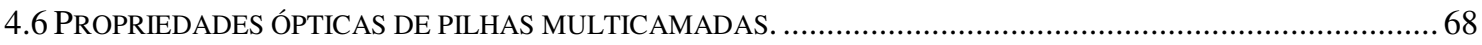

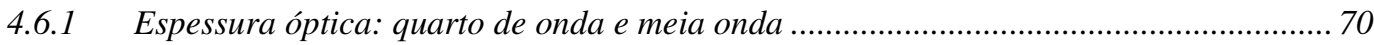

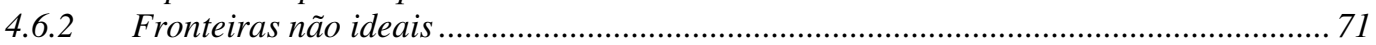

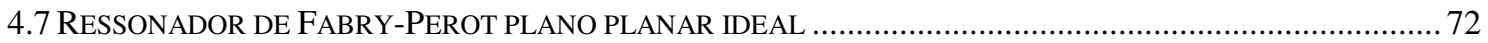

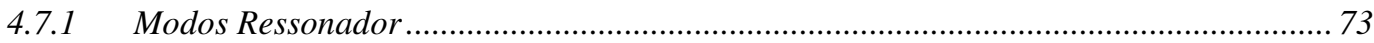

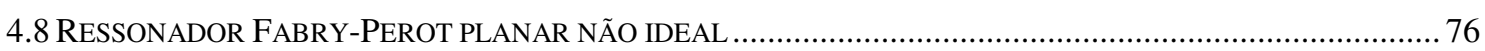

4.8.1 Resposta Espectral ................................................................................................ 76

4.8.2 Perdas associadas ao espelho e ao meio ressonador.................................................... 80

4.8.3 Ângulo de incidência e não paralelismo. .................................................................. 82

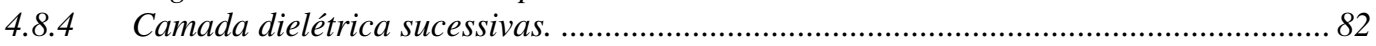

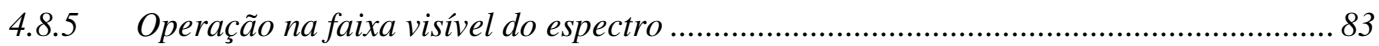

4.8.6 Espectrômetros de Fabry-Perot ................................................................................ 83

4.8.7 Reconstrução do Espectro..................................................................................... 85

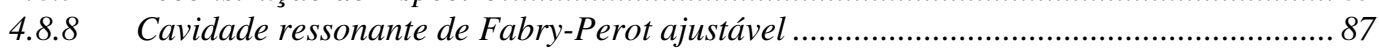

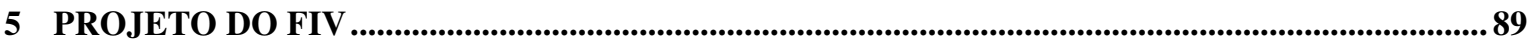

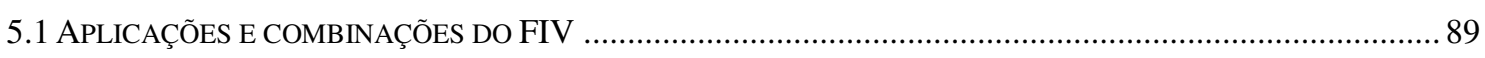

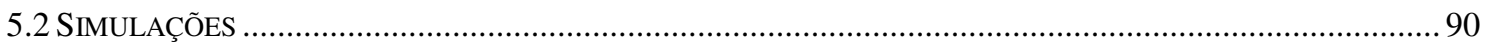

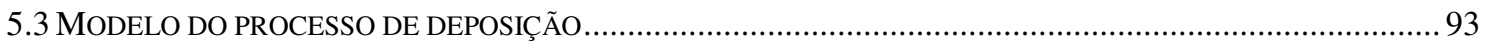

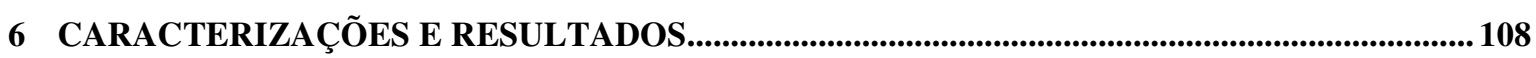


7 DESCRIÇÃO DE UM DISPOSITIVO MULTICANAL ESPECTRAL PARA ANÁLISE

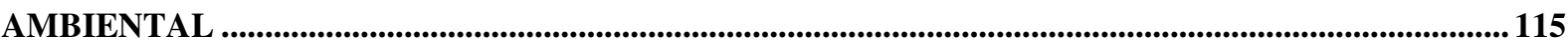

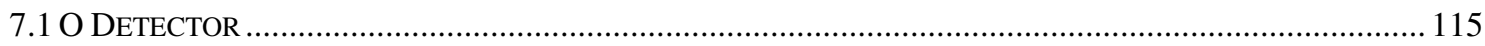

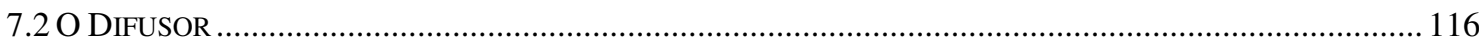

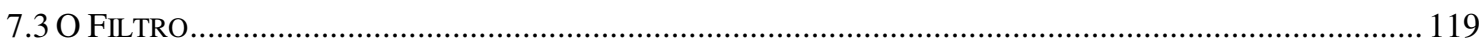

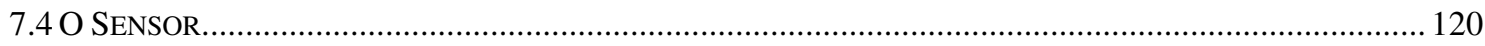

7.5 Uma ARquitetura Para o Dispositivo Multicanal Espectral Para ANÁlise Ambiental..... 124

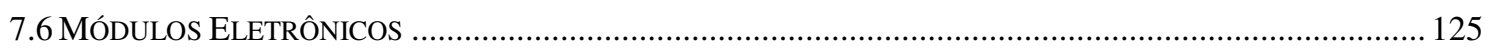

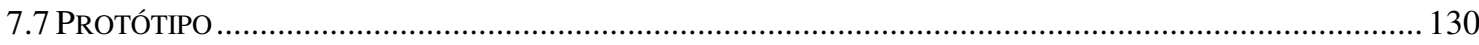

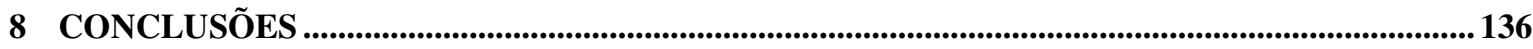

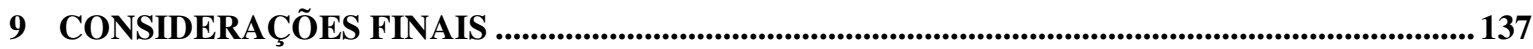

10 PLANOS FUTUROS ............................................................................................................ 138

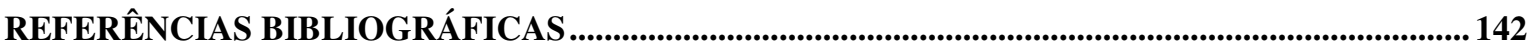

APÊNDICE A - ANÁLISE POR RETROESPALHAMENTO RUTHERFORD (RBS) .......................... 152 


\section{Índice de figuras}

Figura 1.1 - Esquema do detector de comprimento de onda.

Figura 1.2 - Estimativas para a forçante radiativa (FR/2005) média global. Atribuída ao dióxido de carbono $\left(\mathrm{CO}_{2}\right)$, metano $\left(\mathrm{CH}_{4}\right)$, óxido nitroso $\left(\mathrm{N}_{2} \mathrm{O}\right)$, aerossóis bem como para outros agentes e mecanismos significativos. Junto com o valor da forçante em [W/m2] é apresentada também a extensão geográfica típica (escala espacial) da FR e o nível de compreensão científica avaliada (NCC). Adaptado de [13]. 25

Figura 1.3 - Vista externa de um complexo de monitoramento radiativo/fotométrico. Reproduzido de [48]. _ 32 Figura 1.4 - Radiômetro solar automatizado de 10 canais. Instrumento: (a) sistema detector do radiômetro, (b) sistema de direcionamento, (c) sistema de aquisição de dados (DAS), e (d) fonte de alimentação. Reproduzido de [49].

Figura 1.5 - Imagem do radiômetro Modelo MFRSR- (a) Equipamento; (b) Sensor.

http://www.yesinc.com/products/data/mfr7/index.html(03/03/09-22:40hs) 34

Figura 2.1 - Homojunção p-n e o correspondente diagrama de bandas de energia. Na figura, $\mathrm{I}_{\mathrm{D}}$ representa a corrente direta de portadores majoritários e $\mathrm{I}_{\mathrm{ph}}$ a fotocorrente de portadores minoritários. Reproduzido de [51].41 Figura 2.2 - Circuito geral do fotodetector.

Figura 2.3 - A relação sinal/ruído $(\mathrm{S} / \mathrm{N})$ de um fotodetector, em função do sinal de entrada, nos regimes térmico e quântico de detecção. Reproduzido de[50].

Figura 2.4 - Limite teórico de detetividade. D* (linhas tracejadas), imposto pelo ruído de fundo e o limite alcançado por diversos tipos de dispositivos fotodetectores de infravermelho, nas temperaturas de operação indicadas. Reproduzido de [51].

Figura 3.1 - Esquema do espectro eletromagnético.

Figura 3.2- Esquema de um dispositivo espectrométrico chip-sized - (a) Dual In-Line Package (DIP) (b)

Transistor Outline Package (TO-99) .

Figura 4.1 - Representação de uma estrutura multicamadas in-homogênea (isto é, um meio estratificado) em porções constantes onde $\mathcal{E}$, a permissividade, e $\mu$, a permeabilidade, são z-dependentes. A estrutura é invariante ao longo dos sentidos x e y, e $\theta$, para incidência oblíqua, é o ângulo de incidência.

Figura 4.2 - Uma estrutura multicamadas binária periódica em lâminas constantes, periódica com z-dependência na permissividade $\mathcal{E}$ e na permeabilidade $\mu$ e invariante ao longo das direções x e y. A espessura das camadas A e B são a e b, respectivamente. A espessura da célula unitária $\Lambda$, representa o período da estrutura. 61

Figura 4.3 - Esquema da propagação de ondas eletromagnéticas através de filmes finos depositados sobre um substrato. Cada amplitude é definida pelos coeficientes de Fresnel e pelo retardamento de fase.

Figura 4.4 - Esquema da estrutura de pilha representada por uma montagem de camadas.

Figura 4.5 - Caso ideal: componentes transmitido e refletido são ou especular ou perfeitamente difusa [79]. _ 71

Figura 4.6 - Ressonador de Fabry-Perot com espelhos planos. ___ 72

Figura 4.7 - Campo de distribuição dos modos de um interferômetro espelho-planar.____ 74

Figura 4.8 - Diagrama de Blocos representando um sistema realimentado. __ 75

Figura 4.9 - Uma onda reflete múltiplas vezes nos espelhos do ressonador, resultando num deslocamento de fase em cada reflexão. 
Figura 4.10 - Transmissão de onda plana através de um espelho planar Fabry-Perot. 76

Figura 4.11 - Picos de transmissão são igualmente espaçados como função da frequiência.___ 80

Figura 4.12 - Refletância da prata, ouro e alumínio em função do comprimento de onda da radiação [83]. __ 81

Figura 4.13 - Espectrômetro tipo varredura___ 84

Figura 4.14 - Espectrômetro tipo matriz com etalons Fary-Perot, cada um com um fotodetector. ___ 85

Figura 4.15- a) Espectro real de uma fonte de luz monocromática, registro de um espectrômetro “ideal”, b)

Registro do espectro com um instrumento real. __ 85

Figura 4.16 - Exemplo de ajustes da função de Airy pela variação do gap. ___ 87

Figura 4.17 - Exemplo de ajuste da função de Airy pela variação do ângulo de incidência.___ 88

Figura 4.18 - Exemplo de ajuste da função de Airy pela variação do índice de refração do meio interno à

cavidade. _ 88

Figura 5.1 - Combinação de um FIV com um espectrômetro convencional de prisma. __ 90

Figura 5.2 - Montagem com dois FIV.

Figura 5.3 - Esquema do filtro homogêneo de banda estreita. ___ 91

Figura 5.4 - Resposta espectral simulada do filtro homogêneo $\lambda_{0}=671 \mathrm{~nm}$ com, gap de 229,79nm.___ 92

Figura 5.5 - Esquema pictórico do filtro dielétrico de interferência variável FIV de três fases de deposição. _ 93

Figura 5.6 - Resposta espectral simulada de uma variação na espessura da cavidade não homogênea de 183,85 $\mathrm{nm}$ a 344,69 $\mathrm{nm}$ em passos de 1 QWOT=0.25 (diferença na espessura da cavidade de $160 \mathrm{~nm}$ indicada pela cunha no desenho). 93

Figura 5.7 - Representação da geometria do processo de deposição. Reproduzido de [89].___ 94

Figura 5.8 - Representação pictórica do equipamento PLS-500 adaptado. ___ 95

Figura 5.9 - Ilustração da máscara estática proposta e da rotação das amostras. ___ 96

Figura 5.10 - Foto do porta amostras da câmara de deposição, sem a máscara. ____ 97

Figura 5.11 - Foto da câmara de depósito sem o mecanismo de máscara. ___ 97

Figura 5.12 - Alguns Filtros produzidos com cavidade homogêneas. ___ 98

Figura 5.13 - Espectro da amostra na posição n.1 $\left(\lambda_{0}=655,0 \mathrm{~nm}\right)$. 99

Figura 5.14 - Espectro da amostra na posição central n.2 $\left(\lambda_{0}=655,0 \mathrm{~nm}\right)$.

Figura 5.15 - Espectro da amostra na posição n.3 $\left(\lambda_{0}=655,0 \mathrm{~nm}\right)$.

Figura 5.16 - Alocação do espaço horizontal entre o alvo a o porta amostra para acomodar a máscara. ___ 101

Figura 5.17 - (a) Perfil simulado: ramo da espiral logarítmica. Em verde é mostrado o raio mínimo na amostra, em vermelho o raio máximo e em azul o perfil da máscara.(b) Resultado da simulação para a espessura depositada. 102

Figura 5.18 - (a) Perfil simulado: ramo da espiral arquimediana. Em verde é mostrado o raio mínimo na amostra, em vermelho o raio máximo e em azul o perfil da máscara.(b) Resultado da simulação para a espessura depositada.__ 102

Figura 5.19 - Esboço do projeto do dispositivo.___ 103

Figura 5.20 - Desenho do dispositivo.___ 103

Figura 5.21 - Foto do dispositivo realizado. ___ 104

Figura 5.22 - Foto da montagem da máscara no interior da câmara de deposição.___ 104 
Figura 5.23 - Foto do filme de $\mathrm{TiO}_{2}$ sobre vidro. 105

Figura 5.24 - Foto do filme de Al sobre vidro.

Figura 5.25 - Amostra do filtro depositado com cavidade inclinada, realizada em três fases. 106

Figura 5.26 - Esquema pictórico do filtro dielétrico de interferência variável (FIV) de fase única de deposição.

Figura 5.27 - Amostra do filtro depositado com a mascara em uma única fase. Ref. LF3 $\lambda_{0}=408,0 \mathrm{~nm}$ [

$\left.(\mathrm{HL})^{\wedge} 2(\mathrm{H})(\mathrm{L})(\mathrm{L})(\mathrm{H})(\mathrm{LH})^{\wedge} 2\right]$ 107

Figura 5.28 - Amostra do filtro depositado com a mascara em uma única fase. Ref. LF4

$\lambda_{0}=671.0 \mathrm{~nm}\left[(\mathrm{HL})^{\wedge} 4(\mathrm{H})(\mathrm{L})(\mathrm{L})(\mathrm{H})(\mathrm{LH})^{\wedge} 4\right]$ 107

Figura 6.1 - Foto do EDX-720 - Energy Dispersive X-Ray Spetrometer 108

Figura 6.2 - Foto do interior do EDX-720 - Energy Dispersive X-Ray Spetrometer 108

Figura 6.3 - Ajuste de reta pelo método dos mínimos quadrados 109

Figura 6.4 - Resíduos Absolutos resultantes do ajuste 109

Figura 6.5 - Amostras do FIV obtidas pelo processo descrito. 110

Figura 6.6 - Dispositivo de varredura espacial. 111

Figura 6.7 - Resultado da caracterização da amostra FIV1670_1. 112

Figura 6.8 - Resultado da caracterização da amostra FIV2670_1. 112

Figura 6.9 - Ampliação da escala do espectro da amostra FIV2670_1

Figura 6.10 - Deslocamento da transmitância espectral máxima pelo deslocamento espacial - Ajuste de reta pelo método dos mínimos quadrados. 113

Figura 6.11 - Resíduos Absolutos resultantes do ajuste. 114

Figura 7.1 - Esquema pictórico do Conjunto Detector. 116

Figura 7.2 - Ilustração do "método de três fluxos" para o estudo da dispersão e da absorção da luz em um meio turvo. $F_{0}$ representa o feixe de incidência colimado. $F_{1}$ representa o feixe colimado que viaja no sentido positivo de x, $F_{2}$ representa o fluxo difuso no mesmo sentido de $F_{1}$ e $F_{3}$ representa o fluxo difuso no sentido oposto de $F_{2}$. Reproduzido de [93]. 117

Figura 7.3 - Diagrama esquemático da dispersão no volume e da medida da propriedade bidirecional. As linhas pontilhadas representam a luz dispersa e a linha contínua do lado direito da amostra indica a luz (não dispersa) colimada transmitida. Reproduzido de [93]. 118

Figura 7.4 - Aparato instrumental de teste de uma amostra de PTFE. ___ 118

Figura 7.5 - Imagens de AFM de amostras de PTFE usados como difusor.___ 119

Figura 7.6 - Transmitância do difusor. 119

Figura 7.7 -Caracterização da resposta espectral de um filtro $(671 \mathrm{~nm}$, mod.43087- Edmund optics) que pode ser utilizado para evitar as ordens laterais vizinhas. Medições realizadas no espectrofotômetro Cary 17D. 120

Figura 7.8 - Fotografia do dispositivo TSL1410R (1280x1 pixels). 120

Figura 7.9 - Fotografia do dispositivo TSL1401R (128x1 pixels).

Figura 7.10 - Diagrama funcional reproduzido do datasheet (Texas Advanced Optoelectronic Solutions IncTAOSinc)[94].

Figura 7.11 - Foto da tela do osciloscópio do sinal SI e CLK da implementação [94]. 
Figura 7.12 - Foto da tela do osciloscópio do sinal correspondente ao 129a impulso [94].

Figura 7.13 - Responsividade espectral dos fotodiodos - reproduzido do datasheet (Texas Advanced

Optoelectronic Solutions Inc.). Reproduzido de [94].

Figura 7.14 - Diagrama esquemático do funcionamento do Dispositivo Multicanal Espectral Para Análise

Ambiental.

Figura 7.15 - Diagrama de blocos do funcionamento dos módulos eletrônicos de avaliação e performático. _ 125

Figura 7.16 - Modulo eletrônico principal com o MSC1211.

Figura 7.17 - Esquema eletrônico do modulo com o MSC1211 - Conversores ADC e DACs de precisão com MPU-8051 e memória Flash.

Figura 7.18 - Esquema básico de um modulador do conversor ADC sigma-delta. Reproduzido de[97]. 128

Figura 7.19 - Diagrama em blocos de um conversor ADC sigma-delta. Reproduzido de [97]. 128

Figura 7.20 - Modulo eletrônico de avaliação com o Atmega32. 129

Figura 7.21 - Modulo eletrônico de avaliação com o Atmega32, Conversores ADC 10 bits e memória Flash. 130 Figura 7.22 - Detector formado pelo filtro FIV montado sobre o PDA e um circuito de processamento dispostos sob uma lente convergente. 131

Figura 7.23 - Orifício localizado no plano focal da lente. 131

Figura 7.24 - Conjunto detector completo. 132

Figura 7.25 - Módulo eletrônico com o MSC1211Y5 já programado.

Figura 7.26 - Uma varredura do PDA correspondente a uma avaliação do espectro de um fotodiodo laser. 133 Figura 7.27 - Uma varredura do PDA correspondente a uma avaliação do espectro de um fotodiodo laser onde se observa a definição da medida da radiação monocromática incidente em um pixel. 133 Figura 7.28 - Espectro do diodo laser obtido com o protótipo. 134 Figura 7.29 - Espectro de um diodo laser apresentado no site: http://ledmuseum.home.att.net/, medida realizada com espectrofotômetro modelo USB2000 da OceanOptics, pico do comprimento de onda 663,9 nm e largura a meia altura de $2.0 \mathrm{~nm}$. Acessado em 10/09/2009 - 8:00 hs. 134

Figura 10.1 - Simulação do filtro $\left[\left(\mathrm{HL}^{\wedge} 3\right)(\mathrm{H})(\mathrm{L})(\mathrm{R})(\mathrm{L})(\mathrm{LH})^{\wedge} 3\right], \lambda_{0}=675.0 \mathrm{~nm}$, para deposição em camadas inclinadas, representada para a posição correspondente a $d_{c} / 2=203,63 \mathrm{~nm}$. 138 Figura 10.2 - Simulação do filtro $\left[\left(\mathrm{HL}^{\wedge} 3\right)(\mathrm{H})(\mathrm{L})(\mathrm{R})(\mathrm{L})(\mathrm{LH})^{\wedge} 3\right], \lambda_{0}=675.0 \mathrm{~nm}$, para deposição em camadas inclinadas, representada para a posição correspondente a $d_{c} / 2=303,40 \mathrm{~nm}$. 139 Figura 10.3 - Simulação do filtro $\left[\left(\mathrm{HL}^{\wedge} 3\right)(\mathrm{H})(\mathrm{L})(\mathrm{R})(\mathrm{L})(\mathrm{LH})^{\wedge} 3\right], \lambda_{0}=675.0 \mathrm{~nm}$, para deposição em camadas inclinadas, representada para a posição correspondente a $d_{c} / 2=406,10 \mathrm{~nm}$. 139 Figura 10.4 - Simulação do filtro $\left[\left(\mathrm{HL}^{\wedge} 3\right)(\mathrm{H})(\mathrm{L})(\mathrm{R})(\mathrm{L})(\mathrm{LH})^{\wedge} 3\right], \lambda_{0}=675.0 \mathrm{~nm}$, para deposição em camadas inclinadas, representada para a posição correspondente a $d_{c} / 2=506,60 \mathrm{~nm}$. 140 Figura A.1 - Espectro experimental típico e ajuste por simulação obtido com a amostra de alumínio. 132 


\section{Índice de Tabelas}

Tabela 2.1- Energia de banda e respectivo comprimento de onda para alguns materiais semicondutores.. 38

Tabela 5.1 - Projeto do filtro homogêneo de banda estreita $\lambda_{0}=671 \mathrm{~nm}$. 91

Tabela 5.2 - Projeto do filtro FIV $671 \mathrm{~nm}$. 92

Tabela 5.3 - Projeto do filtro homogêneo de banda estreita $655 \mathrm{~nm}$. 98

Tabela A.1 - Sumário das medidas de RBS 


\section{Listas de Abreviaturas}

\begin{tabular}{|c|c|}
\hline ADC & Analog Digital Converter \\
\hline AERONET & AErosol RObotic NETwork - \\
\hline AND & Ácido Desoxirribonucléico \\
\hline APD & Avalanche Photodiode (Fotodiodo de efeito avalanche) \\
\hline AR & Anti Reflector Coating \\
\hline ARM & Quantitative Links Program e a Atmospheric Radiation Measurement \\
\hline BLIP & Background Limited Infrared Photodetect \\
\hline BRDF & Função distribuição refletância bidirecional \\
\hline CAIRE/LBA & Cooperative LBA Airborne Regional Experiment \\
\hline $\mathrm{CCD}$ & Charge Coupled Device (Dispositivo de Carga Acoplado) \\
\hline CETESB & Companhia de Tecnologia de Saneamento Ambiental de São Paulo \\
\hline CFIV & Circular filtro de interferência variável \\
\hline CISC & Complex Instruction Set Computer \\
\hline CMOS & Complementary metal oxide semiconductor \\
\hline CVD & Chemical Vapor Deposition \\
\hline DAC & Digital Analog Converter \\
\hline DAS & Data Aquisition System \\
\hline DCA & Departamento de Ciências Atmosféricas \\
\hline EM & Estação Meteorológica \\
\hline FBG & Fiber Bragg Grating \\
\hline FIV & Filtro de interferência variável \\
\hline FOV & Field of view (campo de visão) \\
\hline FP & Fabry-Perot \\
\hline FR & Forçante radiativa \\
\hline FWHM & Full width at half maximum (Largura a meia altura) \\
\hline GAW & Global Atmosphere Watch programme \\
\hline HPF & High Pass Filter \\
\hline HWOT & Half-wave optical thickness (espessura óptica meia onda) \\
\hline IPCC & Intergovernmental Panel on Climate Change \\
\hline IR & Infra Red (infravermelho) \\
\hline LASER & Light Amplification through Stimulated Emission of Radiation \\
\hline LBA & Large-scale Biosphere-Atmosphere Experiment in Amazon \\
\hline LF & Line Filter \\
\hline LFIV & Linear filtro de interferência variável \\
\hline LIDAR & Light Detection and Ranging \\
\hline LIVF & Linear interference variable filter \\
\hline LPF & Low Pass Filter \\
\hline LVF & Linear variable filter \\
\hline MEMS & Micro Electro-Mechanical Systems \\
\hline MFRSR & Multi-Filter Rotating Shadowband Radiometer \\
\hline NASA & National Aeronautics and Space Agency \\
\hline NCC & Compreensão Cientifica Avaliada \\
\hline NEP & Noise equivalent power \\
\hline NIMs & Metamateriais de índice negativo \\
\hline OMM & Organização Mundial de Meteorologia \\
\hline $\mathrm{PC}$ & Photonic Crystal \\
\hline
\end{tabular}




$\begin{array}{ll}\text { PD } & \text { Photodiode } \\ \text { PDA } & \text { Phodiode Array } \\ \text { PFRs } & \text { Precision Filter Radiometers } \\ \text { PGA } & \text { Amplificador de ganho programável } \\ \text { Pixel } & \text { Picture e Element (aglutinação de palavras) } \\ \text { PMOD/WRC } & \text { Physikalisch-Meteorolgisches } \text { Observatorium / World Radiation Center } \\ \text { POA } & \text { Profundidade óptica espectral do aerossol } \\ \text { PTFE } & \text { Politetrafluoretano (Teflon } ® \text { ) } \\ \text { PVD } & \text { Physical Vapor Deposition } \\ \text { QWOT } & \text { Quarter-wave optical thickness (espessura óptica quarto de onda) } \\ \text { RACCI/LBA } & \text { Radiation, Cloud, and Climate Interactions } \\ \text { RADAR } & \text { Radio Detection and Ranging } \\ \text { RBS } & \text { Retroespalhamento de Rutherford } \\ \text { RISC } & \text { Redudec Instruction Set Computer - } \\ \text { RS232C } & \text { Recommended standard-232C, EIA } \text { RS-232C ou V.24 } \\ \text { SCAR-B } & \text { Smoke Clouds and Radiation in Brazil } \\ \text { SmoCC/LBA } & \text { Smoke, Clouds, Rainfall and Climate } \\ \text { SPR } & \text { Surface Plasmon Resonance } \\ \text { SRA } & \text { Sensoriamento remoto ativo } \\ \text { SRP } & \text { Sensoriamento remoto passivo } \\ \text { VIF } & \text { Variable interference filter } \\ \text { VLSI } & \text { Very Large integrations scale (integração em muito alta escala) } \\ \text { WDXRF } & \text { Fluorescência de raios X } \\ \text { WDXRFS } & \text { Fluorescência de raios X por dispersão de comprimentos de onda } \\ \text { WMO } & \text { World Meteorological Organization (WMO ou em português) } \\ & \end{array}$




\section{Lista de símbolos}

\begin{tabular}{|c|c|}
\hline$A$ & Absorbância \\
\hline$y_{\text {in }}$ & Admitância do meio para o qual a luz entra \\
\hline$y_{\text {out }}$ & Admitância do meio para o qual a luz sai \\
\hline$y_{j}$ & Admitância óptica da camada “ ${ }_{j}$ “ \\
\hline$y_{f s}$ & Admitância óptica no vácuo \\
\hline $\begin{array}{l}\mathrm{Al} \\
U(r)\end{array}$ & $\begin{array}{l}\text { Alumínio } \\
\text { Amplitude complexa }\end{array}$ \\
\hline$A_{0}$ & Amplitude de uma onda plana \\
\hline$\phi_{1}$ & Ângulo do raio transmitido \\
\hline$\AA$ & Angstrom (Ångström) \\
\hline GaAs & Arseneto de Gálio \\
\hline $\mathrm{E}$ & Campo Elétrico \\
\hline $\mathrm{H}$ & Campo Magnético \\
\hline$q_{e}$ & Carga do elétron \\
\hline$C_{d}$ & Capacitância da junção \\
\hline$r$ & Coeficiente da amplitude de reflexão \\
\hline$t$ & Coeficiente da amplitude de transmissão \\
\hline$k$ & Coeficiente de extinção \\
\hline$w$ & Comprimento da região de depleção \\
\hline$\lambda_{0}$ & Comprimento de onda da luz no vácuo \\
\hline$\lambda_{c}$ & Comprimento de onda de corte \\
\hline$h$ & Constante de Planck \\
\hline$I_{D}$ & Corrente direta de portadores majoritários \\
\hline$I_{1 x n}$ & Correntes de saída do espectrômetro \\
\hline$R_{d}$ & Definição ou resolução \\
\hline$\varphi$ & Deslocamento de fase \\
\hline$D^{*}$ & Detectividade (chamado D-estrela) \\
\hline $\operatorname{det} \mathbf{T}$ & Determinante da matrix $\mathbf{T}$ \\
\hline $\mathrm{CO}_{2}$ & Dióxido de carbono \\
\hline $\mathrm{SO}_{2}$ & Dióxido de enxofre \\
\hline$\eta$ & Eficiência quântica \\
\hline$\varepsilon_{g}$ & Energia de $g a p$ \\
\hline$\Lambda$ & Espessura da célula unitária \\
\hline$a$ & Espessura do material A \\
\hline$b$ & Espessura do material B. \\
\hline$D$ & Espessura óptica do filme \\
\hline FSR & Faixa espectral livre (Free spectral Range) \\
\hline$\zeta$ & Fator complexo \\
\hline$G$ & Fator de ganho interno do fotodetector \\
\hline$F_{k}$ & Feixe de incidência colimado \\
\hline
\end{tabular}




\begin{tabular}{|c|c|}
\hline VNDF & Filtro Variável de Densidade Neutra (neutral density filter) \\
\hline $\mathrm{F}$ & Finesse (finura) \\
\hline$I_{p h}$ & Fotocorrente de portadores minoritários \\
\hline$I_{p}$ & Fotocorrente \\
\hline$v$ & Freqüência da onda \\
\hline $\mathrm{Ge}$ & Germânio \\
\hline InGaAs & Heteroestrutura de Índio e Arseneto de Gálio \\
\hline$n$ & Índice de refração \\
\hline$n_{H}$ & Índices de refração do meio $\mathrm{H}$, camada com alto $n$ \\
\hline$n_{L}$ & Índices de refração do meio L, camada com baixo $n$ \\
\hline $\mathrm{B}$ & Indução Magnética \\
\hline$I_{R}$ & Intensidade no ressonador \\
\hline$T_{R}(v)$ & Intensidade transmitida do ressonador em função da freqência da onda \\
\hline$E_{e}$ & Irradiância incidente \\
\hline$\Delta f$ & Largura de banda do fotodetector \\
\hline$R_{L}$ & Load resistence (resistência de carga) \\
\hline $\mathrm{MP}_{10}$ & Material particulado com diâmetro aerodinâmico menor do que $10 \mu \mathrm{m}$ \\
\hline$M_{j}$ & Matriz característica \\
\hline$C_{n n}$ & Matriz de calibração \\
\hline $\mathrm{CH}_{4}$ & Metano \\
\hline $\mathrm{m}$ & Metro \\
\hline$\mu \mathrm{m}$ & Micrometro \\
\hline$\delta_{1}$ & Mudança de fase do feixe de luz ao atravessar a película \\
\hline $\mathrm{nm}$ & Nanômetro \\
\hline$k$ & Número de onda \\
\hline TE & Ondas elétricas transversais \\
\hline TM & Ondas magnéticas transversais \\
\hline $\mathrm{N}_{2} \mathrm{O}$ & Óxido Nitroso \\
\hline$\varepsilon$ & Permeabilidade magnética \\
\hline$\mu$ & Permissividade elétrica \\
\hline$l(x)$ & Posição na dimensão $x$ \\
\hline$P_{o}$ & Potência óptica incidente (fluxo de radiação transportada pela radiação) \\
\hline$\rho$ & Razão da amplitude da luz refletida pela incidente \\
\hline$\tau$ & Razão da amplitude da luz transmitida pela incidente \\
\hline$R$ & Refletância para espécimes e Refletividade para material puro \\
\hline$R_{e q}$ & Resistência de carga ruído-equivalente do fotodetector \\
\hline$R_{e}$ & Responsividade \\
\hline$S / N$ & Signal-to-noise ratio (razão sinal ruído) \\
\hline $\mathrm{Si}$ & Silício \\
\hline$t_{\mathrm{int}}$ & Tempo de integração \\
\hline$t_{r}$ & Tempo de resposta \\
\hline$\tau_{t}$ & Tempo de transição \\
\hline$V_{e s c}$ & Tensão analógica na saída na condição "escura" \\
\hline
\end{tabular}




$\begin{array}{ll}V_{s} & \text { Tensão analógica na saída } \\ t r \mathbf{T} & \text { Traço da matriz } \mathbf{T} \\ T & \text { Transmitância para espécimes e Transmissividade para material puro } \\ v_{m} & \text { Velocidade da luz no meio } \\ c & \text { Velocidade da luz no vácuo } \\ v_{d} & \text { Velocidade de deriva } \\ k_{j z} & \text { Vetor de onda local } \\ \mathrm{W} & \text { Watts } \\ \mathrm{NO}_{\mathrm{X}} & \text { X-óxido de Nitrogênio }\end{array}$




\section{Introdução}

A análise do espectro óptico (detecção óptica do comprimento de onda e a sua monitoração) é muito importante em muitas áreas cientificas, campos de pesquisa, aplicações técnicas e industriais. Algumas das mais conhecidas são: a espectroscopia e a demultiplexação do comprimento de onda nas telecomunicações. Uma área de particular interesse, envolvendo a detecção óptica, é o monitoramento da distribuição espectral de uma fonte de luz. Em comparação com as alternativas eletrônicas os sensores ópticos oferecem muitas vantagens, como por exemplo: são, muito sensíveis, mais robustos e imunes a interferências eletromagnéticas. Inúmeros sensores têm surgido para atender a demanda de aplicações exigentes, como os que se baseiam na variação das propriedades ópticas (como reflexão e transmissão) de certos materiais.

Sensores espectrais especiais que monitoram uma superfície ou objeto, os Surface Plasmon Resonance (SPR), são amplamente utilizados para o rastreamento de interações bioquímicas [1]. Outros grupos de pesquisa desenvolvem biosensores ópticos baseados em cavidades de Fabry-Perot [2] ou filtros de cavidades ressonantes [3] [4]. Também existem aplicações que utilizam a mudança da ressonância óptica para, por exemplo, quantificar o ácido desoxirribonucléico (ADN) [4].

Outro exemplo de um sensor óptico de destaque é o sensor de fibra óptica de grade de Bragg (Fiber Bragg Grating - FBG) [6] e [7]. Um FBG é constituído por uma modulação periódica do índice de refração ao longo do comprimento de uma fibra óptica. Um dispositivo como este reflete um determinado espectro estreito de comprimento de onda, determinado pelo período do perfil de índice de refração. Um estímulo externo (por exemplo, temperatura, tensão mecânica, stress, revestimento biológico, ambiente químico, etc) que mude a periodicidade da grade, desloca conseqüentemente o espectro refletido. Assim, este deslocamento do comprimento de onda é uma medida direta do estímulo externo. Este deslocamento do comprimento de onda tem que ser medido com resolução de detecção muito alta, de forma a permitir a quantificação do estimulo. Os Sensores bidimensionais e tridimensionais de cristais fotônicos (Photonic Crystal - PC) são análogos aos FBG [7]. Nos PCs a modulação periódica do índice de refração é realizada em mais de um sentido. Os cristais podem ser preenchidos ou unidos com uma espécie sob teste e as alterações nestas 
espécies podem ser detectadas monitorando-se as propriedades ópticas de reflexão e de transmissão.

Diversos métodos podem ser usados para detectar pequenas mudanças espectrais. Um instrumento para essa finalidade seria um espectrômetro, que pode ser baseado em uma grade de difração ou em uma configuração interferométrica. Espectrômetros baseados em prismas e grades de difração ou interferométricos como de "mach-Zehnder" ou de "Fizeau" [8] geralmente fornecem informações excepcionalmente boas do comprimento de onda, mas são volumosos, caros e sensíveis à vibração. Os interferômetros à base de fibra óptica não sofrem estas limitações, mas cobrem somente uma faixa espectral limitada. Assim, um detector compacto capaz de oferecer boa resolução na detecção de variações do comprimento de ondas muito pequenas é altamente desejável.

Uma abordagem simples usa vários fotodiodos (photodiode-PD) revestidos com diferentes filtros passa-banda para permitir que apenas uma pequena faixa espectral seja transmitida ao PD. A banda de transmissão de cada filtro é peculiar de modo que cada PD registra diferentes bandas espectrais.

Uma nova abordagem, proposta neste trabalho, combina as propriedades de reflexão e de transmissão de cristais fotônicos bidimensionais com um filtro banda-passante em forma de cunha para obtenção de detectores de comprimentos de onda muito compactos e rígidos.

Assim, neste trabalho, é proposta a combinação de um filtro de interferência de bandapassante variável (variable interference filter-VIF, linear filter interference variable-LFIV, linear variable filter-LVF ou filtro de interferência variável-FIV), que se apresenta nas modalidades circular ou linear (CFIV, LFIV) [9] e [10], com um dispositivo formado de elementos fotossensíveis distribuídos, que podem ser usados para realizar um detector de comprimentos de onda que seja capaz de resolver um deslocamento de comprimento de uma radiação monocromática na ordem de pm [11]. Por outro lado, esta mesma configuração pode ser usada para resolver os componentes espectrais de uma fonte de luz policromática [12] com expectativa de se obter resoluções muito mais modestas. O filtro converte a informação do comprimento de onda da luz incidente em uma distribuição espacial da intensidade que pode ser detectada com precisão elevada utilizando uma matriz de fotodiodos (PDA), constituindo um dispositivo muito robusto e compacto. A Figura 1.1 apresenta esquematicamente como seria o detector de comprimento de onda proposto.

A funcionalidade desta combinação será investigada e avaliada no que diz respeito às propriedades ópticas do filtro, notadamente a sua resposta espectral. Isto inclui o gradiente dos deslocamentos dos picos de transmissão através da superfície do filtro e a largura 
espectral da função de transmissão. Também, será analisada a influência da forma de iluminação do dispositivo.

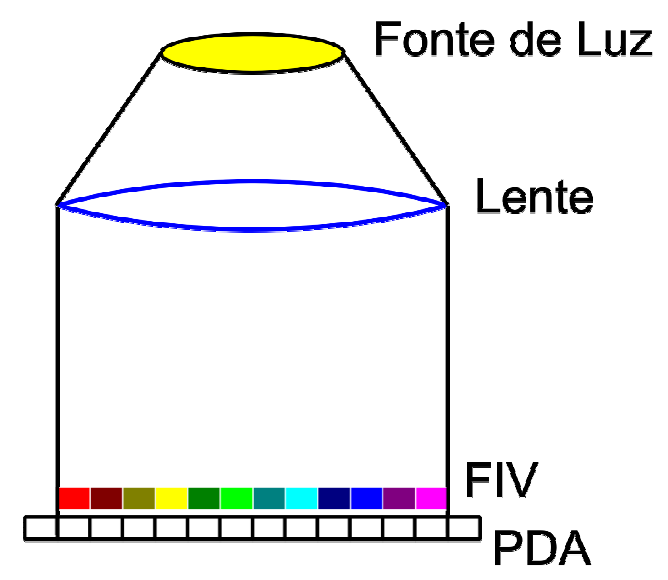

Figura 1.1 - Esquema do detector de comprimento de onda.

Adicionalmente, no escopo deste trabalho, é selecionada uma aplicação que requer as melhores características do dispositivo proposto, tais como a estabilidade dos detectores, a resposta espectral dos mesmos, a sensibilidade térmica e a eficiência de transmissão dos filtros espectrais, e é estudada a viabilidade da construção de um dispositivo multicanal espectral para análise ambiental.

\subsection{Os constituintes atmosféricos e as mudanças climáticas}

As mudanças nas quantidades dos gases de efeito estufa e dos aerossóis na atmosfera e as mudanças nas propriedades da superfície terrestre e na radiação solar, alteram o equilíbrio energético do sistema climático terrestre. De forma geral, essas mudanças são expressas em termos da chamada forçante radiativa, que é usada para comparar a forma como os fatores humanos e naturais provocam o aquecimento ou o esfriamento do clima global [13]e [14].

Os cenários de mudanças climáticas, relatados no Relatório do IPCC 2007 AR4, apontam para uma série de mudanças climáticas globais na temperatura do ar à superfície e nos padrões de precipitação (chuva). Esses cenários são baseados numa variedade de simulações com diferentes modelos que foram validados conforme sua capacidade de representar satisfatoriamente o clima do passado e do presente [15]. Os autores afirmam também que a análise dos efeitos regionais nos cenários futuros, especialmente no caso dos padrões de chuva tem uma incerteza básica que é a própria representação da chuva, que está 
associada aos problemas de representação dos aerossóis, dos processos radiativos e a microfísica de nuvens.

O papel do aerossol nos processos atmosféricos e climáticos, já há algum tempo, tem sido salientado pela comunidade científica internacional. Em 1996 o IPCC avaliou em seu relatório o efeito dos aerossóis atmosféricos como sendo uma das principais fontes de incerteza nos modelos prognósticos de mudanças climáticas [16]. O relatório de 2001 reafirmou que o efeito resultante das partículas de aerossol sobre o balanço de radiação atmosférico e sobre o clima constituía uma das principais fontes de incerteza na tentativa de modelar e prever o clima [15]. No mais recente relatório divulgado em 2007, o IPCC ressalta que os aerossóis atmosféricos, apesar das melhores condições de medições por satélite e baseadas na superfície além de uma modelagem numérica mais abrangente, ainda continuam sendo a principal incerteza na forçante radiativa [13].

A definição de forçante radiativa (FR) em termos gerais significa uma mudança imposta sobre o balanço de radiação planetário. A definição quantitativa mais simples da FR é de uma mudança instantânea do fluxo radiativo na tropopausa [18]. Segundo o IPCC, a FR refere-se à medida da influência de um fator que perturbe o equilíbrio da energia que entra e sai do sistema Terra-atmosfera, representando assim um índice da importância deste fator como possível mecanismo de mudança do clima. A forçante radiativa positiva na superfície tende a aquecê-la, enquanto a forçante negativa tende a esfriá-la [16].

Alguns fatores que são associados como elementos perturbadores no balanço energético do sistema Terra-atmosfera, são: as alterações na quantidade de radiação solar incidente no topo da atmosfera (TOA), mudanças na composição da atmosfera e nas propriedades ópticas da superfície [18]. A Figura 1.2 apresenta a FR e a incerteza associada a cada um dos agentes relevantes para os modelos de prognósticos climáticos utilizados pelo IPCC, cabendo frisar as barras de incerteza da FR atribuídas ao efeito direto e indireto dos aerossóis. No relatório do IPCC de 2007 os valores da FR estimados em 2005 são relativos às condições pré-industriais estimadas para o ano de 1750 , sendo expressos em $\left[\mathrm{W} / \mathrm{m}^{2}\right]$. 


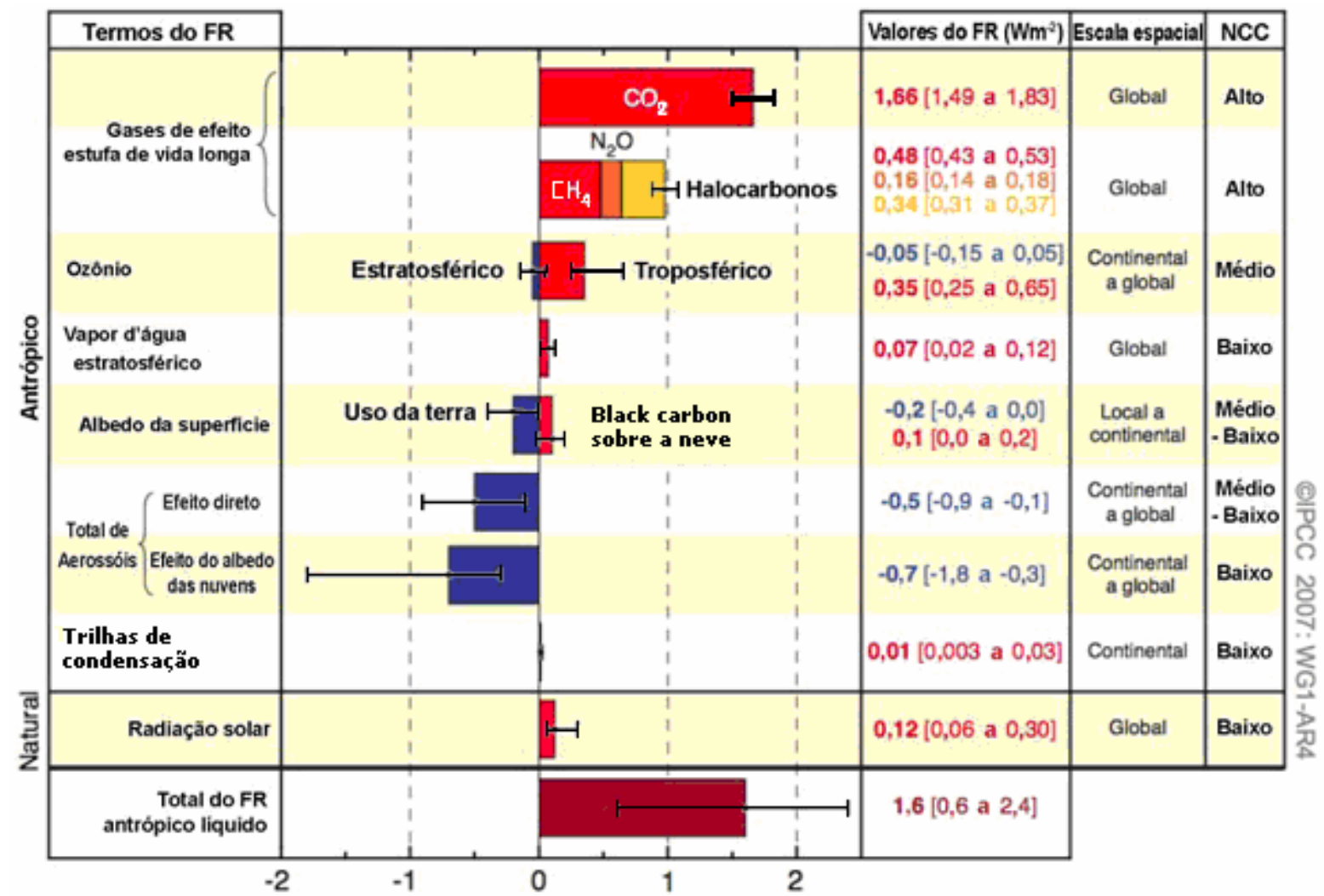

Figura 1.2 - Estimativas para a forçante radiativa (FR/2005) média global. Atribuída ao dióxido de carbono $\left(\mathrm{CO}_{2}\right)$, metano $\left(\mathrm{CH}_{4}\right)$, óxido nitroso $\left(\mathrm{N}_{2} \mathrm{O}\right)$, aerossóis bem como para outros agentes e mecanismos significativos. Junto com o valor da forçante em [W/m2] é apresentada também a extensão geográfica típica (escala espacial) da FR e o nível de compreensão científica avaliada (NCC). Adaptado de [13].

No Brasil, ao longo destas últimas duas décadas, o papel dos aerossóis nos fenômenos atmosféricos vem despertando a atenção da comunidade científica, principalmente em estudos sobre os aerossóis de queimadas da região amazônica e Brasil central e, em menor escala, em estudos sobre o aerossol urbano. Alguns destes trabalhos foram auxiliados por campanhas de medições intensivas e extensivas, realizadas no território brasileiro, que contribuíram para uma melhor compreensão das interações das partículas de aerossol presentes na atmosfera com a radiação solar além do estudo e análise de outras variáveis meteorológicas. Cabe salientar algumas das campanhas ocorridas no Brasil como a Smoke, Clouds and Radiation in Brazil (SCAR-B) que ocorreu entre os meses de agosto e setembro de 1995 [19] e as campanhas desenvolvidas no projeto de Large-scale Biosphere-Atmosphere Experiment in Amazon (LBA). Dentro do projeto LBA vale lembrar a campanha de 1998: Cooperative LBA Airborne Regional Experiment (CLAIRE/LBA), a campanha de 2002 o Radiation, Cloud, and Climate Interactions (RACCI/LBA) e o Smoke, Clouds, Rainfall and Climate (SmoCC/LBA); este último realizado em Rondônia entre os meses de setembro a novembro de 2002 [20]. 
A maior parte dos experimentos e campanhas realizadas estavam associadas, basicamente, ao estudo dos aerossóis atmosféricos de queimadas. O estudo de aerossóis urbanos, em amplo espectro e por longo tempo, apesar dos esforços valorosos de alguns grupos de pesquisa acadêmicos e de instituições governamentais, ainda são reduzidos, principalmente quanto as estimativas de propriedades ópticas do aerossol no território brasileiro [16]. Os trabalhos de Miranda [21] e Corrêa [22] foram pioneiros em estimar propriedades ópticas espectrais do aerossol em São Paulo obtidas por fotometria solar. Porém, somente nos trabalhos de Castanho [23], Rosário [24] e de Sayão [16] as propriedades ópticas dos aerossóis urbanos de São Paulo, obtiveram um tratamento mais sistemático e com uma base de dados maior.

A carência de pesquisas sobre propriedades ópticas espectrais dos aerossóis deve-se principalmente à falta de recursos financeiros e humanos na aquisição e principalmente na manutenção (operação, calibração, aferição, conserto, etc) de redes de monitoramento sistemático no território brasileiro, principalmente em áreas urbanas densamente povoadas e poluídas como a da Região Metropolitana de São Paulo [16]. Vale ressaltar os esforços de escassas redes, que atuam no Brasil, de monitoramento de produtos distintos de aerossóis atmosféricos como os da rede AErosol RObotic NETwork - National Aeronautics and Space Agency (AERONET-NASA), que estima propriedades ópticas do aerossol como a profundidade óptica e o coeficiente de Ångström, e de redes como da Companhia de Tecnologia de Saneamento Ambiental de São Paulo (CETESB) que monitora parâmetros da qualidade do ar próximo ao solo como o $\mathrm{MP}_{10}$ (material particulado com diâmetro aerodinâmico menor do que $10 \mu \mathrm{m}$ ), o $\mathrm{SO}_{2}, \mathrm{o} \mathrm{NO}_{\mathrm{X}}$, além de outros parâmetros e variáveis meteorológicas [23] e [16].

Os aerossóis e outros constituintes atmosféricos gerados em uma região podem ainda ser transportados por centenas a milhares de quilômetros até outras regiões [23]-[26] e [16] o que também justifica o seu intenso e contínuo monitoramento. Como exemplo de transporte de aerossóis por longas distâncias, cabe lembrar o que ocorre com a poeira do deserto do Sahara na África até o sul da América do Sul e o aerossol gerado pelo acidente da usina nuclear de Chernobyl que foi detectado a mais de $1000 \mathrm{~km}$ de distância do local do acidente [26]. O transporte de aerossóis de queimadas da região amazônica e do Brasil central até São Paulo tem sido investigado por alguns autores como Landulfo et al. [27], Castanho [23] e Sayão [16].

Ao contrário dos gases do efeito estufa, cuja concentração e distribuição em todo globo é praticamente constante, a variabilidade de tipos de aerossol, com diferentes 
propriedades ópticas, ocorre tanto espacial quanto temporalmente devido à sua curta permanência na atmosfera e também às diversas fontes emissoras [27]. O tempo de residência das partículas de aerossóis na atmosfera pode variar de minutos a horas, para partículas menores do que $0,001 \mu \mathrm{m}$ e maiores do que $100 \mu \mathrm{m}$, e de uma semana, para partículas entre 0,05 a 2,0 $\mu \mathrm{m}$. Porém, partículas lançadas na estratosfera podem alcançar tempo de residência de meses a anos [26]. Na região metropolitana de São Paulo, de acordo com Castanho [29], as principais fontes de aerossol na fração fina (partículas com diâmetro aerodinâmico menor que 2,0 $\mu \mathrm{m}$ ) são: emissão veicular, poeira do solo, queima de óleo combustível, compostos contendo sulfato e emissões industriais. Para a fração grossa (partículas de aerossol com diâmetro aerodinâmico de 2,0 e $10 \mu \mathrm{m}$ ), a autora também relaciona a poeira do solo, emissão industrial e sal marinho como as principais fontes em São Paulo.

\subsubsection{A interação do aerossol atmosférico com a radiação solar}

As partículas de aerossol interagem direta e indiretamente com a radiação solar. $\mathrm{O}$ efeito direto ocorre por sua capacidade em absorver e espalhar a radiação solar, enquanto que o efeito indireto é causado por atuarem como núcleos de condensação de nuvens. Embora o espalhamento e o efeito indireto auxiliem a resfriar a atmosfera e a superfície, agindo no sentido inverso do efeito estufa, a propriedade de absorção pode influenciar o clima de diferentes maneiras; podendo, por um lado, aquecer e tornar a atmosfera mais estável, mas, por outro lado, podendo inibir a evapotranspiração e, por conseguinte, a formação de nuvens [30].

Em contraste com os gases do efeito estufa que interagem majoritariamente com a radiação em comprimentos de onda na região do infravermelho, as partículas de aerossóis podem influir no balanço de radiação na atmosfera tanto devido à interação com a radiação solar visível bem como com a radiação no infravermelho. Em geral partículas com diâmetros menores que 1,0 $\mu \mathrm{m}$ apresentam alta eficiência no espalhamento da radiação solar incidente no topo da atmosfera. Como consequiência, estas partículas reduzem o valor da energia solar incidente na superfície contribuindo para o resfriamento da Terra [31]. Os aerossóis ao interagirem com a radiação solar na atmosfera promovem a atenuação do feixe direto da radiação bem como a produção de radiação difusa por espalhamento; a própria absorção atmosférica pode ser intensificada conforme a composição química das partículas em questão [32]. 
A magnitude da profundidade óptica do aerossol e a sua dependência com o comprimento de onda da radiação incidente constituem informações necessárias à avaliação dos efeitos do material particulado em suspensão na atmosfera (aerossol) sobre o balanço radiativo e sobre o tempo de exposição do ser humano à radiação ultravioleta [34] e [35]. A relevância da profundidade óptica espectral do aerossol (POA) está na proporcionalidade entre esta e a concentração de partículas em toda coluna vertical da atmosfera. A POA representa, resumidamente, um fator de atenuação exponencial do feixe direto da radiação solar ao atravessar a atmosfera devido à interação com os aerossóis, enquanto que a dependência espectral fornece informações sobre a distribuição de tamanho dos aerossóis [36].

\subsubsection{Sensoriamento remoto}

O sensoriamento remoto basicamente é definido como uma técnica para se obter informações sobre algo através de dados coletados por instrumentos que não estejam em contato físico com os elementos investigados. Assim o sensoriamento remoto é diferente de medições realizadas in situ nas quais as observações específicas são feitas dentro do meio que se estuda (como as realizadas na superfície ou a bordo de aeronaves). Ele envolve a interpretação e inversões de medidas de radiação eletromagnética, tomadas a alguma distância do meio que se quer medir [37]. Por não haver o contato físico entre o sensor e o elemento que se investiga, a forma de transmissão dos dados (do objeto para o sensor) é obtida por interações da radiação eletromagnética com o elemento em estudo.

O sensoriamento remoto pode ser agrupado em dois tipos: ativo e o passivo; e ambos têm sido utilizados no sensoriamento remoto do aerossol a partir da superfície [37]-[28]. O sensoriamento remoto ativo (SRA) emprega radiações de fontes artificiais como as geradas pelos Light Amplification through Stimulated Emission of Radiation (LASER) usados em sistemas de detecção do tipo Light Detection and Ranging (LIDAR). Outra forma de SRA é o que emprega fontes de microondas em Radio Detection and Ranging (RADAR) que freqüentemente são empregados em estimativas de precipitação e estudos de micro-física de nuvens. O SRA emprega o princípio de detecção e análise do retro-espalhamento (backscattering) da radiação ou seja, após emitida, a interação com o meio e o alvo a ser estudado e retorna ao sensor [37]. 
O sensoriamento remoto passivo (SRP) emprega, no seu processo de detecção, fontes naturais de radiação como a solar ou a emitida pelo sistema Terra-atmosfera (radiação de onda longa). O SRP permite estimativas globais tanto para informações da superfície como para a atmosfera [37]. O SRP é uma das técnicas mais empregadas em estimativas de propriedades ópticas dos aerossóis tanto com a instrumentação instalada na superfície (fotometria ou radiometria solar) quanto por sensores abordo de satélites [16].

\subsubsection{Sensoriamento remoto dos aerossóis}

O monitoramento de aerossóis atmosféricos pode ser feito por medidas realizadas na superfície, porém este tipo de monitoramento fornece resultados localizados e representativos somente dos níveis atmosféricos mais próximos da superfície, pois várias características das partículas de aerossol podem apresentar variações com a vertical, isto é, na altitude [25]. Estas medidas são empregadas principalmente em estudos que envolvem poluição atmosférica e saúde humana. Outra característica importante é que em geral medidas realizadas em aeronaves e na superfície alteram as propriedades das partículas, seja por secá-las ou por causa da volatilização de certos compostos constituintes das partículas de aerossol. O sensoriamento do aerossol ainda pode ser feito por sensores abordo de satélites. Apesar da sua abrangência espacial, o emprego desta técnica de monitoramento exige a elaboração de modelos físicos para as partículas de aerossol [25].

Dentro deste contexto a fotometria solar tem sido amplamente utilizada no monitoramento do aerossol a partir de fotômetros solares e radiômetros multi-espectrais [32]. Isso se deve à simplicidade de sua base conceitual associada à alta qualidade dos seus dados [19] e [24]. A vantagem da fotometria solar reside no fato de permitir a determinação de parâmetros micro-físicos das partículas presentes em toda a coluna vertical da atmosfera em condições ambientais, ou seja, sem alterar o ambiente ou as partículas nele inseridas, além de propiciar estudos de longo prazo [16]. A desvantagem da fotometria solar está na falta de informações quanto à distribuição vertical das partículas de aerossol [25].

Historicamente, a observação da redução da intensidade da luz (atenuação), ao atravessar a atmosfera, foi quantificada pela primeira vez em 23 de novembro de 1725 , na Bretanha (França) por Pierre Bouguer. Avanços tecnológicos no século XIX proporcionaram a substituição de estimativas visuais da atenuação da luz por medidas de sensores constituídos por termopilhas. No século XX, com o desenvolvimento da indústria química e de lentes, 
foram construídos os primeiros filtros empregados em novos sensores termodinâmicos, o que melhorou a qualidade das observações como bem propiciou refinar o espectro de leitura dos detectores. A evolução tecnológica da óptica e da eletrônica tem contribuído no desenvolvimento da fotometria solar, principalmente a partir da década de 1960, com o advento dos sensores foto-diodo, fabricados a partir de materiais semicondutores [32]. Vale lembrar que o precursor dos modernos fotômetros solares foi originalmente desenvolvido em 1959, sendo chamado de Voltz hand-held photometer, e possuía apenas duas bandas espectrais especificamente desenhadas para medir a "turbidez" atmosférica [39].

Os instrumentos empregados na técnica de fotometria solar, atualmente são constituídos por um radiômetro capaz de medir o componente direto da radiação solar incidente por um estreito campo de visão (da ordem de $1^{\circ}$ a $3^{\circ}$ ), passando também por filtros de interferência com bandas de transmissão estreitas, da ordem de 6,0 a 10,0 nm [39]. Outros instrumentos são capazes de estimar o componente direto espectral da radiação solar empregando técnicas de sombreamento do disco solar, sem restringir o campo visual de detecção, denominados como radiômetros multi-espectrais [40].

Nas últimas décadas, observações de irradiância solar espectral direcional, efetuadas com radiômetros do tipo Multi-Filter Rotating Shadowband Radiometer (MFRSR) têm sido analisadas de forma a estimar propriedades atmosféricas integradas acima do plano de observação, como a profundidade óptica espectral do aerossol (POA), o conteúdo atmosférico do vapor d'água, do ozônio e do dióxido de nitrogênio [41]-[43].

A acurácia nas estimativas de propriedades ópticas da atmosfera obtidas por fotometria solar depende também de características físicas instrumentais dos detectores empregados, principalmente com relação à sensibilidade e à estabilidade na detecção da radiação solar ao longo do tempo. A estabilidade da detecção ainda continua sendo um dos principais desafios da fotometria solar [16], [24], [32] e [39]. A calibração dos fotômetros e radiômetros solares consiste em estimar a chamada constante solar espectral, que é o valor da radiação solar monocromática estimada para o topo da atmosfera com um determinado instrumento segundo a sua função filtro espectral. Classicamente, segundo Shaw [29], a constante solar espectral é estimada pelo método de Langley Plot, aplicável em localidades com atmosfera limpa como no topo de uma montanha, o que restringe o seu uso devido aos problemas inerentes à técnica e à logística. Este fato pode exigir o emprego de outras metodologias, como o Método Geral, proposto por Forgan [44], para a estimativa da constante solar com medidas no local de operação do instrumento. Segundo recomendações da Organização Mundial de Meteorologia (OMM) a incerteza aceitável na estimativa espectral 
da POA é em torno de 0,02 e sugere como valor ideal 0,01 . Por este motivo, erros maiores do que $2,0 \%$ na constante solar podem acarretar erros maiores do que o recomendado pela OMM [45]. Quanto à estabilidade dos detectores, cabe salientar que a resposta espectral dos mesmos, a sensibilidade térmica e a eficiência de transmissão dos filtros espectrais podem comprometê-la [24].

Algumas redes mundiais de monitoramento da atmosfera empregam fotômetros solares e radiômetros multi-espectrais (Figura 1.3). Entre as mais conhecidas, em escala global, se destaca a rede AERONET - NASA, que também atua no Brasil, empregando fotômetros solares Cimel Eletronique 318A e a rede Global Atmosphere Watch programme (GAW) que pertence à World Meteorological Organization (WMO ou em português OMM), a qual utiliza instrumentos do tipo Precision Filter Radiometers (PFRs), desenvolvidos e fabricados pela Physikalisch-Meteorolgisches Observatorium / World Radiation Center (PMOD/WRC) de Davos, Suiça [36]. Redes de monitoramento nos Estados Unidos (USA) têm empregado também radiômetros do tipo MFRSR como a rede do U.S. Department of Agriculture (USDA) [36]. Outras redes regionais têm utilizado os radiômetros MFRSR como instrumento padrão para o monitoramento de propriedades ópticas dos aerossóis entre elas cabe citar a Quantitative Links Program e a Atmospheric Radiation Measurement (ARM) [46].

Em São Paulo as primeiras medidas de radiação solar espectral que permitissem estimativas de propriedades ópticas do aerossol de forma sistemática, contínua e acurada só foram obtidas a partir de agosto de 1999 [47]. Nesta data o primeiro MFRSR pertencente ao Departamento de Ciências Atmosféricas (DCA) do Instituto de Astronomia, Geofísica e Ciências Atmosféricas da Universidade de São Paulo (IAG-USP) foi instalado junto ao prédio da Estação Meteorológica (EM) do IAG-USP localizado no bairro da Água Funda (Latitude 2339'03' e Longitude -46³7'19'’) [16]. No final do ano de 2000 foi instalado no topo do Edifício Pelletron, que faz parte do Instituto de Física da USP, localizado na Cidade

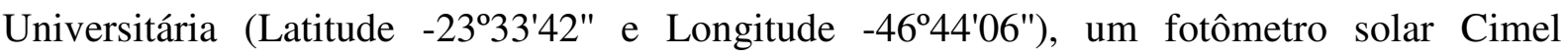
(CE318A) pertencente a rede AERONET.

Considerando-se o exposto até aqui, é salientada a escassez de dados e instrumentação instalada que possam caracterizar uma região tão importante como a Região Metropolitana de São Paulo. 


\subsection{Motivação, estado da arte da instrumentação.}

Foram mencionadas, no final da secção anterior, algumas redes mundiais de monitoramento da atmosfera que empregam fotômetros solares e radiômetros multi-espectrais que compõem, por assim dizer, plataformas instrumentais. Considero que uma única opção de adesão a tais plataformas pode representar uma certa rigidez nas pesquisas e relativa dependência de vez que tais instrumentos necessitam de manutenção e calibrações periódicas. $\mathrm{Na}$ figura abaixo (Figura 1.3) apresenta-se uma vista externa de um complexo de monitoramento radiativo/fotométrico.

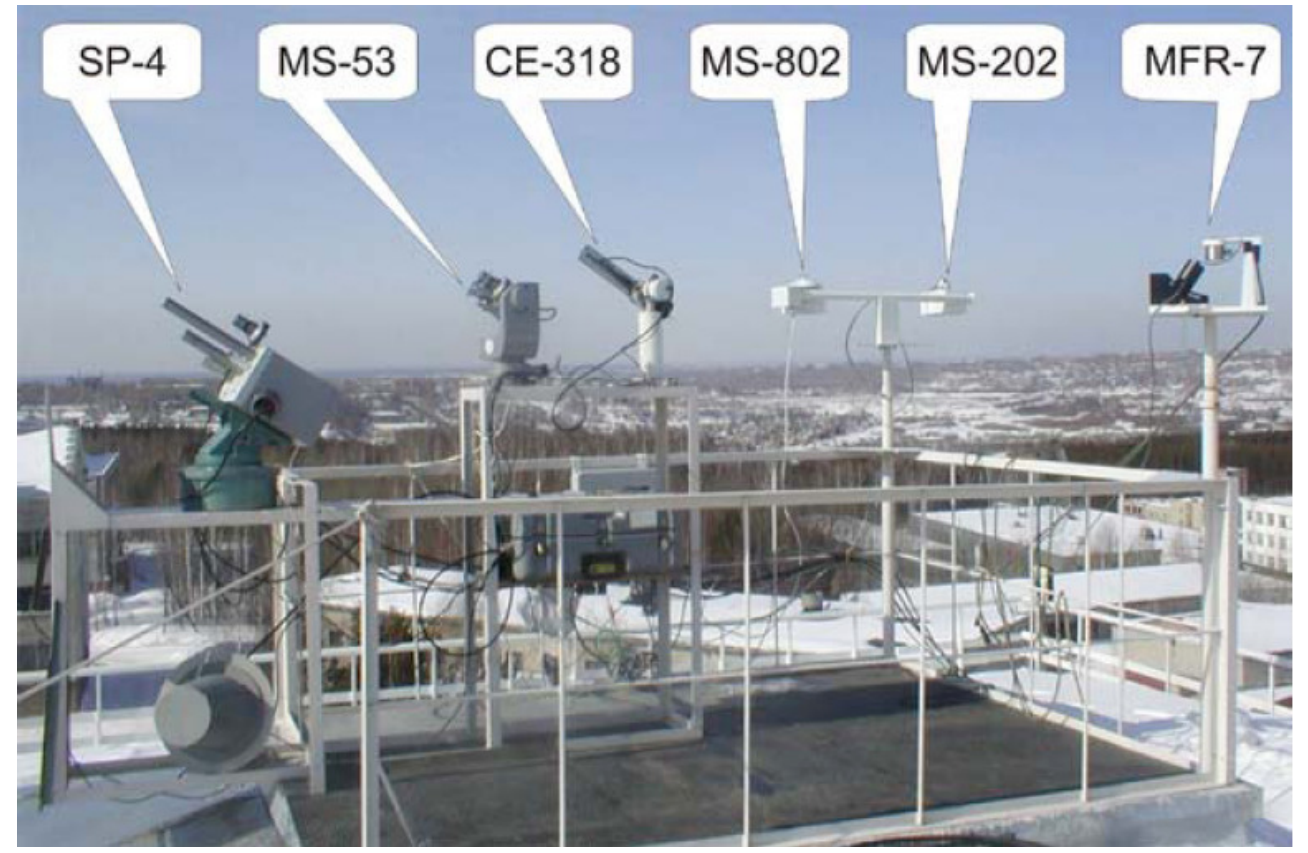

Figura 1.3 - Vista externa de um complexo de monitoramento radiativo/fotométrico. Reproduzido de [48].

Assim, a mencionada escassez de dados e de instrumentação nos motiva a buscar alternativas, soluções e inovações de modo a possibilitar, dentro de uma maior profusão de opções, o surgimento de soluções nacionais para a instrumentação que atendam ao menos em parte as necessidades dos grupos de pesquisa brasileiros que atuam nestes programas científicos de relevância.

Desta maneira, incluí-se no escopo deste trabalho desenvolver uma visão geral do estado da arte da instrumentação empregada e descrever um novo conceito de instrumentação que possa agregar condições de obtenção de dados de qualidade e que permita a comparação destes dados com aqueles disponibilizados por plataformas já existentes. 
Historicamente, um radiômetro solar automatizado foi projetado e fabricado por A. R. EHSANI et al. [49]. Este sistema proposto é um radiômetro multicanal mostrado na Figura 1.4 e usado na monitoração da transmitância espectral atmosférica sobre uma faixa de comprimentos de onda de 380 a 1030 nanômetros. O radiômetro solar consiste em 10 telescópios paralelos, que são apontados para o sol através de um dispositivo elaborado para perseguir a posição do sol. Este dispositivo corresponde a um detector de quadrante automatizado com erro máximo de $\pm 0,05^{\circ}$. Cada canal consiste de um telescópio com um field of view (FOV - campo de visão) definido por um conjunto de aberturas, um filtro de interferência passa-banda (aproximadamente 10 nanômetros), e um detector combinado com um amplificador de corrente. A temperatura de cada módulo composto pelo fotodiodo/amplificador é estabilizada através de um subsistema controlador de temperatura, que assegura a resposta uniforme dos detectores durante no curso da coleta de dados. $\mathrm{O}$ ganho de cada amplificador operacional é selecionado para combinar o alcance dinâmico do sistema para a aquisição de dados do radiômetro (Data Aquisition System-DAS). O DAS controla todas as atividades do sistema do radiômetro solar e é iniciado por um "programa de menus". O DAS automatizado controla o sistema de direcionamento, monitora a temperatura dos detectores e mede e coleta a saída de todos os 10 canais. Os valores coletados são armazenados na memória interna juntamente com a data e instante do levantamento de dados. O sistema de aquisição de dados pode ser conectado a um computador pessoal para transferir os dados armazenados através de uma porta de serial.

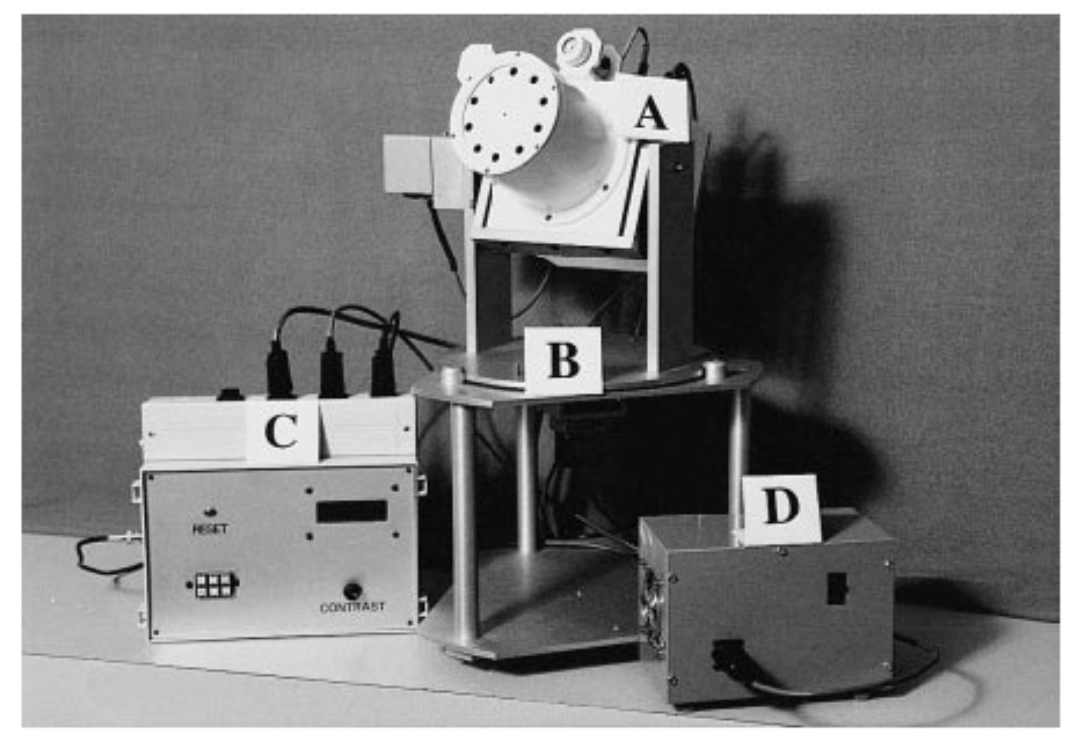

Figura 1.4 - Radiômetro solar automatizado de 10 canais. Instrumento: (a) sistema detector do radiômetro, (b) sistema de direcionamento, (c) sistema de aquisição de dados (DAS), e (d) fonte de alimentação. Reproduzido de [49]. 
Baseados nesta estrutura, atualmente estão disponíveis outros instrumentos que incorporam muitos aperfeiçoamentos, dentre eles o "Multi-Filter Rotating Shadowband Radiometer" MFRSR que é um instrumento de campo que mede simultaneamente as componentes global, difusa e direta normal, da irradiação solar espectral. O MFRSR usa conjuntos independentes de combinações de filtro de interferência e fotodiodos, montados em um invólucro com temperatura controlada, para detectar irradiação espectral em seis comprimentos de onda diferentes mais um canal de banda larga. Um sombreador automatizado é usado alternadamente para sombrear e expor a abertura do detector do instrumento, permitindo a medida dos três componentes da radiação solar, ver Figura 1.5. As componentes global e difusa são medidas diretamente e o componente direto-normal é computado da diferença dos dois componentes medidos. As medidas espectrais no MFRSR são feitas em seis comprimentos de onda: 415, 500, 615, 673, 870, e 940 nanômetros. A escolha dos comprimentos de onda permite a reconstrução simulada do espectro de irradiação espectral solar incidente e a determinação das profundidades ópticas do vapor de água, dos aerossóis, e do ozônio. Adicionalmente um canal de faixa larga mede a irradiação solar total, similarmente a um piranômetro.

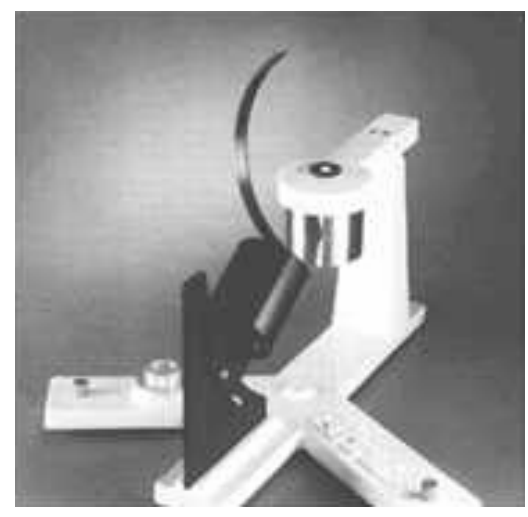

(a) Equipamento

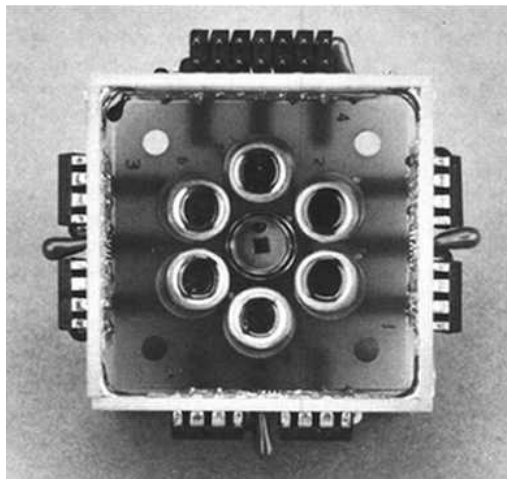

(b) Sensor

Figura 1.5 - Imagem do radiômetro Modelo MFRSR- (a) Equipamento; (b) Sensor. http://www.yesinc.com/products/data/mfr7/index.html(03/03/09-22:40hs) 


\subsection{Organização desta dissertação}

Este capítulo introduz o assunto da análise espectral óptica e apresenta a motivação e os objetivos deste trabalho. O capítulo 2 aborda o assunto da fotodetecção e os conceitos fundamentais relacionados aos fotodetectores.

O capitulo 3 aborda os aspectos da análise espectral da luz visível, da teoria de funcionamento dos espectrofotômetros e da deposição de filmes finos. O capitulo 4 estuda a teoria óptica espectrométrica, considerada neste trabalho no sentido restrito às medições e avaliações das radiações eletromagnéticas espectrais na faixa óptica, revisa a teoria básica da propagação das ondas eletromagnética e considera o ressonador de Fabry-Perot plano-planar ideal para possibilitar o tratamento no capitulo 5 do filtro de interferência variável (FIV), de um método de obtenção deste filtro e de algumas aplicações.

No capitulo 6 são apresentadas as caracterizações e os resultados obtidos, no capítulo 7 é apresentada a descrição do dispositivo multicanal espectral para análise ambiental e nos capitulos 8, 9 e 10 são resumidas as conclusões, feitas as considerações finais e apresentadas as perspectivas de trabalhos futuros. 


\section{Fotodetecção}

A radiação, no sentido geral, pode consistir de partículas carregadas (elétrons, prótons e núcleos atômicos dentre outras partículas elementares), partículas neutras (nêutrons e partículas elementares), e radiação eletromagnética: microondas, infravermelho, visível, ultravioleta, raios $\mathrm{X}$ e raios gama.

A luz, como um fenômeno eletromagnético, é descrita pelos princípios teóricos da radiação eletromagnética. O espectro de comprimentos de onda óptico contém três faixas: ultravioleta (10 a 390 nanômetro), visível (390 a 760 nanômetro) e infravermelho próximo (760 nanômetro a 1 micrômetro) [8]. A luz visível cobre somente uma parte pequena do espectro eletromagnético inteiro, porém é a única parte que pode ser percebida pelo olho humano, contudo, através de sua interação com a matéria, a luz pode ser detectada.

O surgimento dos fotodetectores pode ser datado de 1873 quando Smith descobriu a fotocondutividade no selênio. Em 1905 Einstein explicou o efeito fotoelétrico e Planck resolveu o enigma da emissão do corpo negro introduzindo a hipótese dos quantas [50]. A fotolitografia permitiu a fabricação de dispositivos para formar imagem de planos focais para o espectro visível a partir dos idos anos 1960s [50]. E um grande progresso foi experimentado nesta área com o surgimento dos PDA e CCD’s. A radiação absorvida por um detector interage com ele produzindo alguma forma de sinal elétrico que pode ser processado por um circuito eletrônico associado ao mesmo. A sensibilidade deste sistema está, grosso modo, relacionada com o menor nível de intensidade de radiação incidente e que pode ser detectada.

\subsection{Detectores Térmicos e Detectores Quânticos}

Um detector óptico é um dispositivo que converte um sinal óptico num sinal elétrico. Existem vários tipos de detectores, tais como termopares, detectores piezelétricos, tubos fotomultiplicadores, fotodiodos semicondutores, etc. Os detectores podem ser classificados segundo seu princípio de funcionamento em térmicos ou quânticos, tal como segue: 


\subsubsection{Detectores Térmicos}

Em geral, nos detectores térmicos, a energia eletromagnética absorvida provoca o aquecimento do dispositivo. Isto provoca a alteração de alguma propriedade do material que normalmente é uma função da temperatura, que pode ser avaliada através da medida direta da temperatura (calorimetria), da medida da variação da resistência elétrica do material ou medida de um sinal de corrente ou da tensão termoelétrica (termopares e termopilhas). Este tipo de detector tem uma resposta proporcional à energia total incidente e praticamente independente de um comprimento de onda da radiação. Devido à inércia térmica dos processos (absorção e troca de calor), este tipo de sensor apresenta, relativamente, longos tempos de resposta $(>10 \mathrm{~ms})$ e geralmente não precisam de refrigeração. Entre os principais tipos de detectores térmicos estão, termopilhas, detectores piroelétricos e bolômetros [51] e [52].

\subsubsection{Detectores Quânticos}

Nos detectores quânticos ocorre a conversão direta dos fótons incidentes em portadores de carga através da transição eletrônica em um material semicondutor. Os detectores quânticos podem ser construídos e operados sob duas formas diferentes: fotocondutor (fotoresistor) ou fotovoltaico (fotodiodo).

Fotocondutores - No caso do fotocondutor, os fótons absorvidos provocam um aumento na população de portadores de carga (elétrons ou buracos) fazendo com que a resistência elétrica do dispositivo varie. O circuito de aplicação é análogo ao usado para um bolômetro; todavia a diferença fundamental é que na transição eletrônica, os tempos de resposta são bem menores que aqueles dependentes do acoplamento e inércia térmica do dispositivo e, ressaltando outra diferença também fundamental, para os detectores quânticos, principalmente aqueles de "gap" estreito, a taxa de portadores gerados devido à radiação de fundo na temperatura ambiente é relativamente alta, impondo a necessidade de operação com refrigeração para manter a eficiência.

Fotodiodos - Um fotodiodo é formado por uma junção $p$ - $n$, onde surge a formação de uma zona de transição entre uma região de material semicondutor cuja condutividade elétrica é dominada por portadores de carga tipo- $n$ (elétrons) e uma região cuja condutividade é 
dominada por portadores de carga tipo- $p$ (buracos). A largura $w$ (Figura 2.1) e a simetria dessa região dependem dos processos de fabricação e dos materiais empregados.

Devido ao baixo custo e bom desempenho, os fotodiodos semicondutores são os detectores ópticos mais utilizados nos sistemas ópticos. Entre os fotodiodos semicondutores destacam-se o fotodiodo tipo PIN (P-dopado, I-intrínseco, N-dopado) e o tipo APD (fotodiodo de efeito avalanche).

O princípio fundamental da detecção óptica é a absorção óptica, pois quando um feixe de luz incide num semicondutor, a luz pode ser absorvida (ou não) dependendo do comprimento de onda. Se a energia do fóton for superior à energia de banda do semicondutor então ele é absorvido formando um par elétron-buraco. Se $\varepsilon_{g}$ (energia de gap $\varepsilon_{g}$ representa o intervalo de energia entre as bandas de valência e condução do semicondutor) for a energia de banda do semicondutor, então o comprimento de onda máximo $\lambda_{c}$ absorvido (ou comprimento de onda de corte) é dado por [52]:

$\lambda_{c}=\frac{h c}{\varepsilon_{g}}$

Onde $h$ e $c$ são a constante de Planck e a velocidade da luz no vácuo, respectivamente. Substituindo esses valores para obter $\lambda_{c}$ em nanômetros, resulta:

$\lambda_{c}=\frac{1,24}{\varepsilon_{g}(e V)}$

A Tabela 2.1 abaixo exemplifica alguns comprimentos de onda máximos para alguns semicondutores:

Tabela 2.1- Energia de banda e respectivo comprimento de onda para alguns materiais semicondutores..

\begin{tabular}{ccccc}
\hline & Si & Ge & GaAs & InGaAs \\
\hline $\mathbf{e g}(\mathbf{e V})$ & 1,11 & 0,67 & 1,43 & 0,75 \\
$\boldsymbol{\lambda}_{\mathbf{c}}(\boldsymbol{\mu \mathbf { m }})$ & 1,13 & 1,85 & 0,87 & 1,65 \\
\hline
\end{tabular}

A maioria dos fotodiodos é constituída por uma junção PN que pode ser implementada de dois modos: fotovoltaico e foto-corrente. No primeiro caso os elétrons e buracos são gerados por absorção no material semicondutor resultando em uma diferença de potencial. No modo foto-corrente o semicondutor é polarizado inversamente e o par elétron-buraco, gerado através da absorção, é separado através do grande campo elétrico provocado na região de depleção. Os portadores são responsáveis pela indução da corrente nos terminais do 
semicondutor. Por esta razão, estes têm uma resposta proporcional a intensidade da radiação e são os mais utilizados.

Como já mencionado os fotodetectores podem ser divididos em duas categorias: PIN e APD. Ambos os dispositivos geram pares elétron-buraco na região de depleção, tendo o APD um ganho de corrente interno adicional.

$\mathrm{O}$ fotodetector PIN consiste num semicondutor do tipo $\mathrm{P}$ e $\mathrm{N}$ dopados com Boro e Fósforo respectivamente $\mathrm{PN}$, com uma camada intrínseca intermediária, polarizado inversamente. Na região de depleção não existem cargas livres e a sua resistência é alta. Quando um fóton incidente tem energia maior ou igual ao intervalo energético entre bandas ("band-gap") do semicondutor utilizado, o fóton fornece energia e excita um elétron da banda de valência fazendo-o se deslocar para a banda de condução. Este processo gera pares livres elétron/buraco que são conhecidos como fóton-portadores. O elevado campo elétrico na região de depleção faz com que os portadores se separem e sejam recolhidos pelos terminais da junção inversamente polarizada. Este movimento de cargas provoca um fluxo de corrente no circuito exterior, conhecida como corrente foto-detectada.

Um fotodiodo APD (fotodiodo de avalanche) caracteriza-se por um ganho de corrente interna, devido a ter um grande valor de polarização inversa (da ordem de dezenas a centenas de Volts). Neste dispositivo a absorção de um fóton incidente produz um par elétron-buraco, como nos fotodiodos PIN, mas adicionalmente, o grande campo elétrico que existe na região de depleção acelera os fótons-portadores a uma velocidade suficiente para que as colisões com átomos produzam novos portadores. Estas partículas criadas por ionização são aceleradas por este campo elétrico dando continuidade ao processo de avalanche. Assim, os APD multiplicam (amplificam) internamente a corrente foto-detectada primária.

Construtivamente, a diferença entre um APD e um PIN é a existência de um nível do tipo $\mathrm{P}$ adicional, entre a região intrínseca e a região $\mathrm{N}$. Os pares elétrons-buraco são gerados na região intrínseca e a multiplicação avalanche ocorre na região $\mathrm{P}$ adicionada.

Considerando-se as disponibilidades, contudo, uma boa escolha em favor de um bom desempenho está relacionada à adequação dos limites fundamentais de sensibilidade e de velocidade de resposta á aplicação pretendida, independentemente do tipo de detector utilizado [52]. 


\section{Responsividade e eficiência quântica}

Uma propriedade importante nos fotodíodos é a sua responsividade $R_{e}$, definida como a razão entre a fotocorrente $I_{p}$ e a potência óptica incidente (fluxo de radiação que chega transportada pela radiação) $P_{o}$, e que depende da eficiência quântica $\eta$ do dispositivo (número médio de elétrons gerados por cada fóton incidente).

Como a energia fotônica é $\frac{h c}{\lambda}$, o fluxo de fótons incidentes é $\frac{P \lambda}{h c}\left[s^{-1}\right]$, e a taxa de fotoelétrons produzidos é $\frac{\eta P_{0} \lambda}{h c}\left[s^{-1}\right]$. Assim, a responsividade pode ser obtida da equação:

$R_{e}=\frac{I_{p}}{P_{o}}=\frac{\eta q_{e} \lambda}{h c}[A / W]$

Então se a eficiência quântica $\eta$ for constante, a responsividade cresce com $\lambda$. A eficiência quântica depende de detalhes construtivos dos dispositivos e do comprimento de onda. Um fotodiodo PIN típico, de silício, possui $\eta \cong 0,7$ para $\lambda=900 \mathrm{~nm}$, o que corresponde a $R_{e} \cong 0,5[A / W]$.

\section{Tempo de Resposta}

O tempo de resposta e a largura de banda do fotodetector dependem de três fatores: 1) do tempo de transição dos portadores na região de depleção; 2) da resposta em freqüência, determinada através do circuito RC equivalente, que depende da capacitância do diodo; e 3) da baixa velocidade de difusão dos portadores fora da região de depleção.

Para uma região de depleção com um comprimento $w$, Figura 2.1, o tempo de transição é:

$$
\tau_{t}=\frac{w}{v_{d}}
$$

com $v_{d}$ a velocidade de deriva, isto é, a velocidade dos eletros devida a um campo elétrico externo. 


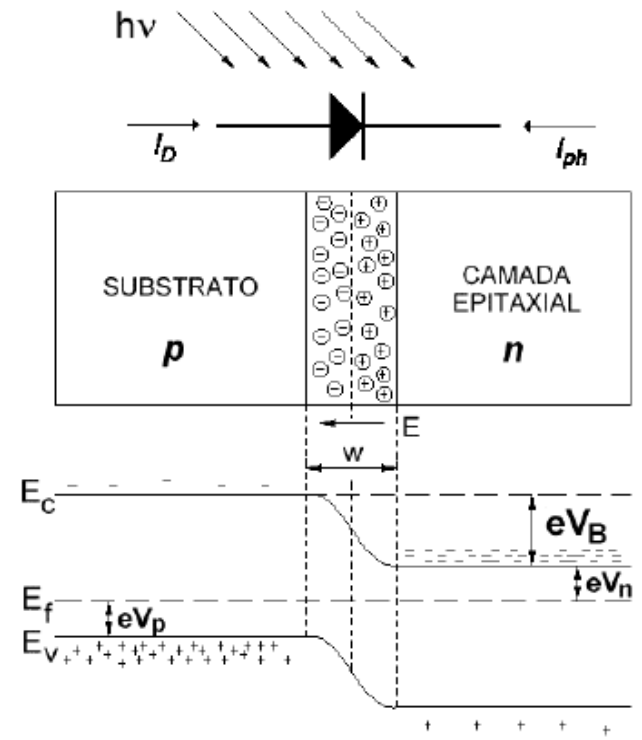

Figura 2.1 - Homojunção p-n e o correspondente diagrama de bandas de energia. Na figura, $I_{D}$ representa a corrente direta de portadores majoritários e $I_{\mathrm{ph}}$ a fotocorrente de portadores minoritários. Reproduzido de [51].

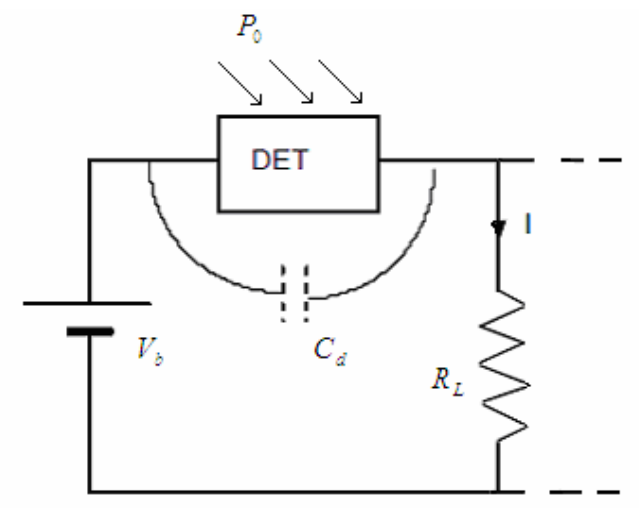

Figura 2.2 - Circuito geral do fotodetector.

A partir da Eq 2.4, quanto menor for $w$ menor será o $\tau_{t}$, no entanto quanto menor for $w$ menor será a eficiência quântica, o que provoca uma menor responsividade . Conclui-se então que deve existir um compromisso entre estes fatores.

A capacitância de um fotodiodo é muito importante, pois está associada com o seu tempo de resposta. Assim, se $A$ for a área do diodo e $w$ o comprimento da região de depleção a capacitância na junção é dada por $C_{d}=\frac{\varepsilon A}{w} \operatorname{com} \varepsilon$ sendo a permissividade do semicondutor.

E o tempo de resposta é dado por: 
$t_{r}=2,19 R_{L} C_{d}=2,19 R_{L} \frac{\varepsilon A}{w}$

Diminuindo-se $w$ reduz-se o tempo de subida (rise time), fazendo aumentar a capacitância do diodo e, assim, deve-se diminuir $R_{L}$ para haver um equilíbrio [50] e [51].

A largura de banda de um fotodetector é dada pela equação [51]:

$\Delta f=\frac{1}{2 \pi R_{L} C_{d}}$

Eq 2.6

Para diminuir o tempo de resposta e aumentar a largura de banda é necessário diminuir $R_{L}$. Para aumentar a eficiência quântica é necessário aumentar o comprimento da região de depleção, mas, por outro lado, aumenta-se o tempo de resposta e baixa a largura de banda. Assim, sempre haverá um compromisso entre estes valores [50]-[52]. Uma técnica bastante utilizada são as heteroestruturas, isto é fotodetector formado por vários semicondutores de diferentes bandas de energia.

\section{Detecção e figuras de mérito}

A avaliação do desempenho de um dispositivo de foto-detecção é feita comparando-o com outros dispositivos similares empregando um conjunto de figuras conhecidas como figuras de mérito. As figuras de mérito são advindas de uma convenção internacional que envolve a medida de diversos parâmetros, como por exemplo, os níveis de sinal e de ruído (signal-to-noise ratio, $S / N$ ) produzidos pelo sensor sob determinadas condições de operação, o que possibilita a comparação, qualitativa e quantitativa, entre dispositivos semelhantes [50].

Tomando um fotodetector como um gerador de uma corrente $I_{p h}$ e sendo $I_{p h 0} \mathrm{O}$ ponto inicial (limiar) do regime quântico, dois regimes de detecção podem ser definidos, conforme o sinal de $I_{p h}$ seja maior ou menos que $I_{p h 0}$ : regime térmico e regime quântico[50].

No regime de pequeno sinal, $I_{p h}<I_{p h 0}$, obtêm-se [50]:

$\frac{S}{N}=\frac{I_{p h}}{\left(2 q_{e} I_{p h 0} \Delta f\right)^{1 / 2}}$

Isto é, a relação de $\mathrm{S} / \mathrm{N}$ é proporcional ao sinal, enquanto que ruído tem um valor constante dado primeiramente pela resistência de carga. Este é o regime térmico da detecção. A Figura 2.3 mostra a tendência da relação de $\mathrm{S} / \mathrm{N}$ (normalizada para $\left(2 q_{e} \Delta f\right)^{1 / 2}$ ), em função da amplitude do sinal $I_{p h} / I_{p h 0}$. Observa-se que, no regime térmico, a inclinação é 20 $\mathrm{dB} /$ decada até o limiar $I_{p h} / I_{p h 0}=1$, e a partir desse ponto a inclinação $10 \mathrm{~dB} /$ década 
encontra-se dentro do regime quântico. $\mathrm{O}$ efeito de um fator de ruído adicional $\mathrm{F}$, relacionado ao processo de amplificação é mostrado igualmente na Figura 2.3.

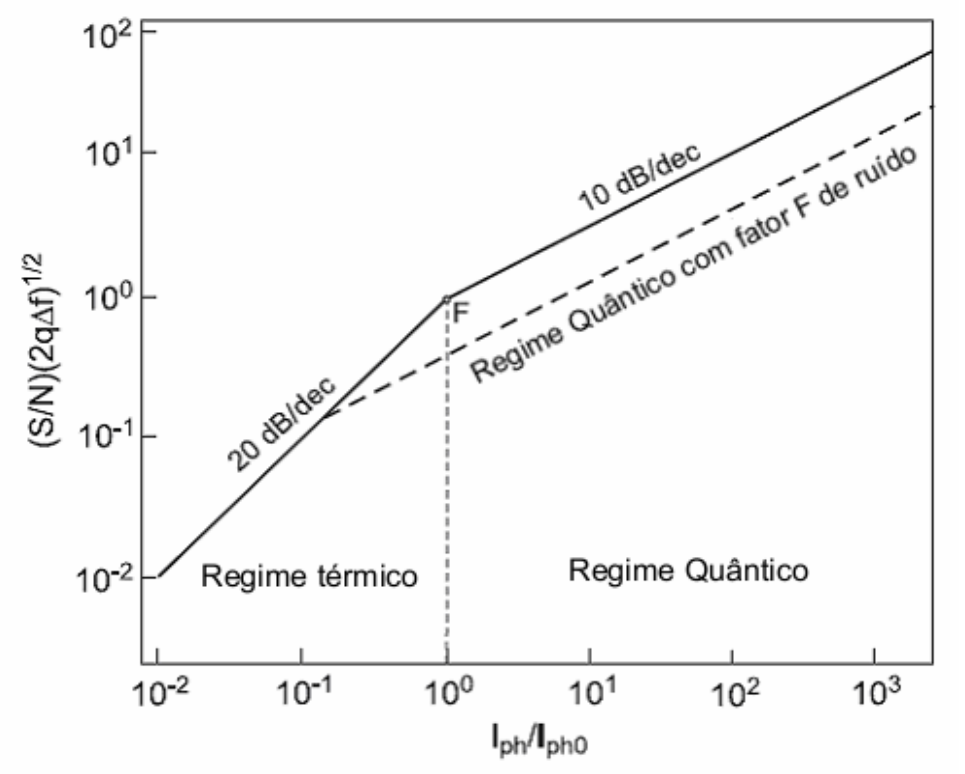

Figura 2.3 - A relação sinal/ruído (S/N) de um fotodetector, em função do sinal de entrada, nos regimes térmico e quântico de detecção. Reproduzido de[50].

O ponto inicial do regime quântico $I_{p h}=I_{p h 0}=I_{d}+\left(2 k T / q_{e}\right) / R_{L} F G^{2}$ [50], é o nível de sinal que corresponde ao ponto de quebra entre os regimes térmico e quântico. Quando a corrente sem iluminação (escura) é muito pequena, o segundo termo é dominante; o eventual ganho interno contribui fortemente porque a resistência de carga equilibra com $G^{2}$. Em todos os casos, $I_{p h 0}$ pode ser interpretado como equivalente ao nível de corrente escura do fotodetector e tem o valor [50]:

$I_{p h 0}=\frac{2 k T / q_{e}}{R_{e q} G^{2}}, \operatorname{com} \frac{1}{R_{e q}}=\frac{1}{R_{F}}+\frac{q_{e}}{2 k T} G^{2} I_{d}$

Assim, define-se $R_{e q}$ como a resistência de carga ruído-equivalente do fotodetector [50].

Para facilitar a comparação entre detectores similares, determinadas figuras de mérito, são definidas. Generalizando a Eq 2.3 é definida a responsividade de tensão por: $R_{e}=\frac{Q_{u}}{P}$

onde $Q_{u}$ pode ser uma quantidade de saída fornecida pelo detector, por exemplo, a corrente $I_{u}$ ou uma tensão $V_{u}$ sendo $\mathrm{P}$ a potência radiante incidente. 
Da mesma maneira que em relação a responsividade, um detector com o menor ruído sobre o sinal útil é o mais desejável. Por isso, a primeira figura de mérito para um detector é o noise equivalent power (NEP) definido como a razão da produção de ruído e a responsividade obtida:

$N E P=\frac{g_{n}}{R_{e}}$

Então, o NEP representa a potência de entrada que fornece na saída uma relação igual a uma unidade, $S / N=1$; que é, uma condição marginal de detecção.

O melhor desempenho do detector corresponde a um NEP menor. Portanto, é mais conveniente definir a sua inversa como uma figura de mérito. Além disso, deve ser levado em conta que, independentemente da fonte de ruído, pode-se esperar que o valor do ruído quadrático seja proporcional à largura de banda $\Delta f$ e da área $A$ do detector.

Assim, é melhor usar como parâmetro intrínseco do ruído de um detector, a relação $N E P / \sqrt{A \Delta f}$, normalizada em relação à área unitária e à largura de faixa. Para simplificar a comparação de diferentes detectores, e ter um parâmetro que aumente enquanto o desempenho melhora, é definida a detectividade $D^{*}$ (chamado D-estrela)[50]:

$$
D^{*}=\frac{(A \Delta f)^{1 / 2}}{N E P}\left[c m H z^{1 / 2} W^{-1}\right]
$$

Esta é a figura de mérito fundamental usada para detectores. Pode ser transformada para a seguinte equação [50]:

$D^{*}=\frac{(A \Delta f)^{1 / 2} S}{P} \frac{S}{N}$

$D^{*}$ é então definido como a relação sinal-ruído $(S / N)$ em rms em uma largura de banda de 1 hertz, por uma radiação incidente de unidade de potência em rms, pela raiz quadrada da área do detector.

O desempenho final do detector é obtido quando o ruído do detector e do amplificador é comparativamente baixo ao ruído do fóton. O ruído do fóton é fundamental no sentido de que não aparece somente da imperfeição do detector ou em sua eletrônica associada, mas do próprio processo de detecção, em conseqüência da natureza discreta do campo de radiação. A radiação que chega no detector é uma combinação do sinal alvo adicionado da chamada radiação de fundo. Existe um limite prático de funcionamento para a maioria dos detectores que é o limite de detecção imposto por flutuações na radiação de fundo (BLIP - Background 
Limited Infrared Photodetect), como ilustrado na Figura 2.4. Este assunto está descrito com detalhes em [50] e [51].

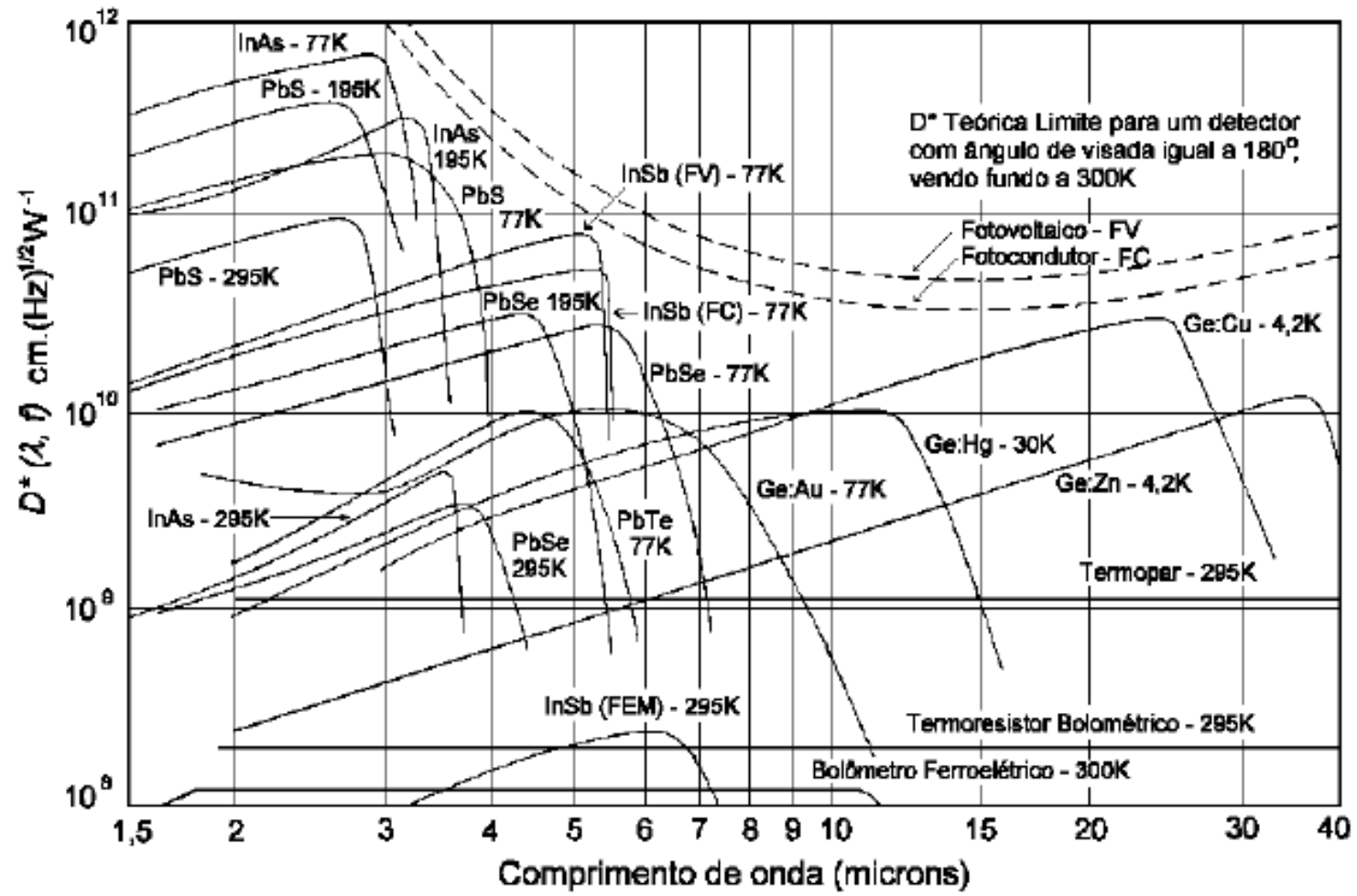

Figura 2.4 - Limite teórico de detetividade. D* (linhas tracejadas), imposto pelo ruído de fundo e o limite alcançado por diversos tipos de dispositivos fotodetectores de infravermelho, nas temperaturas de operação indicadas. Reproduzido de [51]. 


\section{Análise espectral da luz visível}

Fenômenos relacionados à propagação da luz são estudados e descritos por uma área da Física que trata, inclusive, da interação da luz com a matéria. De acordo com a concepção macroscópica, a luz, pela teoria clássica de Maxwell, corresponde a um campo eletromagnético oscilante [53]. A interação microscópica da luz com a matéria, a nível mais fundamental é estudada em sistemas ópticos quânticos [54] que, nesta escala, substitui a teoria clássica. Entretanto, uma faixa muito ampla de fenômenos no mundo macroscópico e em muitos problemas de interesse prático pode ser tratada no âmbito da eletrodinâmica clássica [53]. O campo óptico trata geralmente o comportamento da luz visível, infravermelha, e ultravioleta.

Os resultados e os conceitos obtidos para certas faixas de freqüência podem ser transferidos a outras partes do espectro, dependendo das propriedades dos materiais disponíveis para estas frequiências e dos aspectos tecnológicos relacionados à manipulação destes materiais. Consequientemente, modelos gerais que podem ser usados em toda uma escala de freqüências para descrever apropriadamente fenômenos e dispositivos específicos, são de particular interesse. As estruturas Multicamadas (Multilayer) periódicas e suas propriedades ópticas já são bastante conhecidas e acumulam mais de um século de pesquisa [55]. Na maioria das aplicações, as mais comuns são compostas pelos eficientes refletores de Bragg em variadas estruturas de filtro, que são padrão em muitos sistemas ópticos [55]. Nos últimos anos, estruturas com periodicidade espacial em mais de uma dimensão tornaram-se populares. Estas estruturas são conhecidas como cristais fotônicos (Photonic Crystals - PC) [7]. E não obstante a pesquisa fundamental e aplicada já acumulada, ou talvez por causa disso, os sistemas ópticos multicamadas têm um papel de grande relevância nos sistemas ópticos.

Pela introdução de defeitos específicos nas configurações que se tornam de certa maneira periódicas, ressaltam-se sobremaneira certas propriedades ópticas de transmissão. Os esforços de pesquisa atuais são dirigidos para a exploração e a utilização destas estruturas como cavidades ressonantes em aplicações tais como os lasers, fotodiodos, filtros, sensores, etc. [55]. Adicionalmente, o conhecimento obtido nas pesquisas de estruturas multicamadas pode ser uma base para o refinamento da interpretação e da compreensão qualitativa (às vezes mesmo quantitativa) de estruturas de cristal fotônicos em dimensões mais elevadas [7]. 
A luz visível (Figura 3.1) corresponde a somente uma parte pequena do espectro eletromagnético completo, porém é a única parte que pode ser percebida pelo olho humano. $\mathrm{O}$ olho tem três tipos de receptores: vermelho, verde e azul. Baseado na distribuição espectral da intensidade da onda incidente, uma cor (primária ou uma mistura dos três estímulos) é abstraída mentalmente. Assim, medições mais exatas e seletivas precisam ser executadas pela análise espectral: um processo, em que a faixa inteira da radiação de interesse é separada em seus componentes espectrais e a intensidade de cada componente é medida [56].

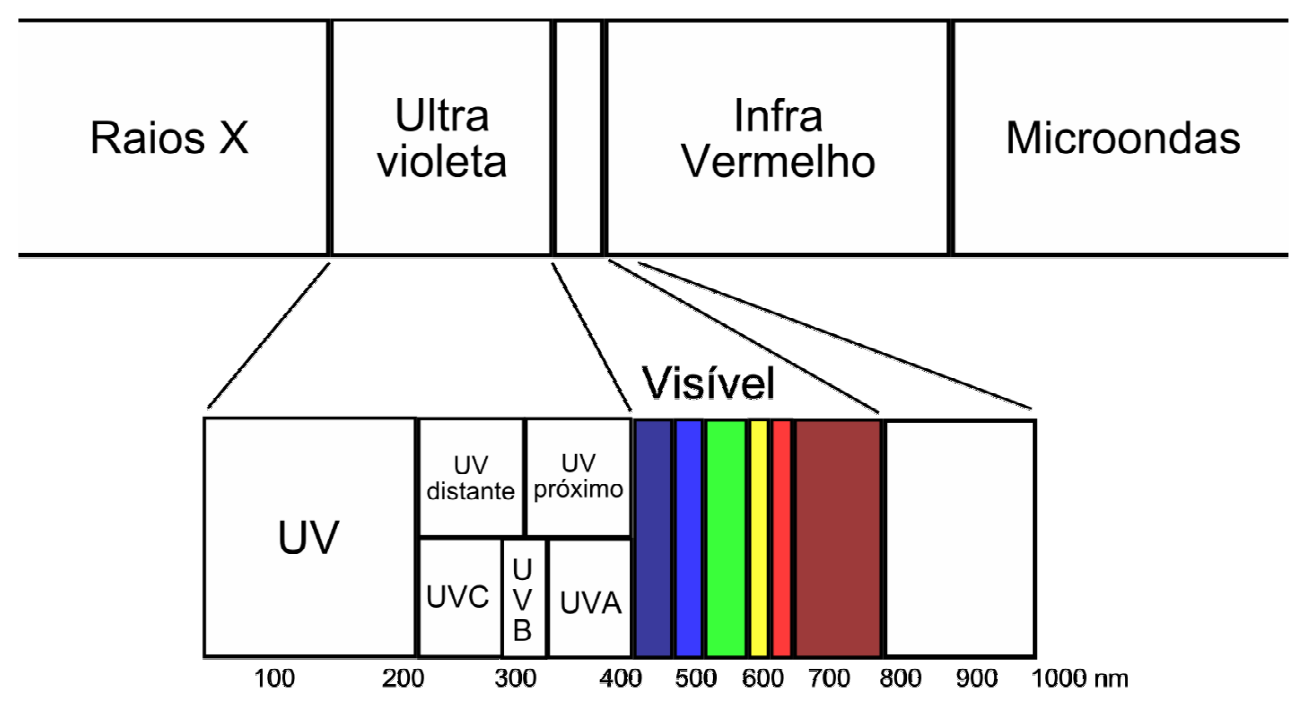

Figura 3.1 - Esquema do espectro eletromagnético.

A análise do espectro óptico é realizada freqüentemente para determinar as características químicas ou ópticas dos materiais. Muitas aplicações exigem a análise espectral em comprimentos de onda visíveis (390 nanômetros a 830 nanômetros - Figura 3.1) [56]. Se o objeto analisado representar uma fonte ativa de radiação visível as informações sobre os processos físicos relacionados podem ser avaliados e extraídos das características espectrais da luz emitida. As aplicações típicas são as análises físico-químicas, tais como a espectroscopia atômica (estudo das linhas espectrais visíveis devido à emissão por isótopos), a astronomia e astrofísica (no estudo de fontes extraterrestres), entre outras. Por outro lado, alguns objetos não são fontes ativas de radiação visível e, nestes casos, uma fonte luminosa externa calibrada pode ser utilizada. Durante sua interação com o objeto, algum dos componentes espectrais da luz incidente são geralmente absorvidos ou refletidos de maneira diferente em cada material. A análise espectral da luz refletida e/ou transmitida pode, conseqüentemente, dar a informações sobre a composição e sobre os processos nos objetos envolvidos. Exemplificando: inspeção de defeitos de produtos na indústria por meio da 
determinação da cor, análise bioquímica (sangue humano, músculo, análise espectral da luz visível nos tecidos, fibras do ADN), identificação de nanopartículas, micro-organismos, bioagentes, toxinas na água, no ar (aerossóis), em alimentos e dispersão da luz por materiais (líquidos, plásticos, polímeros, etc.) [57].

\subsection{Seleção do Comprimento de Ondas}

A análise espectral da luz visível é baseada na calorimetria ou no princípio espectrométrico. Um dispositivo calorimétrico responde a um determinado espectro óptico, isto é, a uma cor, gerando sinais que correspondem às coordenadas de cromaticidade em um sistema padronizado de calorimetria [56]. Mas, para medir a intensidade de cada componente espectral da radiação, um sensor de calorimetria não é apropriado; então se deve usar um dispositivo espectrométrico.

Para executar uma análise espectral, deve-se utilizar um detector seletivo de comprimentos de onda. A parte principal do detector é um elemento que execute temporal ou espacialmente a decomposição da radiação incidente em componentes de banda estreita. Um elemento dispersivo (um prisma, uma grade de difração ou um interferômetro) geralmente é usado para esta finalidade. O método é baseado na dependência angular da deflexão dos comprimentos de onda e no resultado específico para um ângulo de refração (prisma) ou da difração (grade) para cada comprimento de onda. Os prismas exibem uma relação não-linear entre o comprimento de onda e o ângulo de refração e não são usados freqüentemente em equipamentos avançados. Uma grade de difração consiste em uma placa lisa com muitas linhas ou sulcos paralelos onde um feixe luminoso é difratado. As ondas difratadas interferem entre si e dá forma a um padrão de interferência com uma distribuição angular característica dos componentes espectrais. Em um interferômetro convencional, a seleção do comprimento de onda é executada mudando a diferença do caminho óptico entre dois ou mais feixes que interferem um com outro. De todos os tipos diferentes de interferômetro (Michelson, FabryPerot, Fizeau, mach-Zehnder, etc...) [8] o filtro de interferência de Fabry-Perot é o mais freqüentemente utilizado. 


\subsection{Tipos genéricos de espectrômetros}

Os componentes espectrais podem ser medidos, grosso modo, de duas maneiras. Um sistema móvel pode ser usado com um detector e um elemento selecionador do comprimento de onda. O comprimento de onda da radiação a ser detectado é selecionado pela varredura mecânica do elemento selecionador ou do detector (isto é monocromador de varredura). Um espectrômetro do tipo matriz usa uma matriz de detectores (PDA) ou uma matriz de elementos selecionadores de comprimento de onda (p.ex. etalon de Fabry-Perot - neste caso pode ser dispensado o uso de peças móveis) [58].

Uma ampla faixa de espectrômetros, para a análise espectral da luz visível baseada nos diversos elementos de seleção, estão disponíveis no mercado. Estes dispositivos que diferem muito em classes de precisão, têm em comum o fato de serem fabricados de maneira convencional, isto é, consiste num conjunto construído pela utilização de componentes ópticos discretos e de mecânica fina. O parâmetro geral de comparação de diferentes sistemas é o poder de resolução (também chamado de definição), $R_{d}$. A resolução $R_{d}$ é definida como $R_{d}=\lambda / \Delta \lambda$, com $\Delta \lambda$ sendo a diferença entre menor comprimento de onda distinguível em um comprimento de onda específico, $\lambda$.

\subsubsection{Espectrômetros miniaturizados}

Os melhores espectrômetros convencionais envolvem um sistema complexo de lentes e peças móveis (e/ou uma matriz de fotodetectores de alta densidade), e são volumosos e caros. Aplicando-se as técnicas Micromachining, que constitui o conjunto de processos de fabricação de "Micro Electro-Mechanical Systems" [59] (MEMS), pode-se produzir um espectrômetro com tamanho e custos drasticamente reduzidos (produção em alto volume). Além disso, um certo número desses sistemas pode ser combinado para otimizar uma determinada escala espectral e/ou uma resolução esperada. Adicionalmente, um dispositivo óptico integrado tem um sem número de vantagens sobre um sistema óptico convencional, tal como um conjunto simplificado, um alinhamento estável, um tamanho compacto. A vantagem dimensional de um espectrômetro miniaturizado tem, em muitas aplicações, uma importância mais elevada do que sua resolução. 
Um espectrômetro pequeno e portátil tem um potencial enorme para atender as necessidades de sistemas de inspeção ópticas automatizadas em linhas de produção, por exemplo. A identificação da composição de gases e de líquidos, a análise química pela absorção óptica, a caracterização de emissões, a calorimetria e a análise bioquímica são algumas das aplicações onde um espectrômetro miniaturizado pode ser aplicado com vantagens.

A realização de espectrômetros miniaturizados por tecnologia micromachining (de volume e de superfície) já foi extensamente demonstrada e sistemas baseados em filtros Fabry-Perot foram desenvolvidos por diversos grupos de pesquisa [60]-[66].

Considerando a afinidade do modelo da cavidade de Fabry-Perot com processos de micro-eletrônica, isto é, compatibilidade com os processos e facilidade de microminiaturização, muito bons resultados foram obtidos inclusive de micro-sistemas ópticos baseados em uma matriz de etalons de Fabry-Perot executado em tecnologia CMOS (complementary metal oxide semiconductor) [67] e [68].

A tecnologia micromachining de silício criou novas oportunidades para sistemas ópticos e optoeletrônicos. O grande potencial encontra-se na miniaturização dos sistemas ópticos e na extensão de sua funcionalidade. Isto é principalmente devido ao fato que as estruturas móveis micromecânicas, os micro-atuadores e os elementos micro-ópticos podem ser monoliticamente integrados num mesmo substrato. As tecnologias de processamento padrão para a fabricação de circuitos integrados VLSI (integração em muito alta escala) são fundidas com o processamento de sensores [59]. O requisito geral para um sistema integrado é que o processo da microestrutura não deve interferir com o funcionamento adequado do dispositivo microeletrônico integrado, e vice-versa.

A utilidade das microestruturas é muitas vezes questionada em função da falta de aplicações (relativamente à escala de demanda). A limitação mais grave dos micro-atuadores é o fato de que não podem suportar macro-forças ou macro-torques. Entretanto, as estruturas móveis são atrativas para aplicações ópticas onde um modesto deslocamento mecânico pode ser suficiente para interromper um feixe luminoso sem empregar muita força. Comparando com os dispositivos opto-mecânicos de macro-escala, os dispositivos micro-opto-mecânicos são mais simples, menores, mais leves, mais rápidos (frequiências de ressonância mais elevadas), mais robustos e menos caros. Também, a compatibilidade com tecnologia do VLSI (very large-scale integration) torna possível integrar sistemas micro-opto-mecânico através de circuitos de interligações a circuitos condicionadores de sinal no mesmo chip, assim pode melhorar a funcionalidade dos dispositivos. 
Por outro lado, tendo em vista as qualidades desejáveis num dispositivo monoliticamente integrável pela associação de técnicas, processos hibridos e procedimentos disponíveis, o objetivo principal da pesquisa descrita neste trabalho é descrever um sistema espectrométrico que pode ser aplicável em ampla faixa do espectro óptico com elevadas qualidades óptica, mecânica e resolução aceitável (para a operação na parte visível do espectro). O sistema proposto é baseado numa disposição não convencional de um ressonador de Fabry-Perot interposto entre refletores formados por filmes dielétricos (filtros ópticos de interferência) que deverá possuir grande compatibilidade com processos de microeletrônica, isto é, pode ser perfeitamente integrável. Ademais, é objetivo deste trabalho orientar uma aplicação bastante exigente em relação ao seu desempenho: Um dispositivo multicanal espectral para análise ambiental.

\subsubsection{Deposição de Filmes Finos}

Para a obtenção das estruturas periódicas multicamadas, que formam os filtros ópticos de interferência, utilizam-se os filmes finos. Tais filtros ópticos geralmente se apresentam em modalidades como Line Filter (LF), High Pass Filter (HPF), Low Pass Filter (LPF) e Anti Reflector Coating (AR).

Os filmes finos são aplicáveis, em geral, nas áreas de microeletrônica, dispositivos ópticos e eletro-ópticos e revestimentos de materiais. Os óxidos de titânio, por exemplo, são utilizados em revestimentos anti-refletores, filtros de interferência, sensores e capacitores em circuitos integrados.

$\mathrm{Na}$ microeletrônica, os filmes finos desempenham uma função essencial nos dispositivos e circuitos integrados. São utilizados nas conexões das regiões ativas de um dispositivo, na comunicação entre dispositivos, no acesso externo aos circuitos, para isolar camadas condutoras, como elementos estruturais dos dispositivos, para proteger as superfícies do ambiente externo, como fonte de dopante e como barreira para a dopagem. Os filmes finos podem ser condutores, semicondutores ou isolantes, normalmente crescidos termicamente ou depositados a partir da fase vapor.

Normalmente as propriedades de um material na forma de filme são muito diferentes das propriedades do mesmo material na sua forma maciça devido à influência da superfície; a relação entre a superfície e o volume é muito maior no caso do filme. Por outro lado, as propriedades dos filmes são altamente dependentes dos processos de deposição. 
Os processos de formação dos filmes podem ser divididos em dois grupos básicos: crescimento dos filmes pela reação da superfície do substrato com as substâncias presentes no ambiente de processo; crescimento dos filmes por deposição sem reação com o substrato.

No primeiro caso, pode-se obter a oxidação e a nitretação térmica do silício e a obtenção de silicetos pela reação do Silício com filmes metálicos depositados. O segundo caso pode ser subdividido em três subgrupos: 1) deposição química a partir da fase vapor: neste processo, denominado CVD (Chemical Vapor Deposition), onde os filmes são formados pela reação química de espécies convenientes na superfície do substrato. Quando o processo é utilizado para formar filmes monocristalinos ele é denominado epitaxial; 2) deposição física a partir da fase vapor: neste processo denominado PVD (Physical Vapor Deposition), o ambiente de processo é mantido em baixa pressão e as espécies do filme são arrancadas fisicamente de uma fonte, por efeito da temperatura, pelo efeito joule (evaporação) ou feixe de elétrons (e-Beam), ou impacto de íons, átomos ou moléculas ("Sputtering"), que, nesta fase de vapor, se deslocam até o substrato onde se condensam na forma de um filme; e 3) deposição a partir de líquidos: neste processo a espécie, em forma líquida, é gotejada e centrifugada sobre o substrato.

Grosso modo, o mecanismo de crescimento de filmes finos ocorre por meio da deposição de átomos sobre substrato, de acordo com as fases: nucleação; crescimento e coalescência do núcleo; formação de canais e de uma camada contínua; e preenchimento das cavidades.

Os materiais são evaporados, e possibilitam normalmente a formação dos filmes pela condensação (solidificação) de átomos ou moléculas deste vapor sobre o substrato. $\mathrm{O}$ processo de condensação se inicia pela formação de pequenos aglomerados de material, denominados núcleos, espalhados aleatoriamente sobre a superfície do substrato. O crescimento dos núcleos é tridimensional e maior numa direção do substrato. Forças de atração eletrostáticas são as responsáveis pela fixação dos átomos à superfície. O mecanismo de fixação é denominado adsorção química quando ocorre a transferência de elétrons entre o material do substrato e a partícula depositada e adsorção física se isto não ocorrer. A energia de ligação associada à adsorção química varia de 8 eV a 10 eV e a associada à adsorção física é de aproximadamente $0.25 \mathrm{eV}$. Átomos adsorvidos migram sobre a superfície do substrato interagindo com outros átomos para formar os núcleos, esta etapa é denominada nucleação, onde ocorre a formação de núcleos uniformes de tamanhos da ordem de 25 Å. À medida que mais átomos interagem, os núcleos crescem. Quando os núcleos entram em contato uns com os outros ocorre a coalescência que resulta em estruturas maiores. $\mathrm{Na}$ fase de crescimento e coalescência iniciam-se as aglutinações de dois núcleos, resultando em um novo terceiro núcleo, sendo que este resulta menor que a soma das dimensões dos dois primeiros originais, 
caracterizando a diminuição da área total ocupada sobre o substrato. A aglutinação de diversos núcleos promove a formação de ilhas, apresentando uma estrutura cristalográfica bem definida. Estas ilhas aglutinam-se com novos núcleos, tornando-se mais ovaladas e “isoladas”, indicando o início do processo de recristalização.

As ilhas e novos núcleos formados produzem canais e cavidades, que são preenchidos pelos novos núcleos até a formação de um filme contínuo. Após o preenchimento das cavidades os filmes obtidos, de acordo com seu arranjo interatômico, deverão apresentar algumas das seguintes característica: amorfos (sem estrutura cristalina); policristalino, orientados ao acaso (formados por pequenos cristais que definem diversos domínios de diversas direções); policristalino orientado (formado por pequenos cristais com direções próximas); monocristalino (crescimento epitaxial quase perfeito).

Em súmula, os processos PVD produzem filmes finos de qualidade satisfatória e, ainda, se diferenciam dos demais processos por não agredir o meio ambiente, pois não produzem efluentes e utilizam pouca energia e matéria prima. Neste trabalho as deposições foram preparadas por deposição física de vapor (PVD), pelos métodos resistivo e feixe de elétrons.

\subsection{Um sistema espectrométrico}

Neste trabalho se desenvolve um método para obtenção, através da deposição de filmes dielétricos, de um filtro óptico de interferência variável (FIV) e é projetado um artefato composto por este filtro e um dispositivo de matriz de fotodiodos (PDA) para formar um sistema espectrométrico single-chip. Este sistema é um mini-espectrômetro que pode ser apropriado para uma ampla faixa do espectro óptico e infravermelho (IR) próximo. O espectro incidente é filtrado e escalonadamente decomposto no FIV e um determinado componente espectral, que dependente da posição, é transmitido numa dada posição do filtro coincidentemente com a posição do pixel da matriz de fotodiodos integrada ao sistema.

Esquemas pictóricos de dispositivos FIV chip-sized é mostrado nas Figura 3.2 (a) e (b). 
(a)

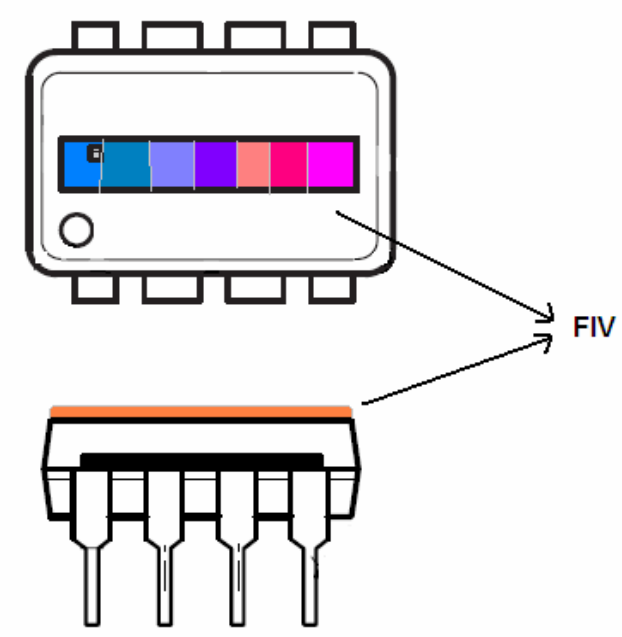

(b)

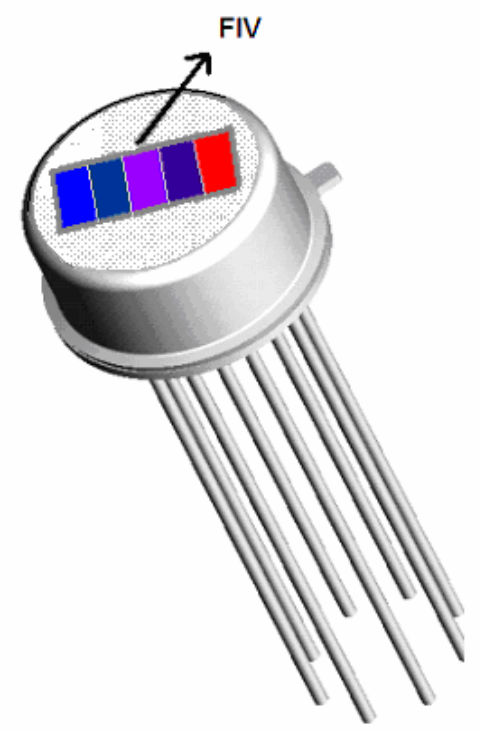

Figura 3.2- Esquema de um dispositivo espectrométrico chip-sized - (a) Dual In-Line Package (DIP) (b) Transistor Outline Package (TO-99) . 


\section{Teoria óptica espectrométrica}

A teoria eletromagnética geral (equações de Maxwell) é a base da análise teórica da propagação da luz. Inicialmente é analisada uma interação de uma onda monocromática de incidência normal e, depois, oblíqua em uma fronteira simples. Estes resultados são usados para derivar equações gerais para refletância e transmitância de uma película fina depositada em um substrato. Em seguida, o método matricial é introduzido para tornar possível derivar a expressão que descreve a interação entre uma onda monocromática e um conjunto de películas finas. Além disso, também são apresentadas as noções de camada equivalente, admissão óptica, camada ausente e espessura óptica quarto de onda.

A parte subseqüente deste capítulo concentra-se em um ressonador plano-planar de Fabry-Perot. As propriedades básicas são derivadas de um modelo idealizado (sistemas lineares com realimentação) e são analisados alguns fenômenos que resultam do ressonador não-ideal. Deriva-se deste tratamento a transmissão espectral, a largura a meia altura máxima (full width at half maximum - FWHM), Finesse (finura - F), poder de resolução (R) e faixa espectral livre (Free spectral Range - FSR).

Este estudo leva em consideração as perdas nos espelhos e na cavidade devido à absorção ou à dispersão e ainda os efeitos da incidência não-perpendicular, do tamanho finito dos espelhos e do não-paralelismo entre eles. Dois tipos possíveis do espelho (dieléctrico e metálico) são considerados e, finalmente, um espectrômetro baseado na estrutura Fabry-Perot é esquematizado.

\subsection{Equação de onda}

A equação de onda é uma equação diferencial de segunda ordem, obtida do sistema original de equações acopladas. As equações (4.1) e (4.2), são as equações de segunda ordem da onda para os campos elétricos e magnéticos respectivamente [53].

$$
\begin{aligned}
& \mu \nabla \times \frac{\nabla}{\mu} \times \mathbf{E}+\varepsilon \mu \frac{\partial^{2} \mathbf{E}}{\partial t^{2}}=0 \\
& \varepsilon \nabla \times \frac{\nabla}{\varepsilon} \times \mathbf{H}+\varepsilon \mu \frac{\partial^{2} \mathbf{H}}{\partial t^{2}}=0
\end{aligned}
$$


No domínio da frequiência, na aproximação de onda plana, as equações de onda tornam-se:

$$
\begin{aligned}
& \mu \nabla \times \frac{\nabla}{\mu} \times \mathbf{E}-\omega^{2} \varepsilon \mu \mathbf{E}=0 \\
& \varepsilon \nabla \times \frac{\nabla}{\varepsilon} \times \mathbf{H}-\omega^{2} \varepsilon \mu \mathbf{H}=0
\end{aligned}
$$

Onde $\mathbf{D}=\varepsilon \mathbf{E}$ e $\mathbf{B}=\mu_{0} \mathbf{H}$.

Para os meios dielétricos, homogêneos e livres de carga, onde o campo elétrico satisfaz as equações $\nabla \mathbf{E}=0$, (4.3) e (4.4) assumem a forma da equação de Helmholtz.

$$
\nabla^{2} \mathbf{E}+\omega^{2} \varepsilon \mu \mathbf{E}=0, \nabla^{2} \mathbf{H}+\omega^{2} \varepsilon \mu \mathbf{H}=0
$$

Freqüentemente é conveniente escrever a quantidade física $\varepsilon \mu$ que aparece na equação de onda na forma alternativa:

$$
\varepsilon \mu=\frac{n^{2}}{c^{2}}
$$

onde $c=\frac{1}{\sqrt{\varepsilon_{0} \mu_{0}}}$ é a velocidade da luz no vácuo e $n^{2}=\varepsilon_{r} \mu_{r}$ é uma quantidade adimensional conhecida como o índice de refração. Observa-se que o índice de refração representa uma construção derivada que não aparece diretamente nas equações de Maxwell. O cuidado particular é exigido com a definição (sinal) do índice de refração, nos casos onde a permissividade e a permeabilidade são quantidades complexas, pois as partes reais não são necessariamente positivas.

O sinal de $n$ obtido da raiz quadrada na expressão para o índice de refração é determinado de acordo com a seguinte regra:

$\Re e(n)<0$ se $\Re e(\varepsilon)<0$ e $\Re e(\mu)<0$

$\mathrm{e}$

$\mathfrak{R} e(n) \geq 0$, em outros casos

Eq 4.8

O termo "metamateriais" de índice negativo" (NIMs) se refere às situações onde a primeira alternativa (Eq 4.7) se aplica. O modelo padrão para a absorção no material é obtido quando a permissividade elétrica e a permeabilidade magnética dos materiais correspondentes são tomadas na sua forma complexa [69], [70]. 
Então, materiais com funções de respostas complexas: permeabilidade $\mathcal{E}(\omega)=\varepsilon_{r e}(\omega)+i \varepsilon_{i m}(\omega)$, permissividade $\mu(\omega)=\mu_{r e}(\omega)+i \mu_{i m}(\omega)$ e índice de refração $n(\omega)=n_{r e}(\omega)+i n_{i m}(\omega)$ complexos, é dado por [53].

$n=\sqrt{|\varepsilon \| \mu|} \exp \left(\frac{i}{2}\left[\operatorname{arccot}\left(\frac{\varepsilon_{r e}}{\varepsilon_{i m}}\right)+\operatorname{arccot}\left(\frac{\mu_{r e}}{\mu_{i m}}\right)\right]\right)$

Eq 4.9

Onde, na presença de dispersão, as quantidades tornam-se dependentes da freqüência.

\subsection{Dispersão e método de matriz de transferência}

Para a propagação das ondas eletromagnéticas através de estruturas planas multicamadas constituídas por lâminas constantes, homogêneas, isotrópicas e na ausência de fontes de carga, as equações de onda vetorial reduzem-se a duas equações escalares desacopladas, onde surgem dois tipos de campos ópticos [53] e [70]: as ondas elétricas transversais (TE) onde o campo elétrico é perpendicular ao plano definido pelo sentido de propagação da onda incidente e da sua projeção em relação às interfaces das camadas, e, as ondas magnéticas transversais (TM), onde campo magnético é perpendicular a esse plano de incidência. Escolhendo as coordenadas cartesianas para descrever a propagação de ondas planas através da pilha multicamadas, onde o eixo $x$ é paralelo aos planos das interfaces das camadas da pilha, enquanto o eixo $z$ é perpendicular à superfície da pilha, tal que as coordenadas $x$ e $z$ definem o plano de incidência.

Para ondas TE o campo elétrico $\mathbf{E}=\left(0, \mathbf{E}_{y}, 0\right)$ é polarizado linearmente na direção $y$. Considerando-se a dependencia temporal do campo como sendo $e^{-i \omega t}$, obtem-se: $\mathbf{E}(\mathbf{r}, t)=\mathbf{E}(\mathbf{r}) e^{-i \omega t}$ com freqüência angular $\omega$ considerada real. Então, sob a excitação pelo harmônico externo, polarizada TE, o campo no meio é descrito pela função escalar $E_{y}(x, z)$ (suprimindo a subscrição y para simplificar a notação). Com esta escolha de polarização as equações de Maxwell reduzem-se à equação de Helmholtz para ondas TE:

$\left[\frac{\partial^{2}}{\partial x^{2}}+\mu(z) \frac{\partial}{\partial z} \frac{1}{\mu(z)} \frac{\partial}{\partial z}+\frac{w^{2}}{c^{2}} \varepsilon \mu\right] E(x, z)=0$

Eq 4.10

Analogamente, o principal componente magnético $\mathrm{H}$ do harmônico temporal das ondas TM com campo magnético y-polarizado, $H(x, y, z)=(0, H, 0)(x, z) e^{-i \omega t}$, satisfaz a equação de Helmholtz 
$\left[\frac{\partial^{2}}{\partial x^{2}}+\varepsilon(z) \frac{\partial}{\partial z} \frac{1}{\varepsilon(z)} \frac{\partial}{\partial z}+\frac{w^{2}}{c^{2}} \varepsilon \mu\right] H(x, z)=0$

A transformada de Fourier, ao longo das interfaces das camadas, separa as partes dependentes em $x$ e $z$ do campo principal, tal que podem ser representados pelas funções:

$$
\begin{aligned}
& E(x, z)=E(z) e^{ \pm i k_{x} x} \\
& H(x, z)=H(z) e^{ \pm i k_{x} x}
\end{aligned}
$$

onde a componente $x$ do vetor de onda $k_{x}$ agora representa um parâmetro que é definido pelo ângulo de incidência (Figura 4.1).

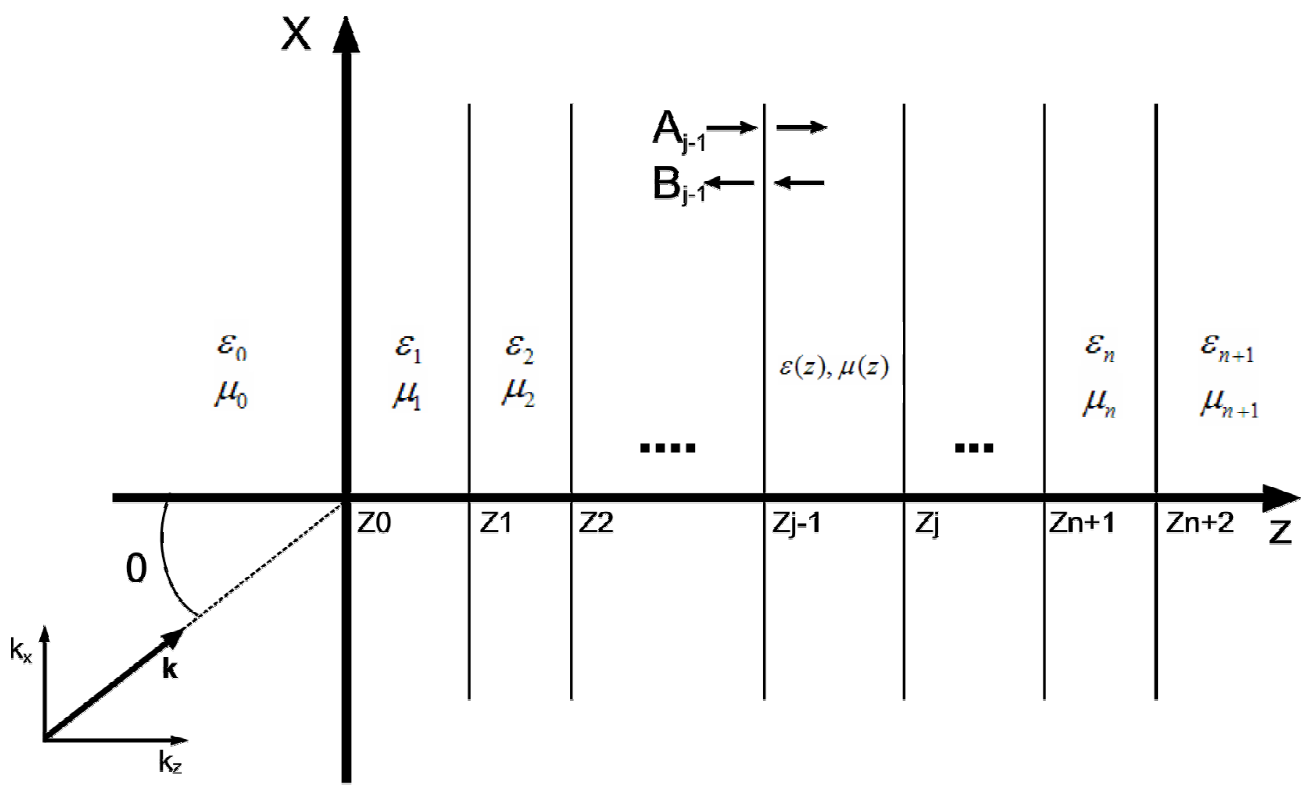

Figura 4.1 - Representação de uma estrutura multicamadas in-homogênea (isto é, um meio estratificado) em porções constantes onde $\varepsilon$, a permissividade, e $\mu$, a permeabilidade, são z-dependentes. A estrutura é invariante ao longo dos sentidos x e y, e $\theta$, para incidência oblíqua, é o ângulo de incidência.

Devido à invariância da permissividade e permeabilidade no sentido $x$ as equações diferenciais (4.30) e (4.31) se tornam

$$
\begin{aligned}
& \left(\mu(z) \frac{\partial}{\partial z} \frac{1}{\mu(z)} \frac{\partial}{\partial z}+\frac{\omega^{2}}{c^{2}} \varepsilon \mu-k_{x}^{2}\right) E(z)=0 \\
& \left(\varepsilon(z) \frac{\partial}{\partial z} \frac{1}{\varepsilon(z)} \frac{\partial}{\partial z}+\frac{\omega^{2}}{c^{2}} \varepsilon \mu-k_{x}^{2}\right) H(z)=0
\end{aligned}
$$

Observa-se que estas equações aplicadas a pontos no interior das camadas são idênticas para as posições em $z$ com propriedades constantes. As diferenças entre as polarizações se manifestam somente nos limites entre as diferentes camadas.

Para ondas TE, as quantidades: 
$E, \frac{1}{\mu} \frac{\partial E}{\partial z}$

Eq 4.15

devem ser contínuas através das interfaces, enquanto que a continuidade de

$H, \frac{1}{\varepsilon} \frac{\partial H}{\partial z}$

Eq 4.16

são exigidas para ondas TM polarizadas.

Observa-se que as seguintes etapas são válidas igualmente para a permissividade e a permeabilidade complexas. As soluções analíticas da equação de Helmholtz para a estrutura multicamadas da Figura 4.1, aplicada a camada do $j$-ésima, podem ser escritas como [74]:

$$
F_{j}=A_{j} e^{i k_{j z}\left(z-z_{j-1}\right)}+B_{j} e^{-i k_{j z}\left(z-z_{j-1}\right)}
$$

onde F substitui o campo E no caso da polarização TE e o campo H para polarização TM, o $k_{j z}$ é o componente $z$ do vetor de onda local na camada $j$, definido por [74]:

$k_{j z}^{2}=\frac{\omega^{2}}{c^{2}} \varepsilon_{j} \mu_{j}-k_{x}^{2}$

Considerando uma situação em que uma onda plana $F_{0}(x, z)=A_{0} e^{i k_{x} x+i k_{0 z} z}$ com a uma dada amplitude $A_{0}$ incidente na estrutura multicamada (dielétrico convencional, transparente), vindo de um meio semi-infinito, homogêneo, com vetor de onda $k_{0 j}=\left(k_{x}, 0, k_{0 z}\right)$. Seus componentes $x$ e $z, k_{0 x}=\left(\frac{n_{0} \omega}{c}\right) \sin \theta$ e $k_{0 z}=\left(\frac{n_{0} \omega}{c}\right) \cos \theta$ são definidos pelo ângulo $\theta$ onde $n_{0}=\sqrt{\varepsilon_{0} \mu_{0}}$ é o índice de refração local do meio de entrada. $\mathrm{O}$ vetor de onda local na camada $j$-ésima pode ser expresso por:

$$
k_{j z}=\frac{\omega}{c} n_{j} \sqrt{1-\frac{n_{0}^{2}}{n_{j}^{2}} \operatorname{Sin}^{2} \theta}
$$

dentro da camada $z \in\left[z_{j-1}, z_{j}\right]$ com a permissividade e permeabilidade local $\varepsilon_{j}$ e $\mu_{j}$, respectivamente e o índice de refração definido por $n_{j}=\sqrt{\varepsilon_{j} \mu_{j}}$.

Fazendo $\eta_{j}=\mu_{j}$ para a polarização $\mathrm{TE}$ e $\eta_{j}=\varepsilon_{j}$ para a polarização $\mathrm{TM}$, as condições da continuidade Eq 4.15 e Eq 4.16 para a interface entre as camadas $j$ e $j+1$ podem ser escritas como: 


$$
\begin{aligned}
& F_{j}\left(z_{j}\right)=F_{j+1}\left(z_{j}\right) \mathrm{e} \\
& \frac{1}{\eta_{j}} \frac{\partial F_{j}}{\partial z}\left(z_{j}\right)=\frac{1}{\eta_{j+1}} \frac{\partial F_{j+1}}{\partial z}\left(z_{j}\right)
\end{aligned}
$$

Estas circunstâncias conduzem a um sistema de equações que relacionam as amplitudes das camadas contíguas através de uma matriz onde é usada a substituição $s_{j}=\frac{k_{j z}}{\eta_{j}}$, a saber:

$$
\left(\begin{array}{l}
A_{j} \\
B_{j}
\end{array}\right)=\frac{1}{2}\left(\begin{array}{ll}
\left(1+\frac{s_{j+1}}{s_{j}}\right) e^{-i k_{k z} d_{j}} & \left(1-\frac{s_{j+1}}{s_{j}}\right) e^{-i k_{j z} d_{j}} \\
\left(1-\frac{s_{j+1}}{s_{j}}\right) e^{+i k_{j z} d_{j}} & \left(1+\frac{s_{j+1}}{s_{j}}\right) e^{+i k_{j z} d_{z}}
\end{array}\right)\left(\begin{array}{l}
A_{j+1} \\
B_{j+1}
\end{array}\right)
$$

onde a propagação separada das ondas direcionais através de todas as camadas de espessura $d_{j}=z_{j}-z_{j-1}$ de acordo com a Eq 4.17 já está incorporada. A multiplicação requerida destas matrizes conecta as amplitudes de cada uma das camadas da estrutura. Se a transferência da amplitude é realizada sobre toda a pilha de camadas, chega-se a uma matriz para o sistema da forma:

$$
\left(\begin{array}{c}
A_{0} \\
r A_{0}
\end{array}\right)=\left(\begin{array}{ll}
m_{11} & m_{12} \\
m_{21} & m_{22}
\end{array}\right)\left(\begin{array}{c}
t A_{0} \\
0
\end{array}\right)
$$

Aqui $r$ e $t$ são os coeficientes da amplitude de reflexão e de transmissão. Assumindo que as regiões de entrada e saída envolvem meios dielétricos convencionais sem absorção, definimos a transmitância como a relação óptica da potência de entrada e saída [70] (relação das intensidades para os planos de observação paralelos à superfície das camadas).

$$
T(\omega, \theta)=\frac{n_{N+1} \cos \theta_{N+1}}{n_{0} \cos \theta_{0}}\left|\frac{1}{m_{11}}\right|^{2}
$$

e a refletância como a relação entre a potência refletida e a potência incidente

$$
R(\omega, \theta)=\left|\frac{m_{21}}{m_{11}}\right|^{2}
$$

Aqui o ângulo $\theta$ de incidência é relacionado ao ângulo $\theta_{N+1}$ do meio de saída através da lei de Snell

$$
n_{j} \sin \theta_{j}=n_{j+1} \sin \theta_{j+1}
$$


onde o $n_{j}$ e $\theta_{j}$ são índices de refração e ângulos (formais) em camadas correspondentes. Esta expressão formal é válida até mesmo para os metamateriais de índice negativo (NIMs). De acordo com a lei de conservação da energia, quando o material apresenta perdas (permissividade e permeabilidade complexas), uma quantidade chamada absorbância pode ser definida como:

$A=1-R(\omega, \theta)-T(\omega, \theta)$

Eq 4.26

Representando a parcela da potência óptica incidente que é absorvida pela estrutura e transformada, por exemplo, em energia térmica no material.

\subsection{Multicamadas periódicas}

Considerando um arranjo multicamadas de dois materiais, A e B, com propriedades ópticas (permissividade e permeabilidade) diferentes, $\left\{\varepsilon_{A}, \mu_{A}\right\}$ e $\left\{\varepsilon_{B}, \mu_{B}\right\}$, como ilustrado na Figura 4.2, mas considerando-se a permissividade e a permeabilidade periódicas, e invariância translacional ao longo dos eixos $x$ e $y$.

$\varepsilon(z+\Lambda)=\varepsilon(z)$ e $\mu(z+\Lambda)=\mu(z)$

Eq 4.27

sendo $\Lambda=\mathrm{a}+\mathrm{b}$ o período, onde a é a espessura do material A e b é a espessura do material B. Este é um modelo tradicional para as estruturas ópticas periódicas adotado neste trabalho. A estrutura possui a simetria translacional discreta em contraste com a simetria translacional contínua de meios homogêneos [71].

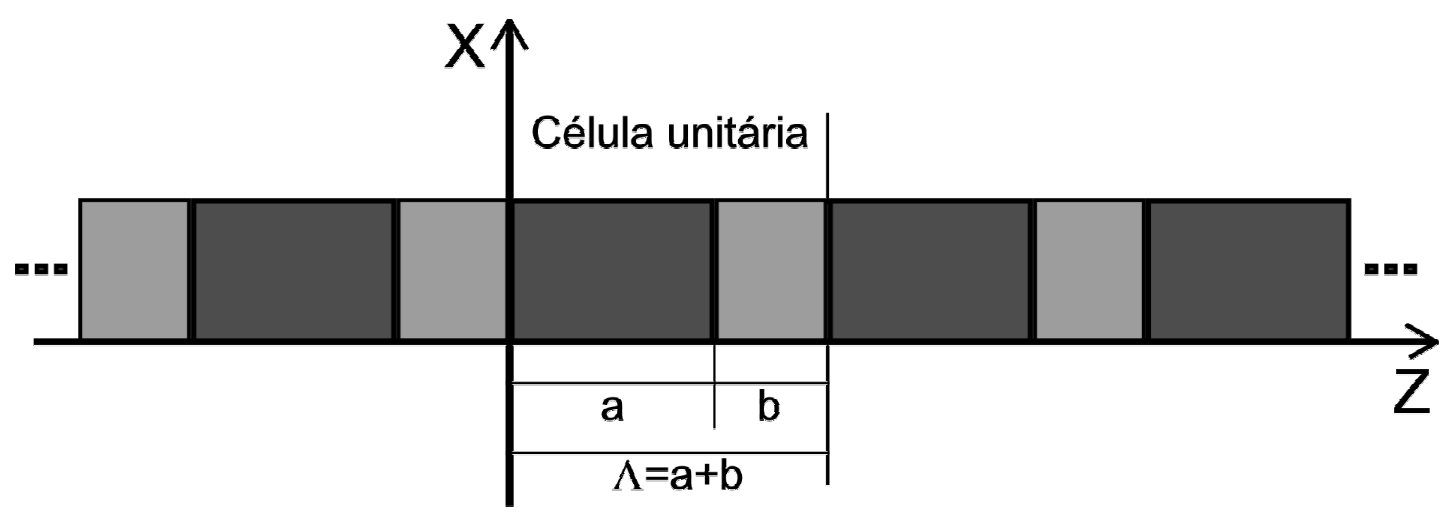

Figura 4.2 - Uma estrutura multicamadas binária periódica em lâminas constantes, periódica com zdependência na permissividade $\varepsilon$ e na permeabilidade $\mu$ e invariante ao longo das direções $x$ e y. A espessura das camadas A e B são a e b, respectivamente. A espessura da célula unitária $\Lambda$, representa o período da estrutura. 
A propagação da onda é descrita pelas equações Eq 4.13 e Eq 4.14 para ambas polarizações; as soluções são periódicas de acordo com o teorema de Bloch-Floquet [72] e [73]. Assim, o campo na estrutura multicamadas periódica pode ser representado pela forma:

$$
F(z+\Lambda)=e^{i K_{B} \Lambda} F(z)
$$

Eq 4.28

onde o $K_{B}$ é o número de onda de Bloch. A matriz de transferência (Eq 4.21) conecta amplitudes nas camadas adjacentes:

$$
\left(\begin{array}{l}
A_{j} \\
B_{j}
\end{array}\right)=\left(\begin{array}{ll}
T_{11}^{(j)} & T_{12}^{(j)} \\
T_{21}^{(j)} & T_{22}^{(j)}
\end{array}\right)\left(\begin{array}{l}
A_{j+1} \\
B_{j+1}
\end{array}\right)
$$

enquanto as amplitudes locais separadas por um período são relacionadas como

$$
\left(\begin{array}{l}
A_{j} \\
B_{j}
\end{array}\right)=\left(\begin{array}{ll}
T_{11}^{(j)} & T_{12}^{(j)} \\
T_{21}^{(j)} & T_{22}^{(j)}
\end{array}\right)\left(\begin{array}{ll}
T_{11}^{(j+1)} & T_{12}^{(j+1)} \\
T_{21}^{(j+1)} & T_{22}^{(j+1)}
\end{array}\right)\left(\begin{array}{c}
A_{j+2} \\
B_{j+2}
\end{array}\right)
$$

Agora, devido ao teorema de Bloch-Floquet e à Eq 4.28, obtêm-se:

$$
\left(\begin{array}{c}
A_{j} \\
B_{j}
\end{array}\right)=e^{-i K_{b} \Lambda}\left(\begin{array}{l}
A_{j+2} \\
B_{j+2}
\end{array}\right)
$$

Devido à periodicidade, as amplitudes na camada $j$ e $(j+2)$ são as mesmas e as equações podem ser escritas com o sistema homogêneo:

$$
\left(\begin{array}{cc}
T_{11}-e^{i K_{B} \Lambda} & T_{12} \\
T_{21} & T_{22}-e^{i K_{B} \Lambda}
\end{array}\right)\left(\begin{array}{c}
A_{j+2} \\
B_{j+2}
\end{array}\right)=\left(\begin{array}{l}
0 \\
0
\end{array}\right)
$$

A solução não trivial existe somente se o determinante da matriz do sistema $\mathbf{T}=\mathbf{T}^{j} \mathbf{T}^{j=1}$ é nulo:

$T_{11} T_{22}-T_{12} T_{21}-e^{i K_{B} \Lambda}\left(T_{11}+T_{22}\right)+e^{i 2 K_{B} \Lambda}=0$

O determinante da matriz de transferência da célula unitária é $\operatorname{det}(\mathbf{T})=1$, como pode ser visto examinando a relação

$$
\operatorname{det} \mathbf{T}=T_{11} T_{22}-T_{12} T_{21}=\operatorname{det} \mathbf{T}^{(j)} \operatorname{det} \mathbf{T}^{(j+1)}
$$

Usando a formula Eq 4.21 da matriz de transferência, segue:

$$
\operatorname{det} \mathbf{T}^{(j)}=\frac{s_{j+1}}{s_{j}} \mathrm{e} \operatorname{det} \mathbf{T}^{(j+1)}=\frac{s_{j+2}}{s_{j+1}}
$$

que conduz a 
$\operatorname{det} \mathbf{T}=\frac{s_{j+1}}{s_{j}} \frac{s_{j+2}}{s_{j}}=1$

onde a condição $s_{j+2}=s_{j}$ é mantida devido à periodicidade adotada. Finalmente, a Eq 4.33 simplificada [71] é:

$\cos \left(K_{B} \Lambda\right)=\frac{1}{2}\left(T_{11}+T_{22}\right)=\frac{1}{2} \operatorname{tr} \mathbf{T}$

A Eq 4.37 associa os valores do vetor de onda de Bloch e da freqüência do campo com a chamada relação de dispersão:

$\omega=\omega\left(K_{B}, k_{x}\right)$

Eq 4.38

Se todas as propriedades materiais (permeabilidade e permissividade) são reais, então $K_{B} \in \mathfrak{R}$. Para uma dada freqüência, $\omega \in \mathfrak{R}$ se e somente se $\left|\cos \left(K_{B} \Lambda\right)\right|<1$. Então as ondas podem propagar-se no meio sem atenuação. Um intervalo das freqüências onde isto é satisfeito é chamado "banda-passante" ou a "faixa de transparência". De um lado pode haver uma escala de freqüências para uma dada estrutura onde $\left|\cos \left(K_{B} \Lambda\right)\right|>1$, dependendo do lado direito da equação Eq 4.37. A solução da equação Eq 4.37 para $\omega \in R$ é caracterizada então pelo valor complexo do vetor de onda de Bloch, com $K_{B} \in C$. Estas faixas de frequiências onde as propagações das ondas são proibidas denominam-se bandgaps, bandas proibidas ou stop-bands.

De fato, a supressão da propagação de ondas para uma faixa de freqüências é uma propriedade intrínseca de todos os meios periódicos. As ondas eletromagnéticas em meios periódicos, com freqüência dentro do bandgap, são do tipo evanescentes, isto é, são atenuadas exponencialmente em amplitude ao se propagarem no meio. Em contraste com estas ondas evanescentes (bandgap), as assim chamadas ondas estendidas, se propagam devido ao fato de que a energia destas ondas está distribuída sobre toda a estrutura. Dessa forma, em analogia com a estrutura de bandas eletrônicas da física do estado sólido, os chamados cristais fotônicos seguem por esse caminho [71]-[73].

A Eq 4.37 pode ser aplicada à análise de uma célula unitária mais complexa (isto é, com mais de duas camadas na pilha unitária do arranjo arbitrário) considerando o traço da matriz de transferência correspondente [71]. A repetição periódica da pilha unitária causa a estrutura de banda proibida (bandgap). As vezes este método, chamado método das superredes, é usado para a análise das estruturas (não-periodicas) finitas onde é feita a suposição de que a periodização artificial não muda a resposta óptica substancialmente [7]. 
Uma outra aproximação para mostrar a origem física dos fenômenos da banda proibida (bandgap) encontra-se na descrição da múltipla dispersão da propagação da onda que atinge uma condição em que as ondas interferem construtiva ou destrutivamente de maneira a suportar ou rejeitar a propagação da onda para determinadas freqüências. Embora este ponto de vista seja tanto físico quanto intuitivamente muito atraente, ele não é, em geral, fácil de ser tratado matemáticamente [7].

\subsection{Multicamadas periódicas com defeitos}

Olhando para os meios periódicos do ponto de vista da simetria, o bandgap pode ser visto como resultado da simetria translacional discreta dos meios periódicos [7]. Ao que se revela, as freqüências das ondas de propagação dentro do bandgap estão suprimidas e todas as ondas são do tipo evanescente. Entretanto, a quebra da simetria dos meios periódicos pode permitir a propagação de algumas freqüências que pertencem à faixa do bandgap. Uma maneira comum de quebrar a simetria translacional é mudar localmente a espessura ou as propriedades dos materiais numa camada específica [7]. As partes periódicas emergentes do cristal fotônico que encerra o local do defeito atuam como espelhos seletivos da freqüência para um ressonador do tipo de Fabry-Perot, formado pela camada defeituosa.

Com um ajuste apropriado dos parâmetros do defeito, as modalidades assim chamadas de defeito podem ser suportadas pela estrutura. Estes são estados localizados com concentração de energia na proximidade do defeito em contraste com os estados estendidos da banda passante na estrutura periódica. Elas possuem um vetor de onda real, vetor de Bloch, na faixa de freqüência do bandgap da estrutura periódica subjacente [7].

Nestas ultimas secções foram apresentadas as equações que descrevem a interação da onda monocromática com uma pilha multicamadas (multilayer stack) em um meio dielétrico, linear e homogêneo. Mencionou-se também que defeitos podem levar a ressonâncias que permite a transmissão de uma freqüência específica pertencente ao bandgap. O interesse agora é a caracterização e a utilização destas ressonâncias dos defeitos que aparecem em estruturas finitas. Esta montagem de filmes finos pode ser usada como elemento selecionador de comprimentos de onda. A deposição de filmes finos tipicamente conta com a diferença nos índices de refração de dois ou mais materiais usados para produzir efeitos de interferência na estrutura multicamadas. A completa teoria básica da óptica dos filmes finos está presente na literatura [72], [74]-[78]. 


\subsection{Propriedades ópticas dos filmes finos}

A representação de uma estrutura formada por deposição de filmes finos de material dielétricos é mostrada na Figura 4.3. A luz incidente vinda do meio incidente sofre múltiplas reflexões e refrações entre as duas interfaces que separam os três meios (meio incidente $n_{0}$, filme $n_{1}$, meio de saída $n_{2}$ ). Se a amplitude da onda incidente é $E_{0}$, a amplitude total da onda refletida é dada pela soma de todas as contribuições dos raios refletidos dentro do meio incidente [8], [53] e [69]:

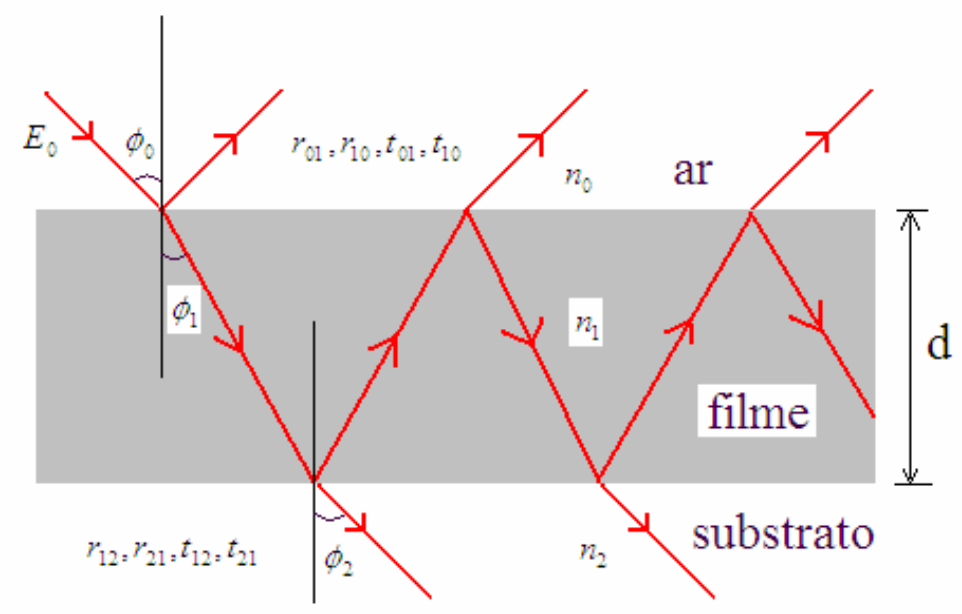

Figura 4.3 - Esquema da propagação de ondas eletromagnéticas através de filmes finos depositados sobre um substrato. Cada amplitude é definida pelos coeficientes de Fresnel e pelo retardamento de fase.

$$
\begin{aligned}
& E_{r e f}=r_{01} E_{0}+r_{12} t_{01} t_{10} E_{0} e^{2 j \delta}+r_{10}\left(r_{12}\right)^{2} t_{01} t_{10} E_{0} e^{4 j \delta}+\left(r_{10}\right)^{2}\left(r_{12}\right)^{3} t_{01} t_{10} E_{0} e^{6 j \delta}+\ldots= \\
& =r_{01} E_{0}+r_{12} t_{01} t_{10} E_{0} e^{2 j \delta}\left[1+r_{10} r_{12} e^{2 j \delta}+\left(r_{10} r_{12}\right)^{2} e^{4 j \delta}+\ldots\right]
\end{aligned}
$$

A razão da amplitude da luz refletida pela incidente resulta em [53]:

$\rho=\frac{E_{r e f}}{E_{0}}=\left(r_{01}+\frac{r_{12} t_{01} t_{10} e^{2 j \delta}}{1-\left(r_{10} r_{12} e^{2 j \delta}\right.}\right)=\frac{r_{01}+r_{12} e^{2 j \delta}}{1+r_{10} r_{12} e^{2 j \delta}}$

onde

$\delta=\frac{2 \pi}{\lambda_{0}} n_{1} d \cos \phi_{1}$

é a mudança de fase do feixe de luz ao atravessar a película ( $\lambda_{0}$ é o comprimento de onda da luz no vácuo). Sendo que $n_{1}$ é o índice de refração no filme, $d$ a espessura do filme e $\phi_{1}$ ângulo do raio transmitido, conforme o esquema da Figura 4.3. 
Da mesma forma que a amplitude refletida foi calculada, calcula-se a amplitude transmitida [53]:

$$
\begin{aligned}
& E_{\text {trd }}=t_{01} t_{10} E_{0} e^{i \delta}+r_{10} r_{12} t_{01} t_{12} E_{0} e^{2 j \delta}+\left(r_{10} r_{12}\right)^{2} t_{01} t_{12} E_{0} e^{4 j \delta}+\left(r_{10} r_{12}\right)^{3} t_{0} 1 t_{12} E_{0} e^{6 j \delta} e^{j \delta}+\ldots= \\
& =r_{01} E_{0}+r_{12} t_{01} t_{10} E_{0} e^{2 j \delta}\left[1+r_{10} r_{12} e^{2 j \delta}+\left(r_{10} r_{12}\right)^{2} e^{2 j \delta}+\ldots\right]
\end{aligned}
$$

A formula para a proporção da amplitude da luz transmitida pela incidente resulta em [53]:

$\tau=\frac{E_{t r d}}{E_{0}}=\frac{t_{01} t_{12} e^{j \delta}}{1+\left(r_{10} r_{12} e^{2 j \delta}\right)}$

A refletividade e a transmissividade são definidas por [53]:

$R=\rho \rho^{*}=\rho^{2}$

e, como $n_{0}=n_{2}$, obtêm-se:

$T=\left(n_{2} / n_{0}\right) \tau \tau^{*}=\tau^{2}$

Assumindo que todos os materiais são ideais, ou seja, homogêneo e não absorvente, tem-se [53]:

$$
R=\frac{r_{01}^{2}+r_{12}^{2}+2 r_{01} r_{12} \cos 2 \delta}{1+r_{01}^{2} r_{12}^{2}+2 r_{01} r_{12} \cos 2 \delta}
$$

$\mathrm{e}$

$$
T=\frac{t_{01}^{2} \cdot t_{12}^{2}}{1+r_{01}^{2} r_{12}^{2}+2 r_{01} r_{12} \cos 2 \delta} \frac{n_{2} \cos \phi_{2}}{n_{0} \cos \phi_{0}}
$$

A espessura do filme é $d$ e, quando $\delta$ é substituído por $\delta+\pi$, isto é $d$ é substituído por $d+\Delta d$ :

$$
\Delta d=\frac{\lambda_{0}}{2 n_{1} \cos \phi_{1}}
$$

A refletividade e a transmissividade das películas dielétricas que diferem na espessura por um múltiplo inteiro de $\lambda_{0} /\left(2 n_{1} \cos \phi_{1}\right)$ são as mesmas. Para a espessura óptica $\mathrm{D}$ do filme (isto é $D=n_{1} d$ ), o coeficiente de reflexão é máximo ou mínimo para a condição:

$$
\frac{d R}{d D}=0
$$

A condição é satisfeita quando $\sin 2 \delta=0$, isto é quando 
$D=\frac{p \lambda_{0}}{4 \cdot \cos \phi_{1}}, \operatorname{com}(p=0,1,2, \ldots)$

Eq 4.50

Distinguimos as duas soluções, onde p é impar e onde p é par:

1) se p é impar, então $\cos 2 \delta=-1$ e a Eq 4.46 resulta:

$R=\left(\frac{r_{01}-r_{12}}{1-\left(r_{01} r_{12}\right)}\right)^{2}$

Eq 4.51

Para a incidência normal:

$$
\begin{aligned}
& r_{01}=\left(\frac{n_{0}-n_{1}}{n_{0}+n_{1}}\right) \\
& r_{12}=\left(\frac{n_{1}-n_{2}}{n_{1}+n_{2}}\right)
\end{aligned}
$$

Que resulta em,

$$
R=\left(\frac{n_{0} n_{2}-n_{1}^{2}}{n_{0} \cdot n_{2}+n_{1}^{2}}\right)^{2}
$$

2) Se pé par, então $\cos 2 \delta=1$ e resulta:

$$
R=\left(\frac{r_{01}+r_{12}}{1+\left(r_{01} \cdot r_{12}\right)}\right)^{2}
$$

Em particular, para a incidência normal:

$$
R=\left(\frac{n_{0}-n_{2}}{n_{0}+n_{2}}\right)^{2}
$$

Desta forma a refletividade é independente de $n_{1}$. Na incidência obliqua, $n_{i}$ precisaria ser substituído por $n_{i} \cos \phi_{i}(i=1,2,3, \ldots)$ em todas as fórmulas. Um filme com a espessura óptica $p \lambda_{0} /\left(2 \cos \phi_{1}\right) \operatorname{com} p=1,2,3, \ldots$ não tem nenhuma influência na intensidade da luz refletida (ou transmitida). Tal camada é referida como "ausente" [70].

Para determinar a natureza dos extremantes (se é ponto de máximo ou de mínimo), partindo de $D=p \lambda_{0} /\left(4 \cos \phi_{1}\right) \operatorname{com} p=1,2,3, \ldots \quad$, deve-se estudar as condições:

$$
\begin{aligned}
& \left(\frac{d^{2} R}{d D^{2}}\right)>0 \\
& \left(\frac{d^{2} R}{d D^{2}}\right)<0
\end{aligned}
$$

isto significa : 


$$
\begin{aligned}
& \left(\frac{d^{2} R}{d D^{2}}\right)>0,(-1)^{p} r_{01} r_{12}\left[1+r_{01}^{2} r_{12}^{2}-r_{01}^{2}-r_{12}^{2}\right]<0 \text { para a primeira condição e } \\
& \left(\frac{d^{2} R}{d D^{2}}\right)<0,(-1)^{p} r_{01} r_{12}\left[1+r_{01}^{2} r_{12}^{2}-r_{01}^{2}-r_{12}^{2}>0\right. \text { para a segunda condição. }
\end{aligned}
$$

Para a incidência normal encontra-se:

- Máximo, se $(-1)^{p}\left(n_{0}-n_{1}\right)\left(n_{1}-n_{2}\right)>0$

- Mínimo, se $(-1)^{p}\left(n_{0}-n_{1}\right)\left(n_{1}-n_{2}\right)<0$

Considerando o primeiro meio como sendo o ar $\left(n_{0}=1\right)$, concluí-se que se a refletividade de uma película que tem uma espessura óptica com valores $\lambda_{0} / 4,3 \lambda_{0} / 4$, $5 \lambda_{0} / 4, \ldots$ etc., é um máximo ou um mínimo dependendo se o índice de refração da película é maior ou menor do que o índice de refração do meio substrato. Para uma película cuja espessura óptica tenha valores $\lambda_{0} / 2, \lambda_{0}, 3 \lambda_{0} / 2$, etc., vale o oposto.

Então, um filme cuja espessura óptica é $\lambda_{0} / 4$, e cujo índice de refração é baixo o suficiente, este pode ser usado como filme anti-reflexivo [70]. A cobertura do substrato com materiais com alto índice de refração permitem altas refletividades. As expressões derivadas ainda não podem descrever uma estrutura multicamadas, e uma nova abordagem precisa ser escolhida.

A terminologia usada neste trabalho usa termos como transmissividade, absortividade e refletividade para propriedades de materiais puros. Para característica de espécimes ou amostras não ideais os termos usados são transmitância, absorbância e refletância, respectivamente.

\subsection{Propriedades ópticas de pilhas multicamadas.}

Esta secção apresenta as técnicas gerais para o cálculo da transmitância e da refletância de uma pilha multicamadas. Aqui é assumido que a estrutura é composta de uma pilha ideal de camadas homogêneas, lisas e paralelas [70] e [71].

A componente tangencial da onda eletromagnética do campo elétrico $\mathbf{E}$ e campo magnético $\mathbf{H}$ precisam ser contínuos através de cada interface da estrutura multicamadas de forma a satisfazer as equações de Maxwell. A refletância $(R)$ da onda que se propaga por um meio (índice de refração $n_{1}$ ) para outro meio (índice de refração $n_{2}$ ) é definido como a razão 
da potência refletida pela incidente, de acordo com a equação Eq 4.56, para incidência normal:

$R=\left|\frac{n_{1}-n_{2}}{n_{1}+n_{2}}\right|^{2}$

A transmitância é 1-R. Reflexões de todas as ondas incidentes ocorrem na interface entre dois meios.

Uma pilha é composta de $q$ camadas conforme a Figura 4.4, cada camada é definida por sua matriz característica. A técnica da multiplicação de matizes (método das matrizes) é usada para calcular as características ópticas da pilha de filmes finos. A solução da Eq. 4.59 é válida somente para o caso da incidência normal.

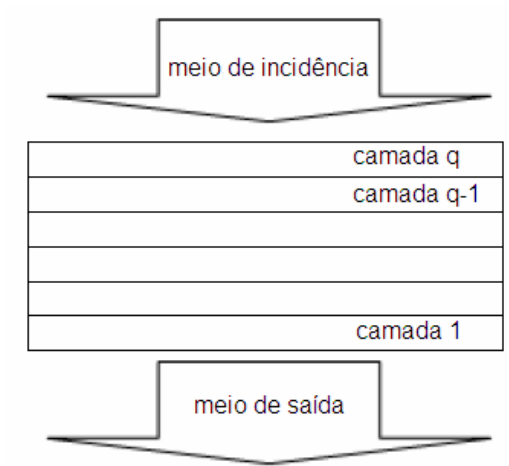

Figura 4.4 - Esquema da estrutura de pilha representada por uma montagem de camadas.

Contudo, cada camada possui o índice de refração $N$, que pode ser complexo, $N=n-k i$. O coeficiente de extinção, $k$, representa a atenuação em meios com perdas. A admitância óptica da camada é $y_{j}=y_{f s} N_{j}$, onde $y_{f s}$ é a admitância óptica no vácuo. Quando uma onda plana com comprimento de onda $\lambda_{0}$, incidência normal, se propaga dentro da cavidade, a matriz característica $M_{j}$ da camada oticamente homogênea, com índice de refração e espessura $z_{j}$, é [70]:

$M_{j}=\left[\begin{array}{cc}\cos \alpha & \frac{i}{y_{j}} \sin \alpha \\ i y_{j} \sin \alpha & \cos \alpha\end{array}\right]$

Eq 4.60

sendo $k_{0}=\frac{2 \pi}{\lambda_{0}}$ e $\alpha=\left(k_{0} N_{j} z_{j}\right)$

A matriz característica final da pilha de filmes é [70]: 
$M=M_{q} \cdot M_{q-1} \cdot \ldots \cdot M_{2} \cdot M_{1}$

Eq 4.61

A refletância e transmitância total da estrutura podem ser calculadas por:

$R=\left|\frac{y_{\text {in }} B-C}{y_{\text {in }} B+C}\right|^{2}$
$T=\frac{4 y_{\text {in }} R_{e}\left(y_{\text {out }}\right)}{\left|y_{\text {in }} B+C\right|^{2}}$

Onde

$\left[\begin{array}{l}B \\ C\end{array}\right]=M\left[\begin{array}{c}1 \\ y_{\text {out }}\end{array}\right]$

Eq 4.64

$y_{\text {in }}, y_{\text {out }}$ são as admitâncias do meios para o qual a luz entra ou sai, respectivamente. A absorbância pode ser calculada para:

$A=1-(R+T)$

Eq 4.65

\subsubsection{Espessura óptica: quarto de onda e meia onda}

É mais conveniente e desejável, como visto em 4.5, calcular a admitância de pilhas de quarto de onda e de meia onda, então, o projeto freqüentemente é especificado em termos de quarto de ondas com respeito ao comprimento de ondas $\lambda_{0}$.

Se a espessura óptica é um número inteiro de quartos de onda (para um comprimento de onda $\lambda_{0}$ de referencia para o qual a deposição foi projetada), a matriz característica do filme fino é descrito pela Eq. 4.60, de onde se deriva [70]:

$M^{\prime}= \pm\left[\begin{array}{cc}0 & i \\ i y_{1} & 0\end{array}\right]$

Eq 4.66

onde $\alpha=m \cdot(\pi / 4)$ e m é um inteiro ímpar.

Para $m$ impar, $\sin \alpha= \pm 1$ e $\cos \alpha=0$. Esta matriz é de fácil manuseio. Tais estruturas QWOT quarter-wave optical thickness (espessura óptica quarto de onda) são geralmente representadas por letras maiúsculas $\mathrm{H}, \mathrm{M}, \mathrm{L}$, assim se referindo, $\mathrm{H}$ a materiais que possuem alto índice de refração, $M$ a materiais intermediários e L a materiais de baixos índices de refração. Para uma espessura óptica de um número inteiro de meia ondas, isto é, 
com $m$ sendo inteiro e par $(\sin \alpha=0$ e $\cos \alpha= \pm 1)$, resulta a matriz unitária, a qual não tem efeito na transmitância e refletância (camada ausente) [7], [70] e [71] :

$M^{\prime \prime} \pm\left[\begin{array}{ll}1 & 0 \\ 0 & 1\end{array}\right]$

O projeto de estruturas de camadas QWOT e camadas HWOT half-wave optical thickness (espessura óptica de meia onda) é refinado por meio de simulações computacionais que levam em conta a dependência do comprimento de ondas das propriedades ópticas de um determinado material.

\subsubsection{Fronteiras não ideais}

Quando um fluxo radiante incide numa superfície (interface não ideal), neste processo ocorrem: transmissão, absorção e reflexão da radiação. A Figura 4.5 mostra um caso ideal onde os componentes transmitidos e refletidos ou são especular ou são perfeitamente difuso. Até agora, somente a transmissão ou reflexão especular foram assumidos. Porém a transmissão e reflexão em uma superfície real, na prática, podem ocorrer: reflexão com componente difusa, reflexão com componente especular, reflexão com componente retrorefletiva, transmissão regular e/ou transmissão difusa.

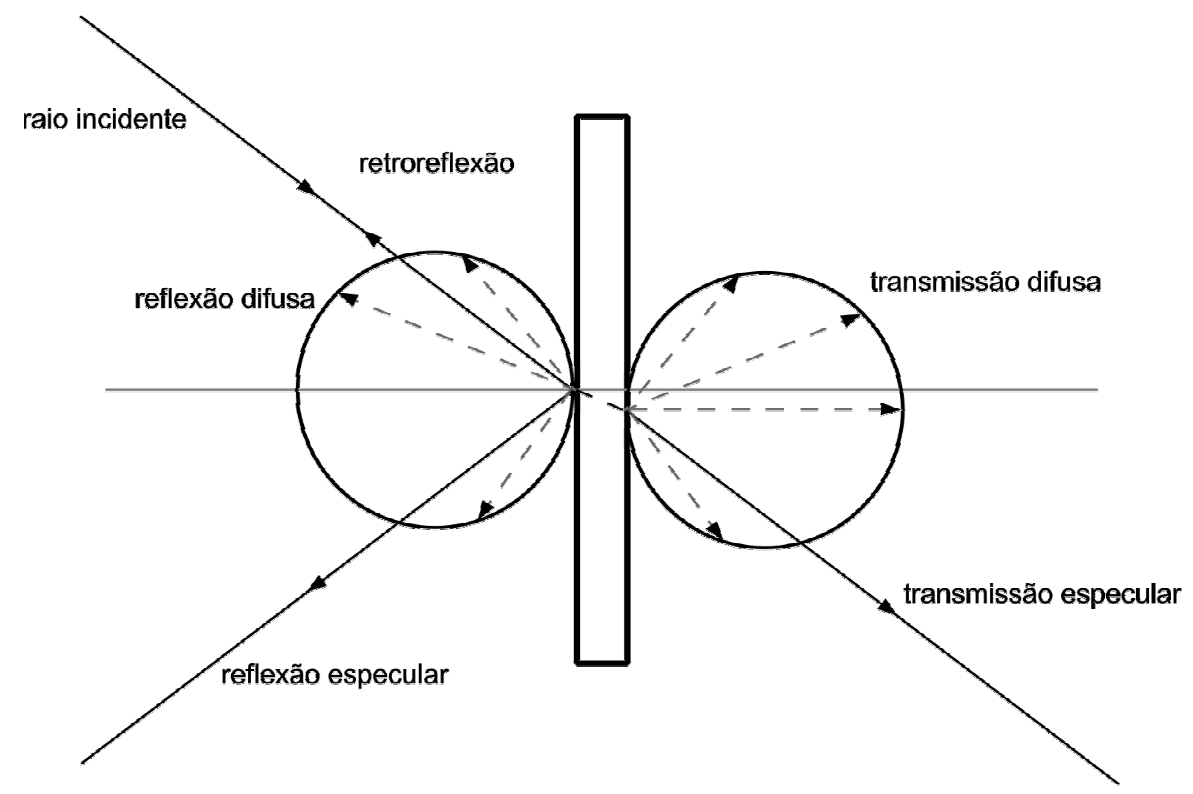

Figura 4.5 - Caso ideal: componentes transmitido e refletido são ou especular ou perfeitamente difusa [79]. 


\subsection{Ressonador de Fabry-Perot plano planar ideal}

Um ressonador óptico confina certos comprimentos de onda da luz e opera como um sistema óptico de transmissão com realimentação: a luz reflete repetidamente no interior do sistema sem escapar. Um ressonador simples (Figura 4.6) que é composto por dois refletores paralelos entre os quais a luz é refletida e transmitida com pequenas perdas é conhecido como ressonador de Fabry-Perot. A seletividade do ressonador óptico de Fabry-Perot permite que seja usado como elemento selecionador de comprimentos de onda em espectrômetros. Pesquisas realizadas têm demonstrado a viabilidade da microfabricação em estrutura vertical com somente um caminho óptico e com razoável performance [2], [7], [8], [64] e [80]. Estes são fortes argumentos para que esta configuração de ressonador seja usada como elemento selecionador de comprimentos de onda no desenvolvimento de micro-espectrômetros para faixas do espectro no visível e infravermelho próximo.

A fabricação de micro-espectrômetros integrados em processos de microeletrônica é limitada por restrições dos processos nas dimensões vertical e horizontal, e são restritas a estruturas planares. Então, a configuração de placas planas do ressonador de Fabry-Perot é mais adaptada a certas tecnologias do que as configurações de placas esféricas do ressonador [68].

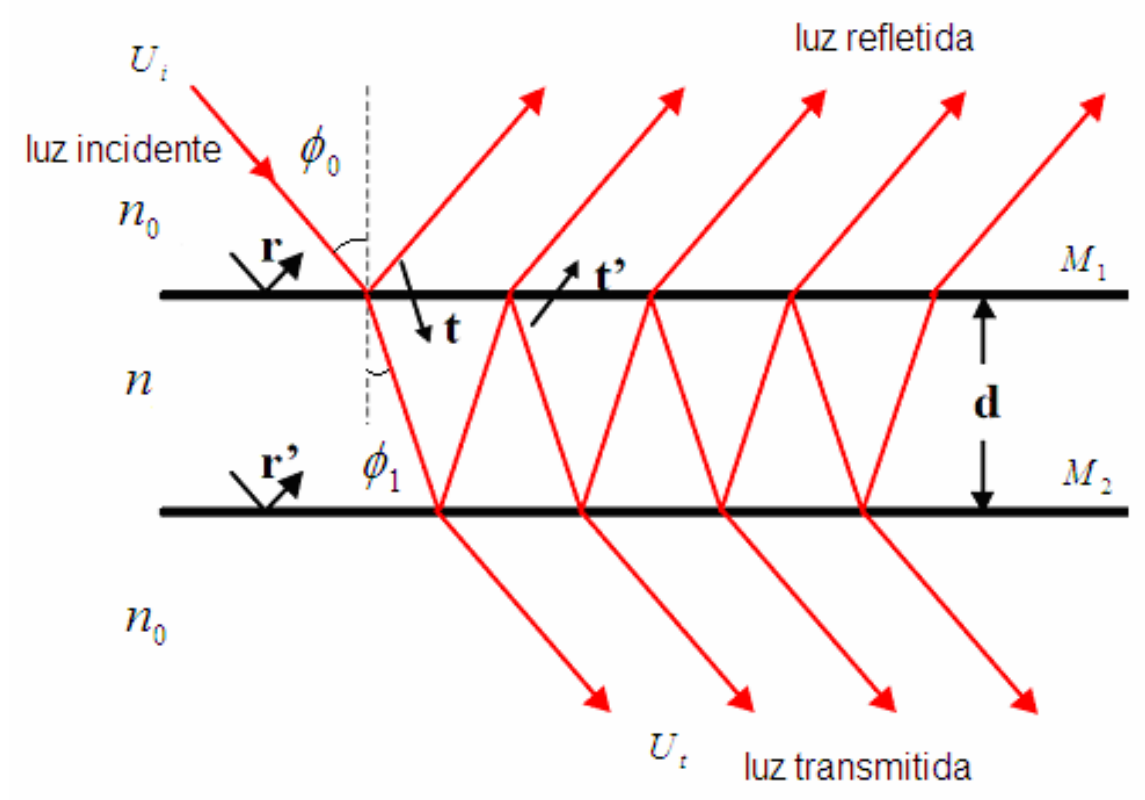

Figura 4.6 - Ressonador de Fabry-Perot com espelhos planos. 
No ressonador ideal de Fabry-Perot os dois espelhos são assumidos perfeitamente paralelos e sem perdas. Também, é assumido que não há absorção no meio ressonador.

\subsubsection{Modos Ressonador}

Uma onda monocromática de freqüência $v=\omega / 2 \pi$ tem a função de onda:

$u(r, t)=R_{e}\{U(r) \exp (j 2 \pi v t)\}$

Eq 4.68

a qual representa o componente transversal do campo elétrico. A amplitude complexa $U(r)$ satisfaz a Eq. 4.5 de Hemlholtz, onde $k=2 \pi v / v_{m}$ é o número de onda e $v_{m}$ é a velocidade da luz no meio. O modo do ressonador são as soluções básicas da equação de Helmholtz. Para o ressonador de espelho plano, a componente transversal do campo elétrico se anula na superfície do espelho, então $U(r)=0$ no plano $z=0$ e $z=d$. O resultado é uma onda estacionária [81]:

$U(r)=A \sin k z$

Eq 4.69

onde A é uma constante que satisfaz a equação de Helmholtz que se anula em $z=0$ e $z=d$ se $k$ satisfaz a condição $k d=q \pi$, onde $q$ é um inteiro.

Esta restrição sobre $k$ resulta valores de $k_{q}=q \pi / d$, de forma que o modo tem amplitude complexa $U(r)=A_{q} \sin k_{q} z$, onde $A_{q}$ são constantes. Valores negativos de $q$ não constituem valores de modos independentes, visto que a função "seno" é impar. Então, os modos do ressonador são ondas estacionárias $A_{q} \sin k_{q} z$; assim os positivos inteiros $q=1,2,3, \ldots$ são chamados números de modos (Figura 4.7) 


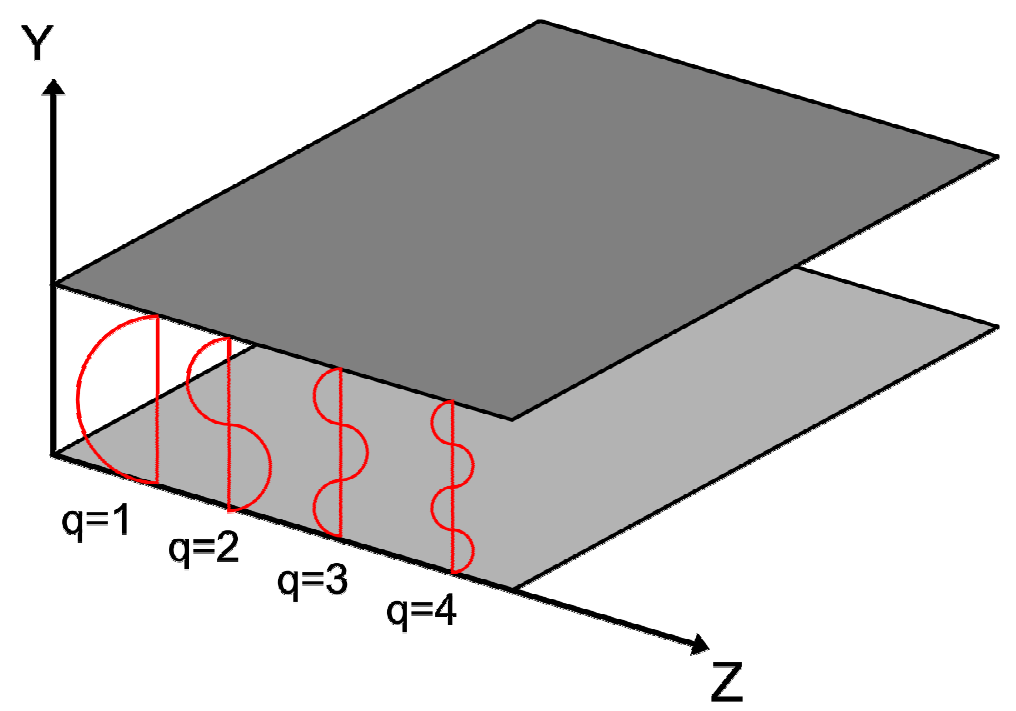

Figura 4.7 - Campo de distribuição dos modos de um interferômetro espelho-planar.

Para uma onda arbitrária que entra em um ressonador, pode-se representar a superposição dos modos, $U(r)=\sum_{q} A_{q} \sin k_{q} z$. A isso segue que a freqüência $v=q v_{m} / 2 d$ é restrita a valores discretos:

$v_{q}=q v_{m} / 2 d$

$\operatorname{com} q=1,2,3, \ldots$

Estas são as frequiências de ressonância do ressonador. Os comprimentos de onda de ressonância são, $\lambda_{q} 2 d / q$ enquanto que $v_{m}=c_{0} / n$ é a velocidade da luz no meio cavidade. A análise para cobrir diferentes modos do espectro pode ser complicada. A redução do número de modos corresponde ao decrescimento do caminho óptico.

O deslocamento de fase dado por uma única viagem de ida e volta de propagação (2d) é:

$\varphi=k 2 d=q 2 \pi$

$\operatorname{com} q=1,2,3 \ldots$

Isto leva para a relação $k d=q \pi$, onde $k$ é o número de onda, como foi definido antes $k=2 \pi v / c$. O ressonador trabalha como um sistema de realimentação: a saída do sistema está em fase com a entrada (Figura 4.8)[82]. 


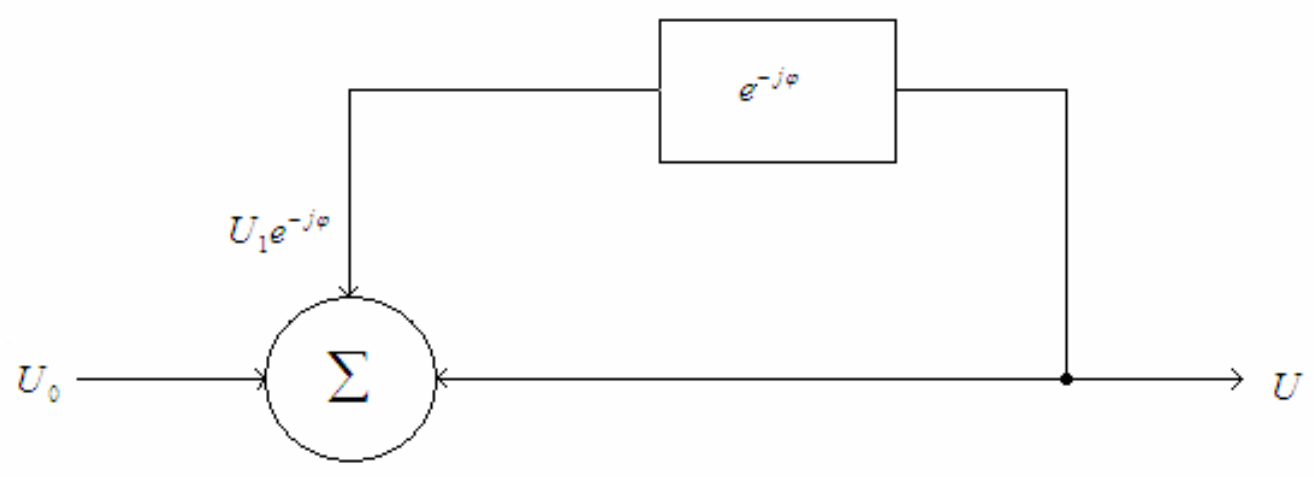

Figura 4.8 - Diagrama de Blocos representando um sistema realimentado.

A onda plana de amplitude complexa $U_{0}$ é refletida para no espelho e se propaga para trás para o espelho 1 quando reflete novamente (a amplitude se torna $U_{1}$ ).

A onda monocromática original $U_{o}$ no ponto $P$ se propaga para a direita ao longo do eixo do ressonador (Figura 4.9).

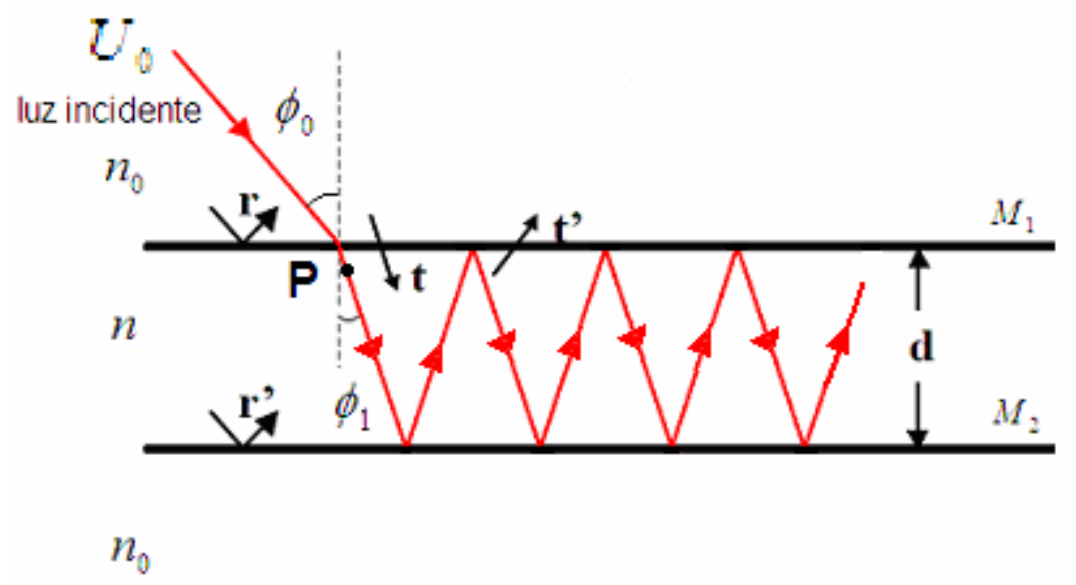

Figura 4.9 - Uma onda reflete múltiplas vezes nos espelhos do ressonador, resultando num deslocamento de fase em cada reflexão.

A onda incidente $U_{0}$ que transpassa $M_{1}$ é refletida no espelho $M_{2}$ e se propaga para o espelho $M_{1}$, onde é novamente refletida. A amplitude em $\mathrm{P}$ se torna $U_{1}$ e $U_{1}$ cria $U_{2}$ em infinitas ondas parciais $U_{0}, U_{1}, U_{2}, \ldots$. Estas magnitudes devem ser iguais, pois não há perdas associadas à reflexão e transmissão. Então a onda total $U$ é a soma dos infinitos números de fasores de igual magnitude:

$U=U_{0}+U_{1}+U_{2}+\ldots$ 


\subsection{Ressonador Fabry-Perot planar não ideal}

Na secção anterior o ressonador planar de Fabry-Perot foi tratado como um sistema óptico de realimentação, que pode ser apropriado ao usar o método das matrizes para procurar a função espectral da transmitância e refletância. Softwares profissionais são disponíveis comercialmente para desenhar e otimizar pilhas de filmes finos baseados no método das matrizes (ex. TFCalc, Design, OpenFilters).

Um ressonador não ideal de Fabry-Perot compostos por dois espelhos semitransparentes com perdas, separado por uma distancia $d$, será agora abordado. O fator de atenuação de amplitude, $r$, será introduzido (para as reflexões e absorção no meio ressonador). Um tratamento de maior rigor do ressonador de Fabry-Perot não ideal pode ser encontrado em [7], [57] e [71]. Inicialmente estudo a resposta espectral e a transmitância do ressonador.

\subsubsection{Resposta Espectral}

A onda plana de amplitude complexa $U_{i}$ e intensidade $I_{i}$ que entra no ressonador de espelho planar e é submetido a múltiplas reflexões e transmissões, é ilustrada na Figura 4.10:

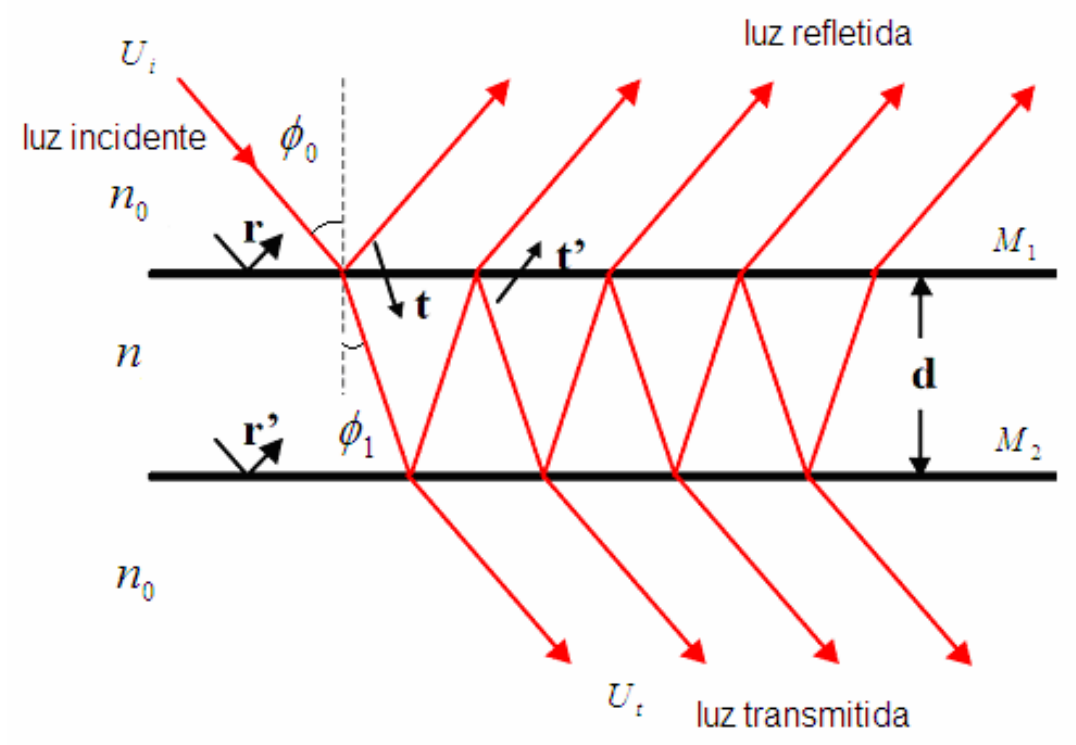

Figura 4.10 - Transmissão de onda plana através de um espelho planar Fabry-Perot. 
No ressonador com perdas, a excursão da onda $U_{0}$ entre os dois espelhos resulta na soma infinita dos fasores. A diferença de fase depois da reflexão em ambos os espelhos é:

$$
\varphi=k 2 d=\frac{4 \pi v d}{v_{m}}
$$

Devido á não perfeição da reflexão dos espelhos e absorções no meio, uma reflexão efetiva é representada por $R$. Isto implica no fator de atenuação da intensidade $R^{2}$. Considerando que $U_{1}=\zeta U_{0}$, com $\zeta=\operatorname{Re}^{-j \varphi}$ e que o fasor $U_{2}$ está relacionado ao $U_{1}$ pelo mesmo fator complexo $\zeta$, e considerando todos os consecutivos fasores, resulta:

$$
\begin{aligned}
& U=U_{0}+U_{1}+U_{2}+\ldots=U_{0}+\zeta U_{0}+\zeta^{2} U_{0}+\ldots \\
& U=U_{0} \cdot\left(1+\zeta+\zeta^{2}+\ldots\right)=\frac{U_{0}}{1-\zeta}
\end{aligned}
$$

A intensidade no ressonador pode ser expressa como:

$$
I=|U|^{2}=\frac{U_{0}^{2}}{\left|1-\operatorname{Re}^{-j \varphi}\right|^{2}}=\frac{I_{0}}{\left(1+R^{2}-2 R \cos \varphi\right)}=\frac{I_{0}}{(1-R)^{2}+4 R \sin ^{2}\left(\frac{\varphi}{2}\right)}
$$

Esta é chamada equação de Airy, que geralmente é reescrita como [8]:

$$
I=\frac{I_{\max }}{1+\left(2 \frac{F}{\pi}\right)^{2} \cdot \sin ^{2}\left(\frac{\varphi}{2}\right)}
$$

Onde $I_{\max }=I_{0} /(1-R)^{2}$, sendo que $I_{0}=U_{0}^{2}$ é a intensidade da onda inicial. $\mathrm{O}$ parâmetro $F$ é conhecido como "Finesse" do ressonador [8]:

$$
F=\frac{\pi \cdot R^{1 / 2}}{1-R}
$$

Pela Eq. 4.77 segue-se que a resposta espectral do ressonador de Fabry-Perot torna-se:

$$
I=\frac{I_{\max }}{1+\left(2 \frac{F}{\pi}\right)^{2} \cdot \sin ^{2}\left(\frac{\pi v}{v_{f}}\right)}
$$

onde $v_{F}=v_{m} / 2 d$ representa a diferença constante entre freqüências adjacentes de ressonância; $\omega=2 \pi v, \quad v_{q}=q v_{m} / 2 d, \quad q=1,2, \ldots$, são as freqüências de ressonância do ressonador. Similarmente a Eq 4.70, obtêm-se em termos de comprimento de onda: 
$q \lambda=2 d$

Eq 4.80

Se a amplitude complexa e a intensidade da onda transmitida são $U_{t}$ e $I_{t}$, respectivamente, e $R_{1}, R_{2}$ são as amplitudes das refletâncias das superfícies internas dos espelhos 1 e 2, onde $T_{1}$ e $T_{2}$ são as amplitudes da transmitância dos espelhos, é possível definir a intensidade da transmitida $T(v)$ do ressonador de Fabry-Perot em função da freqüência $v$ da onda, a saber [8]:

$$
T(v)=\frac{T_{\max }}{1+\left(2 \frac{F}{\pi}\right)^{2} \cdot \sin ^{2}\left(\pi \frac{v}{v_{F}}\right)}
$$

Onde $T_{\max }=T^{2} /(1-R)^{2}, \quad v_{F} \quad \mathrm{o}$ "espaço" entre as freqüências de ressonância adjacentes (faixa espectral livre, FSR), $T=T_{1} \cdot T_{2}, R=R_{1} \cdot R_{2}$ :

$$
v_{F}=F S R=v_{m} / 2 d
$$

Os principais parâmetros que caracterizam a resposta espectral do ressonador FabryPerot são: Finesse (F), largura da banda a meia altura (FWHM), faixa espacial livre (FSR) e poder de resolução $(\mathrm{R})$.

O estudo do ressonador de Fabry-Perot multicamadas de filmes finos, freqüentemente usa o modelo exposto "Funções de Airy para transmissão" [8] para calcular a resposta óptica da cavidade multicamadas. Este modelo simplificado usa uma refletância equivalente de um multilayer e possibilita a representação da cavidade multicamadas por um ressonador com dois espelhos muito fino, e ignora as interações de fase de cada reflexão [8]. Para ressonadores práticos, o método da matriz (usando a matriz característica de cada camada na cavidade e calculando a resposta óptica da pilha de multicamadas) é geralmente usado como base dos algoritmos de softwares e ferramenta de CAD disponíveis [78].

\subsubsection{FWHM e Finesse}

A intensidade da onda transmitida corresponde a "Picos" estreitos que são formados na transmissão. A "finura" ou "agudeza" dos picos, que aumenta com o aumento da refletância, já definida como a Finesse (Eq. 4.78) e é expressa pela razão da separação de picos sucessivos pela largura do pico a meia intensidade (FWHM). O não paralelismo dos espelhos e outros defeitos afetam estas características do espectrômetro. 


\subsubsection{Faixa espectral livre}

O espaço entre freqüências de ressonâncias adjacentes é a FSR Free Spectral Range (faixa espectral livre) (Eq. 4.82 e Figura 4.11). Geralmente, o FSR é a faixa de comprimentos de onda com que espectrômetro pode medir sem ambigüidade. Para interferômetros de FabryPerot com espaçamento $d$ entre espelhos, os picos de transmissão são separados por comprimentos de onda $\Delta \lambda$, a FSR é definida como:

$$
F S R=\frac{\lambda^{2}}{2 d}
$$

Em um Fabry-Perot ajustável a faixa espectral livre (FSR) e a largura de banda (FWHM) podem ser controladas independentemente. O gap da cavidade ajusta a largura espectral livre Eq 4.83, e a refletividade dos espelhos controla a largura de banda (Finesse) Eq 4.78 .

\subsubsection{Poder de Resolução}

O "poder de resolução" ou "resolução", $R$ (critério Rayleigh), que foi apresentado no primeiro capitulo, não deve ser aplicado diretamente ao ressonador de Fabry-Perot (as franjas do interferômetro são diferentes). O poder de resolução do interferômetro de Fabry-Perot é obtido por [8]:

$$
R=\frac{\lambda}{F W H M}=q F=\frac{q \pi \sqrt{R}}{(1-R)}
$$

Sendo $F$ a Finesse, $q$ a ordem do modo, $R$ a refletividade dos espelhos e $\lambda$ o comprimento de onda. A resolução é o produto da Finesse pelo número da ordem. Uma baixa Finesse não resulta necessariamente em uma baixa resolução média; mas isto implica que para se conseguir alta resolução, o espectrômetro precisa ser usado em ordens altas. Então, o poder de resolução depende principalmente do espaço entre espelhos e de sua refletividade. Maiores espaçamentos e/ou alta refletividade resultam em alto poder de resolução. 


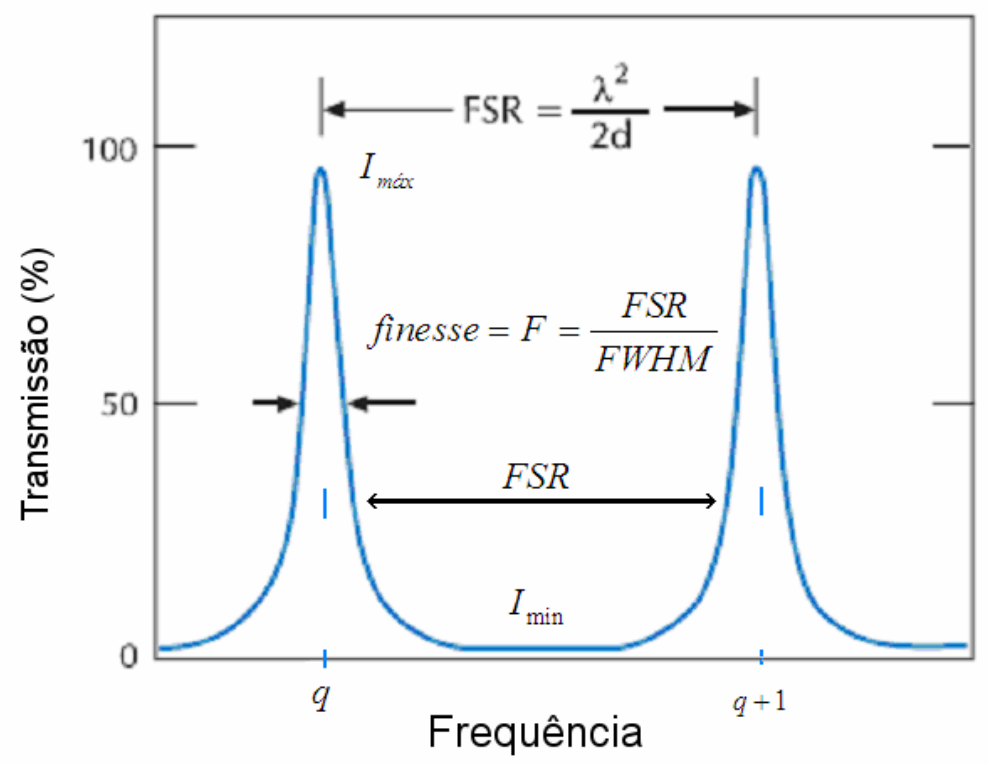

Figura 4.11 - Picos de transmissão são igualmente espaçados como função da frequiência.

\subsubsection{Perdas associadas ao espelho e ao meio ressonador}

A parte mais importante do dispositivo Fabry-Perot (FP) são os espelhos. Para implementar um dispositivo FP são utilizados espelhos de alta refletância com coberturas, tanto de dielétricas quanto metálicas. Os espelhos dielétricos, quando corretamente projetado e fabricado, têm elevado desempenho em suas características (alta refletância e baixas perdas por absorção). São formados pela deposição de uma sequiência de dois (ou mais) filmes dielétricos diferentes e com espessuras bem-controladas, formando uma pilha de muitas camadas; e a performance do filtro é altamente influenciada pela qualidade da deposição dos filmes.

Os filmes de cobertura metálica possuem perdas mais altas que os espelhos de cobertura dielétrica; contudo, eles podem ser mais atrativos em certas aplicações devido à simplicidade de sua fabricação (somente uma camada a ser depositada). Outra vantagem dos espelhos metálicos é que geralmente possuem bom desempenho numa larga faixa espectral. Alumínio, ouro e prata são os metais mais comuns usados para coberturas reflexivas. A Figura 4.12 mostra a refletância para a região que se estende do ultravioleta profundo ao infravermelho próximo no espectro [83] 


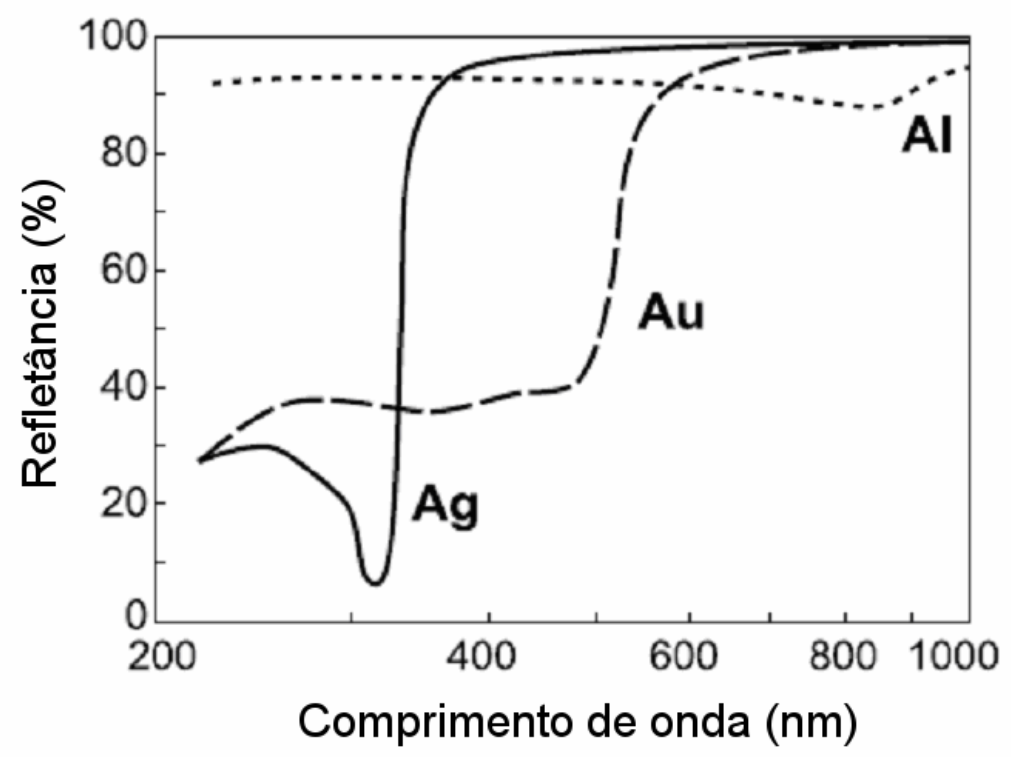

Figura 4.12 - Refletância da prata, ouro e alumínio em função do comprimento de onda da radiação [83].

Filtros Fabry-Perot usando espelhos metálicos não são providos de alta Finesse e alta transmitância simultaneamente, devido à absorção no metal.

A absorção em filmes metálicos é também devida a alta mobilidade dos elétrons. Então, a ação do campo elétrico paralelo à superfície devido à onda incidente é anulada. Esta condição de contorno causa a reflexão da luz. Um filme muito fino é quase transparente a luz quando não há elétrons suficientes para interagir com a luz incidente. Então, a espessura dos filmes metálicos é tipicamente selecionada entre dois extremos: de uma faixa de espessura do metal onde haja elétrons suficientes para interagir com uma onda incidente, de outra em que tais elétrons não possam mover-se livremente. Assim o movimento dos elétrons absorvem a energia da onda e a absorção ocorre [53], [54] e [83].

Uma outra fonte de perdas nos espelhos é a imperfeição nas reflexões, seja devido a rugosidades nas superfícies, perdas por transmissão ou pelo tamanho finito do espelho [83] e [84], [85].

Absorções e espalhamento no meio entre os espelhos são perdas devido ao meio da cavidade. Se definimos o coeficiente de absorção do meio $\alpha_{m}$, o fator de atenuação numa viagem de ida e volta da onda é $e^{-2 \alpha_{m} d}[8]$.

A intensidade da onda nos espelhos de refletâncias $R_{1}$ e $R_{2}$ decresce por um fator $R_{1} R_{2}$ no curso de duas reflexões associadas a uma simples viagem de ida e volta. O fator de atenuação da intensidade total é [84]: 
$R^{2}=R_{1} R_{2} e^{-2 \alpha_{m} d}$

se definimos o coeficiente de perda efetiva total, $\alpha_{r}$, torna-se:

$\alpha_{r}=\alpha_{m}+\frac{1}{2 d} \ln \frac{1}{R_{1} R_{2}}$

Eq 4.86

O tratamento da absorção no filme fino é feito com detalhes em [70].

\subsection{3 Ângulo de incidência e não paralelismo.}

Raios de luz ligeiramente inclinados escapam mais rapidamente do ressonador do que os raios perpendiculares. Isto implica em baixa resolução. Múltiplas reflexões ocorrem entre os espelhos do ressonador plano planar. A informação espectral pode ser derivada variando-se um dos três termos do lado direito da equação:

$q \lambda=2 n d \cos \alpha$

Eq 4.87

sendo $q$ um inteiro, $\alpha$ é ângulo de incidência da luz, $n$ o índice de refração do meio da cavidade e $d$ a distancia entre espelhos (para um gap de ar entre os espelhos a espessura óptica é igual a $d$ e $n=1)$. Se $\cos \alpha=\{1 / 2,1 / 3,1 / 4, \ldots\}, q=1, n=1$ o modo de trabalho é alterado, e a resolução e transmitância são deteriorados.

Se os espelhos não são paralelos, os raios de luz também escapam do ressonador. Em princípio a medida espectral é possível, contudo, ao custo de forte redução da Finesse e da resolução.

\subsubsection{Camada dielétrica sucessivas.}

A estrutura de multicamadas é organizada por uma seqüência de filmes bem caracterizada: HL, HL, HL, ....HL, H. de forma que a matriz característica destas multicamadas é de $2 \mathrm{~N}+1$ camadas, onde $\mathrm{N}$ é o número de vezes em que HL é usada. Com $n_{1}, n_{H}, n_{L}$ os índices de refração do ar (meio incidente) $\mathrm{H}$ a camada com alto $n$ e $\mathrm{L}$ a camada com baixo $n$, respectivamente [86]: 
$M_{2 N+1}=\left[\begin{array}{cc}0 & \left(-\frac{i}{n_{H}}\right)\left(\frac{n_{H}}{n_{L}}\right)^{N} \\ \left(-i n_{H}\right)\left(\frac{n_{i}}{n_{H}}\right)^{N} & 0\end{array}\right]$

Eq 4.88

Isto conduz a refletância [70]:

$$
R_{2 N+1}=\left[\frac{1-\left(\frac{n_{H}}{n_{1}}\right)\left(\frac{n_{H}}{n_{1}}\right)\left(\frac{n_{H}}{n_{L}}\right)^{2 N}}{1+\left(\frac{n_{H}}{n_{1}}\right)\left(\frac{n_{H}}{n_{1}}\right)\left(\frac{n_{H}}{n_{L}}\right)^{2 N}}\right]^{2}
$$

Esta última expressão indica que a refletância aumenta rapidamente, com a razão $\frac{n_{H}}{n_{L}}$ e com $N$.

\subsubsection{Operação na faixa visível do espectro}

O alumínio pode ser o material mais apropriado em termos de compatibilidade com processos de fabricação de microeletrônica, mas tem maiores perdas por absorção que a prata e o ouro no visível e infravermelho (Infra-Red - IR) próximo, conforme a Figura 4.12. Para a região visível do espectro, a prata é a melhor escolha, mas exibe pior estabilidade a longo termo (tendência a oxidar) [83].

O ouro é mais resistente à corrosão que a prata e pode ser a melhor escolha quando se necessita melhor performance espectral. Uma vantagem da prata, se puder ser aplicada em sistemas selados de forma a evitar as manchas, é a característica natural de filtro banda passante, cortando a banda do UV (Figura 4.12).

\subsubsection{Espectrômetros de Fabry-Perot}

Espectrômetros baseados em cavidades de Fabry-Perot convencionalmente podem usar elementos de seleção de comprimentos de onda dispostos como varredura e tipo matriz.

\section{- Seletor de comprimento de onda do tipo varredura}

O interferômetro ajustável Fabry-Perot pode ser usado como elemento selecionador de comprimentos de onda em um espectrômetro do tipo varredura. Pode-se montar um 
espectrômetro usando um resssoador de Fabry-Perot básico e adicionar algumas lentes e um fotodetector no plano focal (Figura 4.13).

Em uma cavidade com o espaço entre espelhos fisicamente ajustável, sintonizam-se diferentes comprimentos de onda de ressonância. Estes filtros de banda passante sintonizável podem ser projetados para varrer uma pequena região de comprimentos de onda para permitir um ajuste espectral preciso.

Então, um projeto de um espectrômetro baseado no Fabry-Perot do tipo varredura requer: alta seletividade, baixa absorção nos espelhos e cavidade e fotodetector de alta resolução, de acordo com a faixa espectral em medição. Uma pequena mudança no espaçamento dos espelhos causa uma mudança na FSR e um substancial deslocamento do comprimento de onda de ressonância, $\lambda_{q}$.

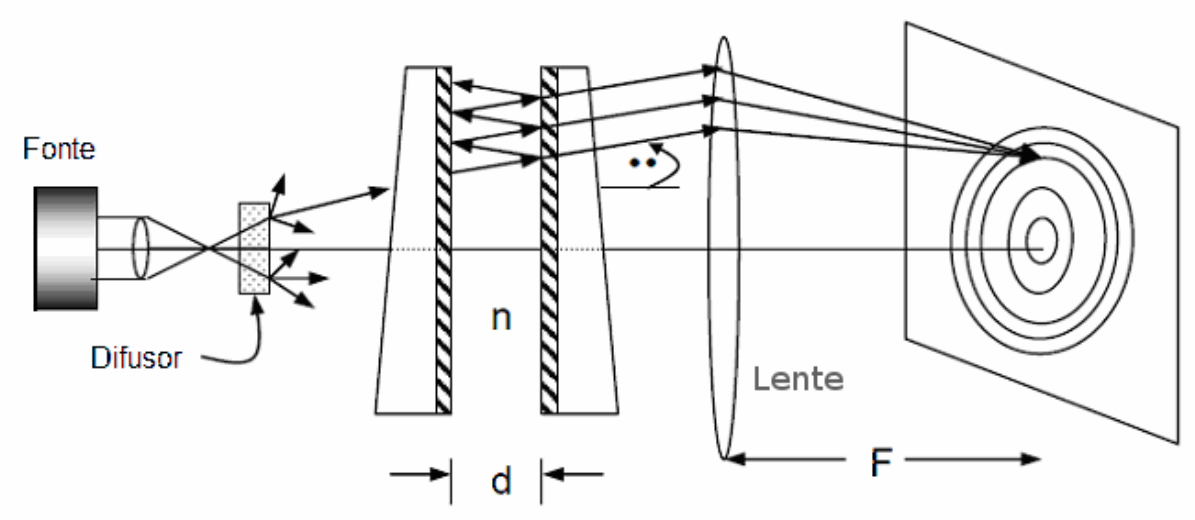

Figura 4.13 - Espectrômetro tipo varredura

\section{- Seletor de comprimento de onda do tipo matriz}

No seletor de comprimento de onda do tipo matriz de etalons Fabry-Perot (cavidades com distancia fixa entre refletores), o meio entre dois espelhos é um filme fino sólido. Cada um dos etalons é formado com largura ajustada para diferentes comprimentos de onda de ressonância. Debaixo de cada etalon um fotodetector é posicionado para medir a corrente elétrica associada com a radiação de comprimento de onda de ressonância correspondente. A Figura 4.14 mostra o espectrômetro tipo matriz. A luz incidente, $I$, é condicionada de tal maneira que todos os etalons são irradiados uniformemente e somente uma fração de toda a luz, $I / n$, encontra os etalons da matriz de n-etalons. A focalização de lentes não é necessária neste caso, pois os fotodetectores são posicionados diretamente debaixo dos etalons. 


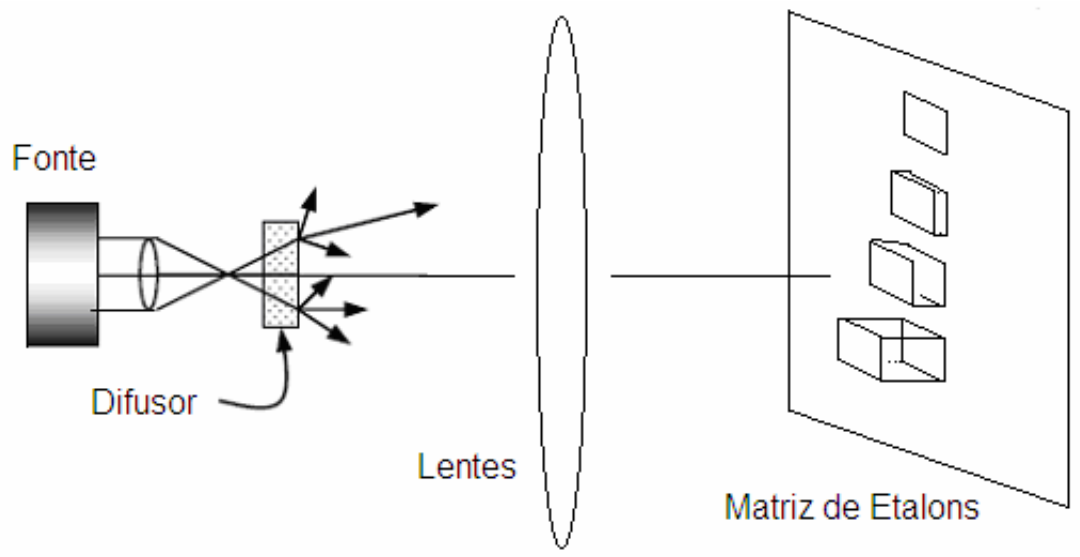

Figura 4.14 - Espectrômetro tipo matriz com etalons Fary-Perot, cada um com um fotodetector.

\subsubsection{Reconstrução do Espectro.}

Um espectro pode ser considerado como a soma de infinitas linhas espectrais monocromáticas de diferentes comprimentos de onda. Um espectrômetro produz uma saída elétrica que assim representa espectro da luz incidente. O espectro de uma fonte de luz então pode ser formado de linhas espectrais simples correspondentes ao comprimento de onda de ondas monocromáticas. Contudo, ao passar pelo espectrômetro o perfil da linha espectral tem uma largura finita (Figura 4.15).

a)

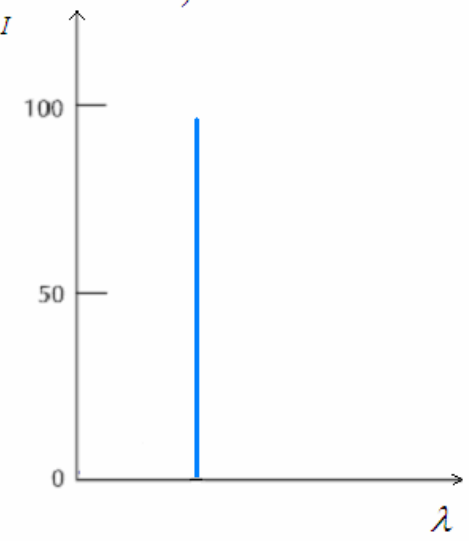

b)

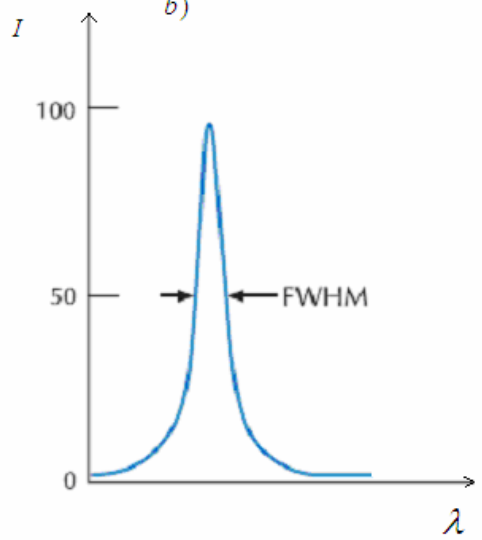

Figura 4.15- a) Espectro real de uma fonte de luz monocromática, registro de um espectrômetro "ideal", b) Registro do espectro com um instrumento real.

Então, a relação entre o perfil da linha espectral medida pelo espectrômetro (resposta a um impulso), o espectro de entrada e o espectro registrado, é definido por:

$$
R(\lambda)=L(\lambda) \bullet P(\lambda)
$$


onde $R(\lambda)$ é o espectro registrado pelo espectrômetro, $L(\lambda)$ o espectro de entrada a ser analisado e $P(\lambda)$ o perfil de linha do espectrômetro. A função gravada $R(\lambda)$ é a convolução do espectro de entrada e da linha do perfil do espectrômetro. O perfil da linha espectral do espectrômetro é função de vários parâmetros: a largura do feixe de entrada, do fenômeno de difração, da qualidade das deposições dos filmes, alinhamentos e aberrações.

O espectrômetro tipo matriz provê um número discreto de respostas espectrais determinado pelo número de canais da matriz de etalons (ajuste da faixa espectral). Se definimos uma matriz de $n$ etalons cobrindo a parte visível do espectro (390 - $760 \mathrm{~nm})$ e se a função resposta do comprimento de ondas para cada etalon é conhecida, o dispositivo pode reconstruir por simulação o espectro de emissão da fonte monitorada.

Considerando um espectrômetro formado por uma matriz de etalons de Fabry-Perot cada um com um detector adequado para um comprimento de onda e uma fonte de luz, que atinge a entrada deste dispositivo, com uma certa distribuição espectral $L(\lambda)$, a resposta individual de todos os etalons para toda faixa espectral pode fornecer a resposta completa do espectrômetro para todos os comprimentos de onda. Quando o espectro de entrada $L(\lambda)$ passa através do espectrômetro a saída é dada pelas $n$ correntes dos $n$ etalons $\left(I_{1}, I_{2}, \ldots, I_{n}\right)$.

Usando a teoria da matriz, é possível definir a matriz $I_{1 x n}$, que representa as correntes de saída do espectrômetro e a resposta do espectro de entrada a ser analisado. A matriz de calibração $C_{n n}$ contem a resposta individual de cada etalon sobre toda a faixa espectral com o incremento determinado pela resolução. O espectro registrado, fornecido pela matriz $R_{1 n}$, é a resposta do espectrômetro para o espectro de entrada na faixa espectral.

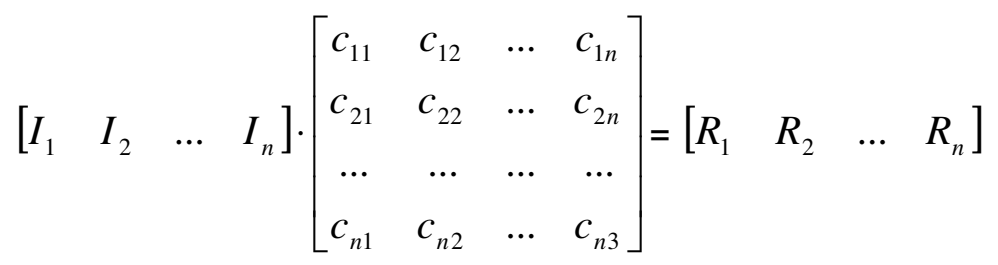

Este espectro registrado e definido como $R_{1 x n}$ é obtido com acurácia que depende do perfil de linha do espectrômetro e da luz dispersa (difusão para o componente óptico e incorreta iluminação do espectrômetro).

Para a otimização dos coeficientes $C$ da matriz para uma faixa específica de comprimentos de onda da fonte de luz de entrada, muitas técnicas de processamento de sinais são usadas para simular o espectro. 


\subsubsection{Cavidade ressonante de Fabry-Perot ajustável}

Muitos grupos de pesquisa atingiram pleno sucesso e ótimos resultados na obtenção de filtros ópticos ajustável de Fabry-Perot. Alguns utilizando o de ajuste mecânico, elétrico (eletrostático), eletro-mecânico (piezoatuadores), etc. Cada um dos conceitos atribui características peculiares e limitações aos dispositivos projetados. Pelo que foi tratado até aqui, a intensidade da luz transmitida através de um etalon na direção $\theta$ é dada pela fórmula de Airy:

$$
I(\delta)=\frac{I_{0}}{1+\frac{4 r}{(1-r)^{2}} \sin ^{2}\left(\frac{\delta}{2}\right)}
$$

Sendo que $\delta=\frac{2 \pi}{\lambda} 2 d \cos \theta, d$ é o gap da cavidade e $\mathrm{r}$ a refletividade dos refletores

Simulando alguns parâmetros na formula de Airy, constata-se que o ajuste ou sintonia de um espectrômetro de Fabry-Perot realiza-se de três maneiras diferentes:

1: Variando a distância do Gap,

2: Variando o ângulo de incidência, e

3: Variando o meio interno da cavidade (entre refletores).

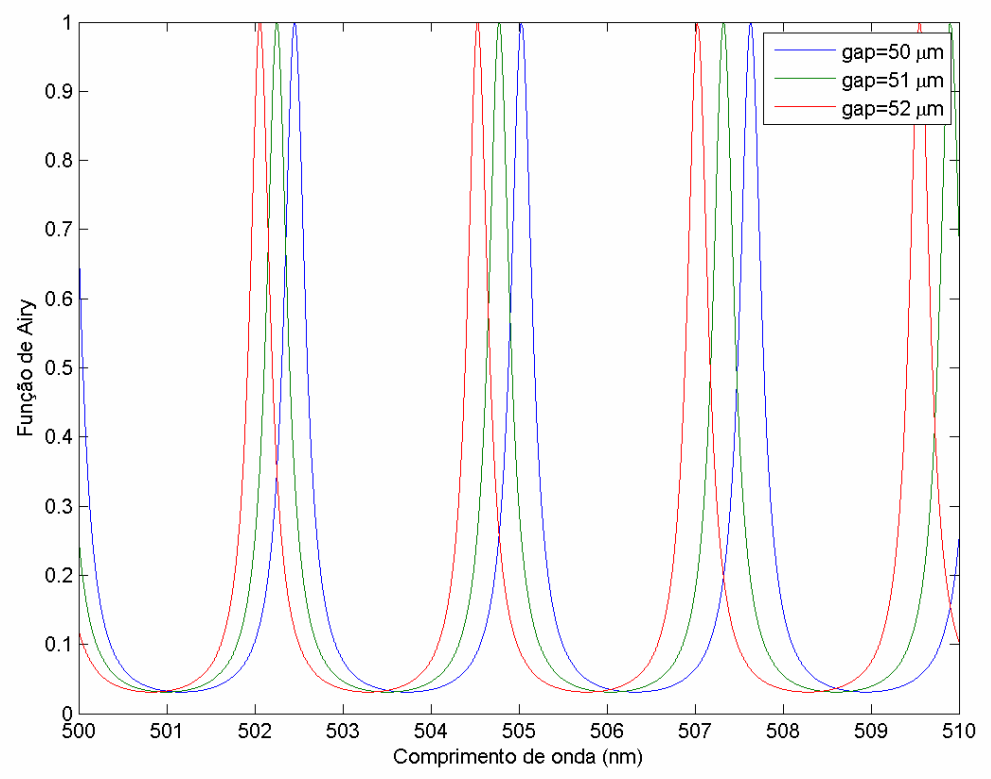

Figura 4.16 - Exemplo de ajustes da função de Airy pela variação do gap. 


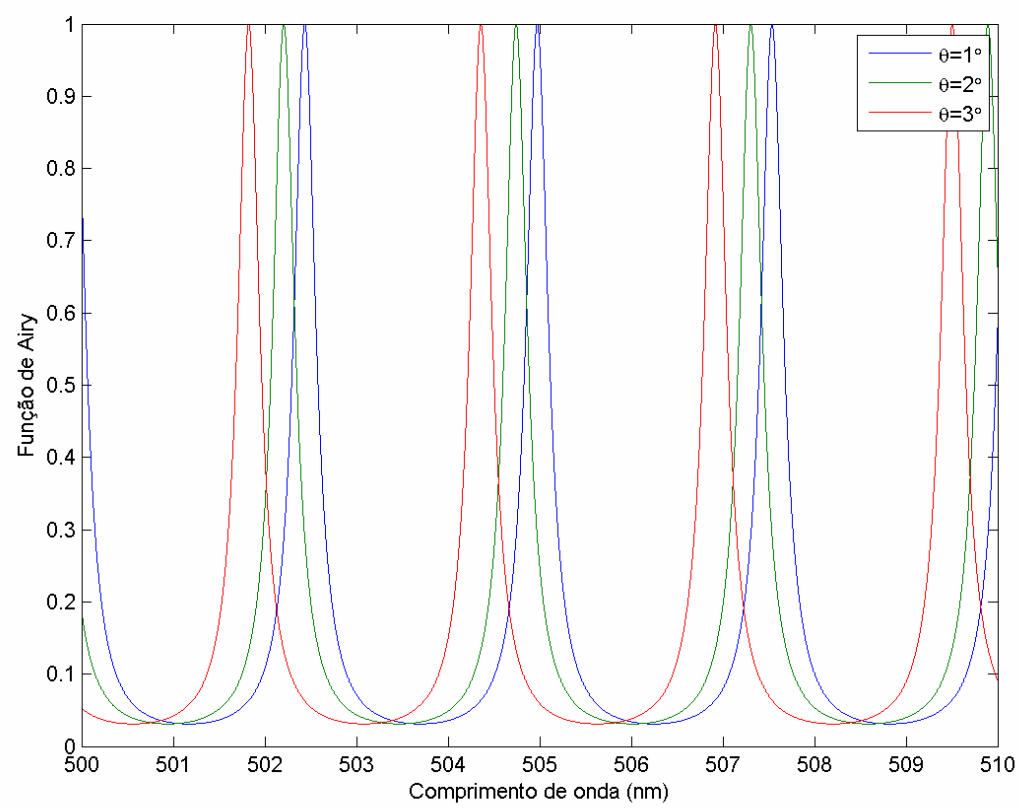

Figura 4.17 - Exemplo de ajuste da função de Airy pela variação do ângulo de incidência.

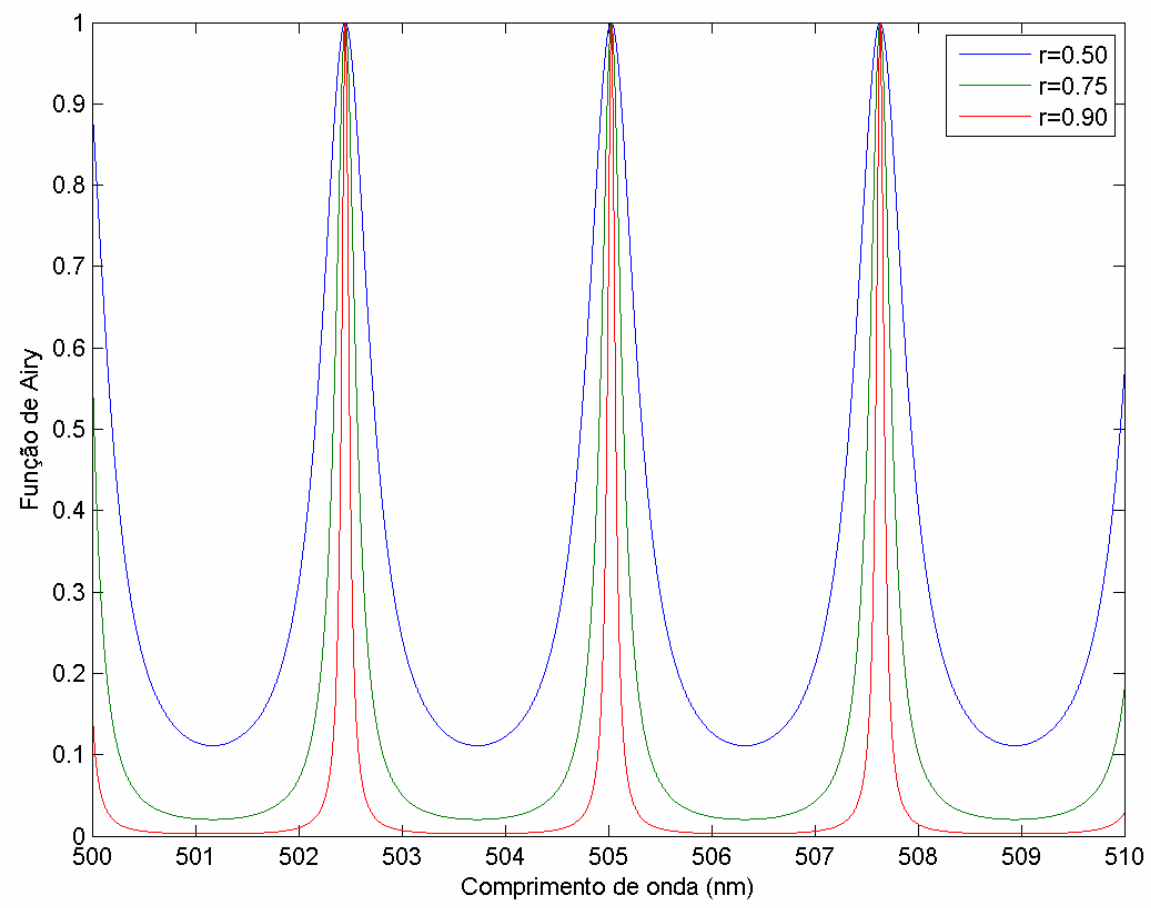

Figura 4.18 - Exemplo de ajuste da função de Airy pela variação do índice de refração do meio interno à cavidade. 


\section{Projeto do FIV}

Filtros de interferência são formados pela deposição de filmes finos em multicamadas de materiais dielétricos (refletores de Bragg) de maneira a formar, neste caso, filtros ópticos do tipo passa-banda. Quando se deseja obter um deslocamento da resposta em comprimentos de onda é necessário o ajuste de um dos parâmetros (gap, ângulo, meio) da fórmula de Airy Eq 4.91. No caso específico em que se deseja um deslocamento apreciável da resposta no comprimento de onda, em um dispositivo sem partes móveis, o recurso do ajuste do ângulo de incidência é proibitivo. Assim resta a alternativa do uso da variação do gap.

Este trabalho se propôs a realizar o estudo, projeto e construção de um filtro baseado na extensão do conceito da variação do gap para se atingir a condição em que ele possa variar linearmente ao longo de uma dimensão e, assim, com esta variação do parâmetro da cavidade, obter sintonia espectral linearmente variável ao longo desta dimensão.

Assim, dessa forma, estes filtros de interferência variável podem ser fabricados para oferecer uma variação da resposta espectral como uma função do espaço em uma ou duas dimensões, (que correspondem ao comprimento e a largura do filtro). Neste caso, é desejável uma diferença na espessura (inclinação) e com a largura o mais planar possível.

O filtro de interferência variável (FIV) de banda passante $\left(\lambda_{0}=671 \mathrm{~nm}\right)$ e de interferência variável, segundo o projeto apresentado na Tabela 5.2 (página 90), deve ter a espessura de cavidade, no centro do comprimento, 229,70nm. As propriedades de transmissão podem ser caracterizadas em algumas posições representativas ao longo do gradiente do filtro. Estas medidas implicam na caracterização do deslocamento do pico de transmissão em função do comprimento definido através da superfície do filtro e da largura a meia altura (FWHM).

\subsection{Aplicações e combinações do FIV}

Uma instalação possível é a combinação de um filtro de interferência variável (FIV) com um dispositivo selecionador de comprimentos de onda, segundo as indicações da Figura 5.1. O FIV define uma linha espectral estreita e o dispositivo selecionador (prisma, grade de difração ou um interferômetro) permite a determinação de linhas espectrais. Assim, cada uma das linhas do espectro selecionada pelo FIV pode ser decomposta pelo espectrômetro e analisado pelo detector. 


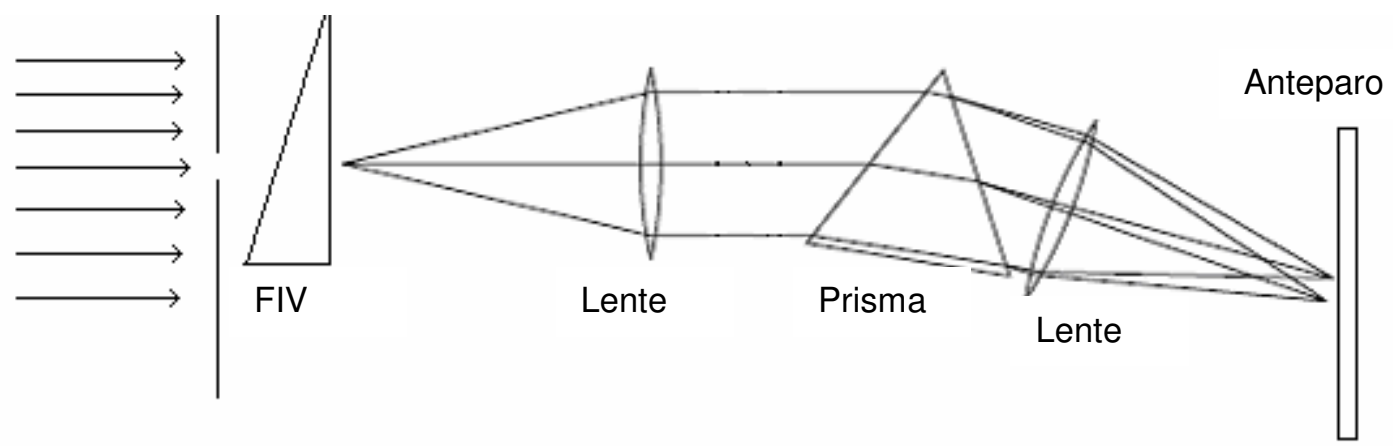

Figura 5.1 - Combinação de um FIV com um espectrômetro convencional de prisma.

Uma outra aplicação para realçar o contraste de um interferômetro é usar mais de um FIV.

FIV 1

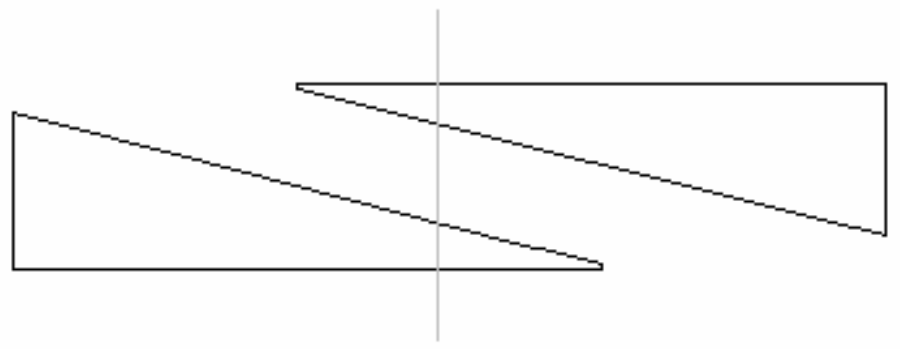

FIV 2

Figura 5.2 - Montagem com dois FIV.

Para superar o problema da faixa espectral livre, uma composição com dois FIVs deslizando um em relação ao outro em contraposição (Figura 5.2), pode ser usada para ressaltar a atenuação de ordens vizinhas. Em uma determinada posição coincidente tem-se uma janela espectral.

\subsection{Simulações}

Dispondo-se dos índices de refração e da espessura $(n i, d i)$ dos materiais utilizados numa deposição em pilha de filmes finos, é possível calcular as propriedades ópticas do filtro resultante. Mais precisamente, as propriedades ópticas dependem da relação da espessura óptica pelo comprimento de onda para cada camada (ni.di)/ $\lambda$.

Definimos, então, o projeto de um filtro de comprimento de onda central de $\lambda_{0}=671 \mathrm{~nm}$ (Tabela 5.1). O projeto do filtro com cavidade inclinada ainda não dispõem de um modelamento e de um software dedicado; assim os cálculos são realizados considerando- 
se uma superposição de vários filtros com os mesmos refletores e variando-se a espessura da cavidade. A superposição foi tomada como solução de projeto para o protótipo. Desta forma, nas simulações e no projeto foram utilizado os softwares: "TF-calc" [87] e "Design" [88], nas versões de demonstração, e o software livre "OpenFiltres" [78], com os quais são otimizados os parâmetros do filtro de interferência variável (FIV). Inicialmente projetamos um filtro óptico de banda estreita convencional (cavidade homogênea), mostrado na Tabela 5.1.

Tabela 5.1 - Projeto do filtro homogêneo de banda estreita $\lambda_{0}=671 \mathrm{~nm}$.

\begin{tabular}{|c|c|c|c|c|c|c|}
\hline & & Material & $\begin{array}{c}\text { Espessura } \\
\text { Óptica }\end{array}$ & $\begin{array}{l}\text { Índice de } \\
\text { Refração }\end{array}$ & $\begin{array}{c}\text { Espessura } \\
\text { (teoria) }\end{array}$ & $\begin{array}{c}\text { Espessura } \\
\text { Depositada }\end{array}$ \\
\hline 15 & $\leftarrow$ & $\mathrm{TiO}_{2}$ & $\lambda / 4$ & 2,28@671,0nm & $72,96 \mathrm{~nm}$ & $\mathrm{~nm}$ \\
\hline 14 & $\leftarrow$ & $\mathrm{SiO}_{2}$ & $\lambda / 4$ & 1,48@671,0nm & $114,90 \mathrm{~nm}$ & $n m$ \\
\hline 13 & $\leftarrow$ & $\mathrm{TiO}_{2}$ & $\lambda / 4$ & 2,28@671,0nm & $72,96 \mathrm{~nm}$ & $n m$ \\
\hline 12 & $\leftarrow$ & $\mathrm{SiO}_{2}$ & $\lambda / 4$ & 1,48@671,0nm & $114,90 \mathrm{~nm}$ & $n m$ \\
\hline 11 & $\leftarrow$ & $\mathrm{TiO}_{2}$ & $\lambda / 4$ & 2,28@671,0nm & $72,96 \mathrm{~nm}$ & $n m$ \\
\hline 10 & $\leftarrow$ & $\mathrm{SiO}_{2}$ & $\lambda / 4$ & 1,48@671,0nm & $114,90 \mathrm{~nm}$ & $n m$ \\
\hline 9 & $\leftarrow$ & $\mathrm{TiO}_{2}$ & $\lambda / 4$ & 2,28@671,0nm & $72,96 \mathrm{~nm}$ & $n m$ \\
\hline 8 & $\leftarrow$ & $\mathrm{SiO}_{2}$ & $\lambda / 2$ & 1,48@671,0nm & $229,79 \mathrm{~nm}$ & $n m$ \\
\hline 7 & $\leftarrow$ & $\mathrm{TiO}_{2}$ & $\lambda / 4$ & 2,28@671,0nm & $72,96 \mathrm{~nm}$ & $n m$ \\
\hline 6 & $\leftarrow$ & $\mathrm{SiO}_{2}$ & $\lambda / 4$ & 1,48@671,0nm & $114,90 \mathrm{~nm}$ & $n m$ \\
\hline 5 & $\leftarrow$ & $\mathrm{TiO}_{2}$ & $\lambda / 4$ & 2,28@671,0nm & $72,96 \mathrm{~nm}$ & $n m$ \\
\hline 4 & $\leftarrow$ & $\mathrm{SiO}_{2}$ & $\lambda / 4$ & 1,48@671,0nm & $114,90 \mathrm{~nm}$ & $n m$ \\
\hline 3 & $\leftarrow$ & $\mathrm{TiO}_{2}$ & $\lambda / 4$ & 2,28@671,0nm & $72,96 \mathrm{~nm}$ & $n m$ \\
\hline 2 & $\leftarrow$ & $\mathrm{SiO}_{2}$ & $\lambda / 4$ & 1,48@671,0nm & $114,90 \mathrm{~nm}$ & $n m$ \\
\hline \multirow[t]{2}{*}{1} & $\leftarrow$ & $\mathrm{TiO}_{2}$ & $\lambda / 4$ & 2,28@671,0nm & $72,96 \mathrm{~nm}$ & $n m$ \\
\hline & $\leftarrow$ & Quartzo & & 1.45 & & \\
\hline
\end{tabular}

Uma representação pictórica da pilha de camadas que compõe o filtro pode ser conforme a Figura 5.3.

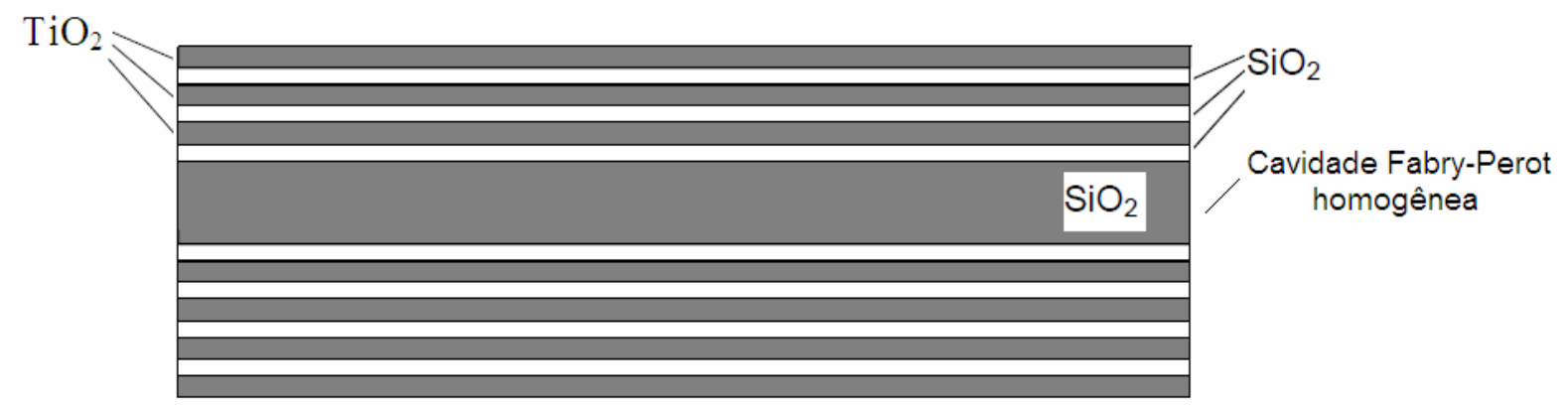

Figura 5.3 - Esquema do filtro homogêneo de banda estreita.

A resposta espectral deste filtro de gap homogêneo de 229,79nm, simulada no programa “Design" da TFG Software, é mostrada na Figura 5.4 


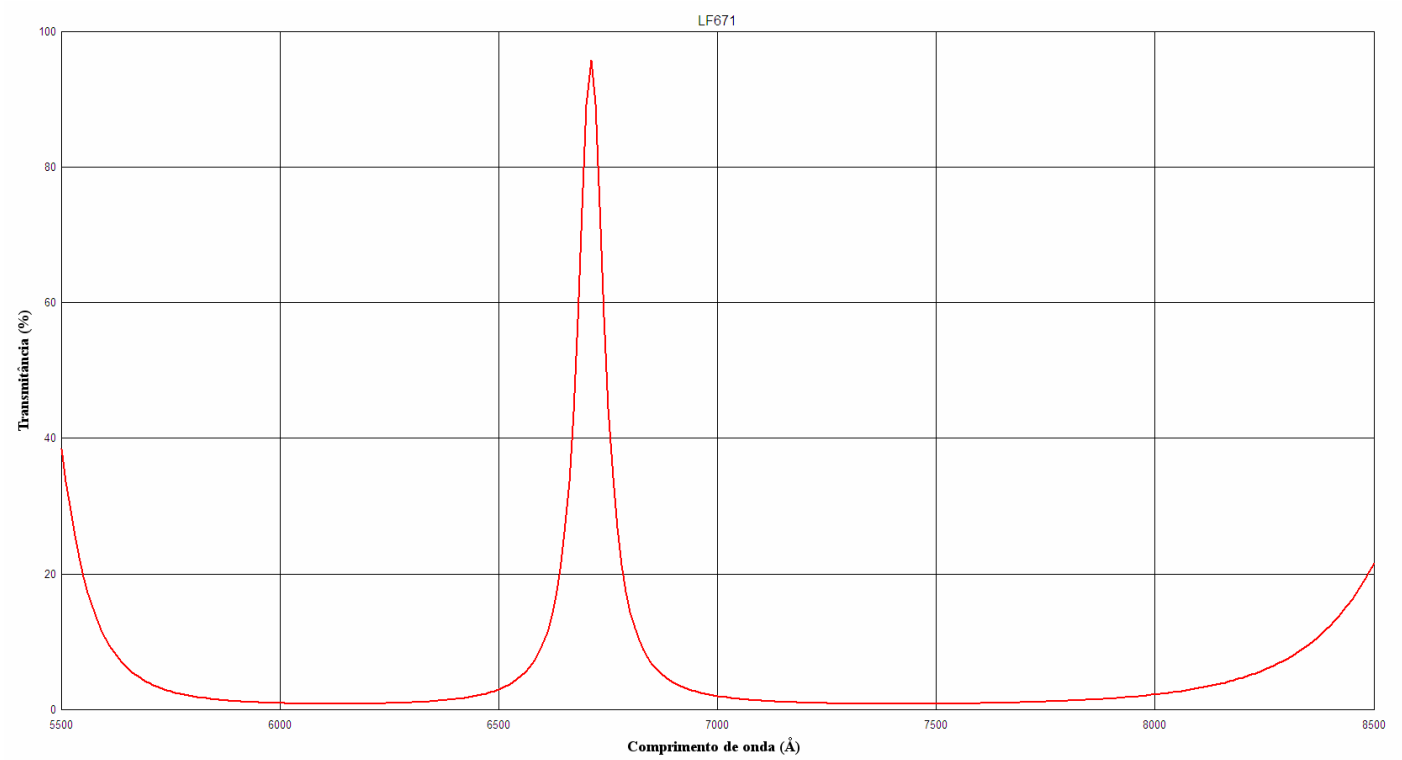

Figura 5.4 - Resposta espectral simulada do filtro homogêneo $\lambda_{0}=671 \mathrm{~nm}$ com, gap de 229,79nm .

Com base no filtro proposto na Tabela 5.1, e na superposição, é considerado o filtro FIV da Tabela 5.2, onde a espessura da camada de $\mathrm{SiO} 2$ correspondente à cavidade deve variar linearmente de 180 a $350 \mathrm{~nm}$.

Tabela 5.2 - Projeto do filtro FIV $671 \mathrm{~nm}$.

\begin{tabular}{|c|c|c|c|c|c|c|c|}
\hline \multirow{2}{*}{\multicolumn{2}{|c|}{$\begin{array}{c}229,79 \mathrm{~nm} \\
\square\end{array}$}} & & \multirow[b]{2}{*}{ Material } & \multirow[b]{2}{*}{$\begin{array}{c}\text { Espessura } \\
\text { Óptica }\end{array}$} & \multirow[b]{2}{*}{$\begin{array}{c}\text { Índice de } \\
\text { Refração }\end{array}$} & \multirow[b]{2}{*}{$\begin{array}{c}\text { Espessura } \\
\text { (teoria) }\end{array}$} & \multirow[b]{2}{*}{$\begin{array}{c}\text { Espessura } \\
\text { Depositada }\end{array}$} \\
\hline & & & & & & & \\
\hline 15 & & $\leftarrow$ & $\mathrm{TiO}_{2}$ & $\lambda / 4$ & 2,28@671,0nm & $72,96 \mathrm{~nm}$ & $\mathrm{~nm}$ \\
\hline 14 & & $\leftarrow$ & $\mathrm{SiO}_{2}$ & $\lambda / 4$ & 1,48@671,0nm & $114,90 \mathrm{~nm}$ & $n m$ \\
\hline 13 & & $\leftarrow$ & $\mathrm{TiO}_{2}$ & $\lambda / 4$ & 2,28@671,0nm & $72,96 \mathrm{~nm}$ & $\mathrm{~nm}$ \\
\hline 12 & & $\leftarrow$ & $\mathrm{SiO}_{2}$ & $\lambda / 4$ & 1,48@671,0nm & $114,90 \mathrm{~nm}$ & $n m$ \\
\hline 11 & & $\leftarrow$ & $\mathrm{TiO}_{2}$ & $\lambda / 4$ & 2,28@671,0nm & $72,96 \mathrm{~nm}$ & $n m$ \\
\hline 10 & & $\leftarrow$ & $\mathrm{SiO}_{2}$ & $\lambda / 4$ & 1,48@671,0nm & $114,90 \mathrm{~nm}$ & $n m$ \\
\hline 9 & & $\leftarrow$ & $\mathrm{TiO}_{2}$ & $\lambda / 4$ & 2,28@671,0nm & $72,96 \mathrm{~nm}$ & $n m$ \\
\hline 8 & & $\leftarrow$ & $\mathrm{SiO}_{2}$ & $\begin{array}{c}\lambda / 2 \\
(0,4-0.74)\end{array}$ & 1,48@671,0nm & $\begin{array}{r}229,79 \mathrm{~nm} \\
(180-350)\end{array}$ & $n m$ \\
\hline 7 & & $\leftarrow$ & $\mathrm{TiO}_{2}$ & $\lambda / 4$ & 2,28@671,0nm & $72,96 \mathrm{~nm}$ & $n m$ \\
\hline 6 & & $\leftarrow$ & $\mathrm{SiO}_{2}$ & $\lambda / 4$ & 1,48@671,0nm & $114,90 \mathrm{~nm}$ & $n m$ \\
\hline 5 & & $\leftarrow$ & $\mathrm{TiO}_{2}$ & $\lambda / 4$ & 2,28@671,0nm & $72,96 \mathrm{~nm}$ & $n m$ \\
\hline 4 & & $\leftarrow$ & $\mathrm{SiO}_{2}$ & $\lambda / 4$ & 1,48@671,0nm & $114,90 \mathrm{~nm}$ & $n m$ \\
\hline 3 & & $\leftarrow$ & $\mathrm{TiO}_{2}$ & $\lambda / 4$ & 2,28@671,0nm & $72,96 \mathrm{~nm}$ & $n m$ \\
\hline 2 & & $\leftarrow$ & $\mathrm{SiO}_{2}$ & $\lambda / 4$ & 1,48@671,0nm & $114,90 \mathrm{~nm}$ & $n m$ \\
\hline \multirow[t]{2}{*}{1} & & $\leftarrow$ & $\mathrm{TiO}_{2}$ & $\lambda / 4$ & 2,28@671,0nm & $72,96 \mathrm{~nm}$ & $n m$ \\
\hline & & $\leftarrow$ & Quartzo & & 1.45 & & \\
\hline
\end{tabular}

Uma representação pictórica da pilha de camadas que compõe o filtro pode ser conforme a Figura 5.5 onde se observa a cavidade não homogênea, isto é, inclinada linearmente. 


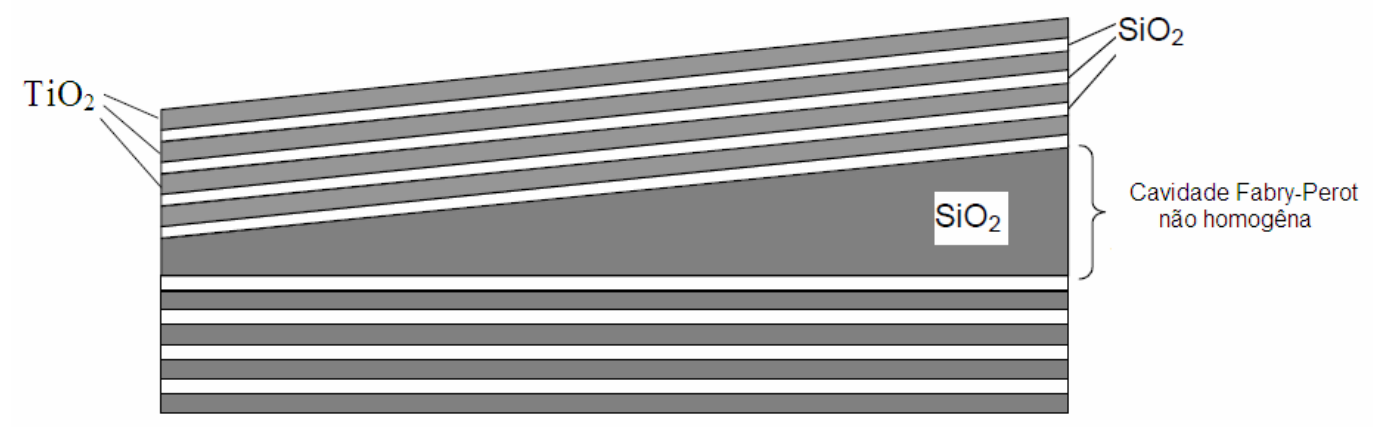

Figura 5.5 - Esquema pictórico do filtro dielétrico de interferência variável FIV de três fases de deposição.

A resposta do filtro convencional de banda estreita de gap de $229,79 \mathrm{~nm}$, simulada no programa "Design" da TFG Software, é mostrada na Figura 5.4

A Figura 5.6 mostra a sobreposição da resposta espectral do FIV para o gap variando de $183,85 \mathrm{~nm}$ a 344,69 nm em passos discretos, simulando a inclinação pretendida.

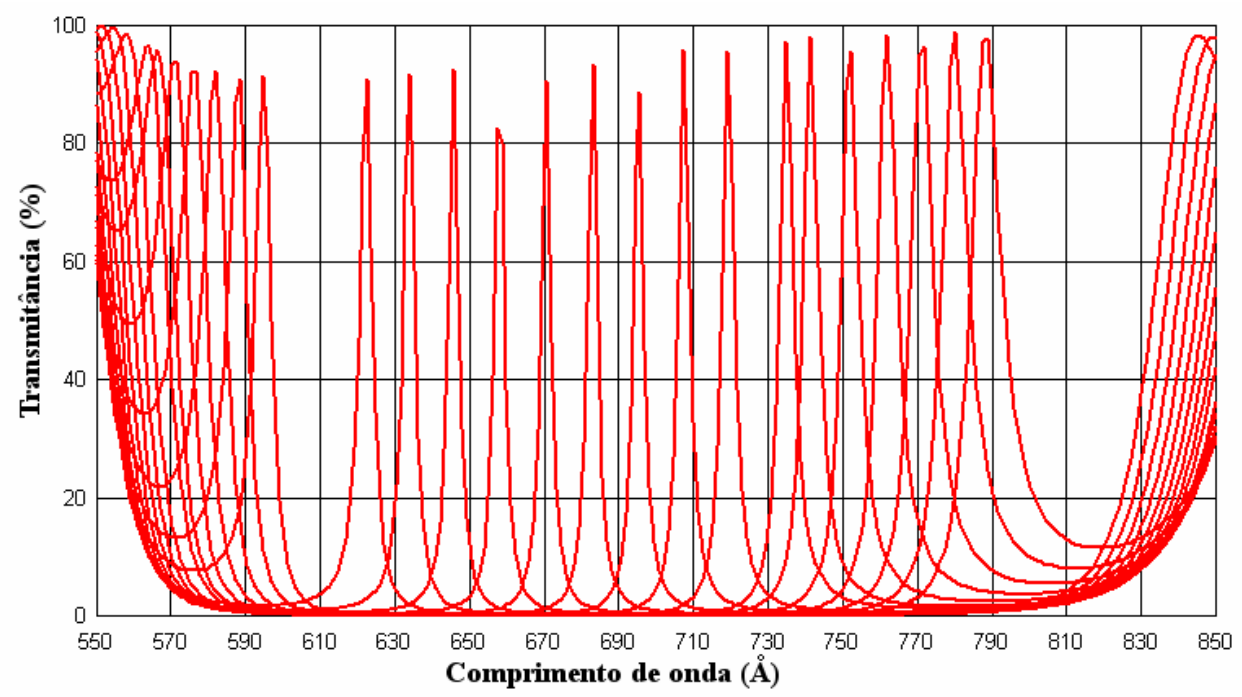

Figura 5.6 - Resposta espectral simulada de uma variação na espessura da cavidade não homogênea de $183,85 \mathrm{~nm}$ a 344,69 $\mathrm{nm}$ em passos de 1 QWOT=0.25 (diferença na espessura da cavidade de $160 \mathrm{~nm}$ indicada pela cunha no desenho).

\subsection{Modelo do processo de deposição}

Os processo de deposição usado neste trabalho é o PVD (Physical Vapor Deposition), nos métodos de evaporação por feixe de elétrons (e-beam) e o de evaporação térmica. Nos processos de deposição de filmes, ocorrem naturalmente variações de espessura sobre a 
superfície depositada. Assim, sempre que se deseja um filtro homogêneo, existe a necessidade de reduzir este fenômeno de maneira a manter as propriedades ópticas pela regularidade da deposição ao longo de toda a superfície. Para aumentar a uniformidade da espessura de deposição, o porta amostras normalmente é colocado a girar na parte superior da câmara de depósito [89].

Mas, por outro lado, neste caso, deseja-se aumentar a não-uniformidade da espessura do produto das deposições, porém de uma maneira controlada e com o objetivo de obter propriedades ópticas espaciais variáveis (gradiente em uma direção), de acordo com o ponto iluminado. Além disso, deseja-se que o filtro resultante seja capaz de resistir a ambientes severos e, para isso, a deposição deve ser realizada com materiais selecionados (materiais hard como, por exemplo, $\mathrm{SiO}_{2} \mathrm{e} \mathrm{TiO}_{2}$ em contraposição aos materiais soft como, por exemplo, $\mathrm{MgF}_{2}$, ou uma mistura $\mathrm{MgF}_{2}+\mathrm{BaF}_{2}$ e $\mathrm{ZnS}$ ) e por processos de deposição de alta energia.

O princípio básico adotado para deposição não uniforme consiste em usar uma máscara mecânica na câmara de deposição para obliterar o jato de material evaporado, controlando a distribuição da espessura. Especificamente é desejada uma deposição inclinada, em forma de cunha, e os parâmetros de ajuste para obter a inclinação da espessura desejada são, a forma da máscara de obliterar (doravante denominada de máscara) e a trajetória da amostra durante processo de deposição, como mostrado na Figura 5.7.

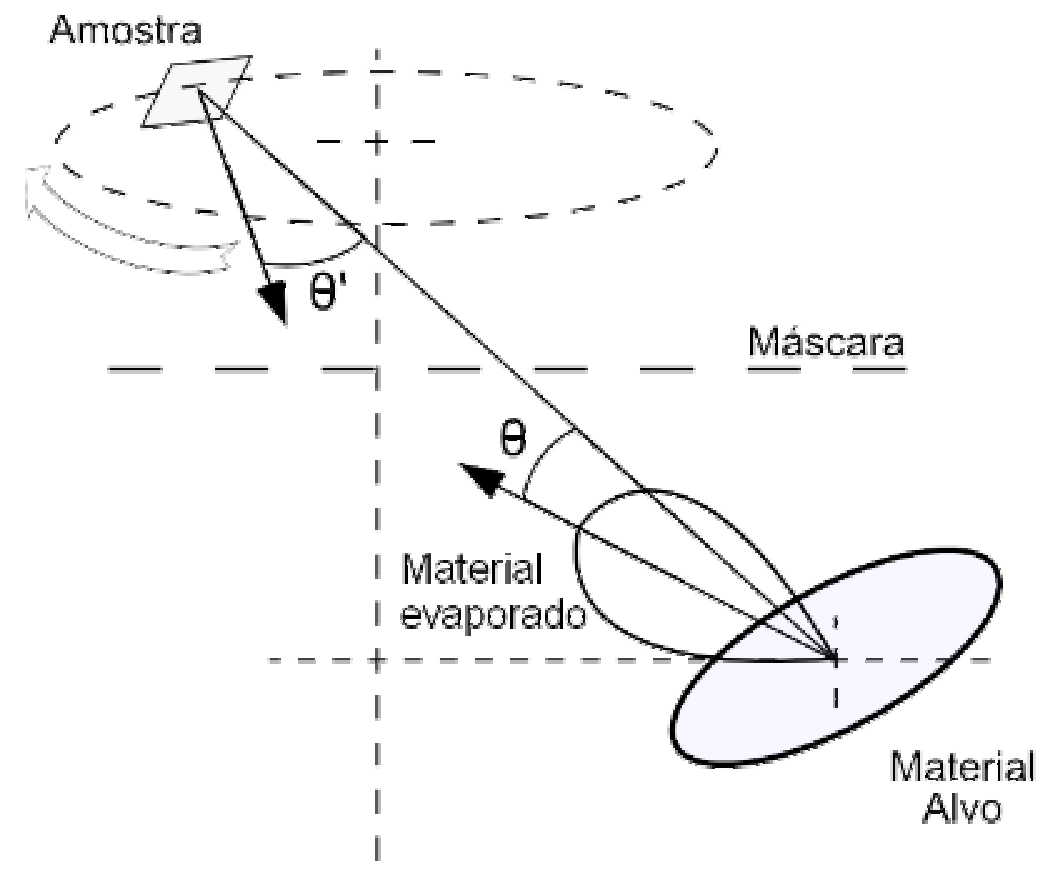

Figura 5.7 - Representação da geometria do processo de deposição. Reproduzido de [89]. 
Como não há disponibilidade de equipamento para essas deposições não uniformes e controladas, houve a necessidade de projetar e produzir uma máscara mecânica a ser adaptada no interior da câmara de deposição, entre o alvo e as amostras, de uma evaporadora BALZER PLS-500, como mostra a Figura 5.8.

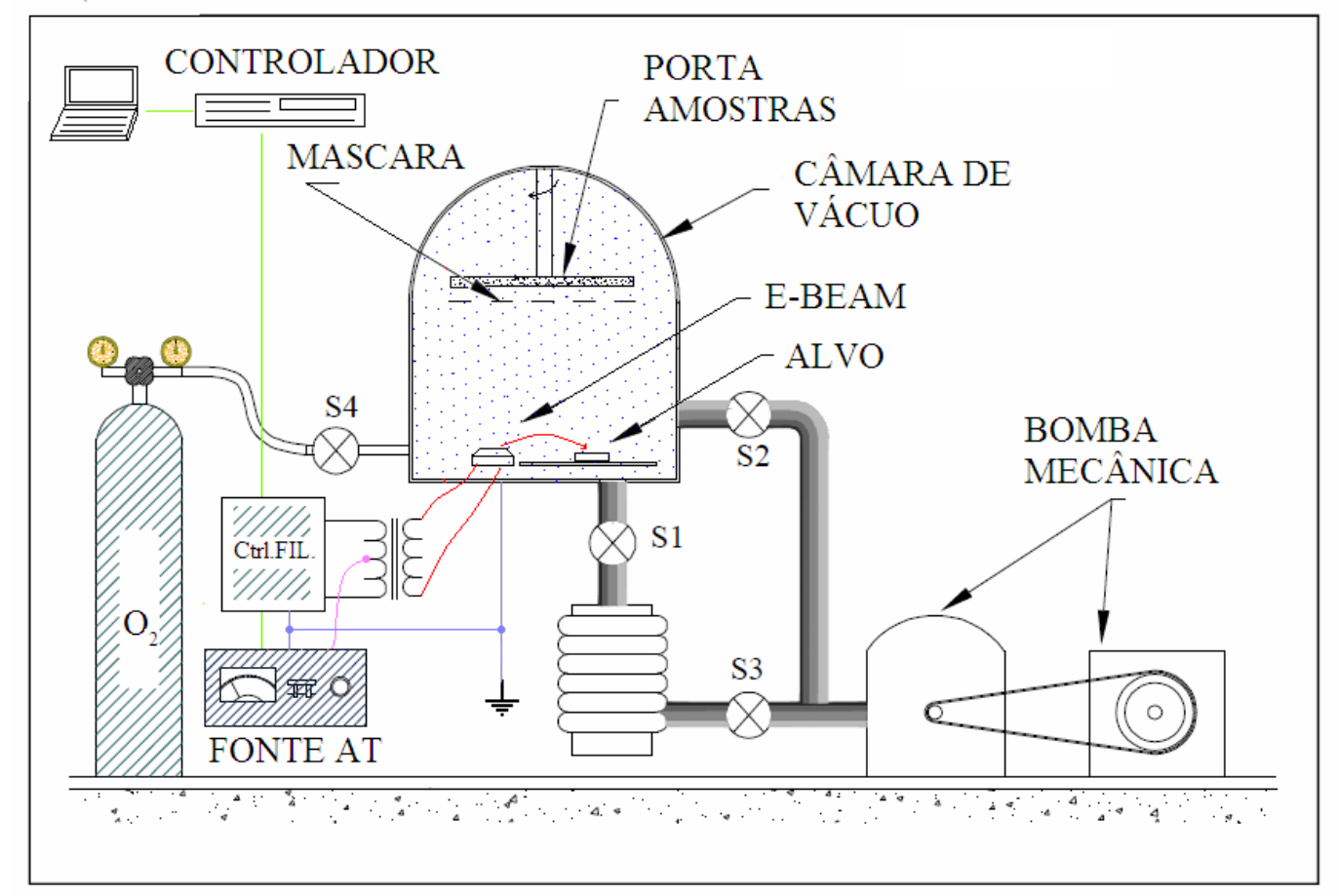

Figura 5.8 - Representação pictórica do equipamento PLS-500 adaptado.

Na prática da construção do filtro com camada inclinada, apresentou-se a questão das alterações necessárias no equipamento de deposição para adaptá-lo a essa nova finalidade. Assim determinou-se que a máscara fosse independente do equipamento. Dessa maneira, considerando essas limitações, é projetada uma máscara adaptável e removível. Essa condição de projeto produziu uma limitação grave nas tarefas de execução dos trabalhos: a necessidade da deposição em três fases com a quebra do vácuo na fase de deposição da camada central (cavidade).

No caso do uso da máscara entre o alvo e a amostra, a influência da máscara utilizada pode ser avaliada para um conjunto de pontos selecionados na amostra. A máscara a ser fixada no interior da câmara entre o alvo e as amostras é ilustrada na Figura 5.9 [89]. 


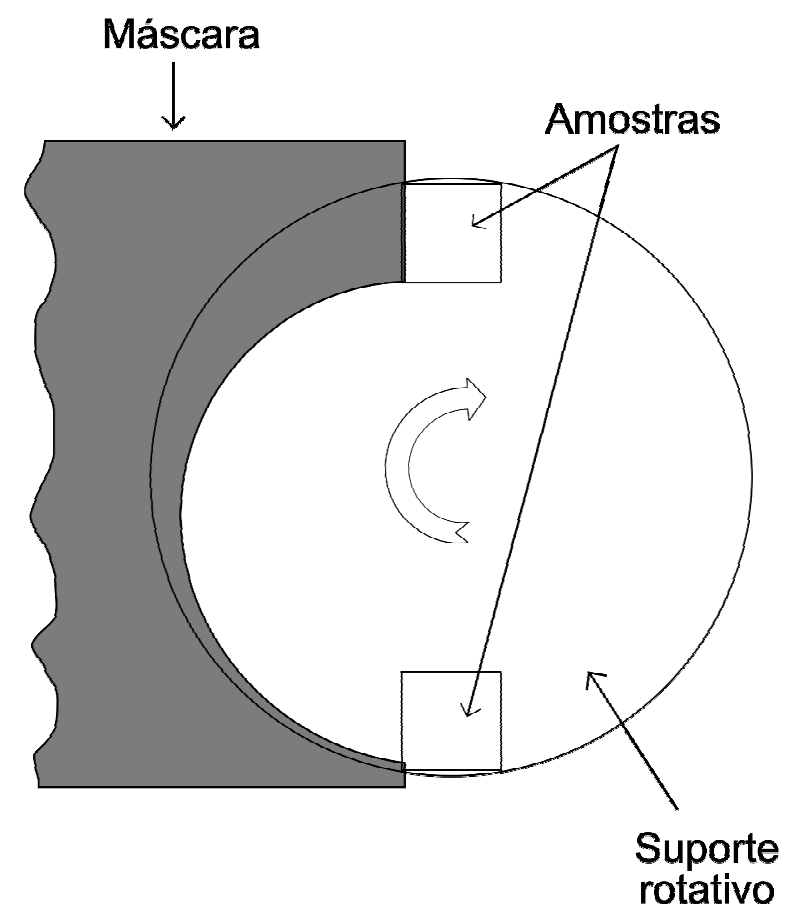

Figura 5.9 - Ilustração da máscara estática proposta e da rotação das amostras.

O equipamento utilizado neste trabalho e a equipe técnica especializada na operação do mesmo pertence ao Laboratório de Filmes Finos do Centro de Laser e Aplicações (CLA) do IPEN, Instituto de Pesquisas Energéticas e Nucleares, que dispõem de uma evaporadora Balzer PLS 500 que conta com bomba mecânica e bomba turbo refrigerada a água. O sistema possui duas fontes de evaporação, resistiva e o por feixe de elétrons, que são utilizadas neste caso. A limpeza dos substratos é feita por processos químicos e físicos antes de serem dispostas na câmara de evaporação e, no interior da mesma, pode-se dispor de um processo de "glow discharge" para assistir o abaixamento da pressão. O monitoramento da espessura é feito através da variação de freqüência de um cristal oscilador acoplado ao sistema de controle e situado no interior da câmara. Este cristal possui uma freqüência própria de vibração que é uma função da sua espessura. O PLS 500 conta com um dispositivo que permite girar e ajustar a rotação do dispositivo porta amostras (planetário), Figura 5.10. O equipamento possui também um sistema de aquecimento de substratos que ajustamos para $150^{\circ} C$. A pressão inicial utilizada é da ordem de $10^{-6} \mathrm{mbar}$ e injetou-se, durante a deposição, gás oxigênio a uma pressão de $2.10^{-4}$ mbar para possibilitar a correta estequiometria na deposição do $\mathrm{TiO}_{2}$ [90] e a pressão de processo na evaporadora foi de $5^{-4}$ mbar. Para as medidas experimentais de caracterização utilizou-se o espectrofotômetro Cary 17D, e um suporte posicionador mecânico, pertencente ao CLA-IPEN e o espectrofotômetro UV VIS IR, marca Perkin Elmer, 
modelo lambda 900, pertencente ao Laboratório de Óptica do Instituto de Pesquisas Tecnológicas do Estado de São Paulo - IPT.

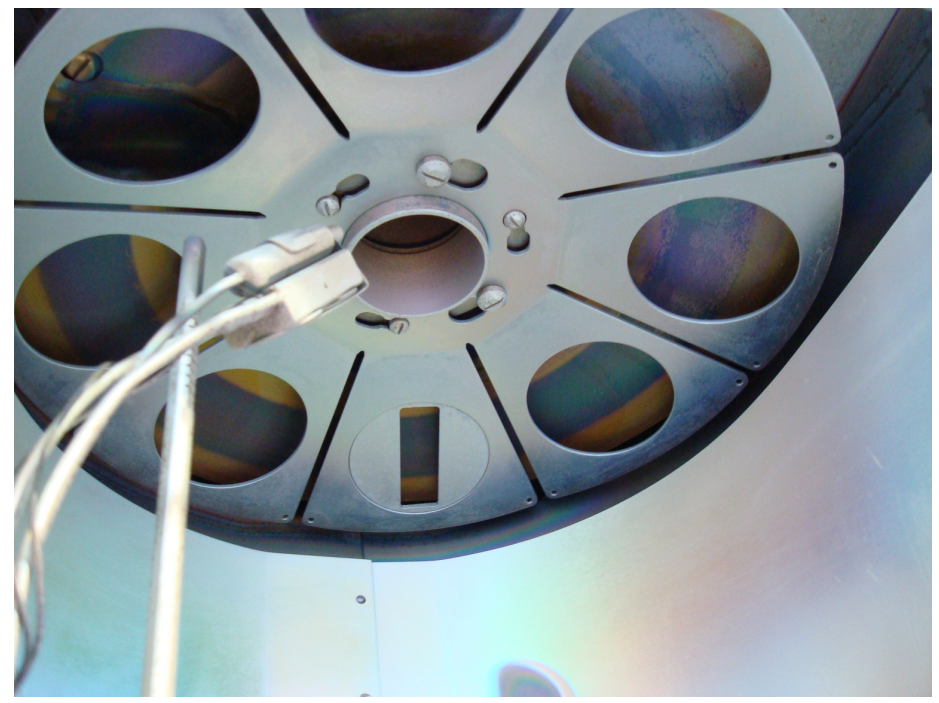

Figura 5.10 - Foto do porta amostras da câmara de deposição, sem a máscara.

Diversos parâmetros que dependem do material e outros relacionados ao equipamento, tais como o sentido e a direcionalidade da fonte evaporadora, inicialmente não eram muito consistentes e, portanto, a previsibilidade era baixa. Contudo, foi utilizada a estratégia de depositar camada única de material em grandes substratos para aperfeiçoar os parâmetros até alcançar uma boa concordância entre as distribuições desejadas e as obtidas nas medidas da espessura.

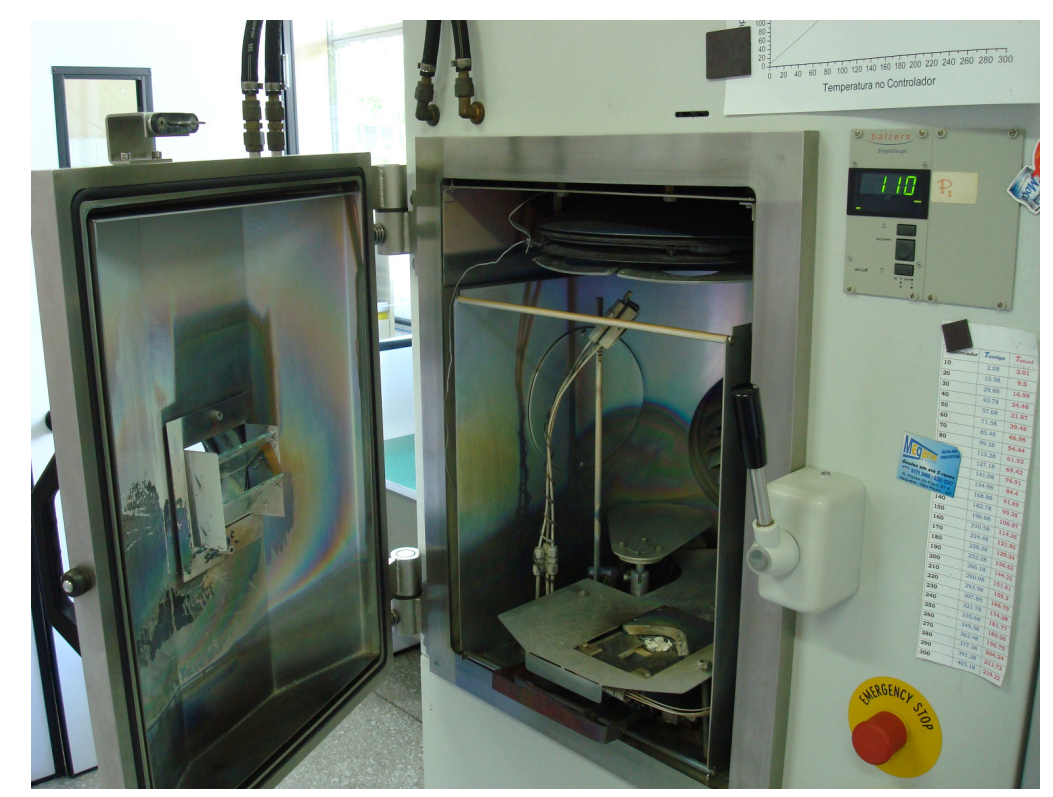

Figura 5.11 - Foto da câmara de depósito sem o mecanismo de máscara.

Inicialmente utilizou-se o equipamento PLS-500 (Figura 5.11) para testes e ajustes, 
quando foram obtidas algumas amostras de filtros de banda estreita usando os chamados materiais moles $\left(\mathrm{MgF}_{2}\right.$ e $\left.\mathrm{ZnS}\right)$.

Tabela 5.3 - Projeto do filtro homogêneo de banda estreita $655 \mathrm{~nm}$.

\begin{tabular}{|c|c|c|c|c|c|c|}
\hline & & Material & $\begin{array}{c}\text { Espessura } \\
\text { Óptica }\end{array}$ & $\begin{array}{l}\text { Índice de } \\
\text { Refração }\end{array}$ & $\begin{array}{c}\text { Espessura } \\
\text { (teoria) }\end{array}$ & $\begin{array}{c}\text { Espessura } \\
\text { Depositada }\end{array}$ \\
\hline 15 & $\leftarrow$ & $\mathrm{ZnS}$ & $\lambda / 4$ & $2.42 @ 655,0 \mathrm{~nm}$ & $54,10 \mathrm{~nm}$ & $n m$ \\
\hline 14 & $\leftarrow$ & $\mathrm{MgF}_{2}$ & $\lambda / 4$ & 1.37@655.,nm & $95,70 \mathrm{~nm}$ & $n m$ \\
\hline 13 & $\leftarrow$ & $\mathrm{ZnS}$ & $\lambda / 4$ & 2.42@655,0nm & $54,10 \mathrm{~nm}$ & $n m$ \\
\hline 12 & $\leftarrow$ & $\mathrm{MgF}_{2}$ & $\lambda / 4$ & 1.37@655,0nm & $95,70 \mathrm{~nm}$ & $n m$ \\
\hline 11 & $\leftarrow$ & $\mathrm{ZnS}$ & $\lambda / 4$ & 2.42@655,0nm & $54,10 \mathrm{~nm}$ & $\mathrm{~nm}$ \\
\hline 10 & $\leftarrow$ & $\mathrm{MgF}_{2}$ & $\lambda / 4$ & 1.37@655,0nm & $95,70 \mathrm{~nm}$ & $\mathrm{~nm}$ \\
\hline 9 & $\leftarrow$ & $\mathrm{ZnS}$ & $\lambda / 4$ & 2.42@655,0nm & $54,10 \mathrm{~nm}$ & $\mathrm{~nm}$ \\
\hline 8 & $\leftarrow$ & $\mathrm{MgF}_{2}$ & $\lambda / 2$ & 1.37@655,0nm & $191,40 \mathrm{~nm}$ & $n m$ \\
\hline 7 & $\leftarrow$ & $\mathrm{ZnS}$ & $\lambda / 4$ & 2.42@655,0nm & $54,10 \mathrm{~nm}$ & $n m$ \\
\hline 6 & $\leftarrow$ & $\mathrm{MgF}_{2}$ & $\lambda / 4$ & 1.37@655,0nm & $95,70 \mathrm{~nm}$ & $\mathrm{~nm}$ \\
\hline 5 & $\leftarrow$ & $\mathrm{ZnS}$ & $\lambda / 4$ & 2.42@655,0nm & $54,10 \mathrm{~nm}$ & $\mathrm{~nm}$ \\
\hline 4 & $\leftarrow$ & $\mathrm{MgF}_{2}$ & $\lambda / 4$ & 1.37@655,0nm & $95,70 \mathrm{~nm}$ & $\mathrm{~nm}$ \\
\hline 3 & $\leftarrow$ & $\mathrm{ZnS}$ & $\lambda / 4$ & 2.42@655,0nm & $54,10 \mathrm{~nm}$ & $n m$ \\
\hline 2 & $\leftarrow$ & $\mathrm{MgF}_{2}$ & $\lambda / 4$ & 1.37@655,0nm & $95,70 \mathrm{~nm}$ & $n m$ \\
\hline \multirow[t]{2}{*}{1} & $\leftarrow$ & $\mathrm{ZnS}$ & $\lambda / 4$ & 2.42@655,0nm & $54,10 \mathrm{~nm}$ & $n m$ \\
\hline & $\leftarrow$ & Quartzo & & 1.45 & & \\
\hline
\end{tabular}

A Figura 5.12 mostra estes filtros, com a chamada cavidade homogênea conforme o projeto da Tabela 5.3, que foram caracterizados em relação as sua resposta espectral, através do espectrofotômetro Cary 17D com resolução de $0,5 \mathrm{~nm}$, e cujos gráficos são apresentados na Figura 5.13, na Figura 5.13 e na Figura 5.15.
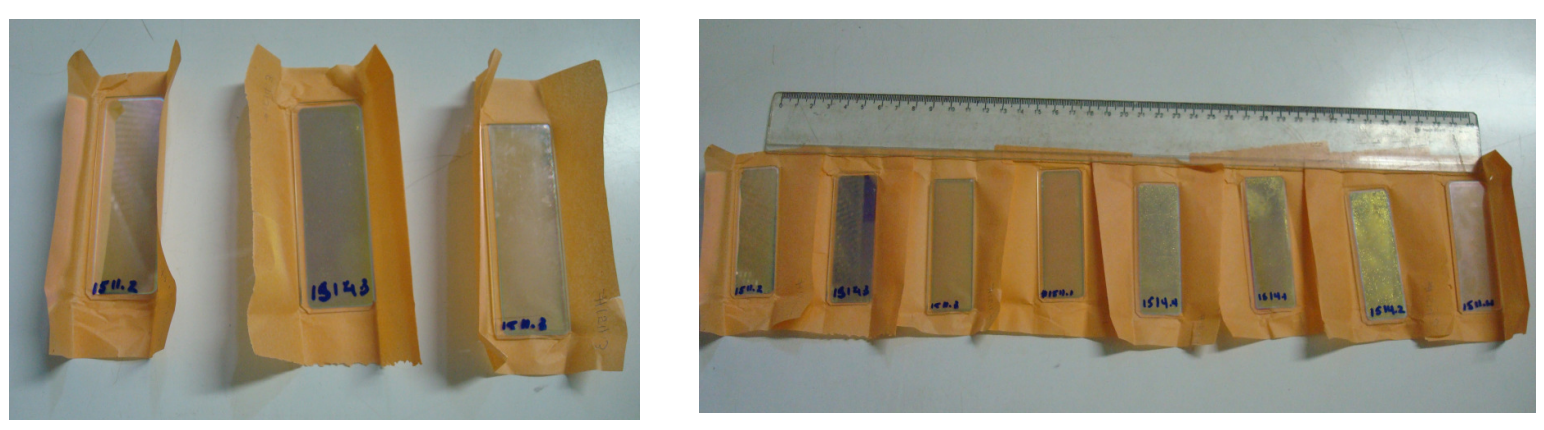

Figura 5.12 - Alguns Filtros produzidos com cavidade homogêneas.

$\mathrm{Na}$ deposição destes filmes, considerou-se que o planetário suporte das amostras é formado por uma calota côncava que gira no interior da evaporadora. Escolheu-se substratos grandes para ressaltar os efeitos dos parâmetros de deposição, e, pretendendo estudar a 
influência do posicionamento das amostras na espessura do material depositado, sendo a posição mais favorável para a deposição uniforme a posição tangencial, fixou-se a amostra na posição radial (Figura 5.10).

Filtro Banda Estreita (652nm)

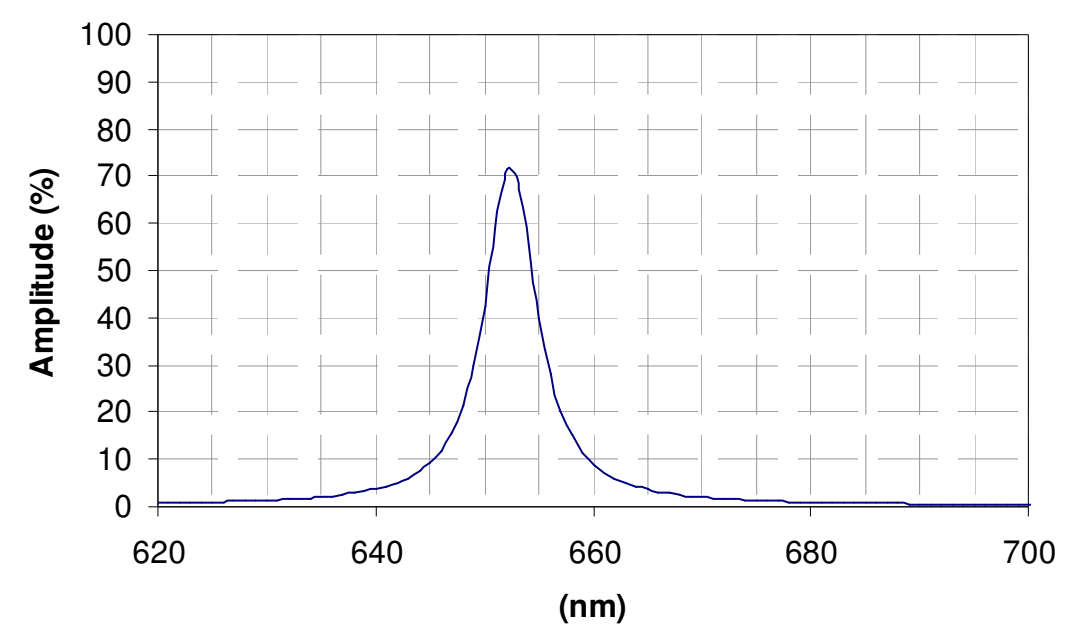

Figura 5.13 - Espectro da amostra na posição n.1 $\left(\lambda_{0}=655,0 \mathrm{~nm}\right)$.

Observou-se no espectro do filtro de linha resultante (Figura 5.13) que o pico de transmitância em uma posição fixa em um dos extremos da amostra ocorre em $652 \mathrm{~nm}$, sendo que o comprimento de onda central previsto deste filtro é $\lambda_{0}=655 \mathrm{~nm}$.

\section{Filtro Banda Estreita (655nm)}

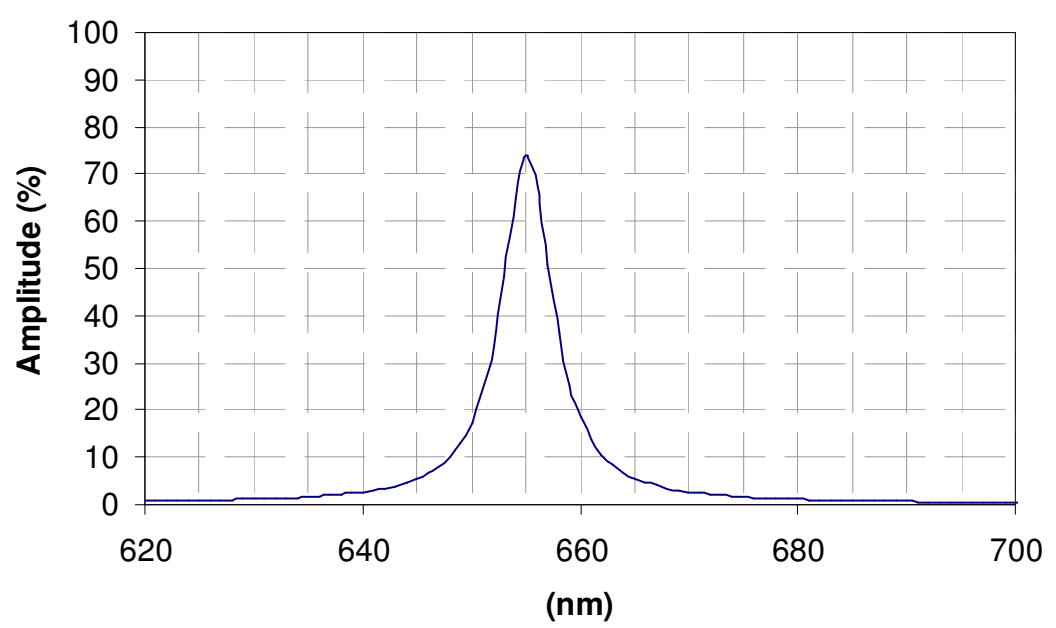

Figura 5.14 - Espectro da amostra na posição central n.2 $\left(\lambda_{0}=655,0 \mathrm{~nm}\right)$. 
O espectro desta amostra obtido para a posição central (Figura 5.14) apresenta o pico de transmissão em $655 \mathrm{~nm}$, conforme esperado.

E o espectro obtido para o extremo oposto da lâmina é apresentado na Figura 5.15, onde se observa que o pico de transmissão é de $657 \mathrm{~nm}$.

Filtro Banda Estreita $(657 \mathrm{~nm})$

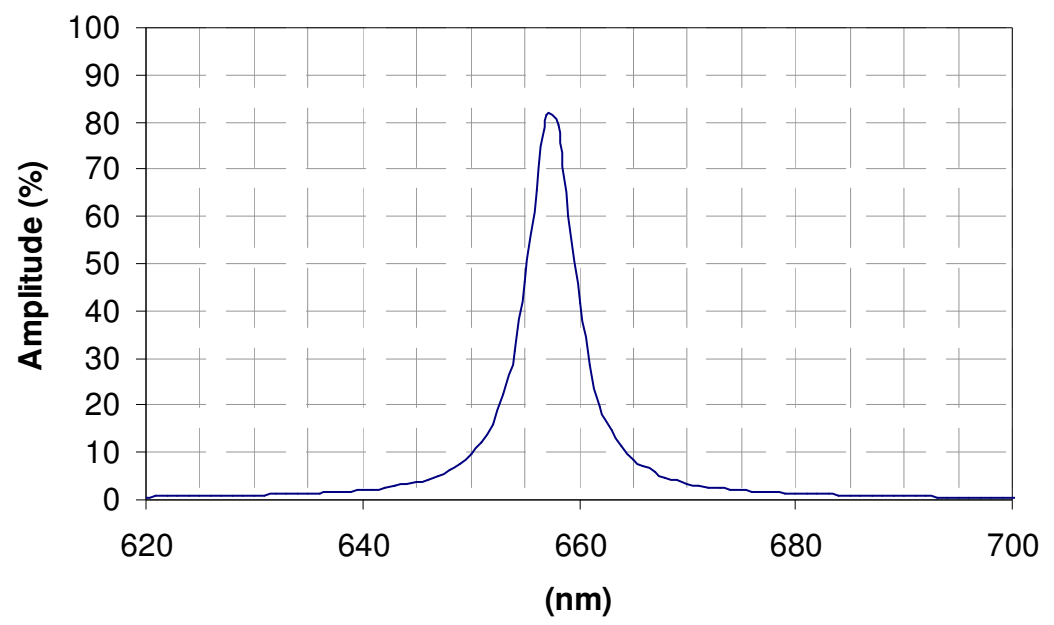

Figura 5.15 - Espectro da amostra na posição n.3 $\left(\lambda_{0}=655,0 \mathrm{~nm}\right)$.

Verificou-se que o efeito da posição da amostra sobre as deposições pode ser considerado marginal, em relação comprimento da mesma, da ordem de $10^{-2} \mathrm{~nm} / \mathrm{mm}$.

$\mathrm{Na}$ continuidade dos trabalhos o projeto da máscara, necessária às deposições das camadas inclinadas, segue o seguinte caminho: determinação do local e da posição da instalação, determinação do formato e caracterização da mesma.

O local e a posição da instalação da máscara no interior da câmara deve ser entre o alvo e as amostras. 


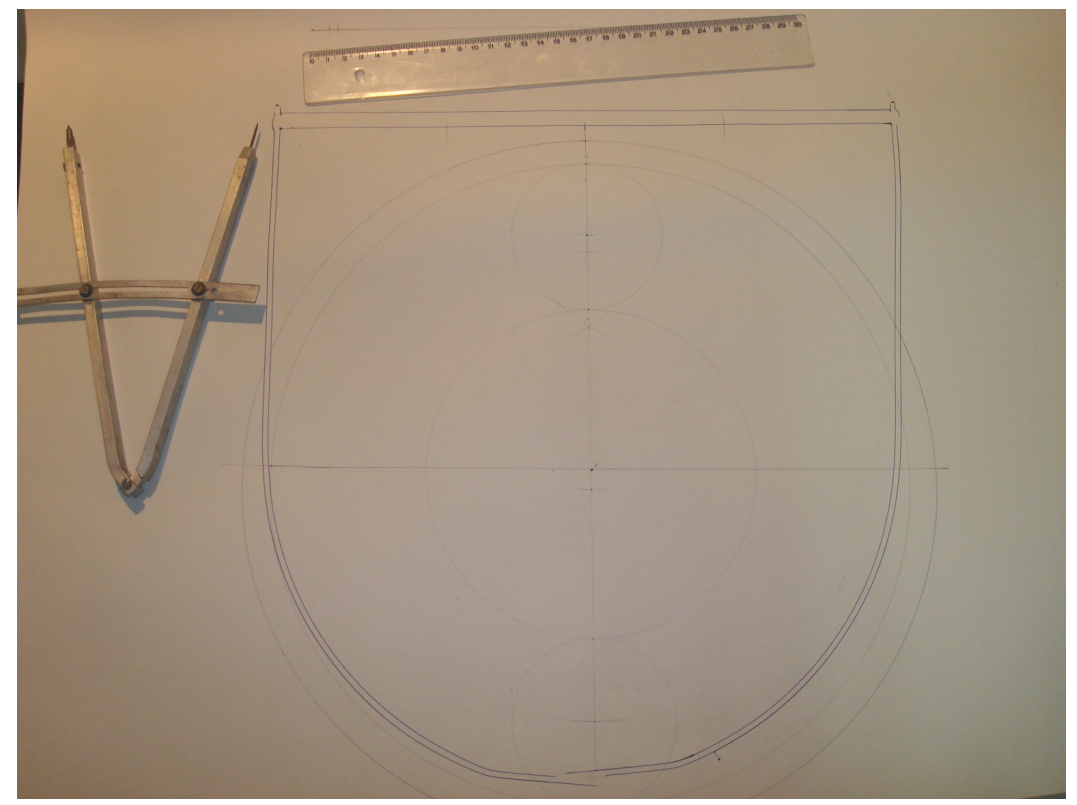

Figura 5.16 - Alocação do espaço horizontal entre o alvo a o porta amostra para acomodar a máscara.

Segue-se a essa alocação do espaço apropriado a receber a máscara Figura 5.16, a realização de simulações para obter a forma adequada da máscara.

Para se obter uma deposição linear em forma de rampa em uma dimensão da amostra, o formato do contorno pretendido, considerando a rotação do porta-amostra, foi selecionado como sendo um ramo de espiral disposto entre um raio menor e um raio maior determinados pelo comprimento da amostra. Tal contorno, realizado em uma lâmina, forma a máscara de sombreamento para as deposições que deve ser instalada entre a fonte do material evaporado e o porta-amostra girante e numa determinada posição próxima das amostras. Para esta seleção e escolha, foi elaborada uma rotina no programa Matlab que simula a situação de uma deposição com taxa constante na qual foi possível se analisar a influencia de diversos perfis para a máscara de deposição. A Figura 5.17 mostra um exemplo do resultado de uma simulação para uma máscara com um perfil de espiral logarítmica. 

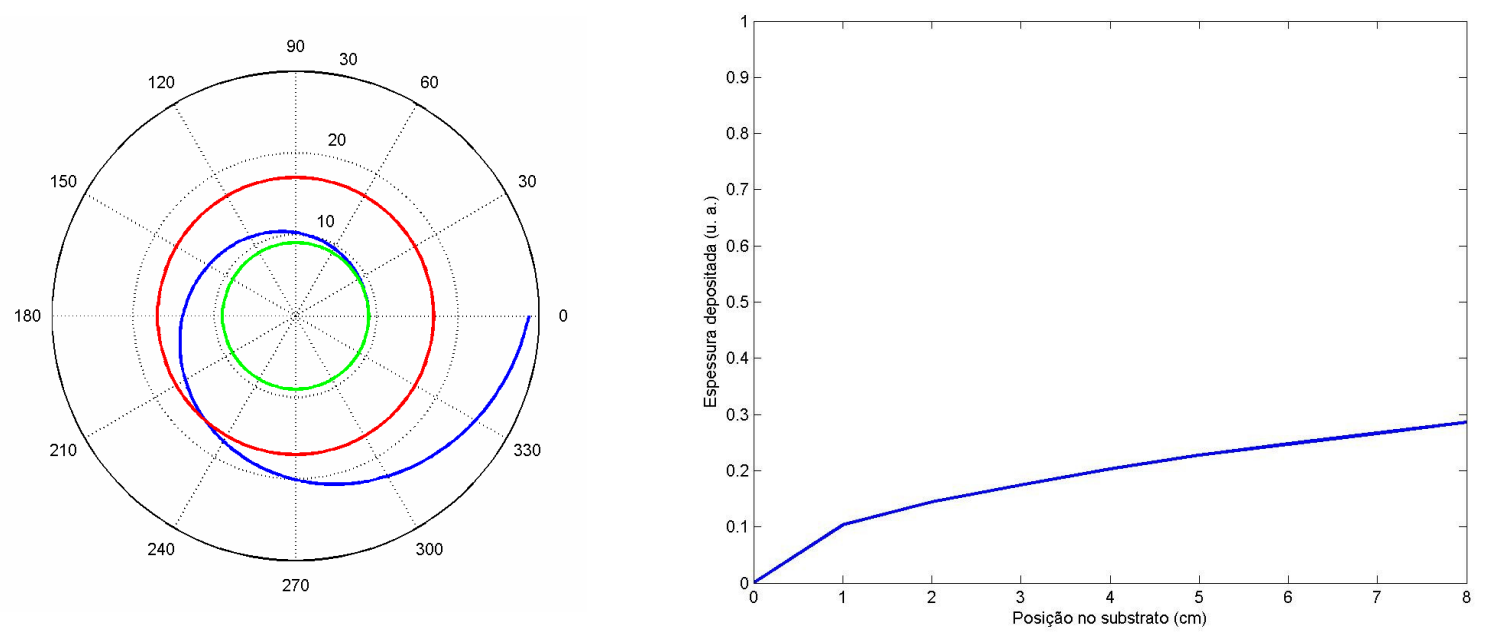

Figura 5.17 - (a) Perfil simulado: ramo da espiral logarítmica. Em verde é mostrado o raio mínimo na amostra, em vermelho o raio máximo e em azul o perfil da máscara.(b) Resultado da simulação para a espessura depositada.

A Figura 5.18 mostra o resultado da simulação da deposição com uma máscara cujo perfil é uma espiral arquimediana.
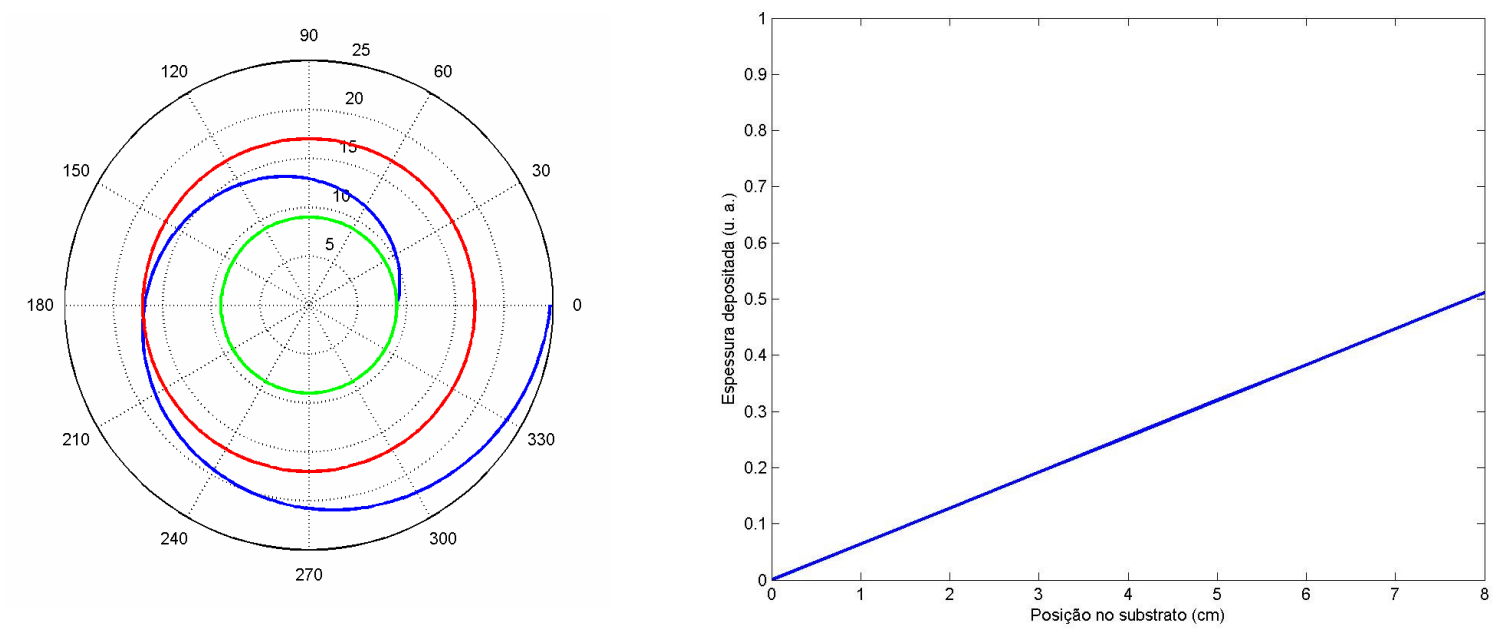

Figura 5.18 - (a) Perfil simulado: ramo da espiral arquimediana. Em verde é mostrado o raio mínimo na amostra, em vermelho o raio máximo e em azul o perfil da máscara.(b) Resultado da simulação para a espessura depositada.

Foi constatado pela simulação que uma máscara com o perfil da espiral arquimediana usada para obliterar o fluxo do material evaporado pode ser bem sucedida na deposição de um filme com perfil de espessura linearmente variável. Seguindo esse resultado, através da listagem do raio da espiral em função do ângulo, foi realizado o esboço do projeto, conforme a Figura 5.19. 


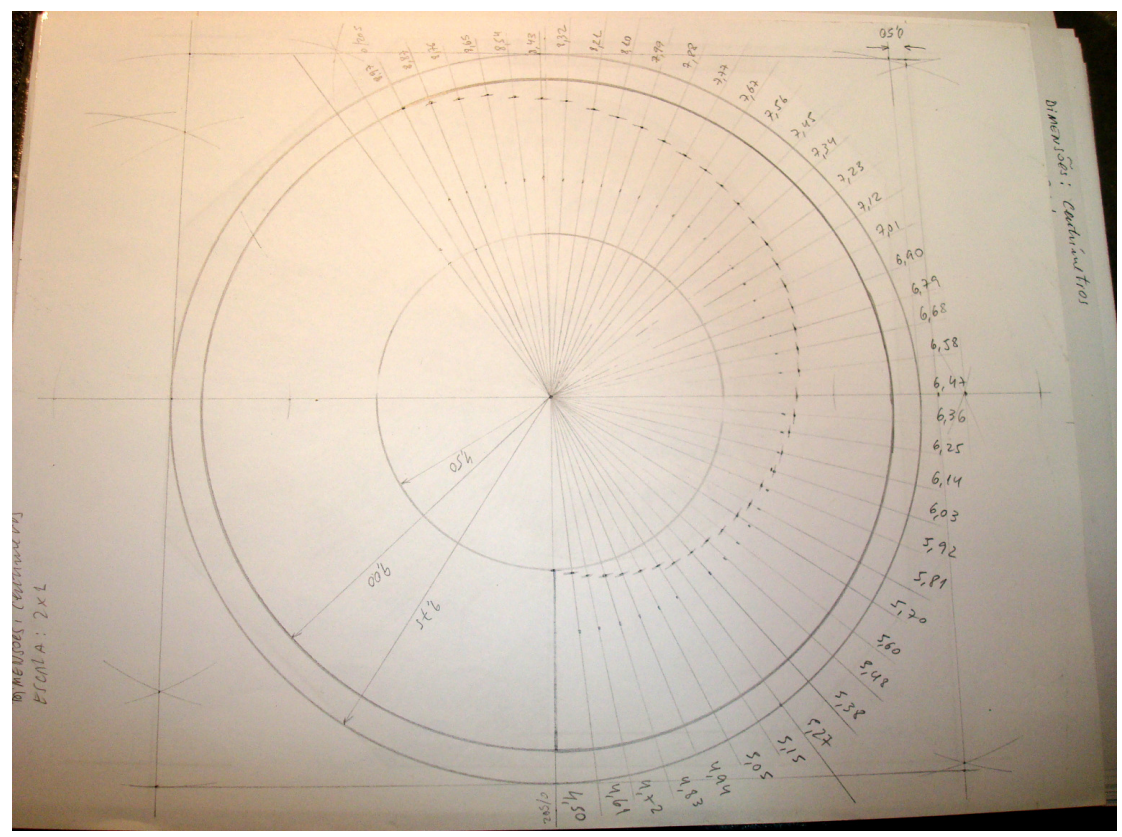

Figura 5.19 - Esboço do projeto do dispositivo.

O desenho da mascara para montagem foi realizado como segue na Figura 5.20:

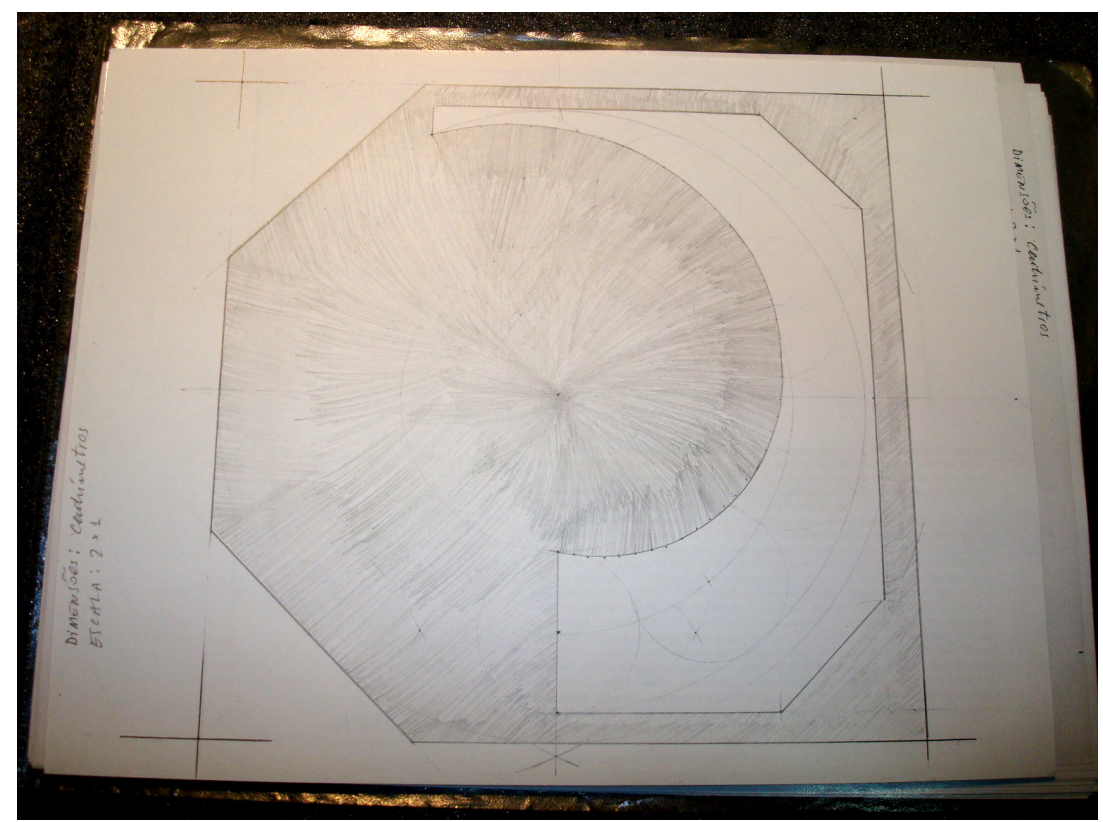

Figura 5.20 - Desenho do dispositivo.

A mascara foi então realizada em uma folha de alumínio de $2 \mathrm{~mm}$ de espessura e é apresentada na Figura 5.21. 


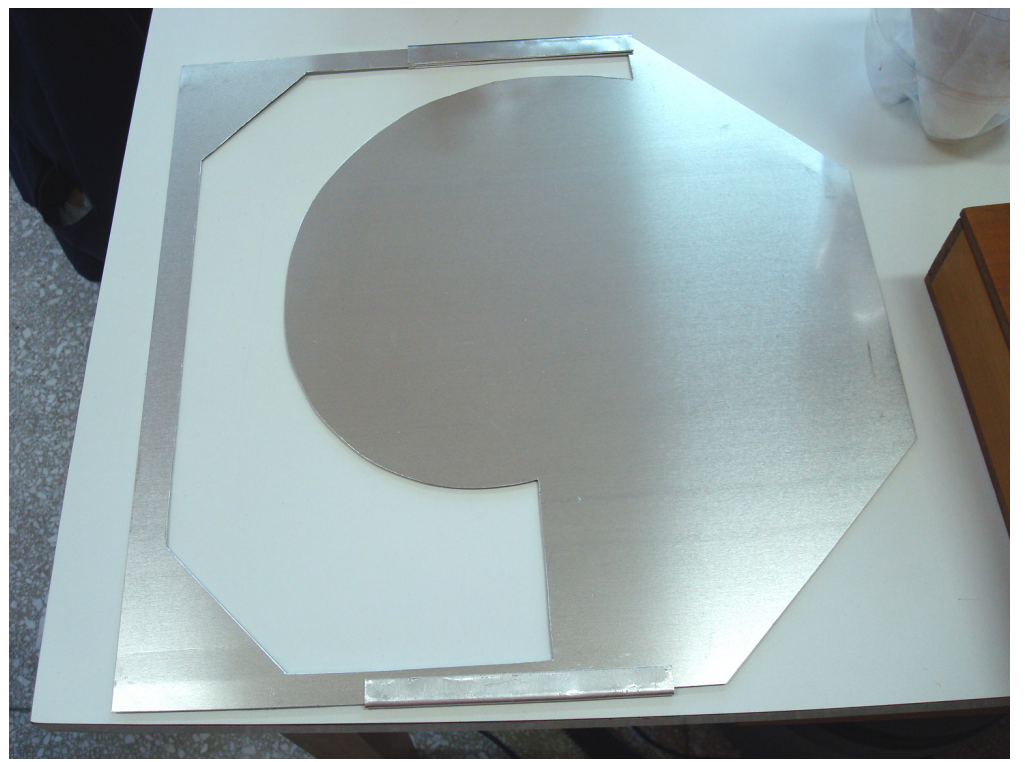

Figura 5.21 - Foto do dispositivo realizado.

A montagem da máscara no interior da câmara de deposição é mostrada na Figura 5.22:

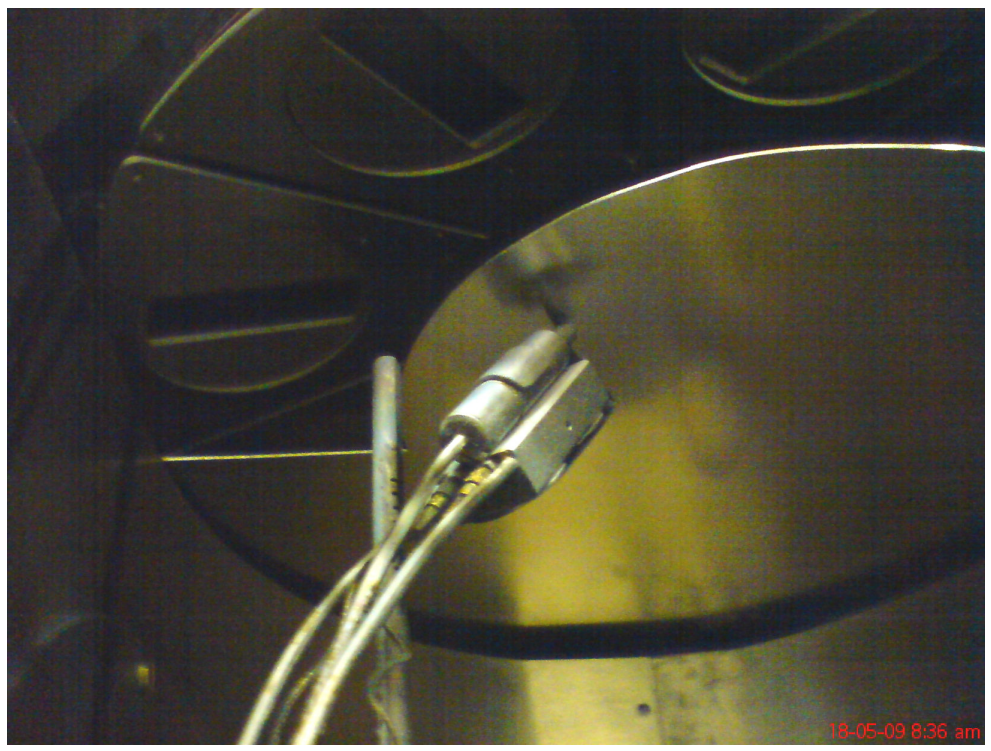

Figura 5.22 - Foto da montagem da máscara no interior da câmara de deposição.

Utilizando a máscara construída, foi depositado um filme de $\mathrm{TiO}_{2}$ sobre um substrato de vidro para efeito da caracterização dos efeitos alcançados. A amostra gerada é mostrada na Figura 5.23: 


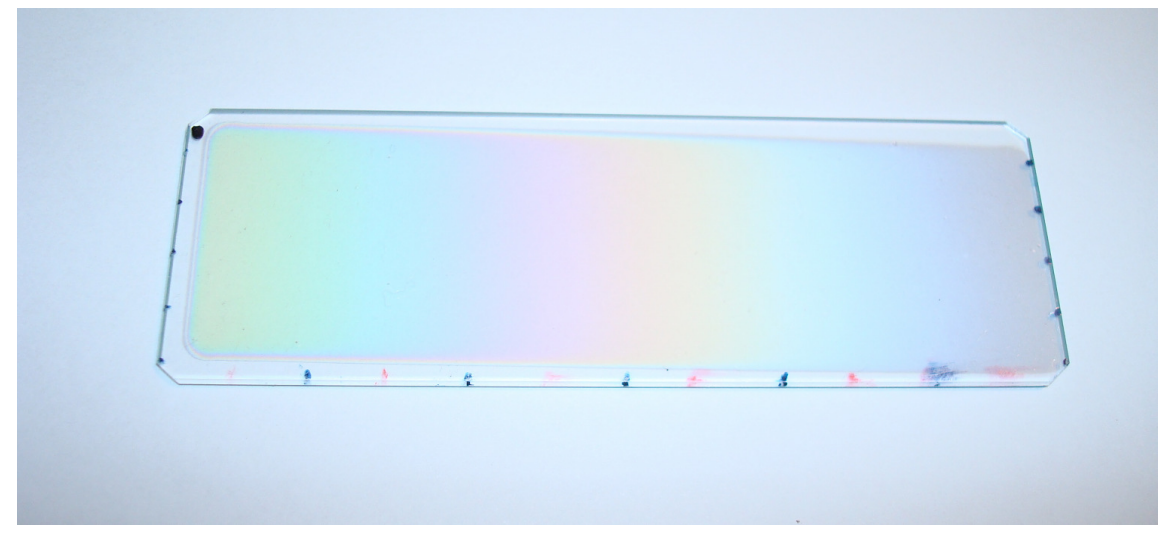

Figura 5.23 - Foto do filme de $\mathrm{TiO}_{2}$ sobre vidro.

Da mesma forma, foi produzida uma deposição de Alumínio sobre vidro, apresentada na Figura 5.24.

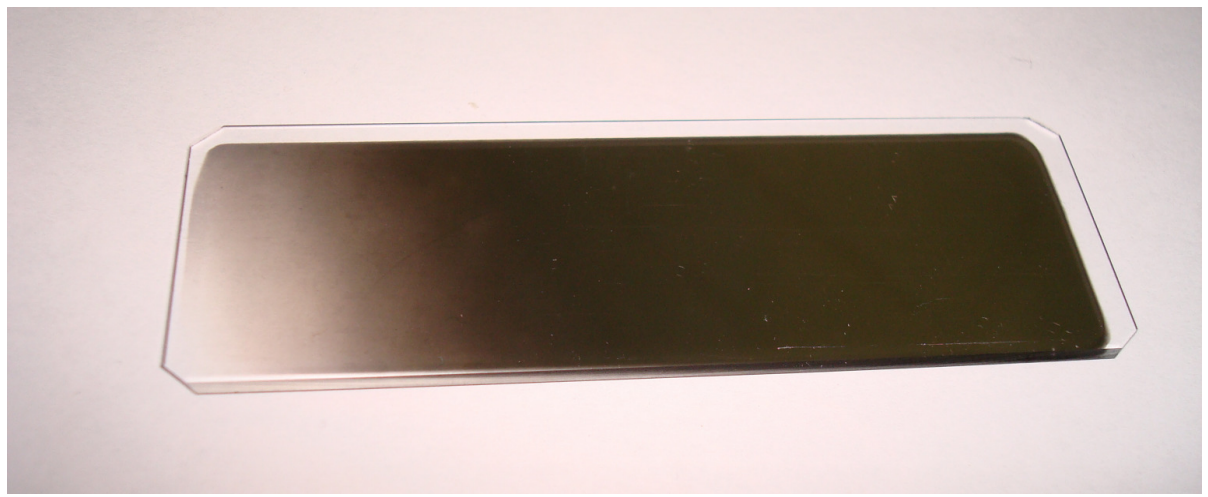

Figura 5.24 - Foto do filme de Al sobre vidro.

O propósito deste trabalho de obter o filtro de interferência linearmente variável (FIV) deve ser atingido com a deposição dos refletores dielétricos multicamadas e a interposição de uma camada inclinada correspondente à cavidade, já o Filtro Variável de Densidade Neutra (VNDF), pode ser obtido com a deposição de metal e a sua subseqüente passivação. Este tipo de filtro (VNDF) pode ser um excelente instrumento para ajustes precisos de espectrofotômetros, monocromadores, lasers, etc., e podem ser usados dois ao mesmo tempo para controlar a transmissão de um feixe óptico, onde são movidos diferencialmente para produzir a variação da energia a ser transmitida.

Contudo, como já mencionado, apresentou-se a necessidade de trabalhar com a restrição de projeto da máscara em que a mesma fosse independente do equipamento de deposição, e isso nos impôs a grave circunstância da quebra do vácuo para a colocação da máscara na etapa correspondente a deposição da camada central (cavidade). Assim, um 
produto do processo de deposição nestas condições foi o mostrado pela Figura 5.25, que apresenta uma amostra com características ópticas diversas da esperada e cuja avaliação indica a presença de efeitos produzidos por contaminações de maior relevância que aqueles efeitos esperados.

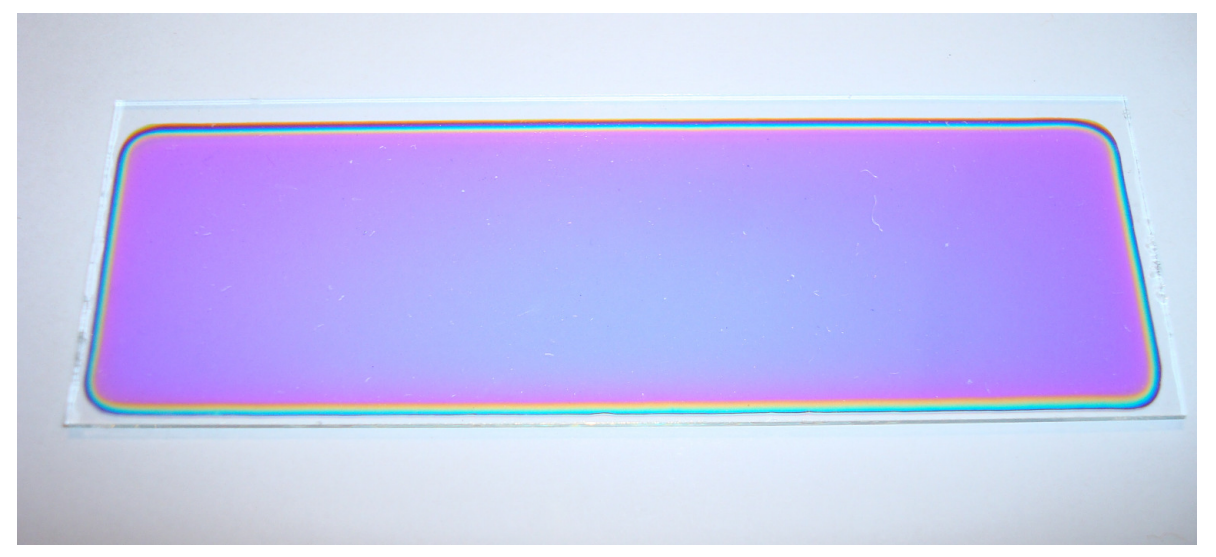

Figura 5.25 - Amostra do filtro depositado com cavidade inclinada, realizada em três fases.

O esforço para contornar este problema é então na direção de evitar a quebra do vácuo e, dessa forma, foram produzidos amostras de filtros em uma só fase de deposição considerando que o valor da refletância mínima dos espelhos de Bragg na faixa considerada fosse preservada, isto é, a deposição foi realizada com a presença da máscara em todo o processo, como esquematiza a Figura 5.26. Contudo, em relação à deposição em três fases, foi obervado nas simulações, que a refletividade dos espelhos dielétricos em fase única aumentam na direção do aumento da espessura, produzindo uma pequena redução da largura a meia altura na mesma direção, efeito oposto àquele previsto para o processo em três fases de deposição.

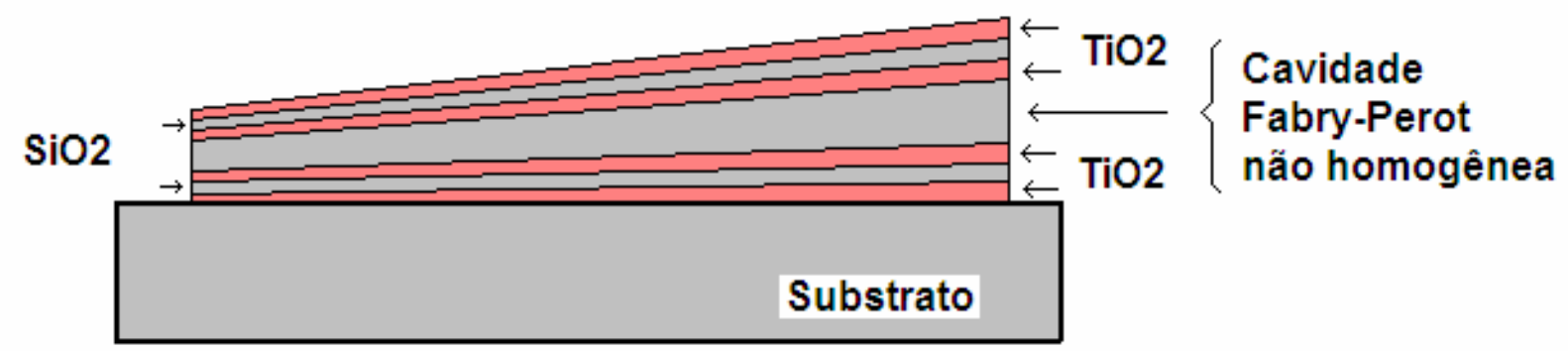

Figura 5.26 - Esquema pictórico do filtro dielétrico de interferência variável (FIV) de fase única de deposição. 
Dois tipos de amostras processadas dessa maneira são apresentados Figura 5.27 e na Figura 5.28.

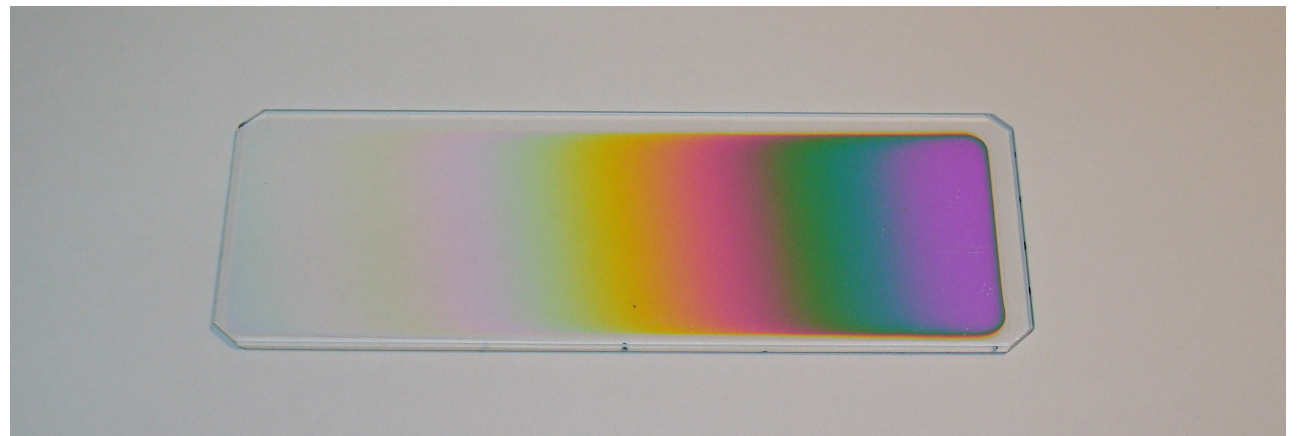

Figura 5.27 - Amostra do filtro depositado com a mascara em uma única fase. Ref. LF3 $\lambda_{0}=408,0 \mathrm{~nm}\left[(\mathbf{H L})^{\wedge} \mathbf{2}(\mathbf{H})(\mathbf{L})(\mathbf{L})(\mathbf{H})(\mathbf{L H})^{\wedge} \mathbf{2}\right]$

A Figura 5.27 apresenta um filtro de $\lambda_{0}=408,0 \mathrm{~nm}$ realizado com a mascara em uma única fase de deposição.

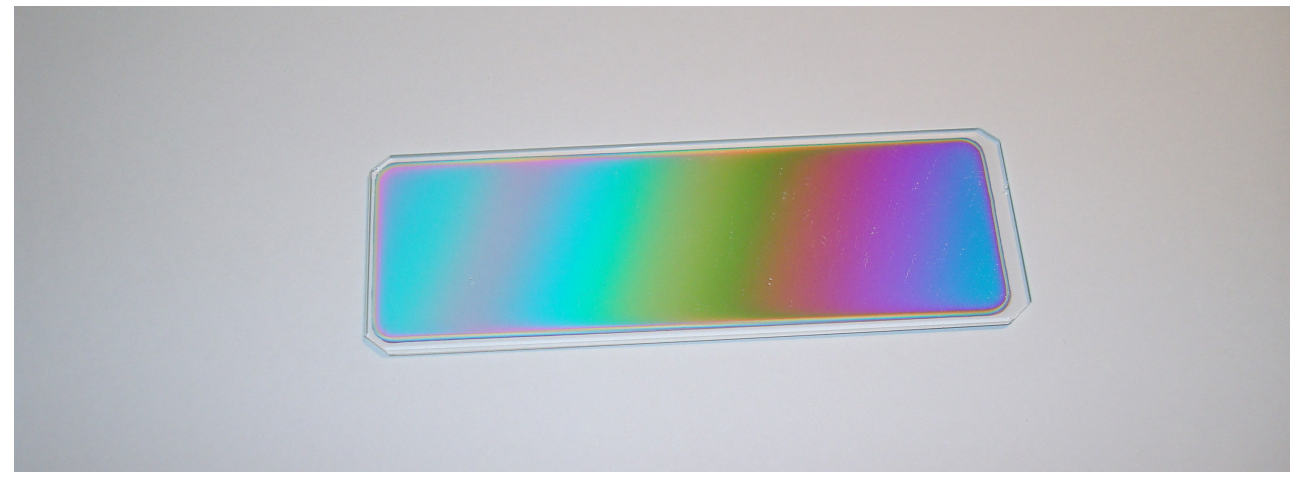

Figura 5.28 - Amostra do filtro depositado com a mascara em uma única fase.

Ref. LF4 $\lambda_{0}=671.0 \mathrm{~nm}\left[(\mathbf{H L})^{\wedge} 4(\mathbf{H})(\mathrm{L})(\mathrm{L})(\mathbf{H})(\mathbf{L H})^{\wedge} 4\right]$

A Figura 5.28 apresenta um filtro realizado em uma única fase de deposição com a máscara para comprimento de onda central de $671,0 \mathrm{~nm}$. 


\section{Caracterizações e resultados}

Conforme Scapin [91] que propõe o uso da Fluorescência de raios-X para a determinação da composição química e da espessura de filmes finos, foram realizadas medidas de espessura da amostra de $\mathrm{TiO}_{2}$ utilizando o equipamento EDX-720 - Energy Dispersive X-Ray Spetrometer, da Shimadzu, pertencente ao IPEN, apresentado na Figura 6.1.

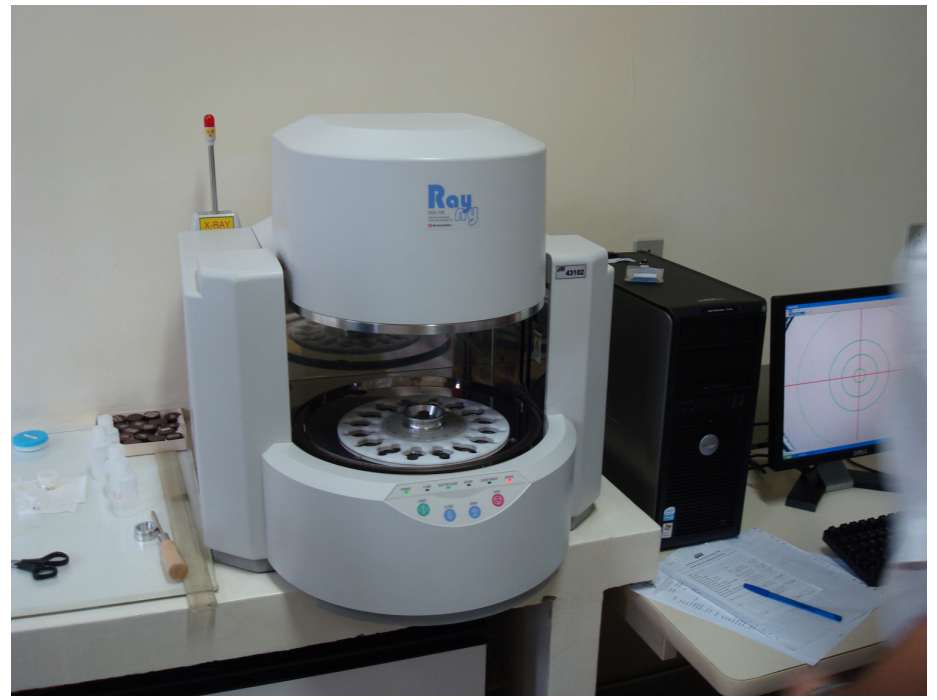

Figura 6.1 - Foto do EDX-720 - Energy Dispersive X-Ray Spetrometer

A amostra foi acomodada na câmara de vácuo do equipamento, conforme mostra a Figura 6.2.

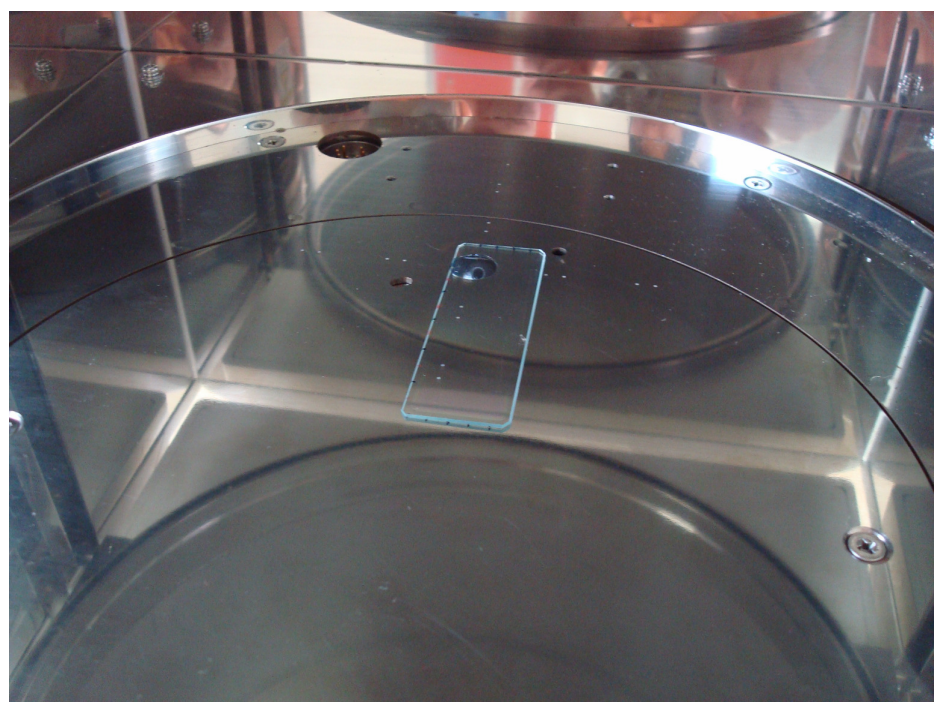

Figura 6.2 - Foto do interior do EDX-720 - Energy Dispersive X-Ray Spetrometer 
Os dados obtidos são mostrados na Figura 6.3:

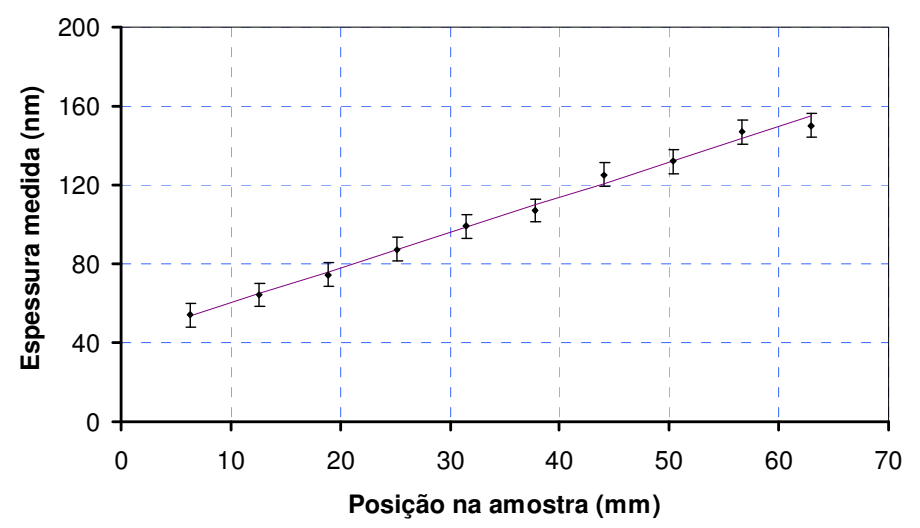

Figura 6.3 - Ajuste de reta pelo método dos mínimos quadrados

E os resíduos calculados, são apresentados na Figura 6.4:

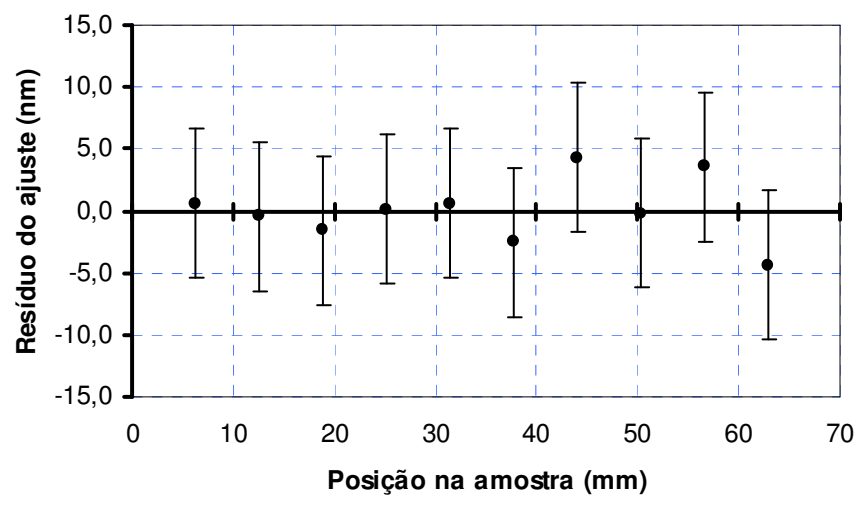

Figura 6.4 - Resíduos Absolutos resultantes do ajuste

Nos gráficos, observa-se a tendência linear dos dados. Com este resultado é possível se demonstrar a viabilidade da utilização de uma máscara com perfil arquimediano, para a deposição de filmes finos inclinados, e, conseqüentemente, para a produção de filtros ópticos de camadas inclinadas, como o que se pretende produzir neste trabalho.

Foram realizadas também medidas de espessura em amostras de Alumínio depositado sobre lâminas de vidro. O tratamento destes dados aponta para um perfil de espessura não linear, contrariando as expectativas desta técnica de deposição.

Para comparação, medidas de espessura destas amostras com perfilômetro (marca TENCOR) e foi constatado um perfil irregular. Contudo, foi encontrada a explicação destas desconformidades pela análise da simulação dos dados obtidos destas amostras por RBS 
(Retroespalhamento de Rutherford), realizadas por bombardeio de $4 H_{e}$ no acelerados de partículas do LAMFI [91]. Estas simulações demonstram que as amostras analisadas, obtidas por e-Beam, constituíram-se de camadas descontínuas compostas de concentrações diferentes de Alumínio e Oxigênio. E, desta maneira, fica evidente a necessidade de depositar o Al por evaporação térmica resistiva em fases intercaladas de deposição em relação à deposição dos óxidos, cuja formação necessita uma pressão parcial de oxigênio, e, assim, minimizar a formação do óxido de alumínio dentro câmara de evaporação.

As amostras preliminares denominadas LF3 e LF4 apresentaram aspectos de difração correspondente aos efeitos desejados, contudo suas propriedades ópticas não corresponderam aos parâmetros do projeto. Ajustes considerando o contorno do obliturador são necessários para se obter a previsibilidade necessária. Dessa maneira, foram realizadas várias sequiências de deposição e obtidas as amostras mostradas na Figura 6.5, agora referenciadas por FIV, com a previsibilidade e a repetibilidade desejadas.

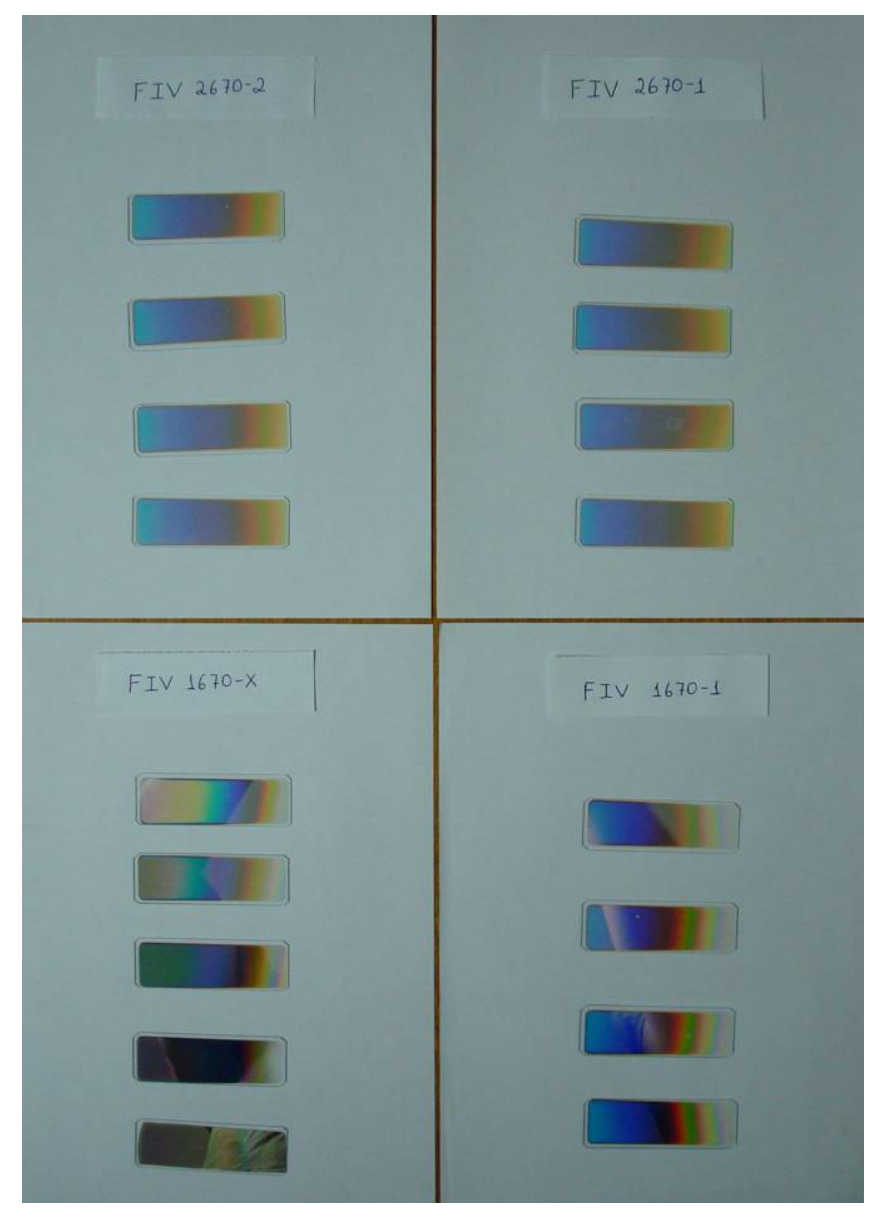

Figura 6.5 - Amostras do FIV obtidas pelo processo descrito.

Assim as amostras de filtros com as camadas inclinadas linearmente (filtros FIV) foram obtidas com o uso do obturador projetado e construído conforme descrito e 
caracterizadas nos seguintes equipamentos: espectrofotômetro UV VIS IR, marca Olis, modelo Cary 17D com dispositivo de varredura espacial adaptado, espectrofotômetro UV VIS IR, marca Perkin Elmer, modelo lambda 900 com dispositivo de varredura espacial (Figura $6.6)$.

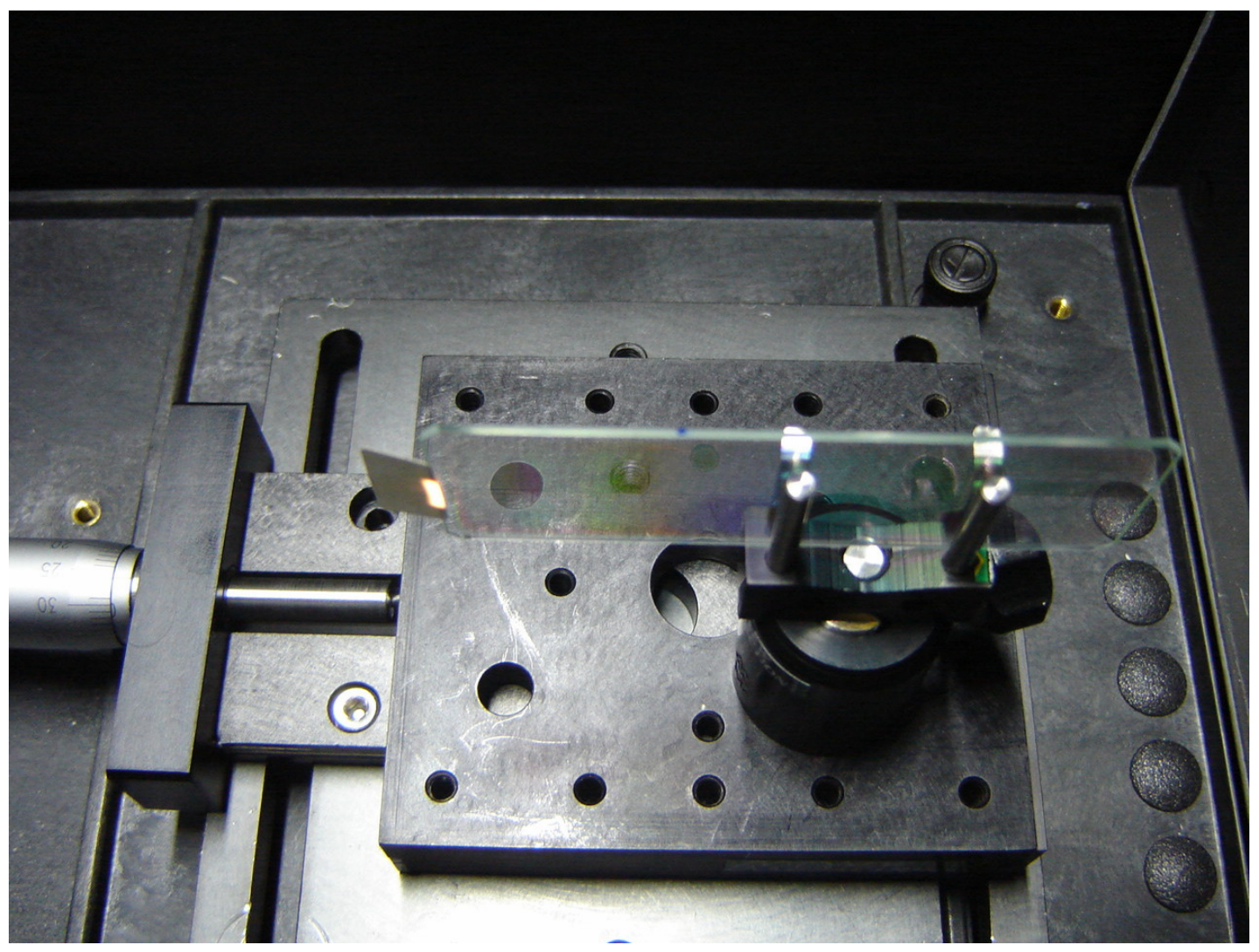

Figura 6.6 - Dispositivo de varredura espacial.

A Figura 6.7 apresenta os resultados obtidos correspondentes as amostras denominadas FIV1670_1 em que se localiza uma banda espectral entre 620 a $730 \mathrm{~nm}$ onde se encontra o efeito desejado. Também se verifica que cada espectro é representado por uma cor que corresponde a uma posição na dimensão do comprimento do filtro. 


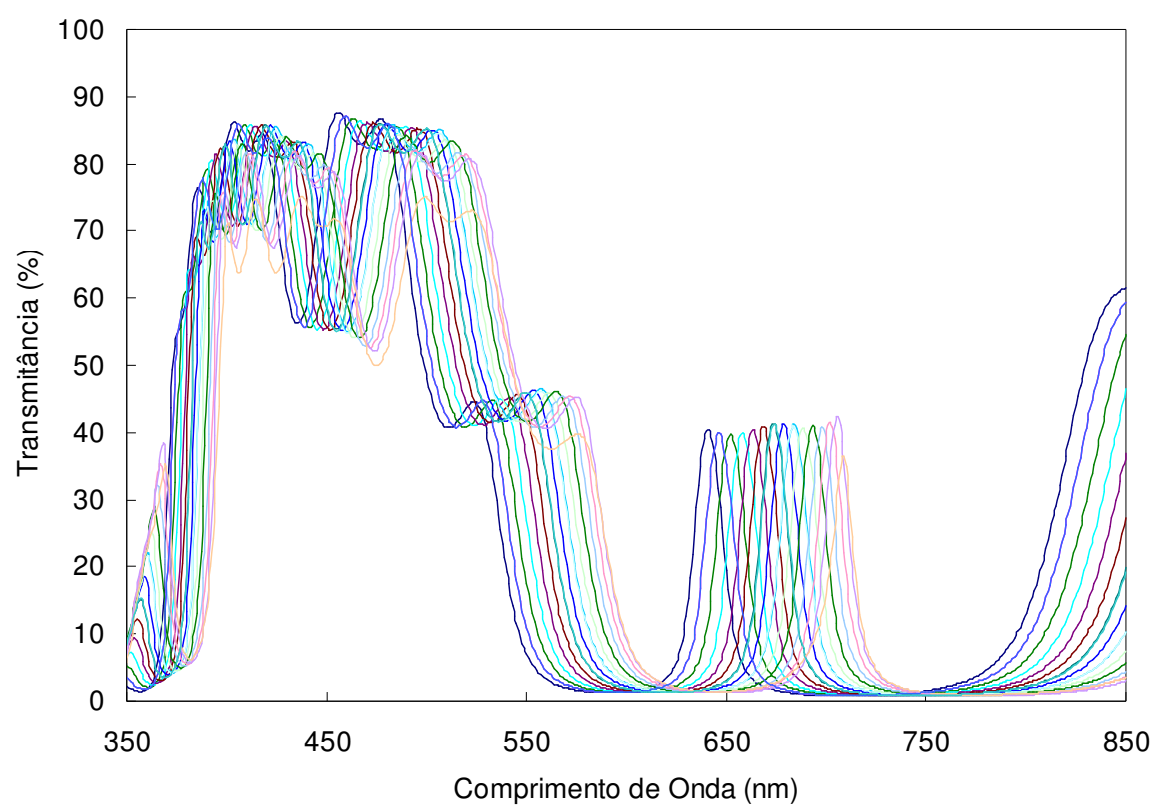

Figura 6.7 - Resultado da caracterização da amostra FIV1670_1.

A Figura 6.8 apresenta os resultados correspondentes a amostra denominada FIV2670_1, onde igualmente um espectro é representado por uma cor correspondente a medida em uma posição do comprimento do filtro, isto é, um espectro espacialmente localizado.

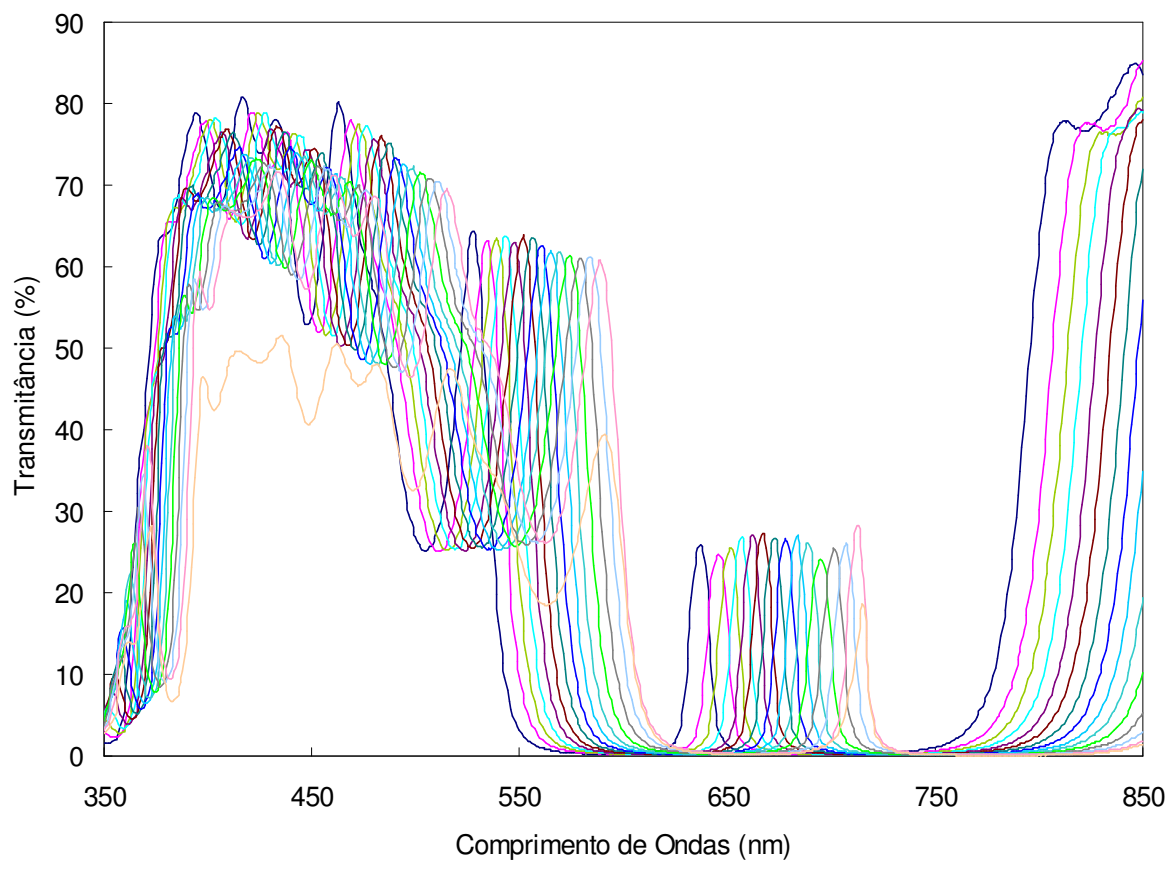

Figura 6.8 - Resultado da caracterização da amostra FIV2670_1.

Separando a faixa espectral ativa e ampliando o gráfico, obtêm-se a Figura 6.9. 


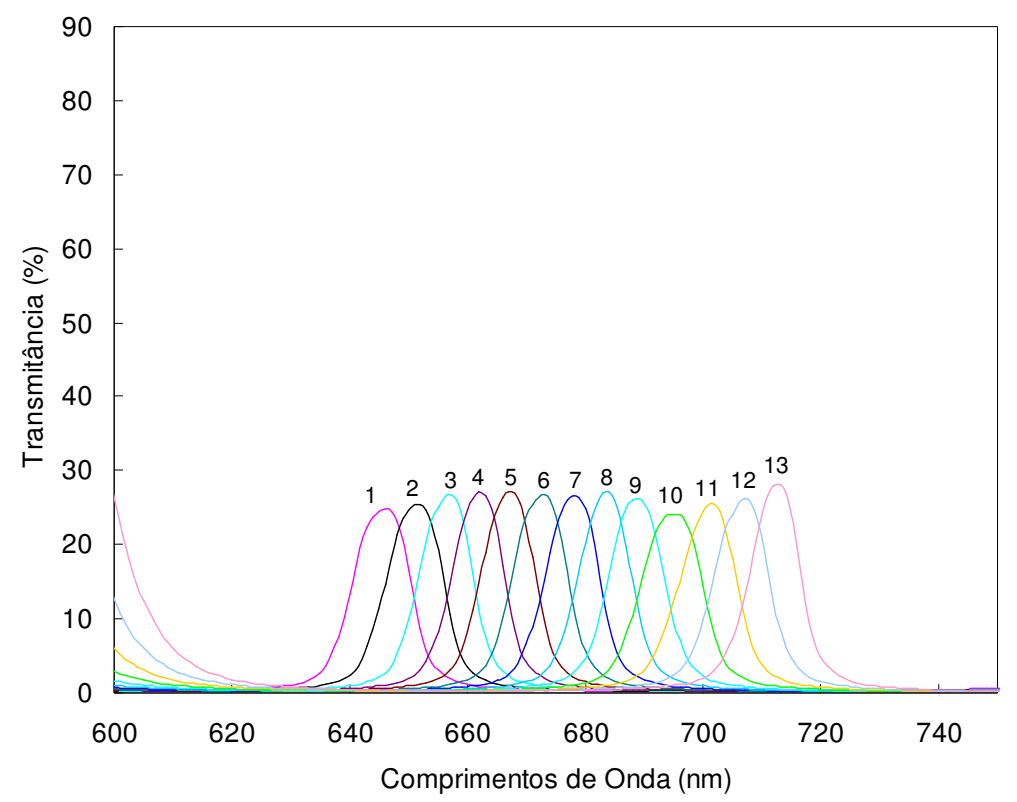

Figura 6.9 - Ampliação da escala do espectro da amostra FIV2670_1

Desta forma, foi calculado o valor máximo para cada pico de transmitância relativamente a sua posição para encontrar a taxa de variação do deslocamento linear do comprimento de onda pelo deslocamento Figura 6.10.

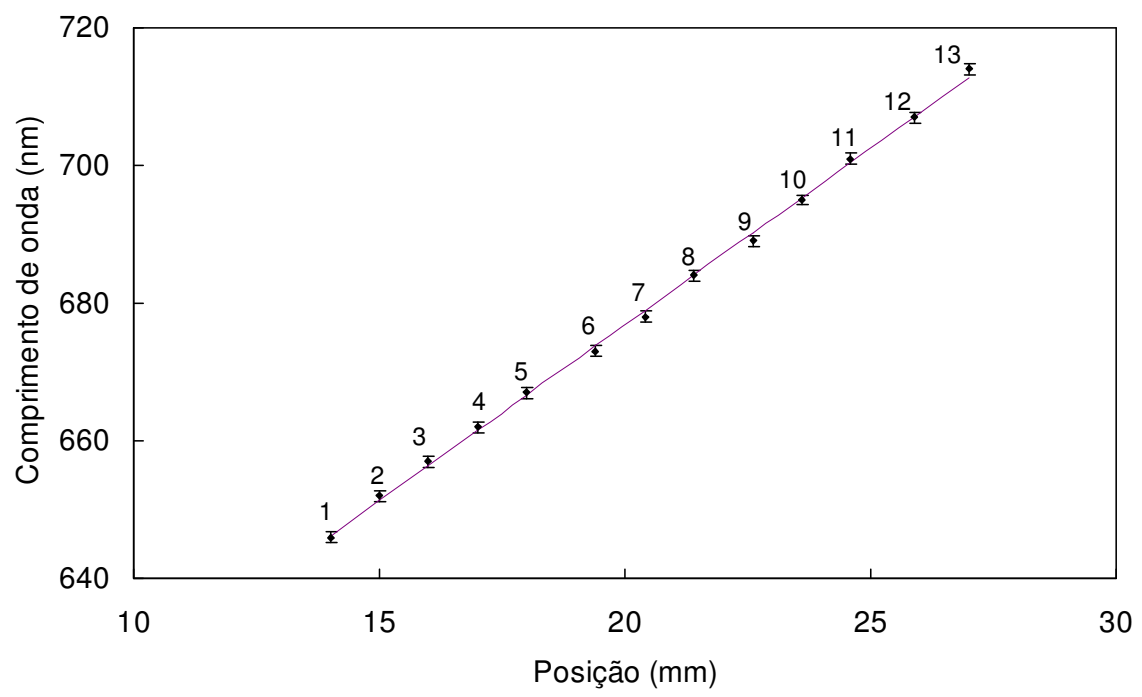

Figura 6.10 - Deslocamento da transmitância espectral máxima pelo deslocamento espacial - Ajuste de reta pelo método dos mínimos quadrados. 


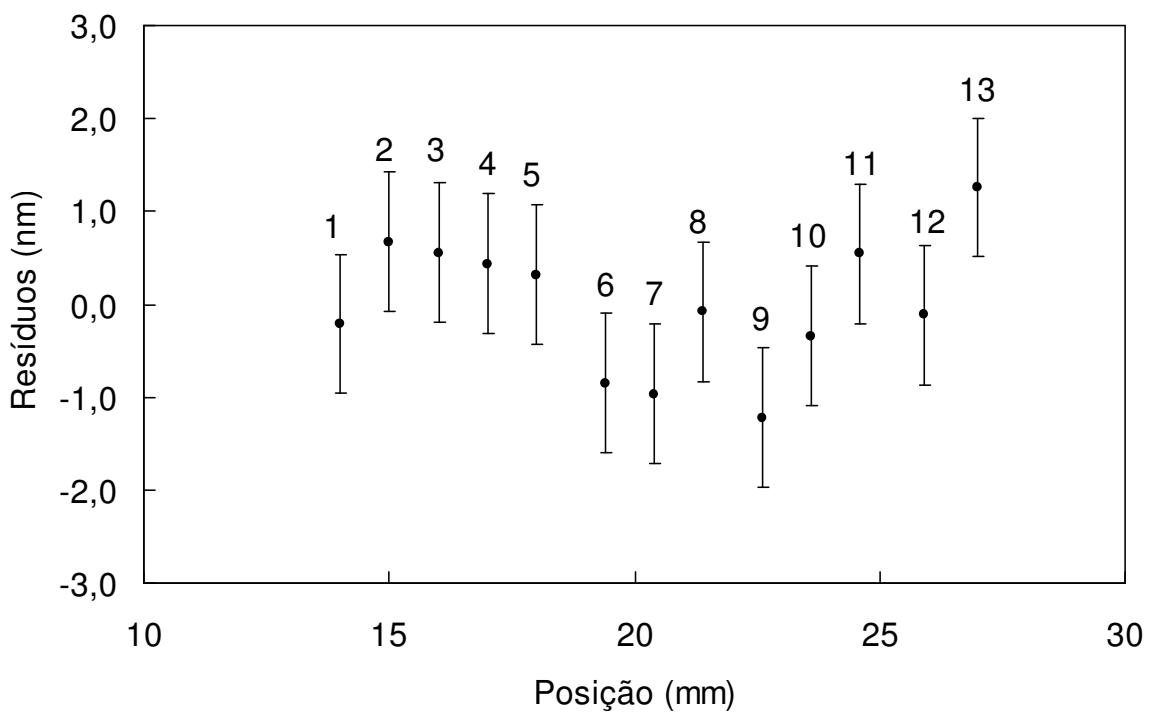

Figura 6.11 - Resíduos Absolutos resultantes do ajuste.

Da Figura 6.10 foi obtida a taxa de 5,12(5) $\mathrm{nm} / \mathrm{mm}$. Considerando o uso do PDA TSL1401 de 128 pixels de 63,5 $\mu \mathrm{m}$ de altura por 55,5 $\mu \mathrm{m}$ de comprimento e distância de centro a centro de $63,5 \mu \mathrm{m}$, calcula-se um comprimento ativo do sensor em 8,13 mm, correspondendo a uma faixa espectral de 41,6(4) nm que pode ser coberta pelo comprimento ativo do filtro de 13,00 mm. E, grosso modo, a faixa de transmissão espectral do filtro e seu comprimento ativo, a faixa espectral do sensor e seu comprimento ativo são combinados para formar a faixa espectral de um dispositivo detector.

Deve-se considerar ainda que, em muitas aplicações, a caracterização dos filtros FIV nos equipamentos espectrofotômetros "convencionais", tais como os utilizados nas medidas apresentadas neste trabalho, podem não atender satisfatoriamente e plenamente os requisitos, já que apresentam um diâmetro do spot da luz incidente da ordem de milímetros e normalmente não possuem dispositivos para o deslocamento espacial das amostras. Para dar conta disso é necessário o desenvolvimento de uma instrumentação dedicada e uma nova metodologia, tal como a sugerida por Laëtitia et al [92], que atenda as exigências da medição da transmitância e refletância localizadas com resolução espacial da ordem de dezenas de micrometros sob um spot da ordem de 100 micrometros. Tal instrumentação é desejável tanto para caracterizar os filmes altamente não lineares (caso do FIV) como para aperfeiçoar os procedimentos para deposição de filmes altamente homogêneos. 


\section{Descrição de um Dispositivo Multicanal Espectral Para Análise Ambiental}

Considerando que, além dos resultados apresentados, pode-se também obter a irradiância incidente em cada pixel como uma função da tensão de saída do amplificador de carga associado a este pixel, pode-se explorar a possibilidade do emprego deste tipo de detector, entre uma ampla gama de aplicações, também na construção de radiômetros espectrais, inclusive numa construção dedicada para análise ambiental.

Deste trabalho é possível inferir que a técnica em pauta possibilita a obtenção de filtros de banda passantes linearmente variáveis em faixas dentro do espectro de $300 \mathrm{~nm}$ a $14 \mu m$. Radiômetros espectrais em determinadas bandas nesta faixa são de grande interesse em avaliações da atmosfera e na obtenção de dados para alimentar modelos atmosféricos que permitem a formação de cenários analíticos.

Assim, este capítulo descreve um dispositivo formado por um detector constituído por um difusor, um filtro de banda larga, uma lente convergente e um conjunto FIV e PDA que formam um detector chip-sized.

\subsection{O Detector}

O conjunto detector espectroradiométrico proposto é baseado numa matriz de fotodiodos (PDA) de silício de 128 elementos e em um filtro de interferência variável (FIV) obtido no capítulo 5 de faixa espectral de $\lambda_{1}$ a $\lambda_{2}$ nm. O FIV converte a distribuição espectral da luz incidente em uma distribuição espacial e tem um gradiente espectral determinado pelos extremos espectrais e seu comprimento $L$ de aproximadamente $\left(\lambda_{2}-\lambda_{1}\right) / L[\mathrm{~nm} / \mathrm{mm}]$. Ver Figura 7.1.

A luz incidente na superfície do FIV é transmitida com seletividade em termos do comprimento de onda, e convertida em sinais elétricos pelos fotodetectores do PDA nas posições correspondentes que pode fornecer uma avaliação da irradiância incidente em cada fotodetector. O FIV é constituído de uma estrutura Fabry-Perot não paralela, formando uma 
cavidade in-homogênea inclinada linearmente. A estrutura do filtro é formada por dois refletores de Bragg (DBR) e uma cavidade inclinada. Conforme descrito em detalhes no capítulo 4 e 5 , a espessura da cavidade numa dada posição, $l(x)$, do filtro determina o comprimento de onda $\lambda_{x}$ que é transmitido pela estrutura, dependendo do índice de refração da cavidade $n_{c}$ (assumido constante).

A discussão sobre a sensibilidade e a faixa espectral do detector é influenciada por diversos fatores. Numa análise inicial, é suposto que o detector é iluminado homogeneamente, isto é, cada posição do FIV recebe a mesma intensidade de luz. Contudo, o objetivo desta aplicação é a monitoração da radiação espectral solar de canais de banda estreita na faixa do visível com a possibilidade de se ajustar, através de programação, os canais espectrais desejados dentro da faixa do detector.

O conjunto detector proposto pode ser apresentado, Figura 7.1, como constituído de um difusor, com a função de espalhar a luz incidente em todas as direções (superfície lambertiana), um filtro banda larga, para suprimir as ordens laterais, um orifício, que representa uma fonte pontual, e uma lente convergente, em cujo foco fica localizado o orifício. O sistema óptico formado pelo orifício e a lente representam uma aproximação de campo distante em relação ao sistema detector que deve ser iluminado igualmente em toda a sua extensão.

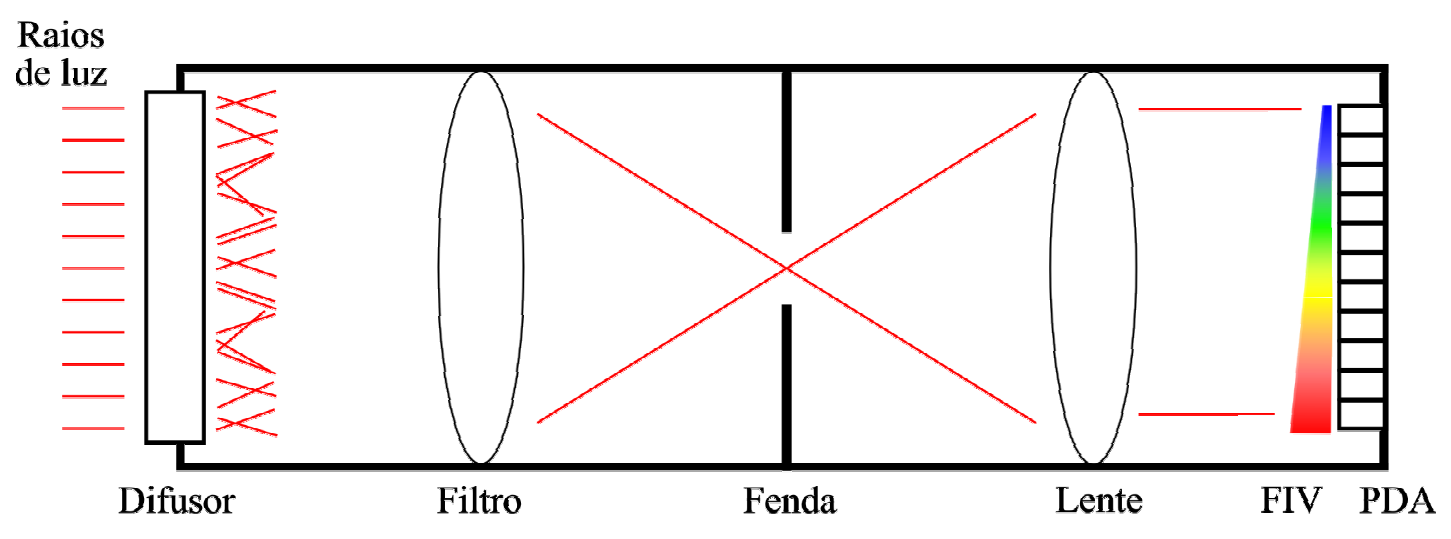

Figura 7.1 - Esquema pictórico do Conjunto Detector.

\subsection{O Difusor}

O espalhamento da luz em um meio turvo, como o politetrafluoretano (PTFE), tem sido estudado em várias áreas, incluindo calorimetria, ciências atmosféricas, astrofísica e 
fotometria [93]. O PTFE é um material altamente espalhador e tem sido considerado como possuidor de propriedades ópticas semelhantes aos tecidos biológicos. Embora muitos estudos tenham avaliado a função distribuição refletância bidirecional (BRDF) de uma placa espessa de PTFE, pouco se sabe no que diz respeito a seu coeficiente de dispersão e da função fase dispersão. As dificuldades para a determinação destes parâmetros são devidas às características de alto espalhamento do PTFE. O coeficiente de dispersão pode ser determinado usando a lei de Beer, se a transmitância colimada de um filme de PTFE espessura fixa poder ser medida [93].

O coeficiente de dispersão de PTFE é estimado para valores acima de $1200 \mathrm{~cm}^{-1}$. Por outro lado, o coeficiente de absorção deve ser inferior a $0,01 \mathrm{~cm}^{-1}$ para que a refletância direcional-hemisférica de uma espessura de 10mm de PTFE esteja acima de 0.98 [93].

Uma das características importantes de PTFE é a produção do espalhamento difuso. A reflexão difusa do PTFE deve-se, principalmente, devido ao espalhamento da luz no volume interior do material. Quando a luz entra no material PTFE, ela é espalhada por microestruturas e se propaga em direções aleatórias antes de escapar do meio.

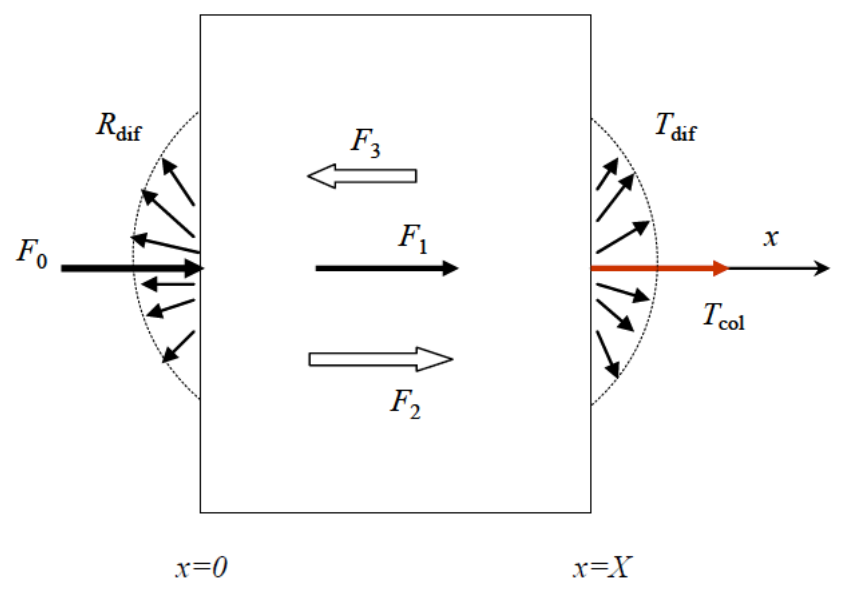

Figura 7.2 - Ilustração do "método de três fluxos" para o estudo da dispersão e da absorção da luz em um meio turvo. $F_{0}$ representa o feixe de incidência colimado. $F_{1}$ representa o feixe colimado que viaja no sentido positivo de $\mathbf{x}, F_{2}$ representa o fluxo difuso no mesmo sentido de $F_{1}$ e $F_{3}$ representa o fluxo difuso no sentido oposto de $F_{2}$. Reproduzido de [93].

No entanto, a menos que filmes de PTFE possam ser feitos mais finos que cerca de quatro vezes o livre caminho médio da luz incidente, é difícil determinar a transmitância colimada. Esta dificuldade também se aplica à determinação do espalhamento em função da fase através da medição da distribuição angular da luz espalhada por um filme de PTFE. 
Além disso, a medida da absorbância do PTFE utilizando uma esfera integradora é problemática, porque o coeficiente de absorção deste material é tão pequeno que a incerteza das medições são muitas vezes indistinguíveis do valor da absorbância.

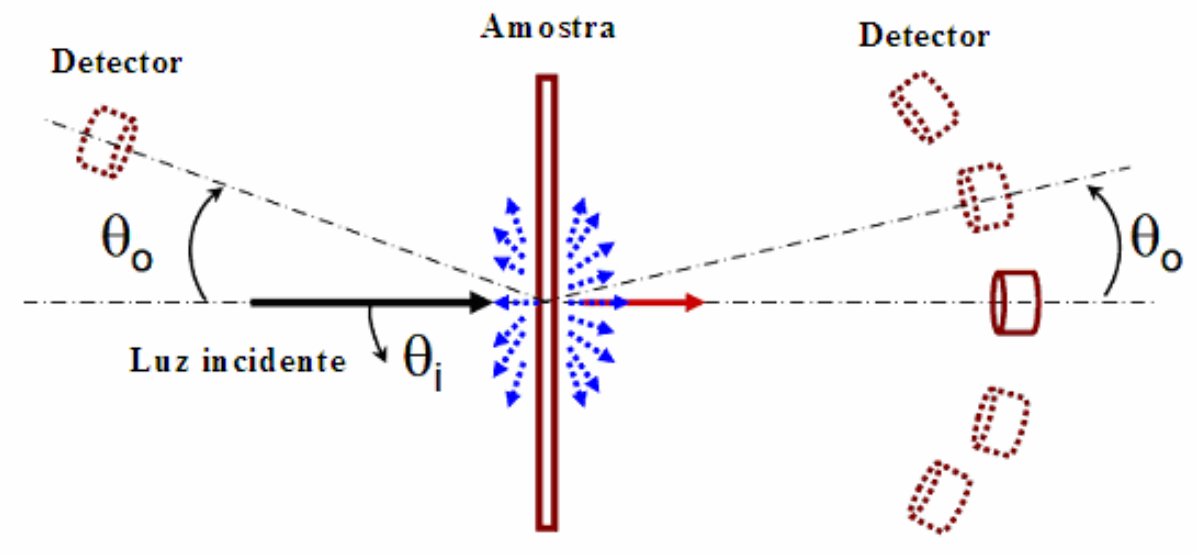

Figura 7.3 - Diagrama esquemático da dispersão no volume e da medida da propriedade bidirecional. As linhas pontilhadas representam a luz dispersa e a linha contínua do lado direito da amostra indica a luz (não dispersa) colimada transmitida. Reproduzido de [93].

Neste trabalho utilizaram-se amostras de PTFE como difusor considerando suas características ópticas, químicas e mecânicas (ótimo difusor, quimicamente inerte e boa resistência mecânica). A Figura 7.4 mostra o aparato usado para uma avaliação.

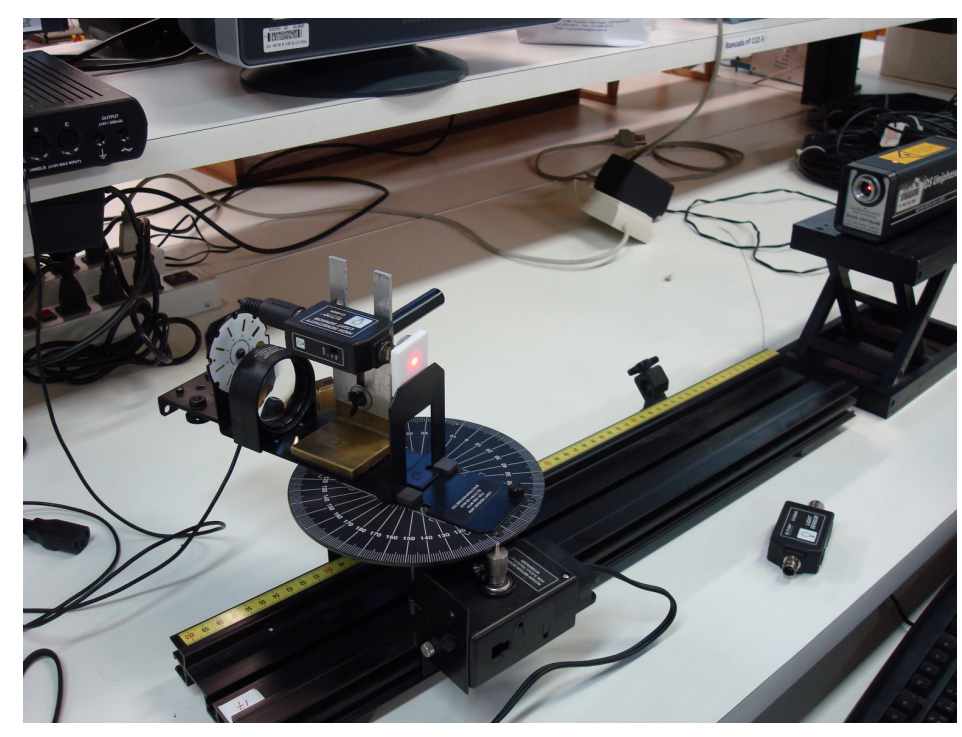

Figura 7.4 - Aparato instrumental de teste de uma amostra de PTFE.

A Figura 7.5 apresenta imagens de AFM e a avaliação da transmitância de duas amostras de PTFE utilizadas como difusor neste trabalho: 

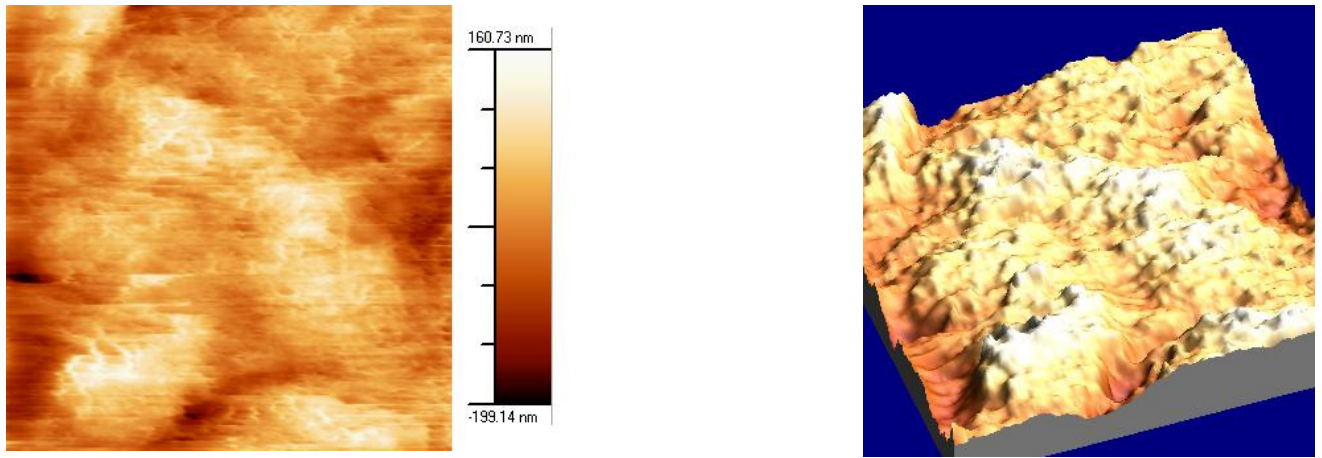

Figura 7.5 - Imagens de AFM de amostras de PTFE usados como difusor.

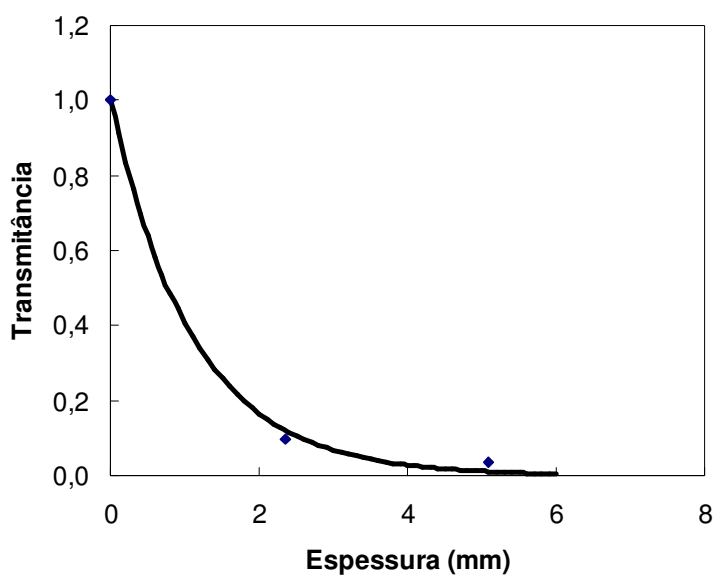

Figura 7.6 - Transmitância do difusor.

\subsection{O Filtro}

Considerando os parâmetros de projeto do detector com o filtro de interferência variável (FIV) (Figura 7.1) e pretendendo evitar o possível problema de bandas laterais, podese utilizar um filtro banda larga para eliminar ordens vizinhas. Onde a banda passante do filtro de banda larga deve ser coincidente com a banda da faixa espectral ativa do FIV. No caso presente dispõem-se somente de um filtro mod.43087- Edmund optics $(\Delta \lambda=10 \mathrm{~nm})$, cujo espectro é apresentado na Figura 7.7. 


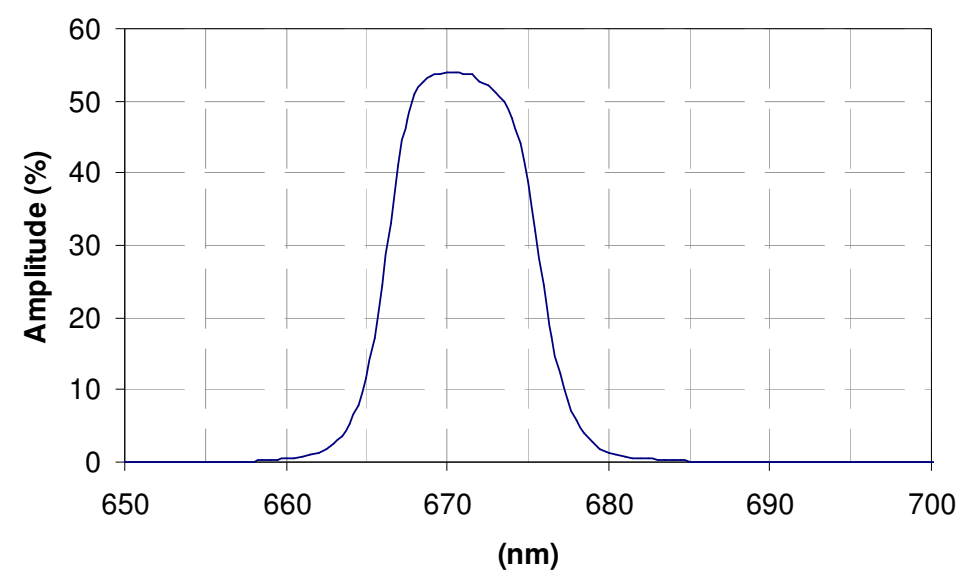

Figura 7.7 -Caracterização da resposta espectral de um filtro (671nm, mod.43087- Edmund optics) que pode ser utilizado para evitar as ordens laterais vizinhas. Medições realizadas no espectrofotômetro Cary $17 D$.

\subsection{O Sensor}

O sensor utilizado na avaliação do filtro de interferência variável (FIV) consiste em um PDA com 1280 fotodiodos arranjados em duas secções de 640 fotodiodos alinhados continuamente em uma disposição linear, cada um deles está associado a um circuito amplificador de carga e a um circuito lógico de multiplexação para prover a leitura de cada pixel. As dimensões relacionadas a cada foto-elemento (pixel) são $63,5 \mu \mathrm{m}$ por $55,5 \mu \mathrm{m}$ com espaçamento de $63,5 \mu m$ de centro a centro e $8 \mu m$ de espaçamento entre pixels. A lógica interna de multiplexação e de controle é simplificada utilizando um simples sinal de “clock" e um sinal de inicialização (serial-input) e pode operar e até $8 M H z$ (TLS1410R TAOSinc) (Figura 7.8) [94].

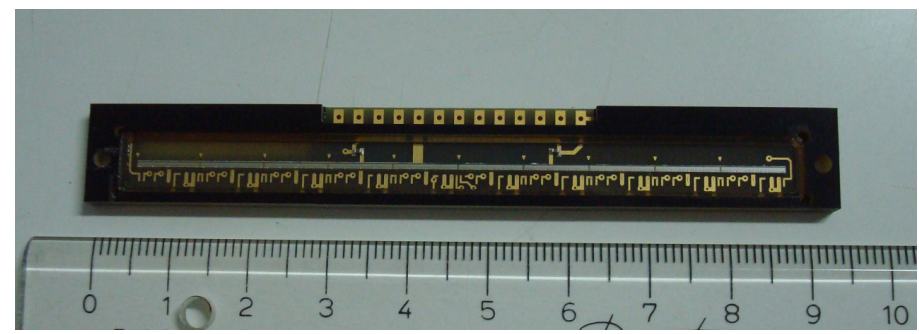

Figura 7.8 - Fotografia do dispositivo TSL1410R (1280x1 pixels).

Esta avaliação consiste na necessidade, devido o uso de laminas grandes como substrato, de fazer uma localização prévia da banda espectral de interesse para proceder a posterior caracterização. 
O sensor proposto para o dispositivo detector descrito consiste em um PDA com 128 fotodiodos (TLS1401R TAOSinc) com as mesmas características dimensionais dos pixels e do sistema lógico de controle do dispositivo descrito anteriormente (Figura 7.9) [94].

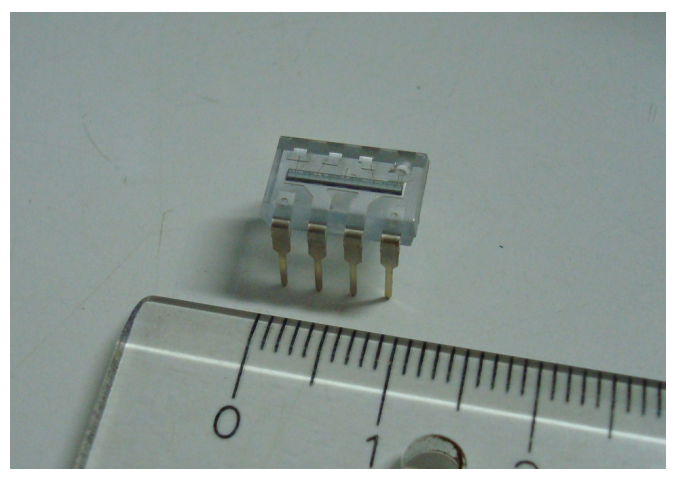

Figura 7.9 - Fotografia do dispositivo TSL1401R (128x1 pixels).

Uma breve descrição funcional dos sensores PDA's é feita com o esquema da Figura 7.10 e vale para ambos os sensores (TSL1401R e TSL1410R) considerando-se a diferença do número de pixels. A energia da luz incidente em um determinado fotodiodo gera uma fotocorrente, que é integrada pelo circuito integrador associado a esse pixel.

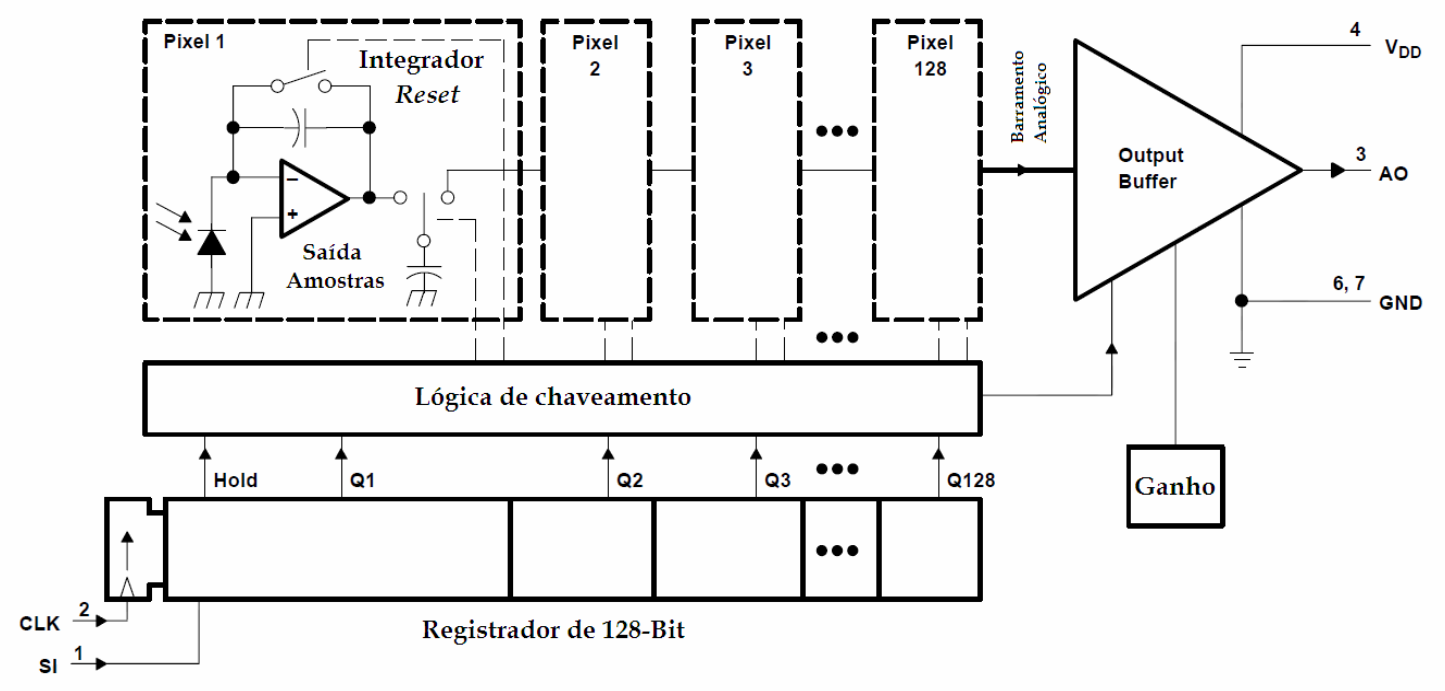

Figura 7.10 - Diagrama funcional reproduzido do datasheet (Texas Advanced Optoelectronic Solutions Inc-TAOSinc)[94].

Durante o período de integração, um capacitor de amostragem é conectado à saída do integrador analógico através de uma chave analógica. A carga acumulada em cada pixel é diretamente proporcional à intensidade luminosa e ao tempo de integração. 
A saída e o reset dos integradores são controlados por um registrador de deslocamento (shift register) de 128 bits e uma lógica de reset. Um ciclo de saída é iniciado com um sinal no terminal Start Integration (SI), visto na parte superior da tela do osciloscópio mostrada na Figura 7.11. Para o funcionamento adequado, após ser mantido ativo por um tempo mínimo, o SI deve ser desativado antes de iniciar um novo ciclo. Um sinal interno, chamado Hold, é gerado a partir da borda de subida SI e transmitido para as chaves analógicas dos circuitos de cada pixel. Isto faz com que todos os 128 capacitores de amostragem sejam desconectado de seus respectivos integradores e inicia-se um período de reset dos integradores.

O pulso SI é “cronometrado" pelo registrador de deslocamento, e a carga armazenada nos capacitores de amostragem é acoplada seqüencialmente, a cada um dos 128 impulsos no terminal "CLK” necessários para a varredura do PDA (parte inferior da Figura 7.11), em um amplificador que gera uma tensão na saída análoga no terminal Analog Output (AO) e o sinal de entrada SI poderá habilitar um novo ciclo depois de completado estes eventos e, simultaneamente, durante os primeiros 18 ciclos de clock, todos os integradores de pixels são restaurados, e o próximo ciclo de integração começa no centésimo vigésimo nono $\left(129^{\circ}\right)$ pulso de clock, visto na Figura 7.12.

Na borda de subida do $129^{\circ}$ pulso de clock, o registrador de deslocamento impõe à saída analógica AO um estado de alta impedância. O $129^{\circ}$ pulso de clock é necessário para encerrar o ciclo com o $128^{\circ}$ pixel e para a reconstituição da lógica interna.

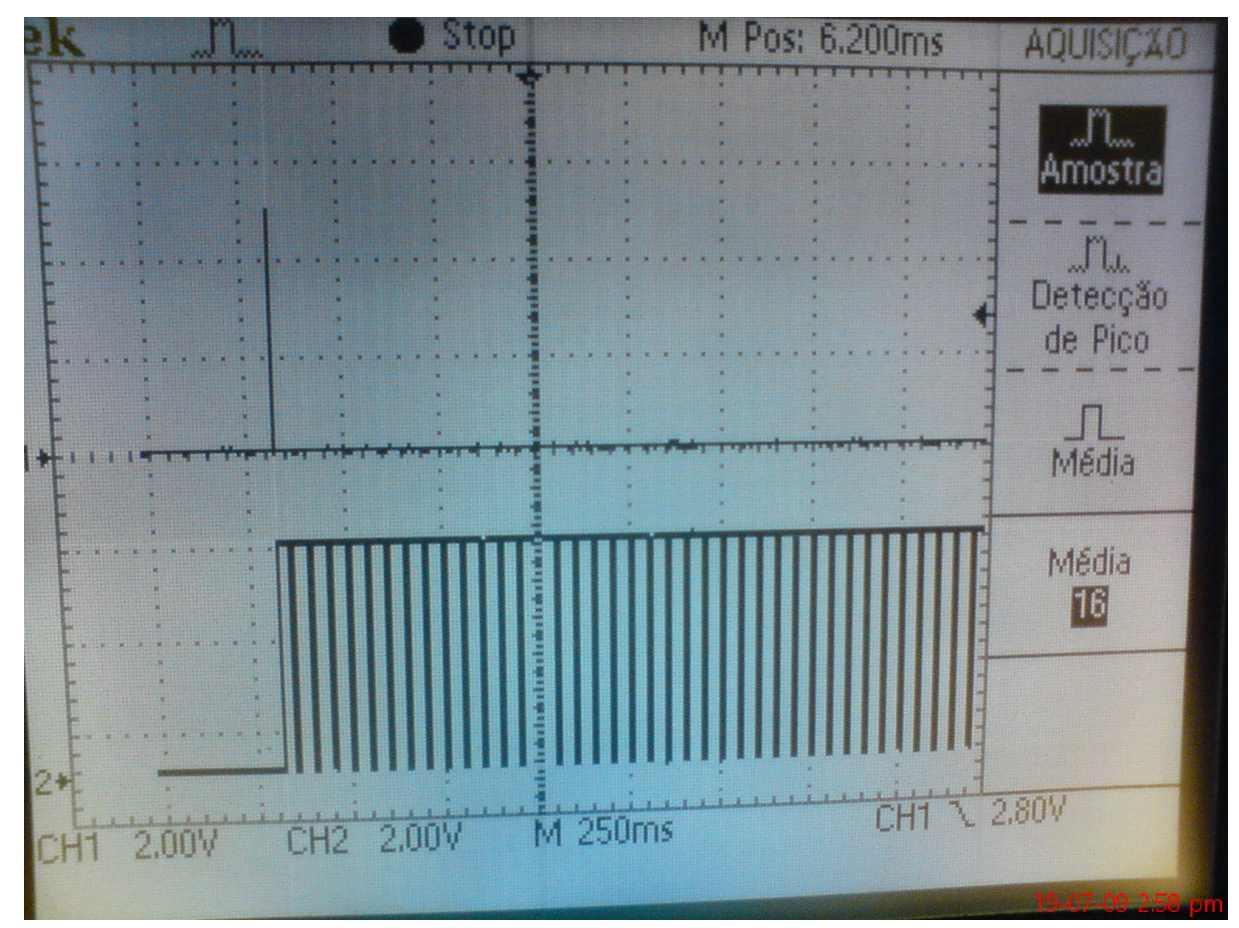

Figura 7.11 - Foto da tela do osciloscópio do sinal SI e CLK da implementação [94]. 


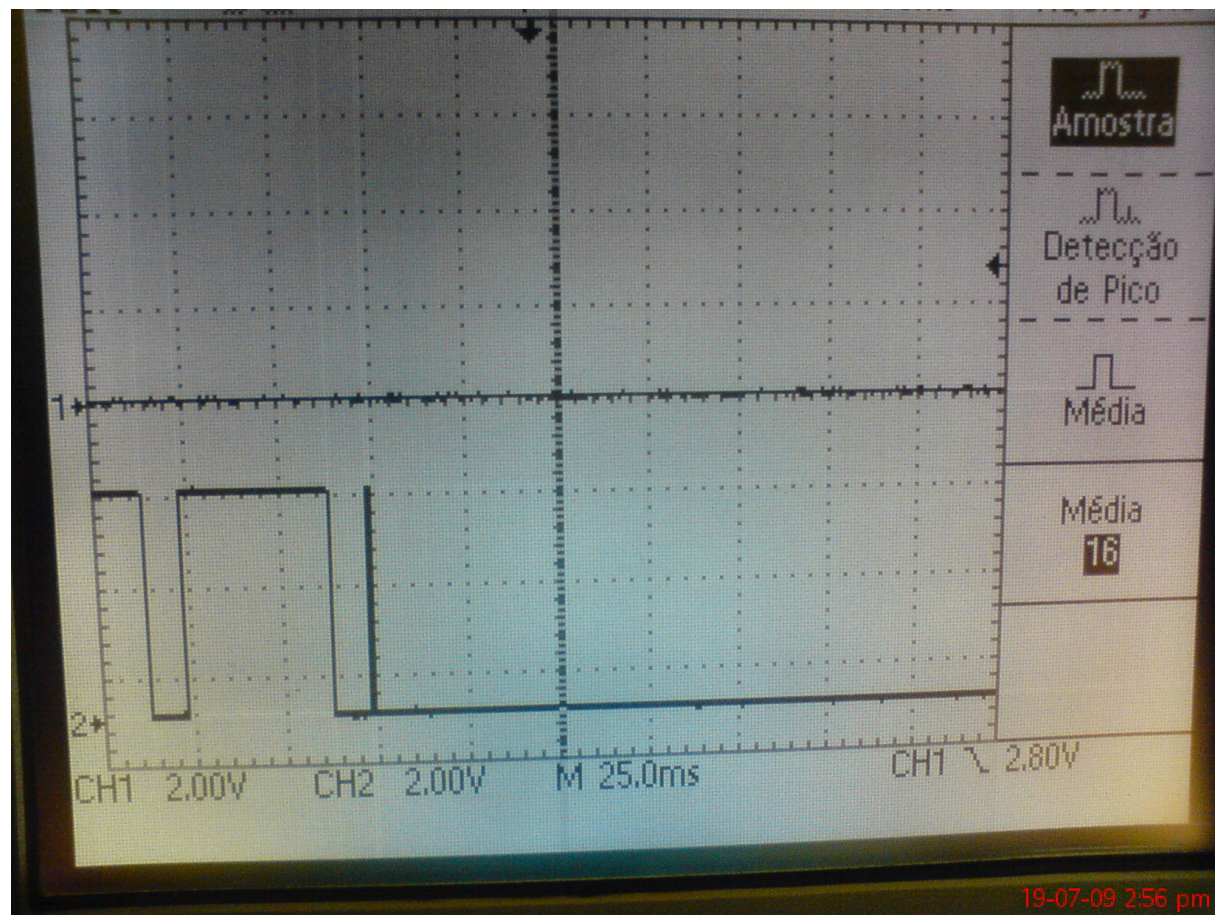

Figura 7.12 - Foto da tela do osciloscópio do sinal correspondente ao 129 impulso [94].

O amplificador de corrente de saída não requer um resistor (pull down) externo na saída. Com VDD $=5 \mathrm{~V}$, a saída nominal correspondente a nenhuma luz na entrada é 0V, a saída correspondente a um nível de luz de entrada de saturação é 4,8 V. A saída correspondente ao estado em que o dispositivo não está na fase de saída, é um estado de alta impedância.

A tensão na saída analógica (AO) é dada por [94]:

$V_{s}=V_{e s c}+\left(R_{e}\right)\left(E_{e}\right)\left(t_{\text {int }}\right)$

sendo:

$V_{s} \quad$ Tensão analógica na saída

$V_{e s c} \quad$ Tensão analógica na saída correspondente a condição "escura” (sem nenhuma luz)

$R_{e} \quad$ Responsividade do PDA para um correspondente comprimento de onda dado em $V /\left(\mu J / \mathrm{cm}^{2}\right)$.

$E_{e} \quad$ Irradiância incidente em $\left(\mu W / \mathrm{cm}^{2}\right)$

$t_{\text {int }} \quad$ Tempo de integração em segundos. 


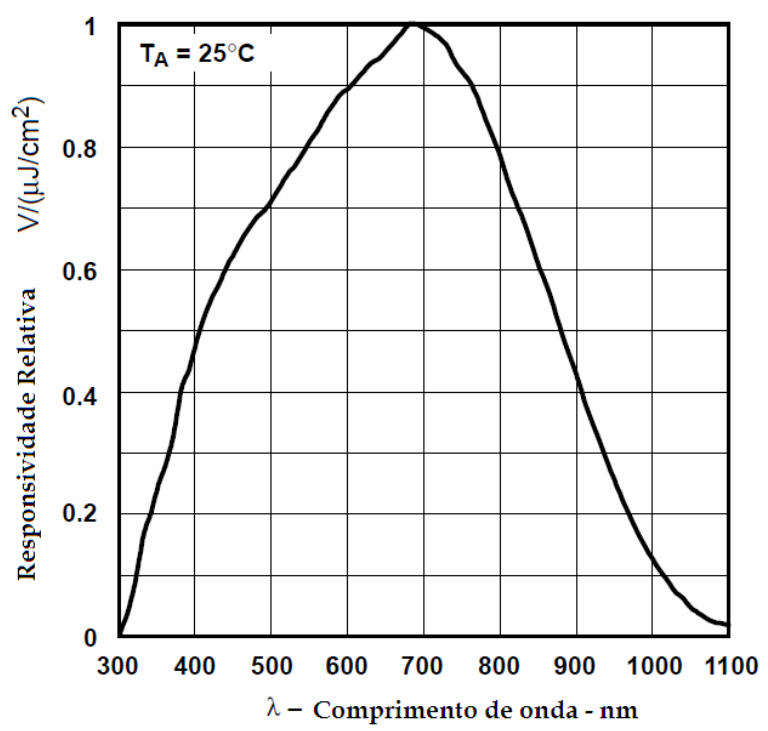

Figura 7.13 - Responsividade espectral dos fotodiodos - reproduzido do datasheet (Texas Advanced Optoelectronic Solutions Inc.). Reproduzido de [94].

A responsividade relativa em função do comprimento de ondas dos fotodiodos pode ser obtida a partir da Figura 7.13 obtida do "datasheet" do PDA.

\subsection{Uma Arquitetura para o Dispositivo Multicanal Espectral para Análise Ambiental}

O objetivo deste trabalho inclui a descrição de um dispositivo microprocessado de aquisição de dados baseado no detector constituído pelo filtro de interferência variável (FIV) de maneira a ser adequado à avaliação da radiação solar que atinge o detector depois de percorrer a atmosfera. Conhecendo-se a radiação no topo da atmosfera é possível, utilizandose de modelos específicos de tratamento destes dados, obter informações correspondentes a processos espectroscópicos da atmosfera de acordo com os canais espectrais disponíveis. Dessa forma, com a viabilidade deste dispositivo, pretende-se demonstrar a possibilidade da construção de uma instrumentação para essa aplicação baseado neste novo conceito de aplicação.

O sistema em questão é constituído, então, pelo detector conectado a um módulo eletrônico dedicado a medir a radiação incidente, armazenando os dados juntamente com o registro do momento de sua aquisição. $\mathrm{O}$ aparelho pode conter também rotinas de correção do ângulo de incidência azimutal da radiação solar, um sombreador robotizado para permitir a 
medição de componentes da radiação solar espectral (componentes global, difusa e direta normal).

O módulo eletrônico possui uma interface de comunicação (RS232C) de forma que, através dela, é possível descarregar os dados adquiridos para serem processados e/ou receber parâmetros de controle de um computador com capacidade de processamento (Figura 7.14).

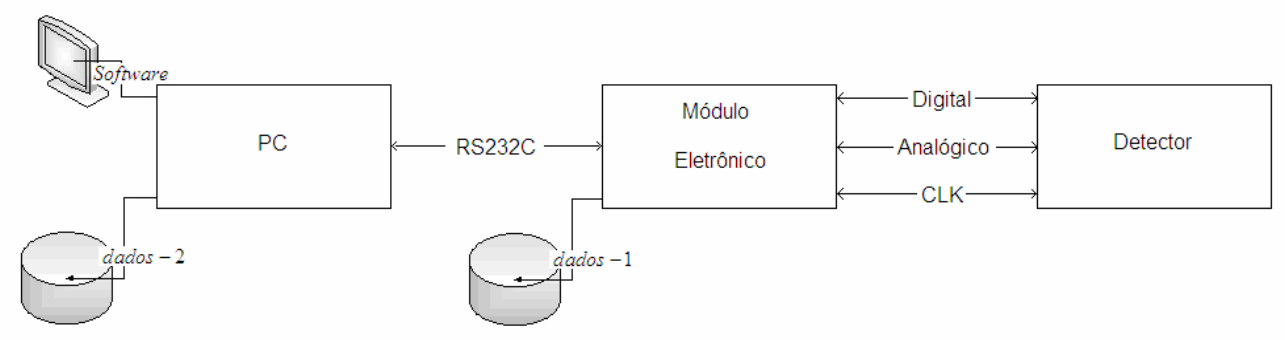

Figura 7.14 - Diagrama esquemático do funcionamento do Dispositivo Multicanal Espectral Para Análise Ambiental.

\subsection{Módulos Eletrônicos}

Devido às necessidades do projeto do detector e da caracterização dos sensores, tornou-se oportuna a disponibilidade de dois módulos independentes associados ao detector como ilustrado na Figura 7.15. Os módulos são: microprocessador MSC1211-Y5, Complex Instruction Set Computer - CISC, mostrado nas Figura 7.16 e Figura 7.17 e outro módulo baseado no microcontrolador Atmega32, Redudec Instruction Set Computer - RISC, mostrado nas Figura 7.20 e Figura 7.21.

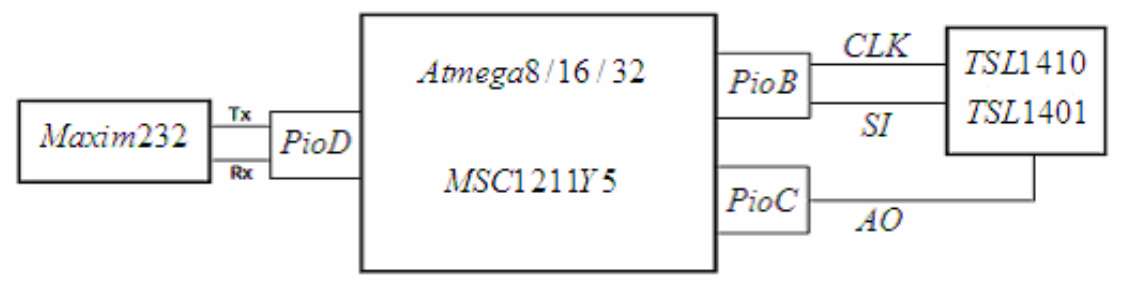

Figura 7.15 - Diagrama de blocos do funcionamento dos módulos eletrônicos de avaliação e performático.

A Figura 7.15 mostra o diagrama funcional dos dois módulos utilizados. O emprego dos dois módulos está associado à necessidade de pré-avaliar o filtro FIV, utilizando-se o próprio sensor do detector, para localizar a banda de interesse nos substratos de grandes dimensões utilizados neste trabalho para posterior caracterização. Esta providência minimiza os recursos e o uso da instrumentação. Todavia, se prevê a necessidade de desenvolver 
instrumentação específica para esse fim, já que a peculiaridade da transmitância espectral do filtro que varia ao longo de seu comprimento, demanda a necessidade de um sistema móvel de coordenadas com resolução da ordem de dezenas de micrometros e de um espectrofotômetro com um spot de iluminação da ordem de 100 micrometros. Então, foi dedicada ao módulo Atmega32, que possui um conjunto de instrução mais compacto e pode ser programado com maior facilidade, a tarefa de avaliar as características do FIV e, dedicada ao módulo MSC1211Y5, que possui um conjunto de instruções mais extenso e uma sistemática de programação mais complexa, a tarefa de adquirir os dados espectrais e de coleta de interesse da aplicação.

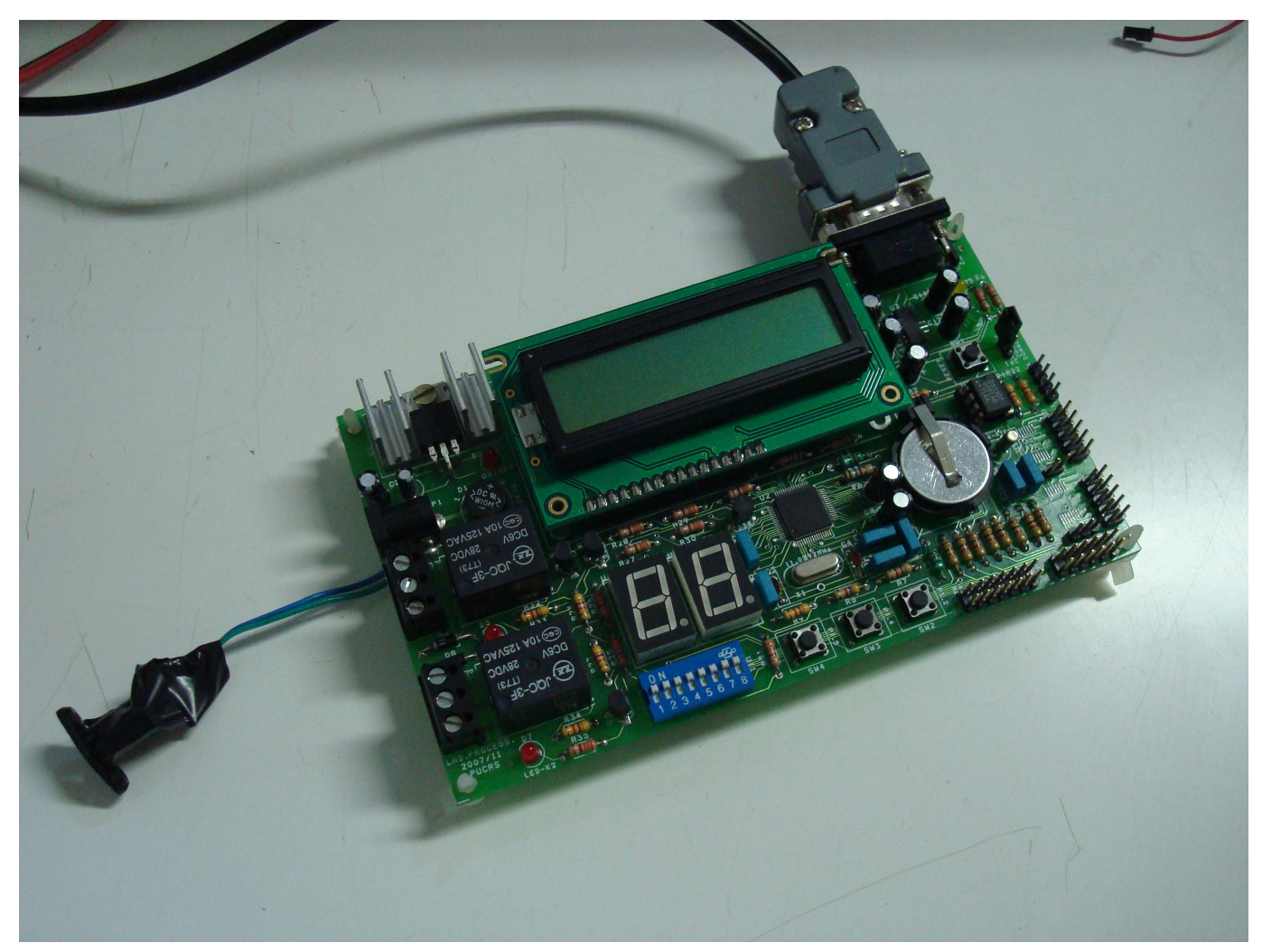

Figura 7.16 - Modulo eletrônico principal com o MSC1211. 


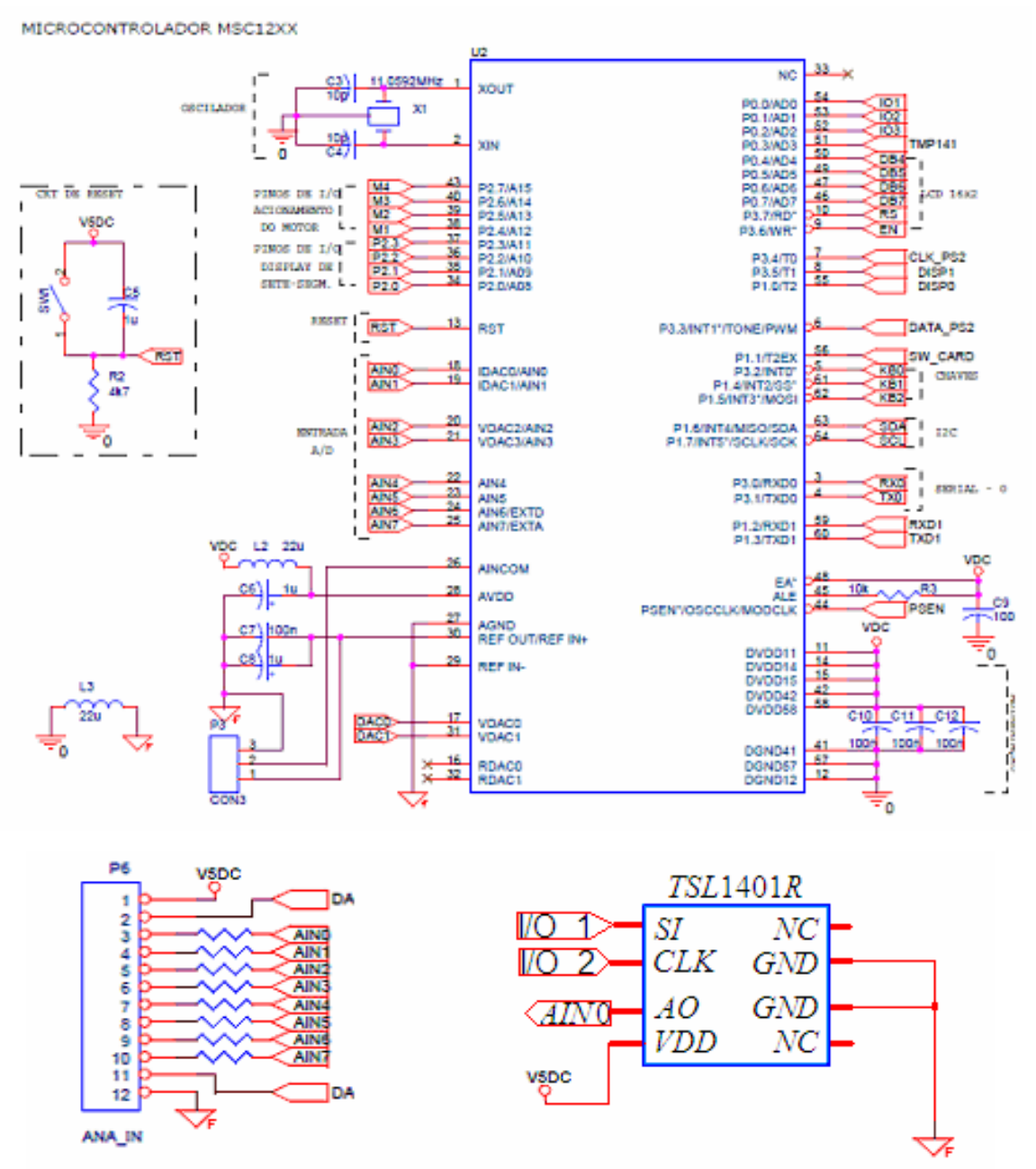

Figura 7.17 - Esquema eletrônico do modulo com o MSC1211 - Conversores ADC e DACs de precisão com MPU-8051 e memória Flash.

Os membros da família MSC121x de microcontroladores usam um núcleo de instruções compatível com o mais difundido 8051. Todos os códigos de instrução têm os mesmos padrões binários e produzem exatamente as mesmas funções lógicas. Entretanto, o MSC121x é aproximadamente três vezes mais rápido na execução para a mesma freqüência de clock, isto porque, ao invés de 12 pulsos de clock por ciclo de instrução, o MSC121x usa quatro. Assim, ele pode manter uma mesma velocidade de processamento trabalhando com um clock mais baixo determinando uma menor dissipação de energia e produzindo menor ruído. Adicionalmente, a ferramenta de software livre SDCC (Small Device C Compiler), pode ser utilizada diretamente para desenvolver programas para o MSC1211.

Características gerais do MSC1211[95]:

- Arquitetura Hardward (memória de programa separado da memória de dados);

- Clock máximo de 40MHz (no projeto foi utilizado um clock de 11,0592MHz); 
- Memória EEPROM interna de 32Kb para programa;

- Endereçamento de memória de programa externa até $64 \mathrm{~Kb}$

- Memória RAM interna de 128 bytes +128 bytes destinados aos registradores de funções.

O MSC1211 possui funções analógicas avançadas e seu sistema ADC (Analog Digital Converter) cumpre as mais estritas exigências para instrumentação analógica, integrando um amplificador de ganho programável (PGA) que atribui ao ADC resolução de nanovolt. O MSC1211 incorpora também um filtro programável, um multiplexador analógico e um sensor de temperatura.

O conversor ADC do MSC1211 é do tipo "sigma-delta" cujo funcionamento é exemplificado no diagrama de blocos da Figura 7.18. Ele usa um tipo peculiar de conversão que pode ser dividida em dois blocos principais: modulador analógico que captura o sinal analógico e o converte em uma cadeia de bits, e módulo filtro digital que tem a responsabilidade de converter o sinal em série do modulador em um número digital válido.

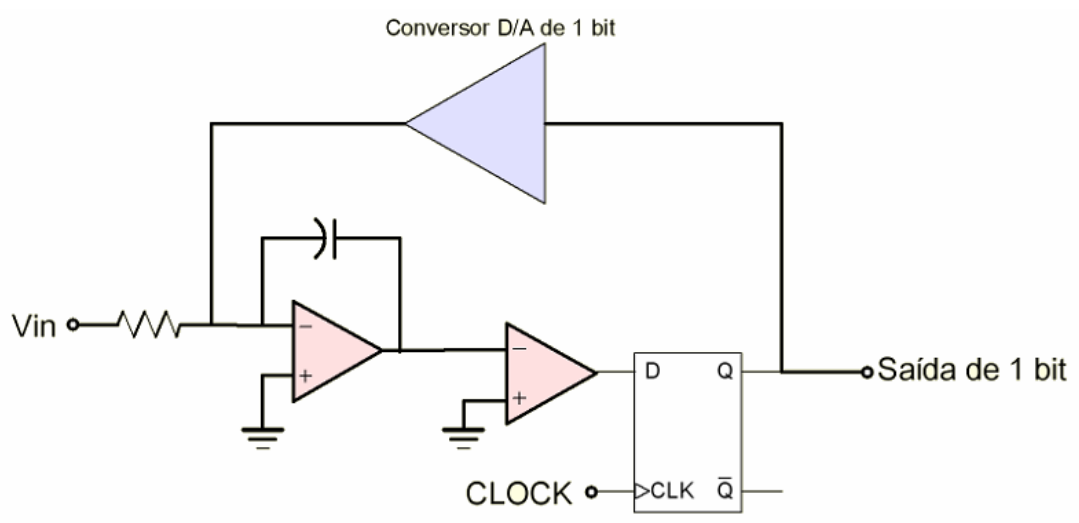

Figura 7.18 - Esquema básico de um modulador do conversor ADC sigma-delta. Reproduzido de[97].

O modulador analógico é semelhante a um conversor ADC por dupla inclinação, apesar de usar um conversor DAC de 1 bit como realimentação. O projeto básico de um modulador sigma-delta pode ser visto na Figura 7.19.

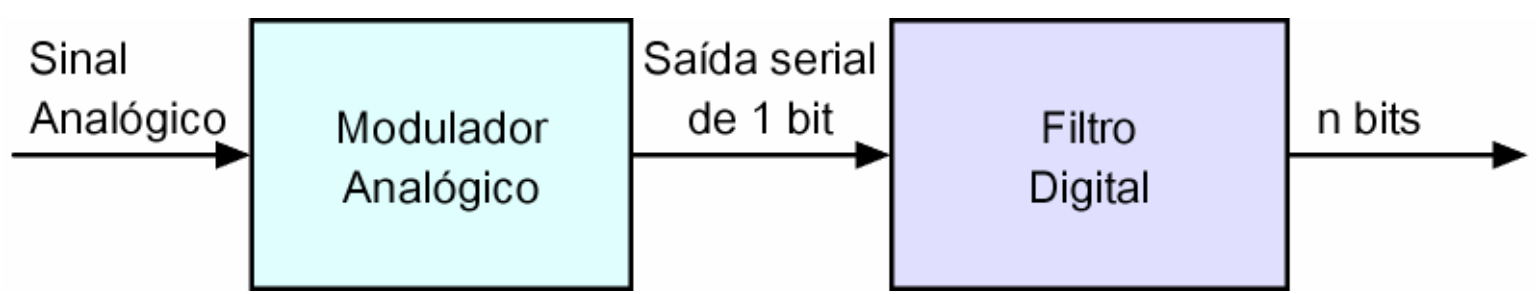

Figura 7.19 - Diagrama em blocos de um conversor ADC sigma-delta. Reproduzido de [97]. 
O sinal analógico que entra no primeiro amplificador operacional, que é um integrador somador, produz um sinal em rampa proporcional à tensão do sinal analógico. Esta forma de onda em rampa encontrada na saída do integrador é então comparada com zero volt pelo segundo amplificador operacional, que dessa forma tem a função de comparador e pode ser considerado um conversor ADC de um bit, já que sua saída terá dois estados, alto ou baixo, dependendo se a saída do integrador é positiva ou negativa. A saída do comparador é armazenada em um flip-flop do tipo D, que é uma memória estática de um bit [97].

Este flip-flop trabalha em uma freqüência muito alta. A saída do flip-flop é usada para realimentar o circuito através de um conversor DAC de um bit. Este conversor DAC de um bit converterá basicamente o "0" ou o " 1 " armazenado no flip-flop em uma tensão de referência positiva ou negativa para ser somado na saída de um integrador-somador.

Portanto, o integrador-somador somará a próxima amostra com o resultado da amostra anterior (uma tensão positiva ou negativa), com o propósito de manter o valor zero na saída do integrador. O resultado é que na saída do flip-flop tem-se uma série de "zeros" e "uns" que correspondem ao dado amostrado: o nível médio da cadeia de bits representa a tensão média do sinal de entrada analógico. Como o clock usado no flip-flop é muito alto, o dado é amostrado várias vezes, uma técnica conhecida como sobre-amostragem (oversampling). Quanto maior o clock, maior a precisão de um conversor ADC sigma-delta.[97]

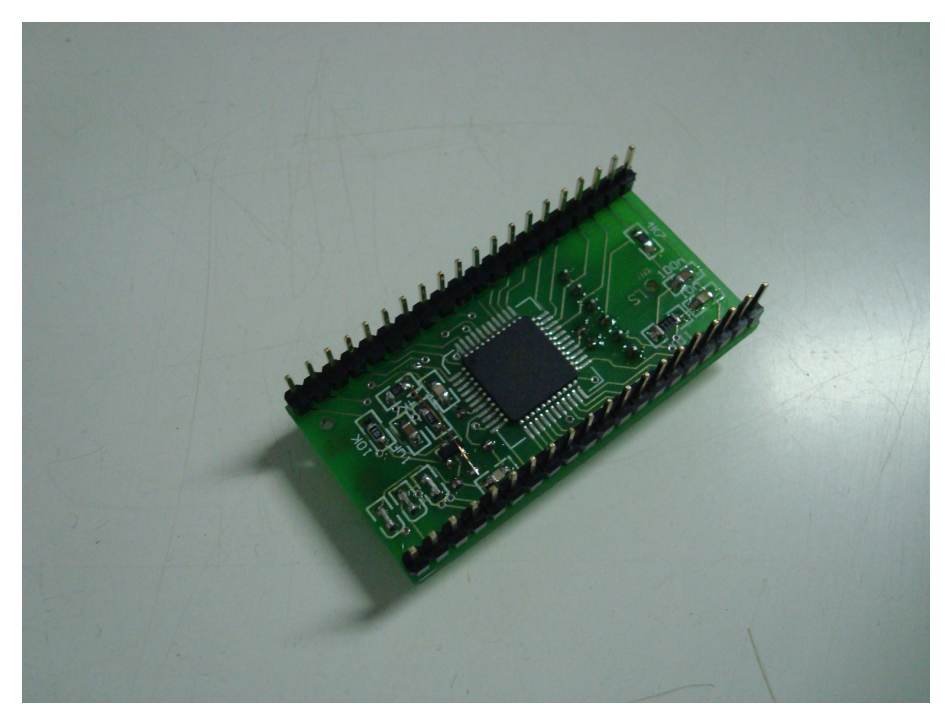

Figura 7.20 - Modulo eletrônico de avaliação com o Atmega32. 


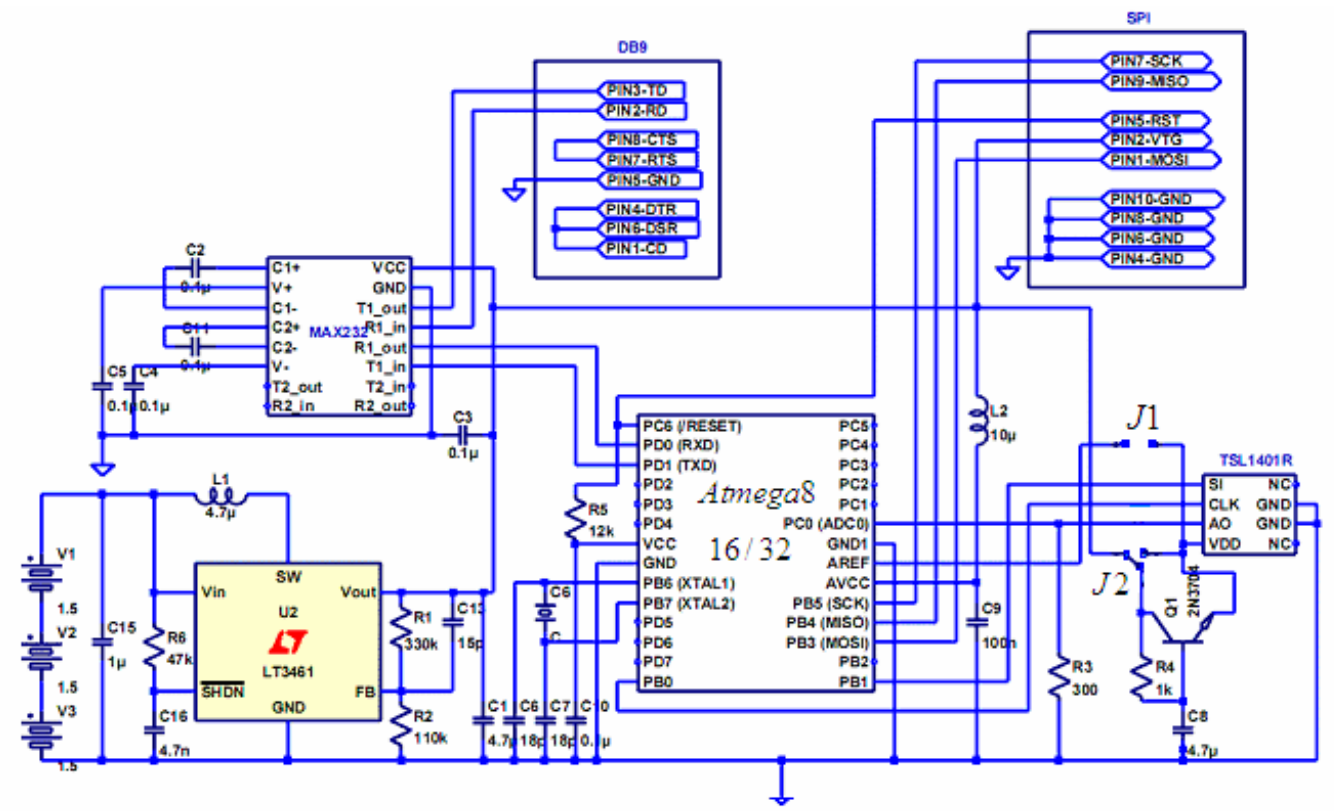

Figura 7.21 - Modulo eletrônico de avaliação com o Atmega32, Conversores ADC 10 bits e memória Flash.

Quanto ao Atmega32, as principais características são [96]:

- Geral: Arquitetura RISC, conjunto de 131 instruções, 32x8 registradores de uso geral, 32K Bytes de memória flash, 1024 Bytes de EEPROM, 2K Byte de memória SRAM.

- Periféricos: duplo 8-bit Timer/Counters, um 16-bit Timer/Counter Mode, oito canais ADC 10-bit e 32 linhas de entrada e saída.

Conforme já mencionado este módulo é dedicado uma avaliação da localização espacial das bandas de interesse dos filtros.

\subsection{Protótipo}

Um protótipo foi construído baseado nas diretivas propostas no escopo deste trabalho, a Figura 7.22 mostra o detector formado pelo filtro FIV montado sobre o PDA (detector chipsized) e um circuito de processamento, dispostos sob uma lente convergente, formando a base do módulo detector. 


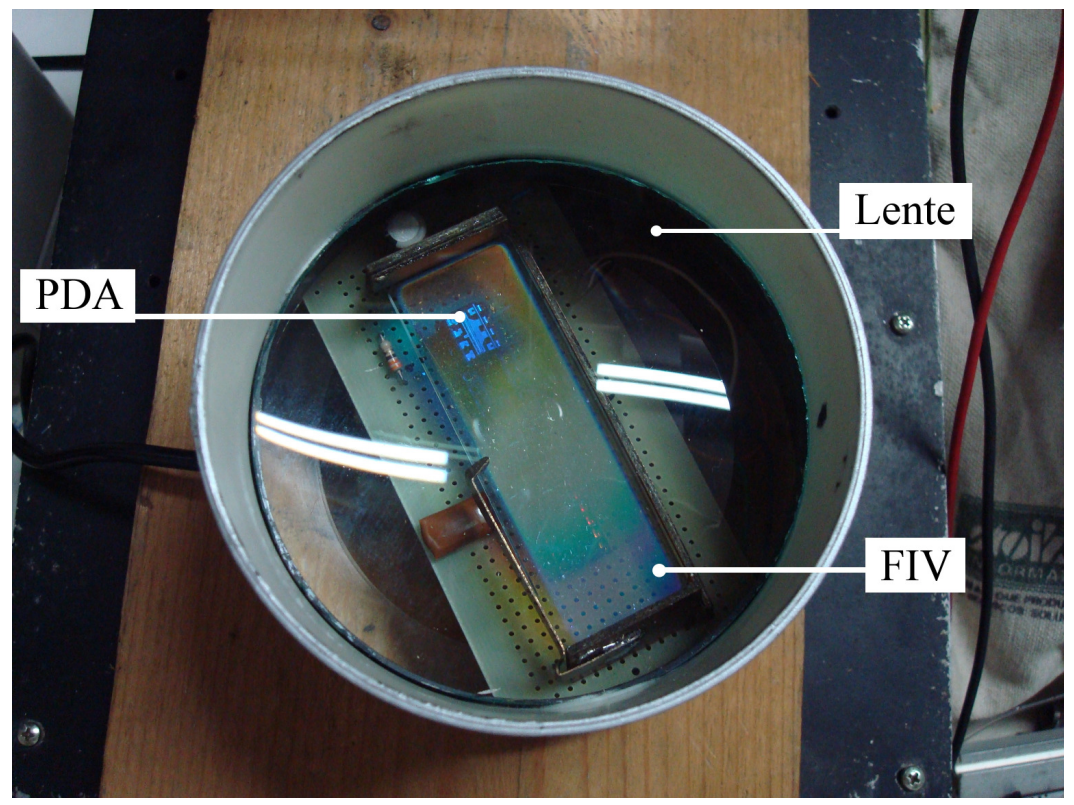

Figura 7.22 - Detector formado pelo filtro FIV montado sobre o PDA e um circuito de processamento dispostos sob uma lente convergente.

A Figura 7.23 apresenta o dispositivo de complemento da óptica do detector

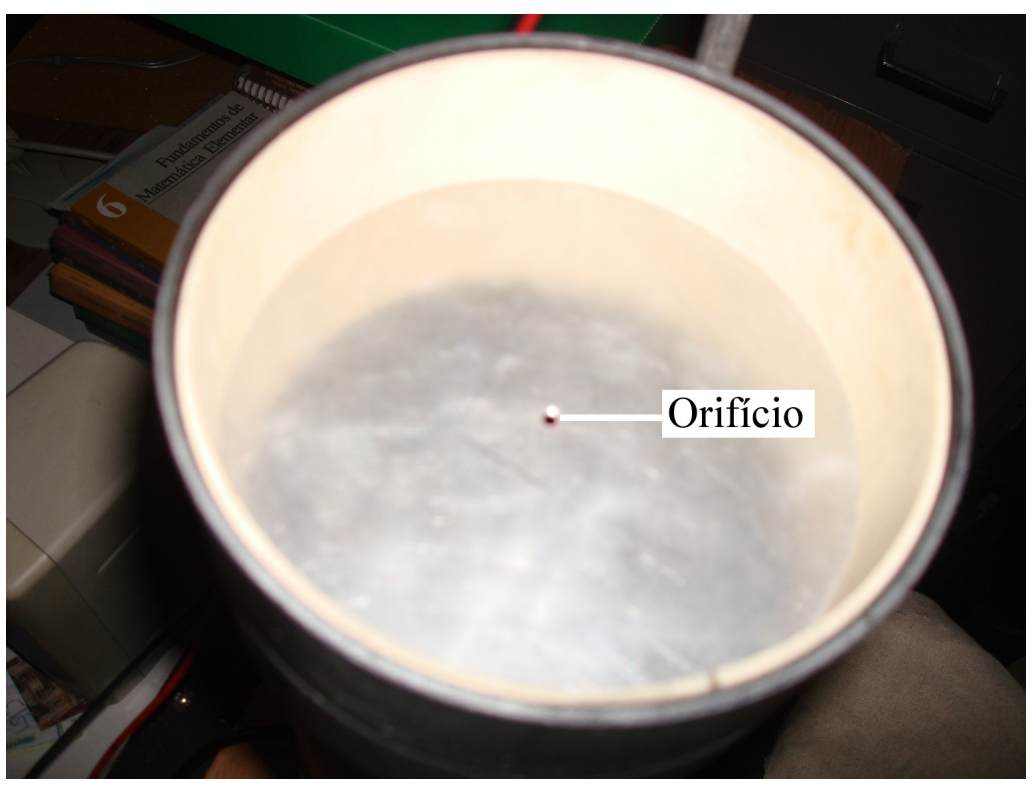

Figura 7.23 - Orifício localizado no plano focal da lente.

E a Figura 7.24 mostra o conjunto detector que deve ser capaz de avaliar o espectro de uma fonte de radiação na banda do detector (FIV e PDA) utilizados. 


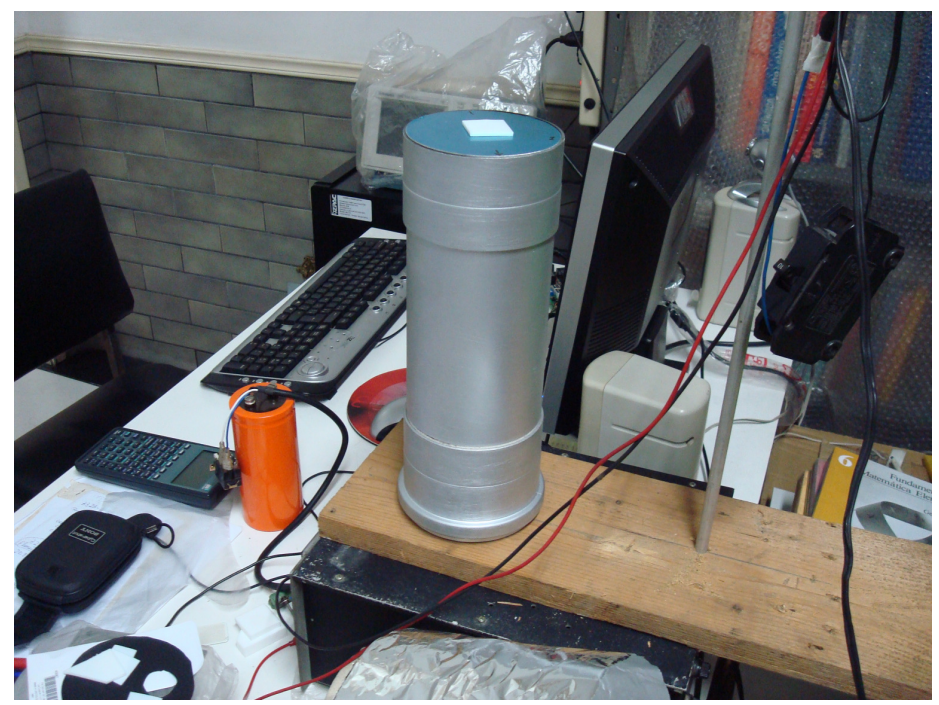

Figura 7.24 - Conjunto detector completo.

A configuração composta do detector, do módulo eletrônico mostrado na Figura 7.25 e do software de aquisição dedicado para esta aplicação, constitui o protótipo do Dispositivo Multicanal Espectral Para Análise Ambiental.

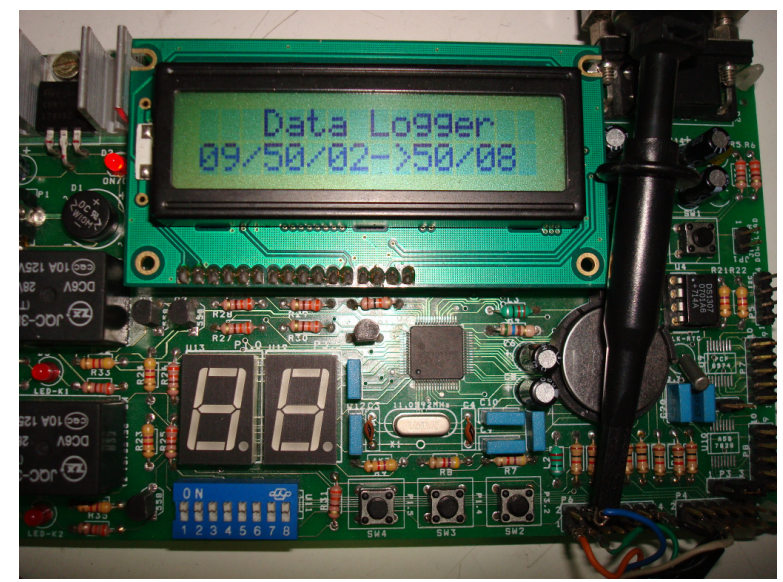

Figura 7.25 - Módulo eletrônico com o MSC1211Y5 já programado.

Considerando o conjunto FIV e PDA e os dados apresentados, espera-se que a menor porção detectável deste detector para uma dada radiação monocromática seja de $0,33 \mathrm{~nm}$. Utilizando o protótipo do Dispositivo Multicanal Espectral Para Análise Ambiental formado pelo módulo detector, com o filtro FIV2671-1 e o PDA TSL1401 juntamente com o módulo eletrônico, procedeu-se uma avaliação do espectro de um fotodiodo laser de fabricação desconhecida, tipo diodo laser de injeção direta, alimentado com uma fonte de tensão ajustável em 4,80 Volts e capacitor de filtragem de $66.000 \mu \mathrm{F}$. 
Medições instantâneas parciais são apresentadas nas telas do osciloscópio mostradas na Figura 7.26 e na Figura 7.27.

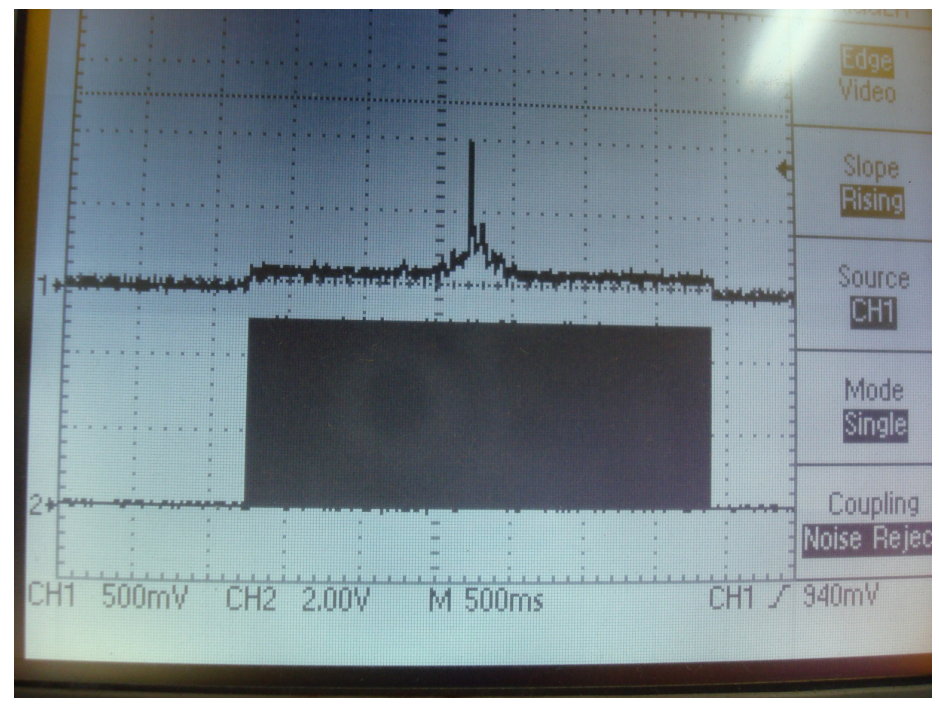

Figura 7.26 - Uma varredura do PDA correspondente a uma avaliação do espectro de um fotodiodo laser.

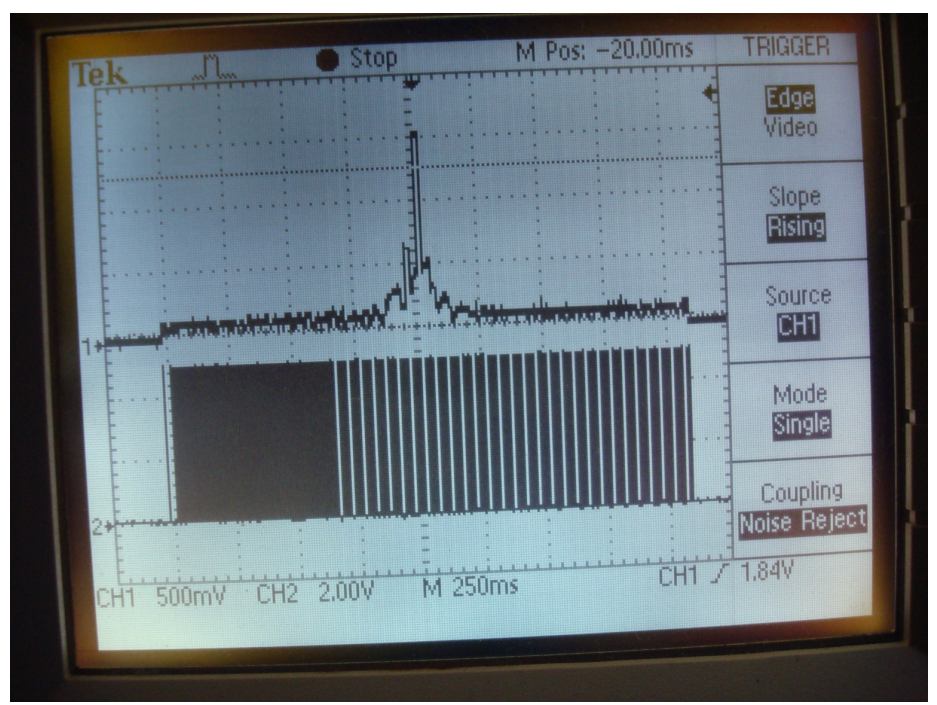

Figura 7.27 - Uma varredura do PDA correspondente a uma avaliação do espectro de um fotodiodo laser onde se observa a definição da medida da radiação monocromática incidente em um pixel.

Uma seqüência de dados correspondente a radiação emitida pelo fotodiodo descrito e incidente no detector foi adquirida pelo módulo eletrônico conforme as diretivas do software e transferida a um PC (personal computer), onde se realizou o tratamento deste conjunto de dados. O resultado é mostrado na Figura 7.28. 


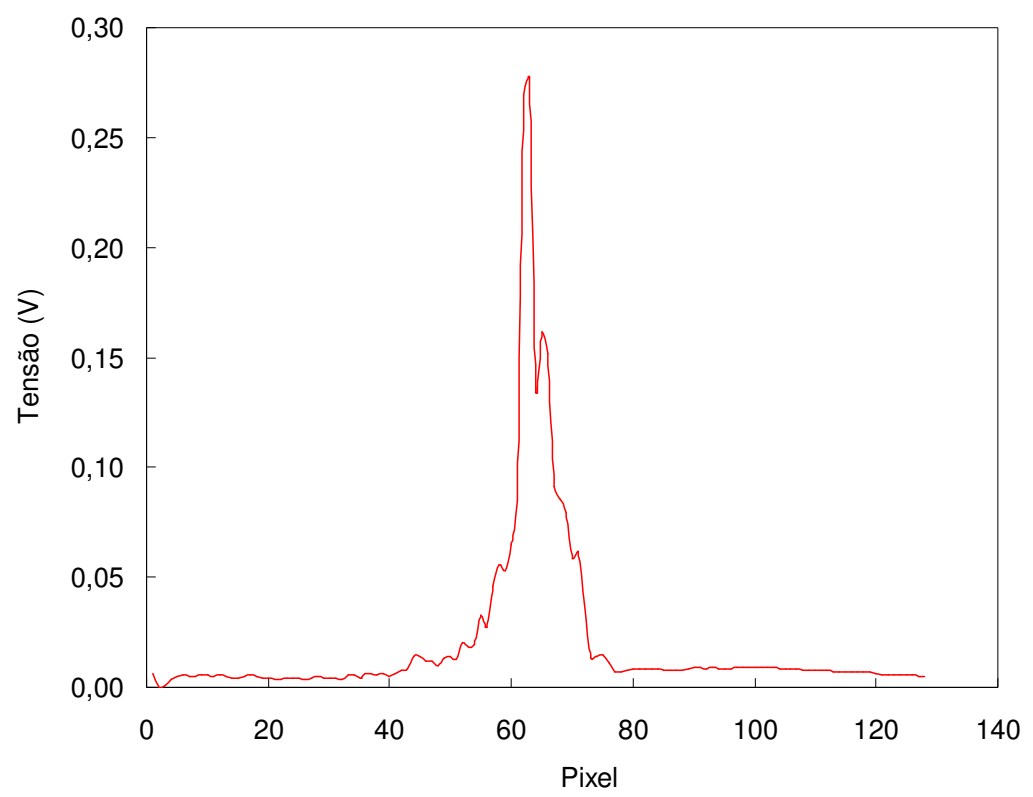

Figura 7.28 - Espectro do diodo laser obtido com o protótipo.

Apenas para simples referência, uma outra avaliação de um diodo laser do mesmo tipo realizada com espectrofotômetro modelo USB2000 da OceanOptics é apresentado na Figura 7.29 .

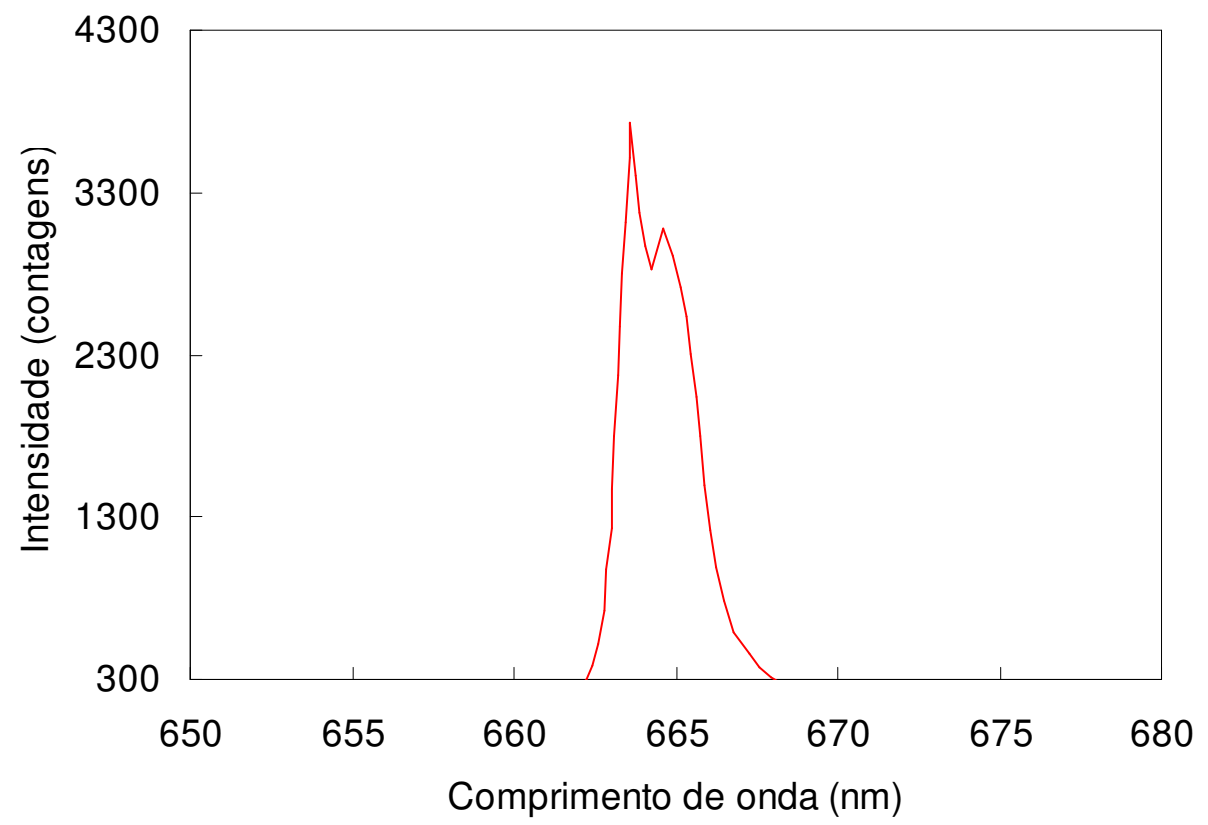

Figura 7.29 - Espectro de um diodo laser apresentado no site: http://ledmuseum.home.att.net/, medida realizada com espectrofotômetro modelo USB2000 da OceanOptics, pico do comprimento de onda 663,9 nm e largura a meia altura de $2.0 \mathrm{~nm}$. Acessado em 10/09/2009 - 8:00 hs. 
Como é possível observar, os espectros das Figura 7.28 e Figura 7.29 apresentam semelhanças, mostrando que o dispositivo é capaz de realizar as medidas pretendidas. Salienta-se que estas medições apresentadas são orientativas, sendo necessária a submissão do protótipo em pauta a uma sistemática de calibração contra uma fonte de radiação certificada e rastreada para a sua perfeita caracterização e, com isso, qualificar e quantificar periodicamente o seu desempenho em conformidade com os requisitos das aplicações sugeridas na introdução deste trabalho. 


\section{Conclusões}

Avaliando os resultados finais, a partir das necessidades iniciais e das possibilidades expressas ao longo da realização deste trabalho, foi constatado o pleno êxito na obtenção do filtro de interferência variável, validando a técnica, o processo e o modelo proposto. Assim ficou demonstrada a obtenção do filtro de interferência variável (FIV) pelo método da introdução de uma máscara para obliterar o jato de material evaporado.

Em súmula: o filtro de interferência variável (FIV) obtido está de acordo com o projeto e simulações; o FIV obtido possui uma boa supressão de bandas laterais; o FIV em conjunto com um PDA foi capaz de avaliar o espectro de uma luz monocromática coerente (laser); e foi possível construir um protótipo nacional composto pelo FIV, PDA, conjunto eletrônico e software.

Por outro lado, concluímos também que, à luz das possibilidades apontadas, é perfeitamente viável o efetivo emprego do arranjo proposto nas aplicações de análise ambiental marcadamente quando apresenta a possibilidade de obtenção de canais espectrais selecionáveis e ajustáveis que podem ser diretamente comparados com os dados obtidos por outros instrumentos concomitantemente, inclusive aqueles citados neste trabalho. Contudo deve-se considerar que, o atendimento às especificações necessárias a esse emprego, demanda trabalhos adicionais e estudos complementares que objetivem estabelecer e aperfeiçoar metodologias de aferição e calibração das medidas espectrais e radiométricas. 


\section{Considerações Finais}

Reiterando a escassez de dados e de instrumentação que nos motivou na realização deste trabalho, destacam-se as possibilidades e as condições para um esforço na busca de alternativas, soluções e inovações de modo a possibilitar, dentro de uma maior profusão de opções, o surgimento de soluções nacionais para uma instrumentação que atenda, ao menos em parte, as necessidades dos grupos de pesquisa brasileiros que atuam em programas científicos de relevância.

O maior problema enfrentado no que se refere à instrumentação, relaciona-se com a predominância estrangeira no fabrico e assistência técnica de manutenção de aparelhos de instrumentação. Fatores como a sofisticação, às vezes inadequadas em relação às nossas peculiaridades, padronização, especificação, exploração das capacidades da aparelhagem, "obsolescência planejada", etc., no que diz respeito à aparelhagem importada; e, qualidade insatisfatória do similar nacional; constituem obstáculos no equacionamento do problema.

Assim, aspectos acadêmicos da formação do capital humano, essenciais para o desenvolvimento cientifico (KNOW WHY), e seu desdobramento no desenvolvimento tecnológico (KNOW HOW), se manifestam também na produção e acumulo de iniciativas e alternativas de soluções nesta área sensível da instrumentação. 


\section{Planos Futuros}

Pretende-se considerar a obtenção de uma maior supressão das ordens vizinhas aprofundando o estudo da introdução, no projeto do filtro FIV, de uma camada intermediária de um refletor entre duas camadas de meia onda que formam a cavidade.

Esta possibilidade foi prevista neste trabalho, por simulação, onde foi utilizado um refletor de camada única interposto na cavidade inclinada feita segundo a deposição determinada pela máscara, para obter uma distribuição de transmitância como é a mostrada nas Figura 10.1 até a Figura 10.4.

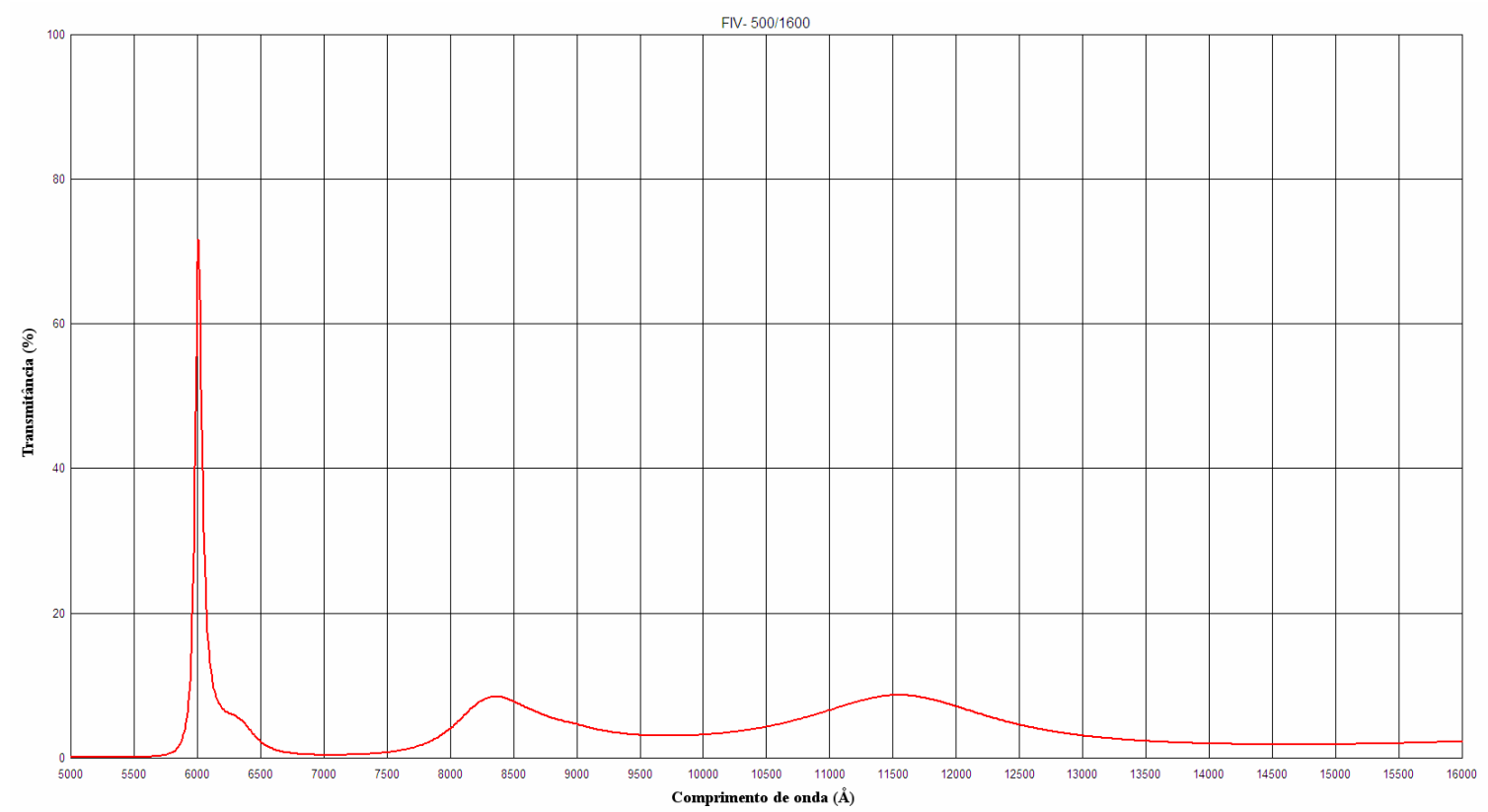

Figura 10.1 - Simulação do filtro $\left[\left(H^{\wedge} \mathbf{L}^{\wedge} 3\right)(\mathbf{H})(\mathbf{L})(\mathbf{R})(\mathbf{L})(\mathbf{L H})^{\wedge} 3\right], \lambda_{0}=675.0 \mathrm{~nm}$, para deposição em camadas inclinadas, representada para a posição correspondente a $d_{c} / 2=203,63 \mathrm{~nm}$.

A Figura 10.1 representa o espectro simulado correspondente a posição onde $d_{c} / 2=203,63 \mathrm{~nm}$. 


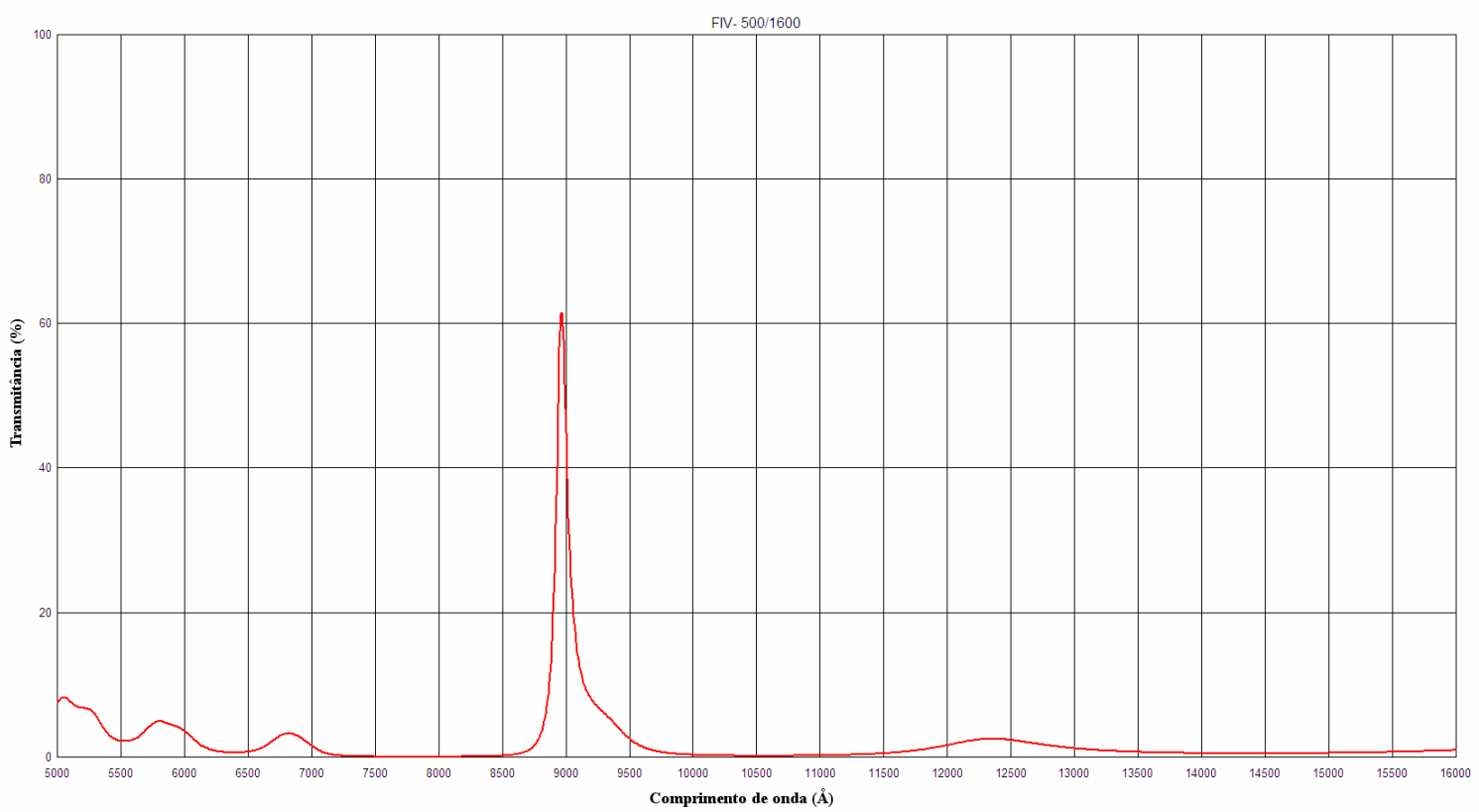

Figura 10.2 - Simulação do filtro $\left[\left(H^{\prime} \mathbf{L}^{\wedge} 3\right)(H)(L)(R)(L)(L H)^{\wedge} 3\right], \lambda_{0}=675.0 \mathrm{~nm}$, para deposição em camadas inclinadas, representada para a posição correspondente a $d_{c} / 2=303,40 \mathrm{~nm}$.

A Figura 10.2 representa o espectro simulado correspondente a posição onde $d_{c} / 2=303,40 \mathrm{~nm}$.

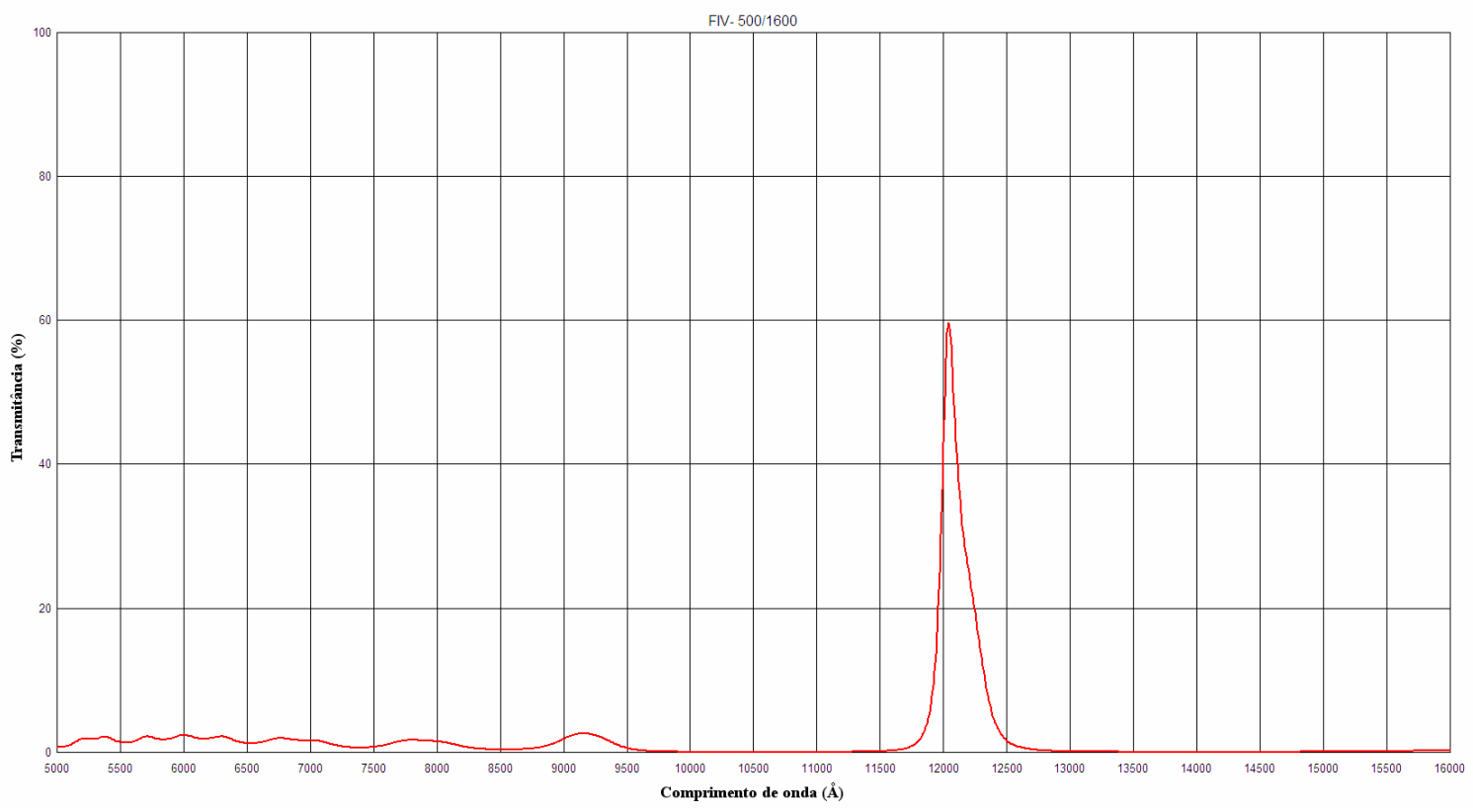

Figura 10.3 - Simulação do filtro $\left[\left(H^{\wedge} \wedge 3\right)(H)(L)(R)(L)(L H)^{\wedge} 3\right], \lambda_{0}=675.0 \mathrm{~nm}$, para deposição em camadas inclinadas, representada para a posição correspondente a $d_{c} / 2=406,10 \mathrm{~nm}$. 
A Figura 10.3 representa o espectro simulado correspondente a posição onde $d_{c} / 2=406,10 \mathrm{~nm}$.

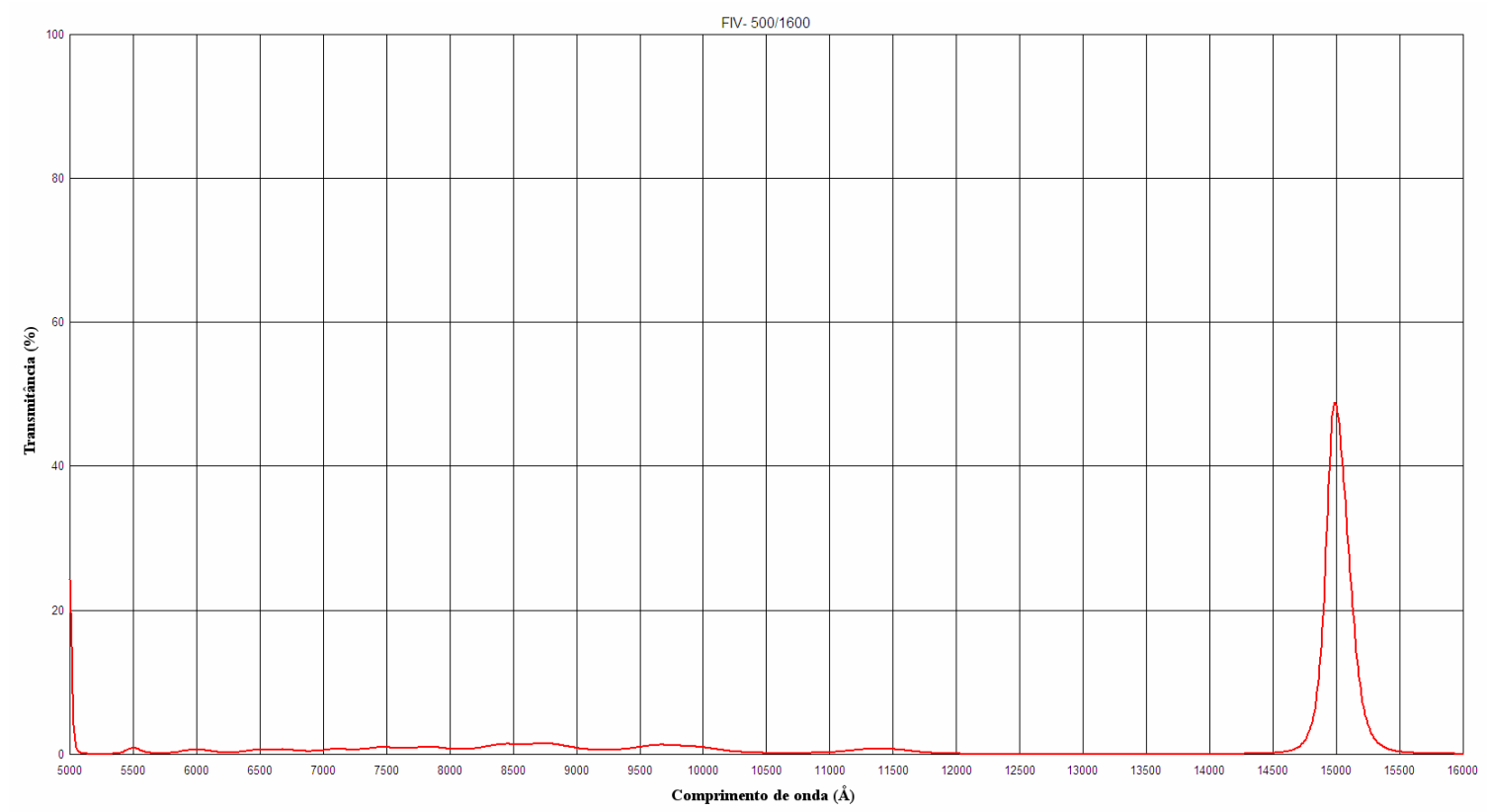

Figura 10.4 - Simulação do filtro $\left[\left(H^{\wedge} L^{\wedge} 3\right)(H)(L)(R)(L)(L H)^{\wedge} 3\right], \lambda_{0}=675.0 n m$, para deposição em camadas inclinadas, representada para a posição correspondente a $d_{c} / 2=506,60 \mathrm{~nm}$.

E a Figura 10.4 representa o espectro simulado correspondente a posição onde $d_{c} / 2=506,60 \mathrm{~nm}$.

Estas simulações apontam para uma nova etapa deste trabalho que, quando atingida, pode permitir a obtenção da desejável combinação de uma larga faixa espectral com uma largura a meia altura (FWHM) bastante satisfatória para atender aplicações exigentes e para servir de base para uma instrumentação aplicável a muitas áreas técnicas e de pesquisa científica e, além disso, pode também permitir a sua integração aos processos de fabricação de dispositivos microeletrônicos.

Este trabalho apresenta como possibilidade de continuação e pesquisas futuras, além da obtenção do FIV para largas bandas no espectro visível (VIS), o estudo das possibilidades técnicas da obtenção deste tipo de filtro para amplas faixas do espectro (UV, VIS e IR $300 \mathrm{~nm}$ a $14 \mu \mathrm{m}$ ), estudo dos processos para sua produção em escala, bem como a integração, desses processos, aos processos de sistemas integrados.

Planos futuros não podem deixar de considerar o desenvolvimento ou a adequação de uma instrumentação que atenda a peculiaridade dos filtros de interferência variável e seja 
capaz de caracterizar as suas transmitâncias e refletâncias localizadas, cujos resultados serão de grande relevância para a otimização da técnica de mascaramento utilizadas na fabricação desses componentes.

A continuação dos trabalhos envolve, a implementação de detectores com PDA's de maior densidade de Pixels para obter maior resolução espectral, a integração da eletrônica no corpo do detector, a adição de dispositivos de compensação da temperatura para minimizar os possíveis efeitos do aquecimento, principalmente no funcionamento em campo aberto, a serem avaliados.

O desdobramento natural e imprescindível deste trabalho é o desenvolvimento de uma sistemática de calibração para os equipamentos que serão montados e que, espera-se, possam fazer parte de uma rede de aquisição de dados integrada com equipamentos distribuídos em todo território nacional.

O FIV tem grande potencial de aplicações nas áreas de sensores, biosensores, espectrofotometria, instrumentação em geral e na industria. 


\section{Referências Bibliográficas}

[1] TORRERI, P., CECCARINI, M., MACIOCE, P., PETRUCCI, T.C. - Biomolecular interactions by Surface Plasmon Resonance technology. Ann Ist Super Sanità. 2005; 41(4):437-441.

[2] AMRAM, Philippe; GEORGELIN, Yvon. A Taste of Fabry and Perot's Dicoveries, In: Physica Scripta, Marseille, France Vol. T86, 76-82, 2000.

[3] LEE, Mindy R.; FAUCHET, Philippe M. Two-dimensional silicon photonic crystal based biosensing platform for protein detection, Opt. Express 15, 4530-4535 (2007).

[4] KURTA, H., CITRIN, D. S. - Coupled-resonator optical waveguides for biochemical sensing of nanoliter volumes of analyte in the terahertz region. Applied physics letters 87, 2411192005.

[5] HAGLMULLER, JAKOB et all, Nanocluster Optical Resonance Devices for Molecular Structure Transduction. Current Nanoscience, 2005, 1, 3-16 3 15734137/05.

[6] DAVIS, Charles M.; ZAROBILA, Clarence J.. Electro-optics handbook - Chapter 21 fiber-optic sensors (www.digitalengineeringlibrary.com) Copyright (C) 2004 The McGraw-Hill Companies.

[7] JOAnNOPOUlOS, John D.; et. al. Photonic Crystals, 2ed. Princeton: Priceton University Press, 2008.

[8] HECH, Eugene. Optics. Third Edition. Reading, Massachusetts: Addison-Wesley, 1998.

[9] KRASILNIKOVA, A. et. al.. Spatially resolved spectroscopy for non-uniform thin film coatings: comparison of two dedicated set-ups, Proc. SPIE 5965, 59651V (2005), DOI:10.1117/12.625183.

[10] LOUISNNRSEN, S. John Measurement of refractive indices and their dispersion, American Mineralogist, Volume 63, pages 394400, 1978. 
[11] SHIMIDT, O., KIESEL P., MOHTA S., JOHMSON, N.M., Resolving pm wavelength shifts in optical sensing, Applied Physics B, Volume 86, , nº, Abril de 2007, pp. 593-600(8).

[12] SCHMIDT, Oliver. Integration of chip-size wavelength detectors into optical sensing systems, M. Sc. Dissertation, Universität Erlangen_Nürnberg, Germany, 2007.

[13] IPCC 2007 - Intergovernmental Panel on Climate Change. Climate Change 2007. The Scientific Basis: Contribution of Working Group I to the Fourth Assessment Report of the International Panel of Climate Change. Edited by Houghton, J. T. et al. Cambridge University Press, New York; 2007.

[14] NOBRE, C. A. - Mudanças climáticas globais e o Brasil: Porque devemos nos preocupar. Boletim da Sociedade Brasileira de Meteorologia - Desafios Associados às Mudanças Climáticas. Vol.31, nº1, 7-11. Abril de 2007.

[15] SILVA DIAS, M.A.; SILVA DIAS, P.L. - As incertezas Regionais nos Cenários de Mudanças Climáticas Globais. Boletim da Sociedade Brasileira de Meteorologia - Desafios Associados às Mudanças Climáticas. Vol.31, nº1, 12-16. Abril de 2007.

[16] SAYÃO, A. C. - Estudo da variabilidade sazonal da profundidade óptica do aerossol em São Paulo a partir de radiômetros MFRSR. Dissertação de Mestrado apresentada ao Instituto de Astronomia, Geofísica e Ciências Atmosféricas, Universidade de São Paulo, 2008.

[17] IPCC 2001 - Intergovernmental Panel on Climate Change. Climate Change 2001. The Scientific Basis: Contribution of Working Group I to the Third Assessment Report of the International Panel of Climate Change. Edited by Houghton, J. T. et al. Cambridge University Press, New York; 2001.

[18] HANSEN, J.; SATO, M. \& RUEDY, R. - Radiative forcing and climate response. Journal of Geophysical Research 102 (D6), 6831-6864; 1997.

[19] TROSNIKOV, I.V. \& NOBRE, C.A. - Estimation of aerosol transport from biomass burning áreas during the SCAR-B esperiment. Journal of Geophysical Research, 103, NO. D24,32.129-32.137, December 27, 1998. 
[20] ANDREAE, M. O.; ROSENFELD, D.; ARTAXO, P.; COSTA, A. A.; FRANK, G. P.; LONGO, K. M.; SILVA-DIAS, M. A. F. - Smoking Rain Clouds over the Amazon Science, 303, 1337-1342, 27 February 2004.

[21] MIRANDA, R. M. - Caracterização físico-química e propriedades ópticas do aerossol urbano na Região Metropolitana de São Paulo. Tese de doutorado, Instituto de Astronomia, Geofísica e Ciências Atmosféricas da Universidade de São Paulo; 2001.

[22] CORRÊA, M. P. - Índice ultravioleta: avaliações e Aplicações. Tese de doutorado, Instituto de Astronomia, Geofísica e Ciências Atmosféricas da Universidade de São Paulo, 2003.

[23] CASTANHO, A. D. A. - Propriedades ópticas das partículas de aerossol e uma nova metodologia para a obtenção de profundidade óptica via satélite sobre São Paulo. Tese de Doutorado, Instituto de Física, Universidade de São Paulo, São Paulo, 2005.

[24] ROSÁRIO, N. M. E do. - Comparação de profundidades ópticas espectrais do aerossol obtidas para São Paulo a partir de um Multifilter Rotating Shadowband Radiometer e do fotômetro solar da AERONET. Dissertação Mestrado, Instituto de Astronomia, Geofísica e Ciências Atmosféricas, Universidade de São Paulo, 2006.

[25] YAMASOE, M. A. - Estudo de propriedades ópticas de partículas de aerossóis a partir de uma rede de radiômetros. Tese de Doutorado, Instituto de Física, Universidade de São Paulo, São Paulo, 1999.

[26] HORVATH, H. - Aerosols an introduction. Journal of Environmental Radioactivity, v. 51, p. 5-25, 2000.

[27] HOLBEN, B. N.; SETZER, A.; ECK, T. F.; PEREIRA, A. \& SLUTSKER - I. Effect of dry-season biomass burning on Amazon basin aerosol concentrations and optical properties, 1992-1994. Journal of Geophysical Research, 101 (D14), 19465-19481; 1996.

[28] LANDUlfo, E.; PAPAYANnis, A.; ARTAXO, P.; CASTANHO, A. D. A.; DE FREITAS, A. Z.; SOUZA, R. F.,;VIEIRA JUNIOR, N. D.; JORGE, M. P.; S'ANCHEZ-CCOYLLO, O. R.; MOREIRA, E D. S. - Synergetic measurements of 
aerosols over São Paulo, Brazil using LIDAR, sunphotometer and satellite data during the dry season. Atmospheric Chemistry and Physics, vol. 3, p. 1523-1539, 2003.

[29] CAStanho, A. D. A. - A Determinação Quantitativa de Fontes de Material Particulado na Atmosfera da Cidade de São Paulo. Dissertação de Mestrado, Instituto de Física da Universidade de São Paulo; 1999.

[30] KOREN, I.; KAUFMAN, Y. J.; REMER, L. A. \& MARTINS, J. V. - Measurement of the effect of Amazon smoke on inhibition of cloud formation, Science 303: 1342 $1345 ; 2004$.

[31] PANDIS, N. S. \& SEINFELD, J. H. - Atmospheric Chemistry and Physics, From Air Pollution to Climate Change. John Wiley \& Sons INC, Canadá; 1998.

[32] SHAW, G.E. - Sun photometry. Bulletin of the American Meteorological Society, 64(1): 4-10; 1983.

[33] WENNY, B. N.; SCHAFER, J. S.; DELUISI, J. J.; SAXENA, V. K.; BARNARD, W. F.; PETROPAVOLVSKIKH, I. V. \& VERGAMINI, A. J. - A study of regional aerosol radiative properties and effects on ultraviolet-B radiation. Journal of Geophysical Research, 103(D14): 17083-17097; 1998.

[34] WENNY, B. N.; SCHAFER, J. S.; DELUISI, J. J.; SAXENA, V. K.; BARNARD, W. F.; PETROPAVOLVSKIKH, I. V. \& VERGAMINI, A. J. - A study of regional aerosol radiative properties and effects on ultraviolet-B radiation. Journal of Geophysical Research, 103(D14): 17083-17097; 1998.

[35] WENNY, B. N.; SCHAFER, J. S.; DELUISI, J. J.; SAXENA, V. K.; BARNARD, W. F.; PETROPAVOLVSKIKH, I. V. \& VERGAMINI, A. J. - A study of regional aerosol radiative properties and effects on ultraviolet-B radiation. Journal of Geophysical Research, 103(D14): 17083-17097; 1998.

[36] MACARTHUR, J. L.; HALLIWELL, D.H.; O. J. N.; N. T. O.; J. R. S.; C. W. - Field comparison of network Sun promoters. Journal of Geophysical Research.108, NO. D19:4596; 2003.

[37] LIOU, K. N. - An Introduction to Atmospheric Radiation. Academic Press. New York, Oxford. $2^{\text {a }}$ edição; 2002.

[38] HOLBEN, B. N.; ECK, T.F.; SLUTSKER, I.; TANDARÉ, D.; BUIS, J. P.; SETZER, A.; VERMOTE, E.; REAGAN, J. A.; KAUFMAN, Y.J.; NAKAJIMA, T.; LAVENU, 
F.; JANJOWIAK, I.; SMIRNOV, A. - A federated instrument network and data archive for aerosol characterization. Remote Sensing of Environment, v. 66, p. 1-16, 1998.

[39] ROLLIN, E. M. - An introduction to the use of Sun-photometry for the atmospheric correction of airborne sensor data. Disponível em: http://www.ncaveo.ac.uk/site-resources/pdf/cimel.pdf . Acesso em: 17 de novembro de 2008.

[40] HARRISON, L.; MICHALSKY, J. \& BERNDT, J. - Automated multifilter rotating shadow-band radiometer: an instrument for optical depth and radiation measurements. Applied Optics, 33(22): 5118-5125; 1994.

[41] MICHALSKY, J. J.; LILJEGREN, J. C. \& HARRISON, L. C. - A comparison of Sun photometer derivations of total column water vapor and ozone to standard measures of same at the Southern Great Plains Atmospheric Radiation Measurement site. Journal of Geophysical Research, 100(D12): 25995-26003; 1995.

[42] AlEXANDROV, M. D.; LACIS, A. A.; CARLSON, B. E. \& CAIRNS, B. - Remote sensing of atmospheric aerosols and trace gases by means of Multifilter Rotating Shadowband Radiometer. Part I: retrieval algorithm. Journal of the Atmospheric Sciences, 59(3): 524-543; 2002a.

[43] ALEXANDROV, M.D.; LACIS, A.A.; CARLSON, B.E.; CAIRNS, B. - Remote sensing of atmospheric aerosols and trace gases by means of Multifilter Rotating Shadowband Radiometer. Part II: climatological applications. Journal of the Atmospheric Sciences, 59(3): 544-566, 2002b.

[44] FORGAN, W. B. General method for calibrating Sun photometer. Applied Optics, 33(21): 4841-4850, 1994.

[45] SHAOCAI, Y.; SAXENA, V. K.; WENNY, B.N.; DELUISI, J.J.; YUE, G. K.; PETROPAVLOVSKIKH, I. V. - A study of the aerosol radiative properties needed to compute direct aerosol forcing in the southeastern United States. Journal of Geophysical Research, Vol. 105, NO (D20): 24739-24749; 2000.

[46] MICHALSKY, J. J.; SCHLEMMER, F. A.; BERKHEISER, W. W.; BERNDT, J. L.; HARRISON, L. C.; LAULAINEN,N. S.; LARSON, N. R.; BARNARD,J. C. Multiyear measurements of aerosol optical depth in the Atmospheric Radiation 
Measurement and Quantitative Links programs, Journal Geophysical Research, 106(D11), 12,099 - 12,107, 2001.

[47] PlANA-FATTORI, A.; DUBUISSON, P.; FOMIN, B.A. \& CORRÊA, M. P. Estimating the atmospheric water vapor content from multi-filter rotating shadowband radiometry at São Paulo, Brazil. Atmospheric Research. Vol. 71, no. 3, pp. 171192. August, 2004.

[48] SAKERIN, S. M.. An Instrumentation Complex for Atmospheric Radiation Measurements in Siberia. Thirteenth ARM Science Team Meeting Proceedings, Broomfield, Colorado, March 31-April 4, 2003.

[49] EHSANI, A. R., REAGAN, J. A., ERXLEBEN, W. H. Design and Performance Analysis of an Automated 10-Channel Solar Radiometer Instrument. Journal of Atmospheric and Oceanic Technology, Tucson, Arizona, Vol. 15, 697-707, Julho.1997.

[50] ROGALSKI, A.; BIELECKI, Z.. Detection of optical radiation, Bulletin of the polish academy of sciences Vol. 52, No. 1, 2004.

[51] BOSCHETTI, Cesar, Detectores de Infravermelho, Princípios e Caracterização, Apostila, www.las.inpe.br/ cesar, acessado em 05/03/2009.

[52] SZE, S. M. Physics of Semiconductor Devices. 2ed. New York: John Wiley \& Sons, 1981.

[53] REITZ, John; MILFORD, Frederick; CHRISTY, Robert. Fundamentos da teoria eletromagnética. Tradução de Renê Balduino Sander. - Rio de Janeiro: Campus, 1982.

[54] REZENDE, Sérgio. Materiais e Dispositivos Eletrônicos. 2ed. São Paulo: Livraria da Física, 2004.

[55] LEQUIME, Michel. Tunable thin film filters: review and perspectives. Advances in Optical Thin Films. In: Proceedings of the SPIE, Volume 5250, pp. 302-311 (2004).

[56] VUOLO, J. H. Visão Humana. Apostila - 2004.

[57] VAUGHAN, J M - Fabry-Perot interferometer: history, theory, practice and applications, 2.ed., Adam Hilger, 1989, 583p. 
[58] BARTEK, M.; et.al., Stray-Ligth compensation in thin-film Fabry-Perot In: Optical filters international conference on solid-state, 10, Sendai, Japan, 1999. p. 240-243.

[59] TUANTRANONT, Adisorn; BRIGHT, Victor M.. Introduction to Micro-ElectroMechanical Systems (MEMS) with Emphasis on Optical Applications. Neotec Technical Journal, Vol.1 No.6, January-February, 2000(227).

[60] KURTH, S.;; HILLER, K.; DÖTZEL, W.; GEßNER, T.; NEUMANN, N.; HEINZE, M.. Tunable infrared filter based on Fabry-Perot-Interferometer. Proc. of Micro System Technologies 2003, Munich (Germany), 2003 Oct 7-8.

[61] CORREIA, J. H.; Emadi, A. R.; WOLFFENBUTTEL, R. F.. UV Bandpass optical filter for microspectrometers, ECS transactions, Vol. 4, No1, pp.141-147, Electro Chemical Society, NJ, USA. 2006.

[62] EKLUND, E. Jesper; SHKEL, Andrei M.. Performance Tradeoffs in MEMS Sensor with High-Finesse Fabry-Perot Interferometry Detection, NSTI-Nanotech 2005, www.nsti.org. ISBN 0-9767985-2-2 Vol.3,2005 p-533-536.

[63] CORREIA, J. H.; BARTEK, M.; WOLFFENBUTTEL, R. F.. High-Selectivity SingleChip Spectrometer for Operation at Visible Wavelengths, In: International electron devices meeting, San Francisco, California, 1998 - "IEDM'98 : proceedings". Piscataway: IEEE, 1998. ISBN 0-7803-4774-9. p. 467-470.

[64] YANG, Heng. Design And Fabrication of A Tunable Fabry-Perot Interferometer/Photodiode Micro-Spectral Image Sensor, M. Sc. Dissertation, University of Notre Dame, Indiana, United States, 2007.

[65] COLE, G. D.; et. al.. Design and analysis of mems tunable vertical cavity semiconductor optical amplifiers, In: International conference on indium phosphide and related materials, USA, 2005, pages 114-117.

[66] NEUMANN, Norbert; et. al.. Tunable infrared detector with integrated micromachined Fabry-Perot filter, J. Micro/Nanolith. MEMS MOEMS 7, 021004 (2008), DOI:10.1117/1.

[67] CORREIA, J.H.. et. al.. Optical Microspectrometer using a Micro-Instrumentation Platform, The 2nd International Conference on Integrated MicroNanotechnology for Space Applications, Pasadena, CA, USA, 11-15 April, 1999, pp. 99-106 
[68] CORREIA, J.H., et. al.. CMOS compatible optical sensors with thin film interference filters: fabrication and characterization, In: Proc. Semiconductor Advances for Future Electronics (SAFE'98), Mierlo, The Netherlands, 25-26 November, Editor: J.P. Veen, (ISBN 90-73461-15-4), 1998, pp. 291-29.

[69] DOBROWOLSKI, J. A.. Optical properties of films and coatings. handbook of optics part 11 (www.digitalengineeringlibrary.com) Copyright (C) 2004 The McGraw-Hill Companies.

[70] THELEN, Alfred J.. Design of optical interference coatings. Optical and ElectroOptical Engineering.West Germany.USA. New York. McGRAW-HILL Book Company.

[71] Maksimovi'c, M.. Optical resonances in multilayer, Ph.D. thesis, University of Twente, ISBN 978-90-365-2657-9. The Netherlands. 2008.

[72] WANG, Z.Y.. Photonic crystal narrow filters with negative refractive index structural defects Progress In Electromagnetics Research, China, 2008, 421-430.

[73] PÉREZ, E, X.. Design, fabrication and characterization of porous silicon multilayer optical devices. M. Sc. Dissertation Universitat Rovira i Virgili.France. ISBN:978-84691-0362-3/DL: T.2181-2007

[74] MAKSIMOVIC, M. et. al.. Field representation for optical defect resonances in multilayer microcavities using quasi-normal modes, Optics Communications, Volume 281, The Netherlands, 2008, p. 1401-1411.

[75] NENKOV, M.; PENCHEVA, T.. Multilayer symmetrical dielectric stacks for needs of near ir heat reflector design. Bulgarian Journal of Physics 25. Russe. 1998. p. 38-48.

[76] DUYAR, O. et. al. Design and Preparation of Antireflection and Reflection Optical Coatings. Turk J Phys, Ankara-TURKEY.2004.

[77] PARDO, B. et. Al. X-UV synthetic interference mirrors : theoretical approach. Revue Phys. Appl... France. 1988. p. 1579-1597.

[78] LAROUCHE, S.; MARTINU, L.. OpenFilters: open-source software for the design, optimization, and synthesis of optical filters, Appl. Opt. 47, Montréal, 2008. p. 219230. 
[79] M. Bass, Handbook of optics, optical society of America, USA. StateMcGraw-Hill, 1995.

[80] Borns, M., Wolf, E.. Principles of Optics- 6ed.- ISBN 0-08-0264382.

[81] KNIPPA, B. D.. Thin film technology based micro-fourier spectrometer, Photonics West Micromachinig and Microfabrication, Conference on MOEMS and Miniaturized Systems III, San Jose, California, USA, 2003.

[82] Mandal, S..Modeling and analysis of an extrinsic Fabry-Perot interferometer performance using MATLAB, India, 2004,en.iust.ac.ir/profs/Sadr/Papers/omdp21.pdf.

[83] CORREIA, J. H.. Silver-based reflective coatings for micromachined optical filters, Journal of Micromechanics and Microengineering, The Netherlands. 1999. pp. 162165.

[84] BARTEK, M.. Quality Factor of Thin-Film Fabry-Perot Resonators: Dependence on Interface Roughness, EUROSENSORS XIII The 13th European Conference on Solid-State Transducers, The Netherlands, 1999.

[85] KLAASSEN,T.. Imperfect Fabry-Perot resonators, Casimir PhD Series. ISBN-10: 908593-018-9. ISBN-13: 978-90-8593-018-1. Delft-Leiden, 2006.

[86] Correia, J. H.. Optical Microssystems in Silicon Based on a Fabry-Perot resonance cavity Application for spectral analysis of visible light. ISBN 90-407-1870-9. The Netherlands. 1999.

[87] http://www.sspectra.com/

[88] http://www.ftgsoftware.com/

[89] ABEL-TIBERINI, L.. Manufacturing of linear variable filters with straight isothickness lines, Proc. of SPIE Vol. 5963, 59630B, Marseille, France.

[90] SANTO, A. M. E. Influence of the oxygen partial and total pressures on the proppertie of DC sputtered titanium dioxide thin films, Final Report CFBEE Student, IPA/Ècole Polytechinique Fédérale de Lausanne, Lausanne, 2000.

[91] SCAPIN, V. O. Determinação da Espessura e Composição Química de Filmes Finos, Dissertação de Mestrado, Instituto de Pesquisas Energéticas e Nucleares - IPEN, São Paulo, 2004. 
[92] Dedicated spectrophotometer for localized transmittance and reflectance measurements, Laëtitia Abel-Tiberini, Frédéric Lemarquis, and Michel Lequime, March 2006 / Vol. 45, No. 7 / APPLIED OPTICS.

[93] Li, Q.. Light scattering of semitransparent media, M. Sc., School of Mechanical Engineering Georgia Institute of Technology. Georgia. USA. May 2008.

[94] http://www.taosinc.com/getfile.aspx?type=press\&file=ts11401r-lf-e8.pdf, acessado em 05/03/2009 e http://www.taosinc.com/getfile.aspx?type=press\&file=ts11410r-e29.pdf acessado em 05/03/2009.

[95] http://www.ti.com/lit/gpn/msc1211y5, acessado em 05/03/2009.

[96] http://www.atmel.com/dyn/resources/prod_documents/2503S.pdf, $\quad$ acessado 05/03/2009.

[97] SANTOS, A. C. T.. Sistema de monitoramento de temperatura para detector de múons do L.H.C.B, Dissertação de Mestrado Profissional Ênfase em Instrumentação Científica, CBPF/RJ, RIO DE JANEIRO 2008. 


\section{Apêndice A - Análise por Retroespalhamento Rutherford (RBS)}

Os espectros foram obtidos no acelerador de íons do LAMFI-IF-USP e analisados através do programa SIMNRA. A figura A.1 mostra um espectro de RBS típico obtido com a amostra analisada.
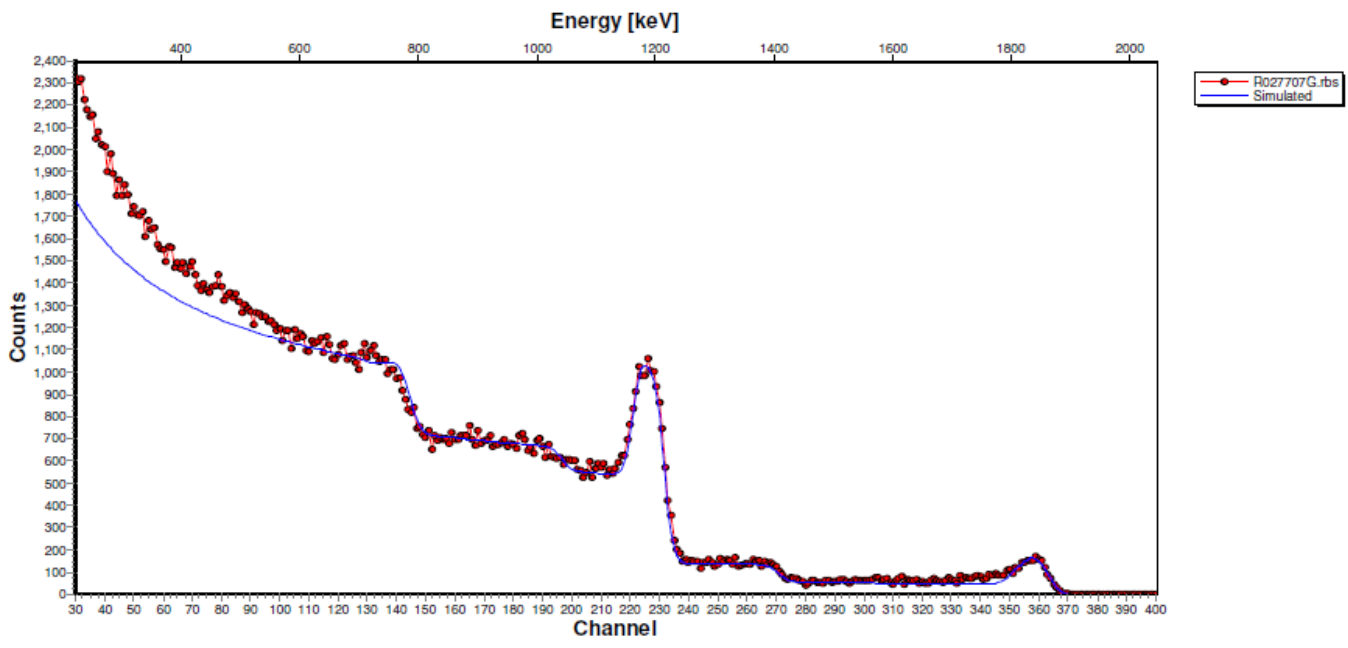

Figura A.1: Espectro de RBS experimental típico e ajuste por simulação - amostra de Al sobre vidro.

Sumário das medidas de RBS. As posições 1, 2, 3 e 4 encontravam-se em linha reta na direção da variação linear da deposição e eqüidistantes umas das outras (distância de $1 \mathrm{~mm}$ ).

Tabela A.1 - Sumário das medidas de RBS.

\begin{tabular}{|c|c|c|c|c|c|}
\hline & & Posição 1 & Posição 2 & Posição 3 & Posição 4 \\
\hline \multirow{4}{*}{ Camada 1} & $\begin{array}{l}\text { Espessura } \\
\left(10^{15} \mathrm{at} / \mathrm{cm}^{2}\right)\end{array}$ & 237,00 & 237,00 & 237,00 & 237,00 \\
\hline & \multicolumn{5}{|c|}{ Concentrações } \\
\hline & $\mathbf{O}$ & 0,2778 & 0,1278 & 0,2230 & 0,1600 \\
\hline & Al & 0,7222 & 0,8722 & 0,7770 & 0,8400 \\
\hline \multirow{4}{*}{ Camada 2} & $\begin{array}{l}\text { Espessura } \\
\left(10^{15} \mathrm{at} / \mathrm{cm}^{2}\right)\end{array}$ & 500,00 & 500,00 & 500,00 & 500,00 \\
\hline & \multicolumn{5}{|c|}{ Concentrações } \\
\hline & $\mathbf{O}$ & 0,6000 & 0,6000 & 0,5156 & 0,5600 \\
\hline & Al & 0,4000 & 0,4000 & 0,4844 & 0,4400 \\
\hline
\end{tabular}

$\overline{\text { Ions: 4He; Energia do ions incidente: }} \overline{2200.00(\mathrm{keV}) \text {; Geometria : Alpha (graus): } 0.00} \overline{\text { Beta (graus): } 10.00 \text { Teta }} \overline{\text { (graus): } 170.00 \text {; Detector: }}$ Estado Sólido. 